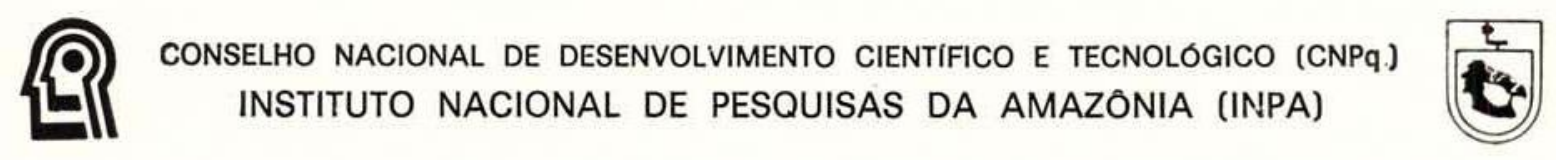

\title{
Revisão taxonômica das espécies de Virola Aublet (Myristicaceae) do Brasil
}

William Antônio Rodrigues INPA - Manaus

ACTA AMAZONICA Vol. 10(1): Suplemento 
RODRIGUES, William Antônio

Revisão taxonômica das espécies de Virola Aublet (Myristicaceae) do Brasil. Manaus, Acta Amazonica, 10(1): Suplemento, mar., 1980.

127 p. ilust.

1. Taxonomia vegetal 2. Fitogeografia I. Título.

CDD 581.981

CDU 581.2(81)

RESUMO: Estuđo crítico e revisäo taxonômica de 35 espécies do gênero Virola Myristicaceae) ocorrentes no Brasil. Consta de uma exposição das razões que motivaram a execução desse estudo, seguida de um esboço histórico dos principais contribuiçōes para o conhecimento do gênero no País e uma descriçăo sucinta de sua importância econômica. Segue uma discussäo da fitogeografia do gênero no Brasil e de seus principais aspectos morfológicos, anatômicos e palinológicos. Dađos sobre fenologia, relaçōes genéricas e evoluçāo do gênero Virola são também apresentados. A principal parte deste estudo é obviamente dedicado à classificaçăo e descriçōes taxonômicas do gênero e das 35 espécies consideradas válidas pelo autor. O trabalho é ilustrado com fotografios, mapas e desenhos analíticos originois de folhas, flores e frutos. 


\section{CONTEÚDO}

Introdução $\ldots \ldots \ldots \ldots \ldots \ldots \ldots \ldots \ldots \ldots \ldots \ldots \ldots \ldots \ldots \ldots \ldots \ldots$

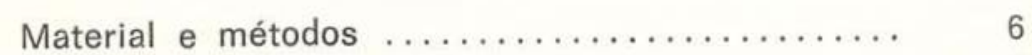

História do gênero $\ldots \ldots \ldots \ldots \ldots \ldots \ldots \ldots \ldots$

Importância econômica $\ldots \ldots \ldots \ldots \ldots \ldots \ldots \ldots \ldots$

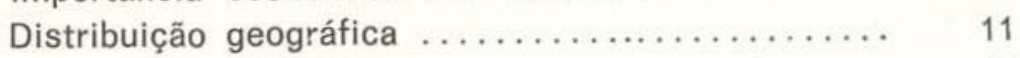

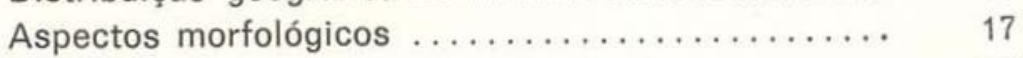

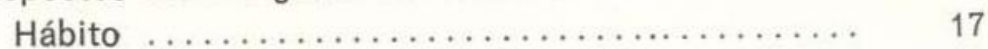

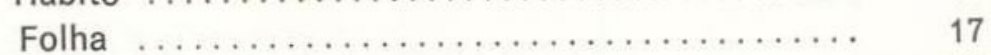

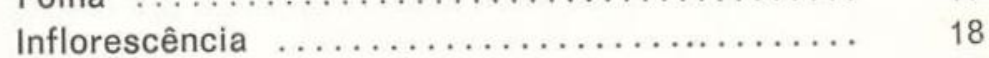

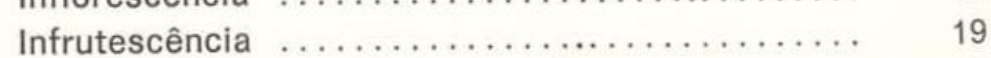

Polem ........................... 20

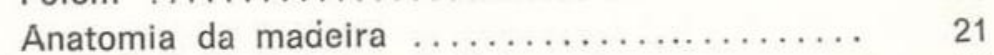

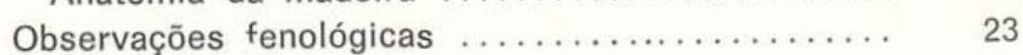

Relações genéricas e evolução .............. 26

Chave para os gêneros americanos ............. 29

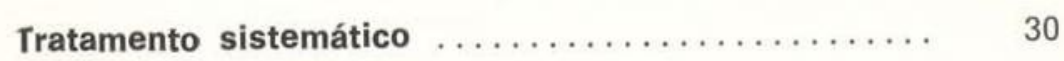

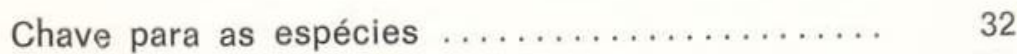

1. Virola albidiflora .................. 37

2. Virola caducifolia .................. 38

3. Virola calophylla .................. 40

4. Virola carinata ................... 44

5. Virola coelhoi ................... 47

6. Virola crebrinervia ............... 47

7. Virola decorticans .................. 49

8. Virola divergens .................. 51

9. Virola duckei .................... 52

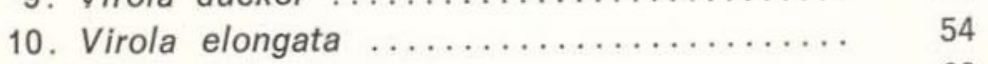

11. Virola flexuosa .................... 60

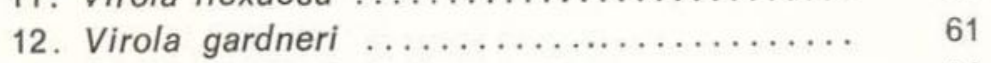

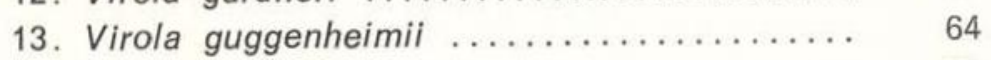

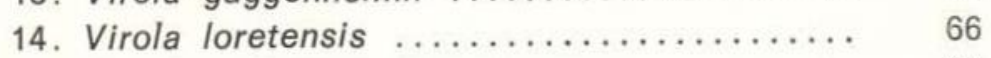

15. Virola malmei .................... 67

16. Virola marlenei .................... 69

17. Virola michelii ................... 69

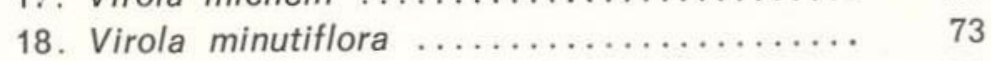

19. Virola mollissima $\ldots \ldots \ldots \ldots \ldots \ldots \ldots \ldots \ldots . \ldots \ldots$

20. Virola multicostata ................ 75

21. Virola multinervia ................ 77

22. Virola obovata $\ldots \ldots \ldots \ldots \ldots \ldots \ldots \ldots \ldots . \quad 80$ 
23. Virola officinalis $\ldots \ldots \ldots \ldots \ldots \ldots \ldots \ldots \ldots, 81$

24. Virola oleifera $\ldots \ldots \ldots \ldots \ldots \ldots \ldots \ldots . .63$

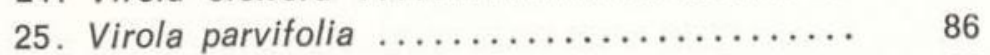

26. Virola pavonis ..................... 87

27. Virola peruviana ..................... 90

28. Virola polyneura ..................... 91

29. Virola rugulosa $\ldots \ldots \ldots \ldots \ldots \ldots \ldots \ldots . \ldots . \ldots . \ldots . \ldots$

30. Virola sebifera ....................... 94

31. Virola sessilis ....................... 100

32. Virola subsessilis .................... 101

33. Virola surinamensis .................. 102

34. Virola urbaniana ...................... 107

35. Virola venosa ........................ 108

Espécies excluídas .................... 111

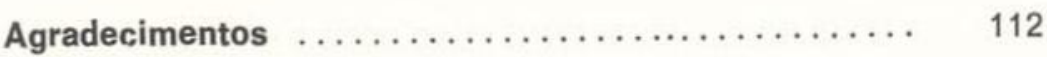

Summary $\ldots \ldots \ldots \ldots \ldots \ldots \ldots \ldots \ldots \ldots \ldots \ldots \ldots \ldots \ldots \ldots \ldots$

Indice das coleções citadas $\ldots \ldots \ldots \ldots \ldots \ldots \ldots \ldots, 114$

índice dos nomes científicos de taxa $\ldots \ldots \ldots \ldots . \quad 119$

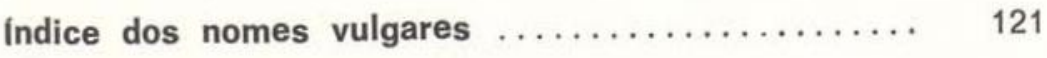

Bibliografia citada $\ldots \ldots \ldots \ldots \ldots \ldots \ldots \ldots \ldots \ldots \ldots \ldots$ 
Esta publicação é restrita à taxonomia das espécies brasileiras de Miristicáceas do gênero Virola, as quais, propcrcionalmente, representam cerca de $75 \%$ de todas as espécies reconhecidas, até hoje, no continente americano.

Uma revisão crítica deste complexo gênero foi necessária a fim de se estabelecer a validade das espécies e relacionar sinônimos, visto que muitos taxa foram publicados no passado (veja índice) e, ainda, perdurava certa confusão nos nomes encontrados nos herbários e na vasta literatura existente.

Embora um completo estudo do gênero exigisse maior número de expedições botânicas, visando, especialmente, ao preenchimento dos muitos vãos ainda subsistentes nas coleções de herbário, a revisão de todas as espécies de Virola de nossa flora parece justificada, não só pelo valor econômico que representa a maioria de suas espécies para o País. como pela sua ampla dispersão no território nacional (veja fig. 1). Ressalte-se também que, com as mais recentes e variadas expedições botânicas, realizando freqüentes levantamentos da flora brasileira, uma vasta e valiosa coleção de exsicatas do gênero se acumulava nos principais herbários nacionais e estrangeiros e já se ressentia da falta de uma adequada e imediata revisão taxonômica, visto que o último trabalho, que se conhece, feito neste sentido, data de cerca de 40 anos atrás (Smith, 1937), o qual, no entanto, era de âmbito mais geral. Abrangia não só todas as espécies de Virola conhecidas na época como as demais Miristicáceas americanas. Afora este excelente trabalho citado, daquela data para cá, quase nada mais foi feito com o intuito colimado da atualização do conhecimento deste grupo, a não ser alguns inestimáveis, porém esparsos trabalhos de Ducke, referentes às espécies exclusivas da Hiléia amazônica brasileira.
Em geral, as espécies de Virola são conhecidas, vernacularmente, no Brasil por "ucuuba", em toda a região amazônica, "urucuba", no Nordeste e "bicuíba", no Sul, e no comércio madeireiro, pelo mesmo nome do gênero.

O termo "virola", escolhido por Aublet para denominação de seu novo taxon, foi tirado do nome vulgar de Virola sebifera, usado pelos índios Sinemari da Guiana Francesa.

$\mathrm{O}$ gênero, até há pouco tempo sem grande importância, vem ultimamente merecendo a atenção da Ciência, depois que se divulgou que algumas de suas espécies são usadas por certas tribos da Amazônia no preparo de um rapé alucinogênico e no envenenamento de flechas para caça. Neste sentido, várias contribuições vêm sendo publicadas, recentemente, sobre Etnobotânica e Química destas plantas, destacando-se os trabalhos de Schultes (1954, 1969a, 1969b e 1970), Schultes \& Holmstedt (1968 e 1971), Agurell et al. (1969) Prance (1970, 1972a e 1972b), Cassady et al. (1971), Braz Filho et al. (1973), Oliveira et al. (1973). Maia \& Rodrigues (1974) e outros. O mesmo, também, se pode referir à madeira de algumas de suas espécies, mormente a $V$. surinamensis, cujo valor econômico só recentemente foi reconhecido. Pelo volume total de toras brutas comercializadas na Amazônia, esta espécie se sobrepõe às demais. Em 1972, por exemplo, dentre todas as essências destinadas e recepcionadas pelas indústrias madeireiras regionais, a "ucuuba de várzea" representou quase a metade do volume total de toras empregadas pelas serrarias e fábricas de desenrolados e compensados (EMBRAPA, 1974).

O interesse do autor pelas Miristicáceas, e, em particular pela Virola, vem de muito tempo, não só devido ao seu reconhecido valor econômico como pela abundância relativa de suas espécies na mata amazônica, tantas ve- 
zes comprovada durante as freqüentes viagens que o autor teve que empreender na região para coleta de material botânico ou para execução de estudos ecológicos. Como o Estado do Amazonas, dentre todas as demais unidades da Federação, é o melhor aquinhoado pela riqueza de espécies (veja fig. 1), este interesse foi muito maior, pois o meio era como se fosse um herbário vivo a the oferecer uma invejável e privilegiada oportunidade de fazer uma revisão muito mais objetiva do gênero que qualquer outro, que não teve esta mesma sorte.

$\mathrm{O}$ autor deve reconhecer também que, para execução deste trabalho, recebeu de John Simon Guggenheim Memorial Foundation um valioso estímulo, com a bolsa que lhe foi beneplacitamente outorgada em 1971 para o estudo exclusivo das espécies americanas de $\mathrm{Mi}$ risticáceas e visita aos principais herbários mundiais, que mantêm coleções clássicas desta família. Graças a esta valiosa ajuda, pôdese, privilegiadamente, examinar a maioria dos tipos de seu interesse e reunir uma extensa e rara bibliografia básica.

Os planos de estudo do autor não se limitam apenas ao gênero no Brasil. Devem abranger em futuro todas as espécies do continente americano e os demais gêneros neotropicais afins, cujo número de espécies, estimativamente válidas, montam hoje a cerca de 89 .

Do total de 48 espécies válidas deste gênero, exclusivamente neotropical, 35 foram reconhecidas neste trabalho para todo o Brasil.

\section{MATERIAL E MÉTODOS}

Para realização deste estudo, o autor baseou-se, principalmente, nos conceitos e tratamentos taxonômicos valiosos de Warburg (1897), Smith (1937) e Ducke (1936, 1938, 1939, 1945 e 1950) pelas razões seguintes: o primeiro, foi o único monografista na época que emitiu conceitos básicos até hoje aceitos sobre o tratamento taxonômico da família inteira e que conseguiu definitivamente esclarecer e restaurar o gênero Virola, reduzido por De Candolle (1856, 1860), Bentham \& Hooker (1880) e Prantl (1891) à simples seção do único gênero adotado por eles na época, Myristica.
Smith, o segundo maior monografista da família, o mérito do seu trabalho está no utilissimo estudo que empreendeu, exclusivamente. sobre os gêneros neotropicais de Miristicáceas, inclusive Virola, pelas críticas geralmente válidas da maioria das espécies aceitas por ele e pela redução necessária que foi obrigado a fazer de muitos taxa mal definidos.

Afora esses dois excelentes monogratistas, o autor não pôde prescindir das valiosas contribuições de Ducke, indiscutivelmente, um dos maiores botânicos que a Amazônia já teve. Seus estudos sobre a família são importantes não só pelas inúmeras espécies novas que descreveu (25 ao todo, das quais apenas 5 não foram aceitas), como pela larga visão que tinha de todas as espécies ocorrentes na Amazônia, graças às suas próprias observações de campo, frutos de uma longa e proficiente vivência na região. Muitas das informações sobre as espécies discutidas neste trabalho tiveram respaldo nas opiniões pessoais deste renomado botânico, emitido em seus preciosos trabalhos e nas anotações apostas às etiquetas de suas clássicas coleções.

A presente revisão é baseada no método clássico da morfologia comparada. Todos os elementos vegetativos, flores e frutos são utilizados para caracterização específica dos binômios.

A introdução deste trabalho começa com uma exposição das razōes que motivaram a execução deste estudo, seguida de um esboço histórico das principais contribuições, ao conhecimento do autor, relacionadas com o gênero no País e uma descrição sucinta de sua importância econômica. Segue uma discussão da distribuição geográfica do gênero em todo o território brasileiro e de seus principais aspectos morfológicos. Dados sobre a fenologia de várias de suas espécies, obtidos, especialmente, de material de herbário, são comentados. Como meras conjeturas, as possíveis relações genéricas e evolução de Virola são também discutidas, baseadas, em geral, na morfologia externa por falta de conhecimento da citologia do gênero. A principal parte deste estudo é devotada à classificação e descrição taxonômica do gênero e das espécies reconhe- 
cidas nesta revisão. A literatura que acompanha cada binômio é a mais completa que se pôde reunir. Foi colocada propositadamente para servir de orientação a todos que deseja. rem empreender estudos mais completos de cada espécie aqui tratada.

A escolha da ordem alfabética para disposição das espécies nesta monografia foi baseada em Leenhouts (1968), que sugere essa ordem como uma das alternativas válidas, especialmente quando há um grande número de taxa semelhantes.

A possivel afinidade que o autor vê entre as espécies é a mesma que foi adotada na ordem de entrada de cada binômio na chave para reconhecimento das espécies. Uma chave para os gêneros neotropicais foi incluída para mostrar as suas relações intergenéricas e afinidades. Acompanham o trabalho diversas figuras, mapas, quadros e gráficos. As descriçōes são acompanhadas por fotografias ou desenhos analíticos originais das folhas, flores e frutos de todas as espécies. As ilustrações, cuidadosamente supervisionadas pelo autor, podem ser consideradas complementares das descrições escritas. Aparecem no texto perto das espécies a elas concernentes, o mesmo ocorrendo com os mapas de distribuição das espécies. As citações das coleções constituem uma parte importante nas revisões. Por isto foram incluídas no final de cada descrição e num índice especial, o mesmo ocorrendo com os nomes vulgares e utilidades das piantas, os quais foram extraídos em sua maioria da vasta literatura compulsada e das etiquetas de herbário. Quando um coletor não tinha seu número próprio de coleta, era tomado para referência o número do herbário onde sua principal coleção estava guardada.

A maioria dos tipos foi examinada pelo autor no Brasil e nos herbários dos Estados Unidos; Colômbia e Europa. Todos os fotótipos disponíveis, tanto pessoais como os da coleção do Museu de História Natural de Chicago (F) foram de inestimável subsídio, durante o andamento da revisão.

A informação de que toda a coleção clássica de Miristicáceas do herbário de Viena havia sido destruída durante a II Guerra Mundial foi comprovada pessoalmente pelo autor durante a sua última estada na Europa, enquanto que a do Museu Botânico de Berlim-Dahlen the foi fornecida em carta de 3 de setembro de 1975 pelo Prof. Dr. Paul Hiepko, chefe do Departamento de Fanerógamos daquela famosa instituição de pesquisa. Por esta razão diversos lectótipos e um possível neótipo tiveram de ser apontados obrigatoriamente neste trabalho.

Foram as seguintes as abreviações adotadas no texto e nas coleções examinadas:

$$
\begin{aligned}
& \text { descr. ampla = descriptio ampla } \\
& \text { est. = estéril } \\
& \text { excl. specim. = exclusis specimenibus } \\
& \text { fig. } \quad=\text { figura } \\
& \text { fl. } \quad=\text { flor } \\
& \text { frag. } \quad=\text { fragmento } \\
& \text { fr. } \quad=\text { fruto } \\
& \text { ibid. } \quad=\text { ibidem } \\
& \text { id. } \quad=\text { idem } \\
& \text { ilust. = ilustração } \\
& \text { I.c. = loco citato } \\
& \text { n.v. }=\text { non vidio } \\
& \text { nom. illegit. = nomen illegitimum } \\
& \text { nom. non rite public. }=\text { nomen non rite publi- } \\
& \text { catum } \\
& \text { nom. nud = nomen nudum } \\
& \text { n. sp. = nova species } \\
& \text { pro syn. } \quad=\text { pro synonymo } \\
& \mathrm{s} / \text { data } \quad=\text { sem data } \\
& \text { s. } \mathrm{n} . \quad=\text { sem número } \\
& \text { sens. lat. = sensu lato } \\
& \text { sphalm. }=\text { sphalmate } \\
& \text { syn. nov. = synonymum novum } \\
& \text { t. = tab. = tabula }
\end{aligned}
$$

Para as citações dos herbários consultados, foram adotadas as abreviações constantes do "Index Herbariorum" de Holmgren \& Keuken (1974), mais as seguintes siglas:

IPT: Instituto de Pesquisas Tecnológicas de São Paulo.

MBM: Museu Botânico Municipal de Curitiba.

SHMT: Herbarium Mattogrossense Saddianum. 
Para a presente revisão, as coleções consultadas foram as seguintes:

Botanical Museum and Herbarium, Copenhague (C) (U)

Botanical Museum and Herbarium, Utrecht

Botanische Staatssammlung, Munique (M).

British Museum of Natural History, Londres (BM).

Chicago Natural History Museum, Chicago (F).

Escola Superior de Agricultura de Viçosa. Divisão de Botânica, Viçosa (VIC).

Economic Herbarium of Oakes Ames, Cambridge (ECON).

Gray Herbarium, Harvard University, Cambridge $(\mathrm{GH})$.

Instituto Agronômico do Norte, Belém (IAN).

Instituto Botânico, Caracas (VEN).

Instituto de Botânica, São Paulo (SP).

Instituto de Ciencias Naturales, Bogotá (COL).

Instituto Nacional de Pesquisas da Amazônia, Manaus (INPA).

Jardim Botânico do Rio de Janeiro (RB).

Muséum d'Histoire Naturelle, Paris ( $P$ )

Museu Goeldi de História Natural, Belém (MG).

Museu Nacional do Rio de Janeiro, (R).

Naturhistoriska Riksmuseum, Estocolmo (S).

Naturhistorisches Museum, Viena (W).

New York Botanical Garden, Nova Iorque (NY).

Rijksherbarium, Leiden (L) .

Royal Botanic Gardens, Kew (K).

Staatsinstitut für Allgemeine Botanik, Hamburgo (HBG).

U.S. National Herbarium, Washington (US).

\section{HISTORIA DO GENERO}

A primeira descrição e ilustração de $\mathrm{Vi}$ rola é feita por Aublet (1775). Baseia-se em V. sebifera, espécie-tipo colhida por ele duran- te as suas explorações botânicas na Guiana Francesa. Adota para o nome genérico a mes. ma nomenclatura vulgar usada pelos índios Sinemari para a espécie-tipo. Situa o seu novo gênero na classe Dioecia Hexandria do sistema sexual de Lineu.

Swartz (1788) não aceita o novo gênero de Aublet e coloca-o na sinonímia de Myristica.

Jussieu (1789) põe Virola na Classis VI, Ordo IV (Lauraceae) de seu sistema de classificação e associa-o com Laurus T.L., Ocotea Aubl., Ajouea Aubl., Myristica LS. e Hernandia PI. L.

Necker (1790) propõe o nome Sebophora como "species naturalis" para a designação unitária de Virola sebifera Aubl., o qual, de acordo com o Art. 20 do Código Internacional de Nomenclatura Botânica (1972), teve de ser rejeitado por se assemelhar a nome genérico, sendo, por conseguinte, considerado invalidamente publicado.

Schott (1823) apresenta, pela primeira vez, uma adequada descrição de uma nova es. pécie sob o nome provisório de Myristica oleifera, que mais tarde (1827) tenta substituir por $M$. bicuhyba, com uma curta diagnose.

Martius em Spix \& Martius (1828) publica Myristica officinalis, desconhecendo que era um homônimo de uma espécie já descrita anteriormente por Lineu fil. e ao descrecrê-la, confunde-a com $V$. oleifera, gerando com isto grande confusão, que perdurou durante muito tempo, só sendo aclarada com a monografia de Warburg (1897).

Endlicher (1841) reduz Virola a uma das suas duas Seções do gênero Myristica.

Lindley (1847), em seu The Vegetable Kingdom, reconhece o gênero Virola, mas mantém Myristica Bicuiba e M. officinalis sepa. radas.

Bentham (1853) publica o primeiro trabaIho de real valor sobre o tratamento taxonômico das espécies americanas de Miristicáceas. Nesse trabalho, onde ele só reconhecia o gênero Myristica para toda a família, a flora neotropical é acrescida de 9 espécies novas, passando a contar com um total de 12 espécies, divididas em 3 grupos distintos, que ele reco- 
nhecia de acordo com os caracteres diferenciais do androceu e nervação foliar. Desse total, 8 estavam relacionadas com Virola: $M$. carinata, $M$. venosa, $M$. officinalis, $M$. subsessilis M. elongata, $M$. cuspidata, $M$. theiodora e $M$. punctata.

De Candolle (1856), em seu Prodromus, conserva a família com um único gênero e divide-a em 13 Seções. Virola e Sychnoneura são as únicas Seções criadas por ele de interesse para o presente estudo, as quais se separavam pelos mesmos caracteres principais usados inicialmente por Bentham. Nessas 2 Seções são descritas 12 taxa novos: $M$. sebifera var. curvinervia e var. cordifolia; $M$. mocoa, M. membranacea, M. peruviana, M. gardneri, $M$. sessilis, $M$. gracilis, $M$. cuspidata var. rufula, $M$. uaupensis e $M$. mollissima.

No estudo exclusivo das espécies brasileiras de Miristicáceas para a Flora Brasiliensis, De Candolle (1860) mantém sem modificação o mesmo tratamento taxonômico emitido no trabalho citado anteriormente e ilustra sua monografia com diversos desenhos. 21 espécies e 3 variedades são reconhecidas por ele para o Brasil das Seções Virola e Sychnoneura. Destes taxa, apenas $M$. macrophylla seria mais tarde transferida para outro gênero (Iryanthera).

Bentham \& Hooker (1880), no Genera Plantarum, reduzindo as 13 Seções de De Candolle em 7, mantêm a Seção Virola e junta Sychnoneura e Iryanthera, na Seção Otoba.

Prantl (1891), em Die natürlichen Pflanzenfamilien, conserva as 13 Seções estabelecidas por De Candolle, sem qualquer modificação.

Warburg (1897), a maior autoridade da família e, sem dúvida, o único que conseguiu dar um adequado e definitivo tratamento sistemático à família inteira, reconhece 15 gêneros em vez de um apenas, Myristica. O seu conceito sobre os gêneros propostus é tão perfeito que até hoje vem sendo adotado pela maioria dos botânicos, mesmo os mais conservadores. Em sua valiosa monografia, encontram-se minuciosas discussões sobre filogenia, anatomia e morfologia, fitogeografia, evolução hipotética, utilidades e classificação da família toda. Seu trabalho, no entanto, tem, justificavelmente, muitas falhas, decorrentes, naturalmente, em sua maioria, da grande deficiência de material para uma análise mais perfeita. Assim, sua chave de espécies em geral é quase imprestável, a distribuição geográfica das espécies é muito incompleta e vaga, e muitas de suas espécies e variedades foram forçosamente reduzidas a sinônimos. Também, as Seções Oxyanthera e Amblyanthera, propostas por ele para o gênero Virola, baseadas especialmente no comprimento proporcional das anteras e andróforos, foram consideradas inconsistentes por força da análise de maior número de exemplares do que o monografista dispunha na ocasião. Sua monografia reconhecia 27 espécies de Virola, das quais 10 eram novas e 19 ocorriam no Brasil. Dentre as novas espécies propostas por ele, são de interesse para o estudo da flora brasileira as seguintes: V. urbaniana, V. schwackei, V. rufula, V. araujovii, V. glaziovii, V. rugulosa e V. calophylla.

Markgraf (1923) descreve V. calophylloidea, baseado em material de Ule, colhido no Estado do Amazonas (Manaus).

Ducke, o maior botânico que a Amazônia já teve neste século, através de diversos artigos publicados em revistas nacionais e estrangeiras $(1933,1936,1938,1939,1945,1947$ e 1950), descreve novas espécies, estabelece conceitos sobre algumas espécies de Virola, fornece novos dados botânicos, morfológicos, fenológicos e ecológicos de várias espécies do gênero e sumariza seus conhecimentos de campo sobre esse grupo (1936), elaborando uma chave sinóptica de todas as espécies de Virola conhecidas para o Brasil na época, dividindo-as em 7 grupos distintos de acordo com os caracteres do fruto e do androceu.

Os trabalhos de Ducke, juntamente com suas preciosas coleções botânicas, feitas especialmente na Amazônia brasileira, são inestimáveis subsídios para o conhecimento atual do gênero no Brasil.

Malme (1935), na relação de suas coleções feitas no Brasil, cita 3 espécies de Virola colhidas em Mato Grosso e descreve a nova variedade latifolia de V. glaziovii. 
Smiťh (1936), no estudo da importante coleção krukoviana, publica $V$. flexuosa e $V$. lepidota como novas espécies para o Estado do Amazonas. Com a descrição destas novas espécies, Smith inicia uma série de estudos sobre todas as espécies de Miristicáceas ocorrentes na flora neotropical, cujo trabalho mais importante para o Brasil é, sem dúvida, a sua clássica revisão das espécies americanas da referida família (1937), na qual mantém os gêneros delimitados por Warburg, faz um estudo crítico de todos os 5 gêneros neotropicais, reduz, necessariamente, algumas espécies à sinonímia e cria outras. Propõe a divisão de Virola nos seguintes grupos: Mollissimae, Sebiferae, Calophyllae, Rugulosae, Surinamenses e Subsessiles. Das 37 espécies reconhecidas por ele, 30 são citadas para o Brasil. Completa este trabalho de Smith, o estudo palinológico de Wodehouse de 36 espécies dos 5 gêneros americanos, sendo que, só de Virola, 17 foram examinadas.

Machado (1949), em sua tese para o provimento do cargo de Professor Catedrático da Cadeira de Botânica Aplicada à Farmácia, faz um estudo extensivo, em especial da $V$. bicuhyba (sic), do ponto de vista botânico, ecológico, anatômico e farmacológico. Neste trabalho, inclui uma chave para os gêneros brasileiros de Miristicáceas e divide todas as espécies brasileiras conhecidas por ele da família em grupos de acordo com uma chave sinóptica que apresenta. Prejudicado, talvez, pela falta de melhores fontes bibliográficas compiladas, notam-se algumas falhas no seu estudo, inclusive quanto ao verdadeiro nome da espécie ( $V$. oleifera), que já há 12 anos atrás havia sido restabelecido por Smith em sua excelente monografia.

Uphof (1959), em Pflanzenreich, na sua síntese de todos os gêneros de Miristicáceas, mantém de modo geral o mesmo tratamento sistemático proposto por Smith (1937) do gênero Virola. Apenas transfere para Seção os seus 6 grupos e restabelece os taxa de Warburg: V. oleifera var. schenckii, V. venosa var. pavonis e var. martii. Na relação de espécies de cada Seção, Uphof procura corrigir os erros cometidos por Smith, não incluindo algumas espécies em mais de uma Seção.

Reitz (1968) e Hatschbach (1972), no estudo das Miristicáceas para a flora regional, respectivamente, de Santa Catarina e Paraná, tecem minuciosas e separadas considerações taxonômicas sobre $V$. oleifera.

Rodrigues (1972), na revisão bibliográfica de $V$. surinamensis, faz detalhadas considerações sobre o aspecto botânico, anatômico, ecológico, silvicultural e tecnológico dessa importante espécie amazônica e enriquece seu trabalho com diversas ilustrações.

\section{IMPORTÂNCIA ECONOMMICA}

Grande parte deste tema é abordado mais extensivamente junto com a descrição botânica de cada espécie. Isto não impede, no entanto, que um comentário mais sucinto seja dado aqui.

Desde os primórdios do descobrimento do Brasil, já se dava valor a algumas espécies de Virola como planta útil da flora brasileira sob a denominação indígena de "hiboucouhu", "bicuíba" e "ucuuba". Dentre as mais conhecidas estão a $V$. surinamensis e a $V$. sebifera, pela produção do comercialmente conhecido "sebo de ucuuba", gordura proveniente das sementes destas espécies, de emprego tecnológico importante, ainda hoje, na saboaria, produção de velas etc... Esta gordura é formada de ácidos graxos saturados (cáprico, láurico, mirístico, palmítico e esteárico) e insaturados (oleico e linoleico). Dentre os componentes da gordura, assume grande importância econômica a trimiristina, um triglicérico de elevado valor na confecção de cremes e sabões para barba, ou emoliente graxo em inúmeros preparados farmacêuticos. Seu elevado preço demonstra as necessidades industriais e reflete a intensa procura para dar maciez e suavidade nas fórmulas de perfumaria e cosméticos.

As ucuubas ainda provam o seu elevado valor nas confeitarias com a obtenção da trilaurina, um triglicerídeo de especial poder nutritivo. 
A torta, proveniente dos resíduos do material gorduroso, apresenta razoável teor em nitrogênio e é aplicada como alimento para gado, ou usada como adubo em mistura com cinzas.

A madeira de ucuuba é largamente empregada na fabricação de compensados, e, como conseqüência do processo industrial, permite o uso dos resíduos de produção na confecção de papéis tipo Kraft de boa qualidade. Os índices físicos obtidos a partir da madeira são meIhores (Rodrigues, 1972).

Algumas espécies de ucuuba ou bicuíba entram na medicina popular para a cura do reumatismo, artritismo em geral, cólicas, dispepsias e erisipelas. Segundo Le Cointe (1947), o cozimento da casca destas espécies é empregado nas assepsias de feridas como coadjuvante da cicatrização. A seiva cozida juntamente com camapu (Physalis sp.) é usada nas hemorroidas.

Agurell et al. (1968, 1969), Blair et al. (1969), Cassady et al. (1971), Braz Filho et al. (1973, 1976a) Gottlieb et al. (1973, 1975a, b.), Oliveira et al. $(1973,1976)$ e outros, analisando quimicamente diversas espécies de Virola, isolaram e identificaram várias classes de compostos como, e. g., alcalóides (triptaminas, $\beta$-carbolinas), diarilpropanóides (virolanos e virolanois, lignanas e neolignanas), cromanonas, flavonóides (flavanas, isoflavonas e pterocarpanos), estilbenos, esteróides (sitosterol e stigmasterol) etc.. Alguns destes compostos já têm valor medicinal comprovado e outros estão sendo testados para este fim.

Lima et al. (1955) demonstrou que os extratos das amêndoas de $V$. gardneri apresentavam atividade contra germes grã-positivos e germes ácido-resistentes.

Schultes et al. (1969) salientaram o emprego do. rapé preparado da resina da casca de $V$. theiodora $(=V$. elongata e $V$. calophylla como poderoso alucinógeno entre várias tribos indígenas da região amazônica. Estudos químicos das folhas, cascas e raízes destas espécies mostraram possuir derivados triptamínicos (N-metiltriptaminas, triptamina, N, N-dimetiltriptamina, 5-metoxi- N, N-dimetiltriptamina), compostos estes, realmente, com atividade desta natureza.

Barata \& Baker (1973) verificaram que o extrato hexânico das folhas de $V$. surinamensis tem ação protetora contra a infecção por Schistosoma mansoni, quando aplicado topicamente. A ação quimioprofilática da esquistossomose pertence, possivelmente, segundo os autores citados, a uma lignana ainda não identificada pelos métodos físicos e químicos.

Estruturalmente, muitos dos compostos (lignana) isolados de espécies de Virola aproximam-se de outras substâncias da mesma classe possuidoras de ação anti-mitótica.

\section{DISTRIBUIÇÃO GEOGRAFICA}

Virola é um gênero circunscrito apenas à flora neotropical. Dos 5 gêneros de Miristicáceas próprios da América, é o mais amplamente disperso. Sua distribuição vai da Guatemala e Antilhas Menores à Bolivia e Brasil Meridional (Rio Grande do Sul) e da costa ocidental da Colômbia e Equador à do Atlântico, no Brasil. O maior número de espécies está na bacia amazônica, notadamente na parte ocidental, sendo por isso considerada o centro de distribuição do gênero(') (veja quadro 1 e fig. 1). No Brasil, quase todas as unidades da Federação têm representantes do gênero, exceto 2 ou 3 Estados. Conforme se afasta da Hiléia em direção ao Sul, o número de espécies vai diminuindo gradativamente até ao Rio Grande do Sul, o extremo meridional de dispersão do gênero não só no Brasil como na América, com apenas uma única espécie $(V$. oleifera Smith).

Prefere tanto as matas de galeria como as dos terrenos de baixo platô, porém não é raro encontrarem-se espécies também em altiplanos e em encostas de serras. Nos Andes, por exemplo, $V$. peruviana Warb. foi registrada a

(1) - Segundo Ducke \& Black (1954), a bacia do rio Negro junto com a do Solimões constituem o centro principal de dispersão desta família, nas Américas. 
2100m. sobre o nível do mar e, no Brasil, V. sebifera Aubl. foi assinalada na serra dos Pirineus, Goiás, a $1300 \mathrm{~m}$. No Parque Nacional de Itatiaia, Rio de Janeiro, V. gardneri Warb. e V. oleifera Smith têm sido vistas freqüentemente em altitudes acima de $700 \mathrm{~m}$.

Conforme se supõe, o centro de distribuição mundial da pantropical família das Miristicáceas é a Ásia tropical da India à Poliné$\left.s i a{ }^{2}\right)$. Além da América e Ásia, a família existe também na África e em Madagascar, perfazendo ao todo 15 ou 16 gêneros e cerca de 400 espécies (Uphof 1959; Hutchinson, 1964). Esses gêneros formam grupos bem definidos geograficamente. Nenhum dos gêneros de cada grupo ocorre naturalmente em qualquer outra dessas 4 áreas maiores de especiação. Esta separação da família em áreas amplamente disjuntas sugere uma distribuição geográfica mais contínua no passado, provavelmente antes do Cretáceo, quando os continentes ainda estavam unidos, conforme a teoria da translação continental ou das pontes continentais. A favor desta hipótese, deve-se levar em consideração que a dispersão das sementes de Miristicáceas a longas distâncias, através do oceano, não seria normalmente possível, segundo Warburg (1897), especialmente pelas seguintes razões:

a) não existem mecanismos especiais tanto no pericarpo do fruto como nas sementes, pelos quais elas pudessem ser transpoitadas a grandes distâncias;

b) seu peso específico é muito elevado para permitir a sua flutuação;

c) a testa da semente, por ser relativamente fina, não a proteje da ação da água salgada por muito tempo;

d) o embrião é rapidamente perecível;

e) a amêndoa é comumente muito grande para ser levada por pássaros mesmo a curtas distâncias.

Tudo isto, além de inúmeras outras evidências, tem servido para se admitir que as Miristicáceas já estavam mundialmente espa-
Ihadas quando os continentes se separaram, provavelmente, depois do Cretáceo.

Corrobora essa idéia também a descoberta de alguns fósseis neste continente, pertencentes à flora do Eoceno ou começo do Oligoceno, descritos por Engelhardt apud Berry (1916) e Berry $(1916,1919,1929)$. No entanto, à falta de melhores dados paleobotânicos e citológicos, qualquer tentativa para explicar a atual distribuição geográfica da família não passa de mera especulação.

$\mathrm{O}$ muito que se pode dizer, no entanto, em particular sobre o gênero Virola, é que este, presumivelmente, se desenvolveu de uma população isolada geograficamente após o Cretáceo e que as suas várias espécies se originaram posteriormente, talvez no Pleistoceno, em diferentes áreas de refúgio que se supõe tenham existido.

As 35 espécies aqui reconhecidas de $\mathrm{Vi}$ rola ocupam pelo menos 3 das maiores zonas florísticas brasileiras (veja quadro 2): florestas da Hiléia amazônica, florestas costeiras e cerrados. As florestas da Hiléia amazônica têm diversos tipos distintos de vegetação com nomes locais: a) matas de terra firme - vegetação densa nunca alagável; b) matas de várzea - vegetação periodicamente inundável pelos rios de água barrenta, rica de sedimentos; c) matas de igapó - vegetação quase permanente ou periodicamente inundável pelos rios, em geral, de água escura e pobre de sedimentos; d) caatinga ou pseudocaatinga vegetação especial, inteiramente distinta das caatingas do Nordeste, em geral baixa, raquítica e muito densa, geralmente de folhagem esclerosada, persistente, sobre solo silicoso, podzolizado, branco, super-úmido e muito pobre. É freqüentemente encontrada na região do rio Negro e, ocasionalmente, em outras partes da bacia amazônica, com diferentes denominações locais: campina, carrasco, etc.

As matas costeiras compreendem a faixa de vegetação que se esṫende ao longo da costa atlântica desde o Rio Grande do Norte até o nordeste do Rio Grande do Sul.

(2) - Segundo recente comunicação pessoal de J. E. Armstrong, o centro de origem e dispersão das Myristi. caceae, bem como das famílias relacionadas, Annonaceae e Canellaceae, são os trópicos do Novo Mundo (carta de 12/11/76). 
Os cerrados mais característicos ocupam uma extensa área do centro-oeste brasileiro. É uma formação com amplo gradiente fisionômico e floristicamente semelhante. Os cerrados mais típicos são constituídos de árvores e arbustos tortuosos, mais ou menos esparsos, de casca muito grossa e folhas coriáceas, com o solo coberto em geral de tufos graminosos e outras plantas herbáceas. Cerrado é aqui em. pregado no sentido mais amplo, correspondendo às seguintes designações regionais: tabuleiro, campo cerrado, cerradão, savana, savana arborescente etc. Ocorrem nos Estados de Minas Gerais, Goiás, boa parte de Mato Grosso, parte dos Estados de São Paulo e Paraná, estando ainda representados nos Estados do Maranhão, Piauí, Bahia e trechos de Pernambuco. Na Amazônia, aparecem também, principalmente, nos Territórios de Roraima e Amapá e em forma de "ilhas" de vegetação savanóide incrustadas em plena floresta amazônica.

O quadro 2, que mostra a distribuição das espécies, até agora conhecida, de Virola pelas diferentes zonas brasileiras de vegetação, foi baseado no mapa das zonas brasileiras de vegetação do Conselho Nacional de Geografia, modificado por Ferri (1955) apud Ferri (1974).

Melhores informações sobre estes tipos de vegetação encontram-se, e.g., em Ferri (1974), Hueck (1972), Joly (1970), Pires (1973), Veloso (1966), etc.

A maior parte das espécies de Virola concentra-se na mata amazônica e bacias adjacentes, em diferentes tipos de vegetação. As poucas espécies que aparecem nas matas costeiras, não ocorrem na Hiléia. Mantêm-se, em geral, isoladas nessa formação e têm uma distribuição regular. V. gardneri Warb. acompanha em geral, a costa atlântica desde o Estado de Pernambuco até São Paulo, sendo daí em diante substituída pela $V$. oleifera, a qual continua seguindo a costa até o nordeste do Rio Grande do Sul. R. Klein (comunicação pessoal) informa que esta espécie avança até 100 km abaixo, no Rio Grande do Sul.

$\mathrm{Na}$ Amazônia, poucas espécies têm uma dispersão mais ou menos uniforme e ampla. A maioria parece ter áreas restritas de disper- são ou de refúgio, porém pouco se sabe ainda a respeito. Dentre as mais características pela sua dispersão, destacam-se a $V$. surinamensis Warb., V. elongata Warb., V. calophylla Warb., V. sebifera, V. pavonis Smith, V. carinata Warb., V. michelii Heckel e V. venosa Warb..

Das 5 espécies características do cerrado. 4 são peculiares do Brasil Central: V. sessilis Warb., V. subsessilis Warb., V. malmei Smith e V. urbaniana Warb.. As 2 primeiras são, caracteristicamente, arbustivas e cada uma parece ocupar nichos próprios.

Algumas espécies caracterizam determinados habitats a que estão adaptadas. Assim, V. surinamensis Warb. identifica, em geral, as matas de várzea da Amazônia, enquanto a sua vicariante, $V$. carinata Warb., as matas de igapó. Outras são muito tolerantes a qualquer tipo de vegetação e solo, podendo, portanto, ser encontradas em várias comunidades florestais como, por exemplo, a V. pavonis Smith, que habita não só as matas de terra firme como as de igapó e, ocasionalmente, as pseudocaatingas amazônicas. A V. sebifera Aubl. é um outro caso típico: tanto pode ser encontrada na mata como no cerrado.

Até hoje nenhuma Miristicácea foi assinalada nas caatingas do Nordeste.

Algumas espécies passam por muito raras ou endêmicas em determinada região ou tịpo de vegetação, outras são amplamente dispersas, ultrapassando, inclusive, as nossas fronteiras. Dentre estas, as mais importantes são a $V$. surinamensis Warb. e a $V$. sebifera Aubl. A primeira, espécie muito abundante, particularmente na parte oriental da bacia amazônica, tem uma distribuição muito interessante - é a única até então conhecida que se estende para o norte pelo arquipélago das Antilhas até Guadalupe. Esta espécie foi também, estranhamente, coletada por Glaziou no século passado em Minas Gerais e Rio de Janeiro. A presente indicação de sua ocorrência disjunta nestes Estados deve ser posta em dúvida mormente porque vários fatos semelhantes, ocorridos com esse mesmo botânico, assim levam a admitir. V. sebifera Aubl. é a mais dispersa e a mais abundante de todas, na América tropi- 
QUADRO 1 - Distribuição geográfica até agora conhecida do gênero Virola no Brasil.

$\vec{D}$

\begin{tabular}{|c|c|c|c|c|c|c|c|c|c|c|c|c|c|c|c|c|c|c|c|c|c|c|c|c|c|c|c|c|c|c|c|c|c|c|c|}
\hline & \multicolumn{35}{|c|}{ Espécies } \\
\hline $\begin{array}{c}\text { Unidades } \\
\text { da Federação }\end{array}$ & 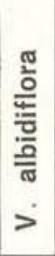 & 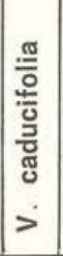 & 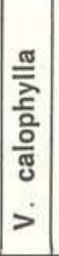 & 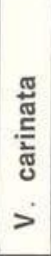 & 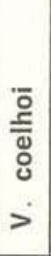 & $\begin{array}{c}\frac{\pi}{2} \\
\frac{2}{0} \\
\frac{\mathrm{c}}{2} \\
\frac{0}{0} \\
\frac{0}{0} \\
> \\
>\end{array}$ & 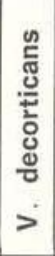 & 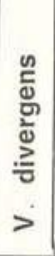 & 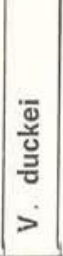 & 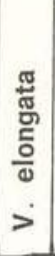 & 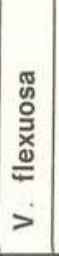 & 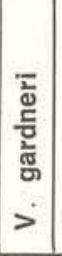 & 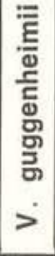 & 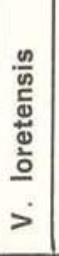 & $\begin{array}{l}\bar{\Phi} \\
\frac{\bar{\Xi}}{\text { ฮ }} \\
\text { Е } \\
>\end{array}$ & 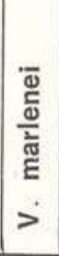 & $\begin{array}{l}\frac{E}{\bar{D}} \\
\frac{\mathrm{C}}{\mathrm{E}} \\
\mathrm{E} \\
>\end{array}$ & 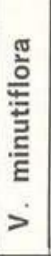 & 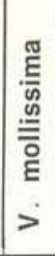 & 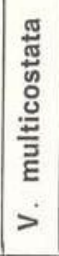 & 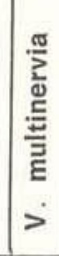 & 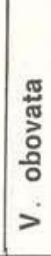 & 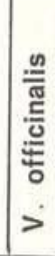 & 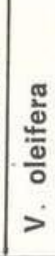 & 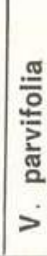 & & 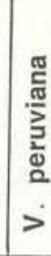 & > & > & 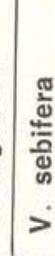 & 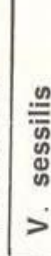 & 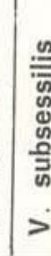 & & & 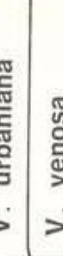 \\
\hline Acre & $x$ & & $\mathrm{x}$ & & & & & $\mathrm{x}$ & & $\mathrm{x}$ & & & & $\mathrm{x}$ & & & & & $\mathrm{x}$ & & & & & & & & $\mathrm{x}$ & & & $\mathrm{x}$ & & & & & \\
\hline Alagoas & & & & & & & & & & & & $\mathrm{x}$ & & & & & & & & & & & & & & & & & & & & & & & \\
\hline Amapá & & & & & & & & & & $x$ & & & & & & & $x$ & & & & & & & & & & & & & $\mathrm{x}$ & & & $\mathrm{x}$ & & $\mathrm{x}$ \\
\hline Amazonas & $x$ & $\mathrm{x}$ & $\mathrm{x}$ & $x$ & $\mathrm{x}$ & & $\mathrm{x}$ & $x$ & $\mathrm{x}$ & $x$ & $x$ & & $\mathrm{x}$ & $\mathrm{x}$ & & $\mathrm{x}$ & $x$ & $\mathrm{x}$ & $\mathrm{x}$ & $\mathrm{x}$ & $\mathrm{x}$ & $\mathrm{x}$ & & & $\mathrm{x}$ & $\mathrm{x}$ & $\mathrm{x}$ & $\mathrm{x}$ & $\mathrm{x}$ & $\mathrm{x}$ & & & $x$ & & $\bar{x}$ \\
\hline Bahia & & & & & & & & & & & & $\mathrm{x}$ & & & & & & & & & & & $x$ & & & & & & & & & $x$ & & & \\
\hline Ceará & & & & & & & & & & & & & & & & & & & & & & & & & & & & & & & & & $x$ & & \\
\hline Distrito Federal & & & & & & & & & & & & & & & & & & & & & & & & & & & & & & $\mathrm{x}$ & & & & & \\
\hline Espírito Santo & & & & & & & & & & & & $\mathrm{x}$ & & & & & & & & & & & & $\mathrm{x}$ & & & & & & . & & & & & \\
\hline Goiás & & & & & & & & & & & & & & & & & & & & & & & & & & & & & & $\mathrm{x}$ & & $x$ & & & 6 \\
\hline Maranhão & & & & 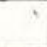 & & & & & & & & . & & & & & $\mathrm{x}$ & & & & & & & & & & & & & $\mathrm{x}$ & & & $\mathrm{x}$ & & 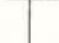 \\
\hline Mato Grosso & & & $\mathrm{x}$ & & & & & & & $\mathrm{x}$ & & 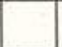 & & & $\mathrm{x}$ & & & & & & & & & & & $\mathrm{x}$ & & & & $\mathrm{x}$ & $\mathrm{x}$ & & & & . \\
\hline Minas Gerais & & . & & & & & & & & & & $\mathrm{x}$ & & & & & & & & & & & $\mathrm{x}$ & $\mathrm{x}$ & & & & & & $\mathrm{x}$ & & & & & \\
\hline Pará & & $x$ & $x$ & $\mathrm{x}$ & & $x$ & & $\mathrm{x}$ & & $x$ & & & & & & & $x$ & & & $\mathrm{x}$ & & & & & & & & & & $\mathrm{x}$ & & $\mathrm{x}$ & $\mathrm{x}$ & & $\mathrm{x}$ \\
\hline Paraíba & & & & & & & & & & & & & & & & & & & & & & & & & & & & & & . & & & & & \\
\hline Paraná & & & & & & & & & & & & & & & & & & & & & & & & $\mathrm{x}$ & & & & & & & & & & & 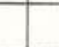 \\
\hline Pernambuco & & & & & & & & & & & & $\mathrm{x}$ & & & & & & & & & & & & & & & & & & & & & & & \\
\hline Piauí & & & & & & & & & & & & & & & & & & & & & & & & & & & & & & & & & & & \\
\hline Rio de Janeiro & & & & & & & & & & & & $\mathrm{x}$ & & & & & & & & & & & & $\mathrm{x}$ & & & & & & & & & & & \\
\hline Rio Grande do Norte & & & & & & & & & & & & & & & & & & & & & & & & & & & & & & & & & & & \\
\hline Rio Grande do Sul & & & & & & & & & & & & & & & & & & & & & & & & $\mathrm{x}$ & & & & & & . & & & & & \\
\hline Rondônia & & $\mathrm{x}$ & $\mathrm{x}$ & & & & & & & $\mathrm{x}$ & & & & & & & & & $\mathrm{x}$ & $x$ & & & & & & $\mathrm{x}$ & & & & $\mathrm{x}$ & & & & & $\mathrm{x}$ \\
\hline Roraima & & & & & & & & & & $\mathrm{x}$ & & & & & & & $\mathrm{x}$ & & & & & & & & & & & & & $\mathrm{x}$ & & & $\mathrm{x}$ & & \\
\hline Santa Catarina & & & & & & & & & & & & & & & & & & & & & & & & $\mathrm{x}$ & & & & & & & & & & & \\
\hline São Paulo & & & & & & & & & & & & & & & & & & & & & & & & $\mathrm{x}$ & & & & & & $\mathrm{x}$ & & & & & \\
\hline Sergipe & & & & & & & & & & & & & & & & & & & & & & & & & & & & & & & & & & & \\
\hline
\end{tabular}


QUADRO 2 - Distribuição até agora conhecida das espécies de Virola pelos diferentes tipos de vegetação do Brasil.

\begin{tabular}{|c|c|c|c|c|c|c|}
\hline \multirow[b]{4}{*}{$\begin{array}{l}\text { Espécies } \\
\text { (Virola) }\end{array}$} & \multicolumn{6}{|c|}{ Tipo de Vegetação } \\
\hline & \multicolumn{5}{|c|}{ Floresta Tropical Úmida } & \multirow[b]{3}{*}{ 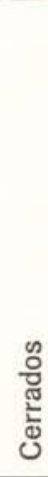 } \\
\hline & \multicolumn{4}{|c|}{ Hiléia Amazônica } & \multirow[b]{2}{*}{ 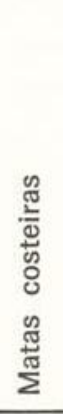 } & \\
\hline & 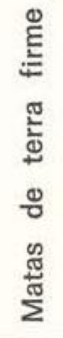 & 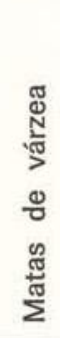 & 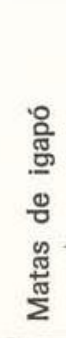 & 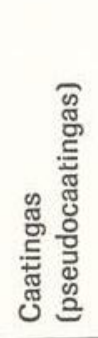 & & \\
\hline 1 - V. albidiflora & $x$ & & $x$ & & & \\
\hline $2-$ V. caducifolia & $x$ & & & & & \\
\hline $3-$ V. calophylla & $\mathrm{x}$ & & & & & \\
\hline $4-$ V. carinata & & & $x$ & $x$ & & \\
\hline $5-$ V. coelhoi & $\mathrm{x}$ & & + & & & \\
\hline $6-$ V. crebrinervia & $\mathrm{x}$ & & 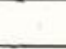 & & & \\
\hline 7 - V. decorticans & $\mathrm{x}$ & & & & & \\
\hline $8-V$. divergens & $\mathrm{X}$ & & & & & \\
\hline $9-$ V. duckei & $\mathrm{X}$ & & $\mathrm{X}$ & $\mathrm{X}$ & & \\
\hline $10-\mathrm{V}$. elongata & $\mathrm{x}$ & $\mathrm{x}$ & $\mathrm{x}$ & & & \\
\hline 11 - V. flexuosa & $\mathrm{x}$ & & & & & \\
\hline $12-$ V. gardneri & & & & & $\mathrm{x}$ & \\
\hline $13-V$. guggenheimii & $\mathrm{x}$ & & & & & \\
\hline $14-\mathrm{V}$. loretensis & & $x$ & & & & \\
\hline 15 - V. malmei & & & & & & $\mathrm{x}$ \\
\hline 16 - V. marlenei & $x$ & & & & & \\
\hline $17-$ V. michelii & $x$ & & & & & \\
\hline $18-$ V. minutiflora & $x$ & & & & & \\
\hline 19 - V. mollissima & $\mathrm{x}$ & $\mathrm{x}$ & $x$ & & & \\
\hline $20-$ V. multicostata & $x$ & & & & & \\
\hline $21-$ V. multinervia & $x$ & & & & & \\
\hline $22-$ V. obovata & & $x$ & $x$ & & & \\
\hline $23-$ V. officinalis & & & & & $x$ & \\
\hline $24-$ V. oleifera & & & & & $\mathrm{x}$ & \\
\hline 25 - V. parvifolia & & & & $x$ & & \\
\hline 26 - V. pavonis & $x$ & & $x$ & $x$ & & \\
\hline 27 - V. peruviana & $x$ & $x$ & & & & \\
\hline $28-V$. polyneura & & $x$ & & & & \\
\hline $29-$ V. rugulosa & & & $x$ & & & \\
\hline $30-$ V. sebifera & $x$ & & & & & $x$ \\
\hline $31-V$. sessilis & & & & & & $x$ \\
\hline $32-$ V. subsessilis & & & & & & $\mathrm{X}$ \\
\hline $33-V$. surinamensis & & $\mathrm{x}$ & & & & \\
\hline $34-\mathrm{V}$. urbaniana & & & & & & $x$ \\
\hline $35-$ V. venosa & $x$ & & & & & \\
\hline
\end{tabular}


cal continental, desde Nicaragua até São Paulo. É uma das espécies melhor conhecidas dos cerrados brasileiros.

Prance (1973), baseando-se em 4 famílias mais representativas da flora amazônica, propõe 16 áreas de refúgios pleistocênicos para a bacia amazônica. Sua hipótese fundamenta-se no fato de que em épocas passadas hou- ve prolongados períodos de seca na região, provocando com isto a retração e desdobramento da floresta em pequenas áreas disjuntas ou refúgios de mata e a conseqüente especiação de povoações previamente isoladas, antes que estas áreas voltassem a se expandir e se interligassem novamente. Conforme se pode verificar, examinando os mapas de distribui-

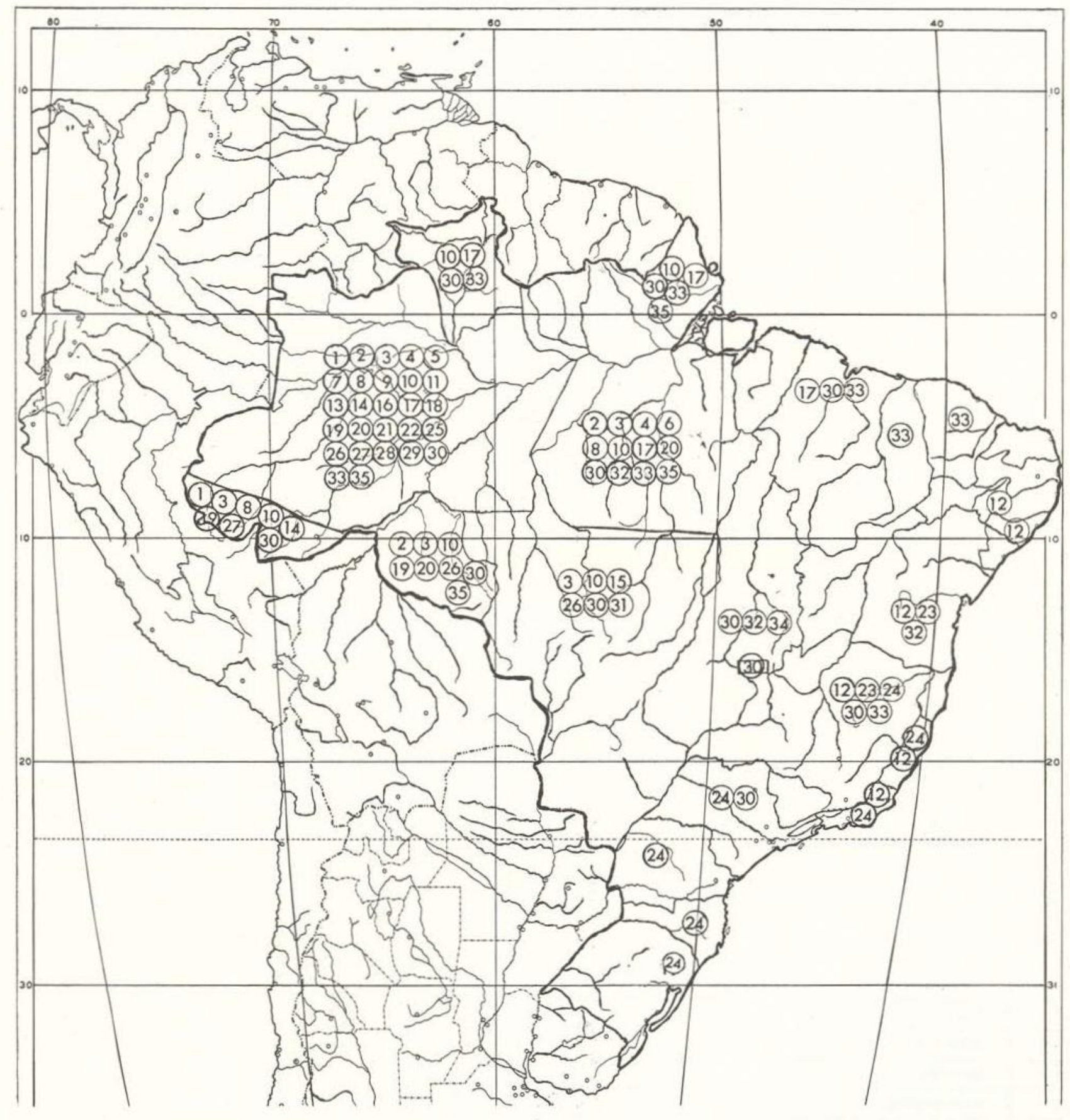

Fig. 1 - Distribuição atual das espécies de Virola no Brasil. O número dentro de cada círculo corresponde ao da ordem de espécies relacionadas no Quadro 2. 
ção de algumas espécies apresentadas neste trabalho, a coincidência das áreas de refúgio, propostas por esse ilustre botânico com as de algumas espécies de Virola, nem sempre é facilmente distinguivel.

Admite-se que possa haver áreas de refúgios na bacia amazônica, conforme deixam transparecer alguns fatos históricos, porém a perfeita delimitação dessas áreas, presentemente, é quase impraticável, levando em conta que a maior parte da Hiléia amazônica permanece, ainda, inteiramente desconhecida e inacessivel, ainda hoje.

Inventários florestais específicos para avaliação da potencialidade de madeira da ucuuba ( $V$. surinamensis Warb.) foram realizados por Glerum (1962) e Instituto do Desenvolvimento Econômico-Social do Pará (1972), respectivamente no Baixo Tocantins e Ponta de Pedras, Pará. Dentre os vários estudos fitossociológicos importantes, em que são feitas alusões à presença de Virola em diferentes comunidades vegetais brasileiras, convém destacar os trabalhos de Aubréville (1961), Bastos (1960), Ducke \& Black (1954), Heinsdijk \& Bas. tos (1963), Pires \& Koury (1959), Ratter et al. (1973), Rodrigues $(1961,1963)$. Soares (1970). Tavares et al. (1971), Veloso (1946, 1947), Veloso \& Klein (1957, 1959) e Segadas-Viana (1965).

Melhores considerações sobre a fitogeografia e ecologia do gênero podem ser encontradas no tratamento taxonômico de cada espécie.

Diversos mapas ilustram este trabalho, os quais por si mesmos são auto-explanatórios sobre a atual distribuição das 35 espécies de Virola, reconhecidas para o território brasileiro.

\section{ASPECTOS MORFOLÓGICOS}

Hábito - As plantas do gênero Virola são todas lenhosas. Variam de pequenos arbustos a enormes árvores de cerca de $40 \mathrm{~m}$ de altura e fuste até cerca de $120 \mathrm{~cm}$ de diâmetro. As de menor porte são encontradas no cerrado do Brasil Central, tais como V. sessilis e V. subsessilis, cuja altura geralmente não ultrapassa
$1 \mathrm{~m}$, quando adultas. São sempre dioicas, nunca monoicas, como comumente acontece no gênero simpátrico, Iryanthera. O tronco é essencialmente monopodial ortotrópico e a ramificação, verticilada plagiotrópica, às vezes com sapopemas ou raízes-escoras de grande plasticidade na base.

Da casca, gèralmente de pequena espessura, escorre, quando ferida, um suco castanho que, em contato com o ar, se oxida e se torna avermelhado ou cor de sangue. Em geral, são perenifólias porém, em $V$. caducifolia, $V$. multicostata e, menos acentuadamente, talvez, em V. flexuosa, constitui um caráter particular destas espécies desfolharem-se totalmente durante a maior parte do período de floração, quando na maioria do gênero a renovação de folhas antecede geralmente a floração. Tanto as partes jovens da planta como os ramos da inflo. rescência e, freqüentemente, as folhas, flores e frutos estão associados com tricomas dos mais variados aspectos (Warburg, 1895). No gênero, os mais comuns são estrelados e dendríticos. Além desses tricomas, também săo facilmente encontráveis os articulados, os ramificados de apêndices curtos, os bifurcados e os simples. Os estrelados podem ser estipitados ou sésseis. A durabilidade deles pode também variar de espécie para espécie. Numa e noutra espécie tanto há os persistentes como os que se desprendem totalmente depois de um certo tempo, que pode ser muito variável.

FolHa - As folhas são dísticas, simples, alternas, de margem inteira, submembranáceas a coriáceas, e de forma oblonga ou elíptica. O tamanho é muito variável. As de maior comprimento $(50 \mathrm{~cm}$ ou mais) ocorrem muito comumente em $V$. decorticans e $V$. multinervia.

Em geral são pecioladas, porém em $V$. ses. silis e $V$. subsessilis, o peciọlo é tão curto que as folhas mais se parecem sésseis. A base da lâmina varia de amplamente cordada (e.g. V. calophylla e V. sebifera) a atenuada ou cuneada como em $V$. obovata e o ápice freqüentemente é acuminado ou cuspidado, mais raramente um tanto emarginado (e.g., V. parvifo(ia). A pubescência na maioria das espécies ocorre na página inferior das folhas, porém $V$. decorticans e $V$. guggenheimii também a têm, caracteristicamente, na página superior. 
Na primeira espécie, os tricomas são simples ou bifurcados e mais ou menos permanentes, enquanto na segunda, são geralmente ramificados desde a base e frequentemente desapare. cem com o tempo. Muitas destas pubescências podem ser vistas a olho nu, porém há as que são tão diminutas que só podem ser distinguidas através de microscópio, tal como em V. calophylla e V. coelhoi.

A nervação caracteriza a maioria das espécies tanto pelo número de nervuras secundárias como pela sua disposição na lâmina foliar. $V$. flexuosa, V. crebrinervia e V. multicostata distinguem-se, à primeira vista, das demais espécies afins não só pela maior densidade delas como pela sua disposição paralela e retilínea até quase às margens da lâmina. A presença normal de nervuras terciárias reticuladas ou mais ou menos paralelas e impressas na página superior das folhas é uma característica genérica. Em V. rugulosa, são marcantes na superfície originalmente bolhosa das lâminas foliares.

INFLORESCÊNCIA - A inflorescência de ambos os sexos pode ser subterminal ou mais comumente axilar, nunca cauliflora ou ramiflo. ra, como freqüentemente ocorre no gênero Iryanthera. Sua dimensão é muito variável, porém nas do sexo feminino são em geral relativamente menores que as do sexo masculino. Em V. loretensis, as inflorescências masculinas $\in$ femininas chegam a ser tão caracteristicamente compridas e pendentes que chamam logo a atenção no campo. O tipo de inflorescência masculina é muito variável de uma espécie para outra, ou de um grupo para outro, pelo tipo de ramificação que apresenta. Entre essas espécies, podem-se encontrar inflorescências 1-, 2-, 3- ramosas, até as de ramificação livre e ampla. A fig. 2 ilustra alguns dos ar ranjos que podem ser encontrados no gênero. O tipo racemiforme parece ser, evolutivamen. te, o mais avançado de todas as inflorescências. Os pedúnculos das inflorescências masculinas podem ser, caracteristicamente, aplanados como em $V$. officinalis ou subteretes. na maioria. Brácteas são sempre decíduas. Muitas são inconspícuas ou nulas, porém outras são relativamentne grandes e distintas especialmente em $V$. multinervia e algumas espécies afins. Em V. surinamensis e outras espécies muito próximas, são notavelmente localizadas, distalmente, na inflorescência, envolvendo fascículos florais mais novos. Bractéolas são sempre ausentes.
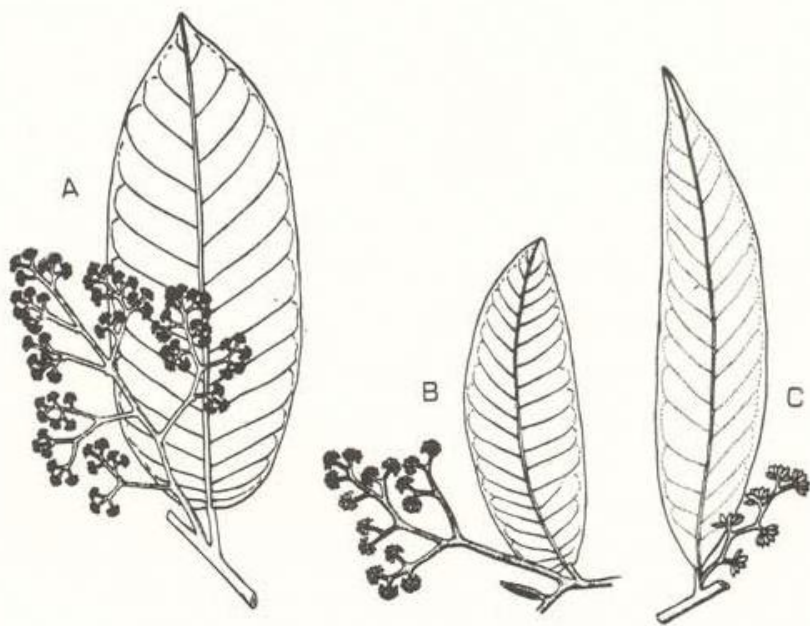

Fig. 2 - Alguns tipos característicos de inflorescência de Virola: A) livremente ramificada; B) uni- ou biramosa; C) racemiforme ou simples.

Fascículos florais masculinos, dispostos em geral distalmente, ná inflorescência, são muito variáveis em número de flores, porém há algumas espécies, cujos fascículos chegam a ter até cerca de 100 flores cada um, como em V. minutiflora. O perigônio pode ser membranáceo ou tenuemente carnoso, infundibuliforme, 3- ou 4 (raro 5)- lobado desde menos de $1 / 3$ até quase a base de seu comprimento total. Freqüentemente, esses lóbulos podem apresentar, caracteristicamente uma visivel nervura mediana. O tamanho do androceu também é muito variável, o mesmo ocorrendo. proporcionalmente, entre andróforo e antera. $O$ menor androceu medido tinha cerca de $0,6 \mathrm{~mm}$ de comprimento e o maior, $2,5 \mathrm{~mm}$ (V. subsessilis). Há um grupo de espécies que se distingue facilmente pelo maior ou menor comprimento proporcional entre andróforo e antera, porém há um outro grupo em que essa relação não é bem definida, tornando-se, por conseguinte, difícil elaborar grupos taxonômi$\cos$ baseando-se, enfaticamente, nessas relações, como tentaram antes De Candolle (1856) e Warburg (1897). Veja fig. 3 e 4 . Alguns 
andróforos são filiformes, outros carnosos, alguns são caracterizados pelo estrangulamento brusco na parte distal, como em V. calophylla e V. malmei. As anteras podem ser apiculadas ou obtusas no ápice, soldadas inteiramente ou divergentes distalmente, porém nunca livres totalmente como acontece com muita freqüência nos outros gêneros americanos, exceto apenas em Osteophloem. A fig. 3 a-m ilustra alguns tipos de androceu ocorrentes no gênero. As inflorescências femininas geralmente são mais curtas que as masculinas e suas flores caracteristicamente maiores. O ovário é séssil, monocarpelar, densamente tomentoso e com um único óvulo basal. Quase sempre o estilete é muito curto ou nulo e o estigma geralmente bífido, muito pequeno e quase séssil.

INFRUTESCÊNCIA - A infrutescência costuma ser curtamente pedunculada, com exceção apenas de raras espécies tal como $V$. loretensis, comentada anteriormente. Os frutos são subglobosos, elípticos ou oblongos, nunca transversalmente elípticos, como em geral ocorre nos gêneros Iryanthera e Osteophloem. Muitos são essencialmente carenados, outros lisos. 0 pericarpo varia de muito fino a espesso e lenhoso como em $V$. albidiflora e outras. A pubescência pode variar de uma espécie para outra e mesmo dentro de uma mesma espécie. Outros frutos, como os de $V$. sebifera, são densamente pilosos a princípio, passando a glabrescentes ou puberulentos com o tempo.

Muitas outras espécies apresentam essas mesmas características. Frutos densa e persistentemente setuloso-tomentosos ocorrem, notadamente, em alguns grupos de plantas como em $V$. Ioretensis, $V$. mollissima, $V$. divergens, V. multinervia e $V$. decorticans. A maioria das sementes é envolvida por um arilo avermelhado e laciniado quase totalmente ou pelo menos além da metade de seu comprimento total. V. oleifera e V. gardneri distinguem-se das demais espécies pelo arilo pouco laciniado. Na primeira espécie, o arilo só é laciniado no terço superior e seus lóbulos são poucos e relativamente largos, terminando, distalmente. por uma ponta subaguda.

A. semente é mais ou menos da mesma forma do fruto, isto é, globosa ou elíptica.
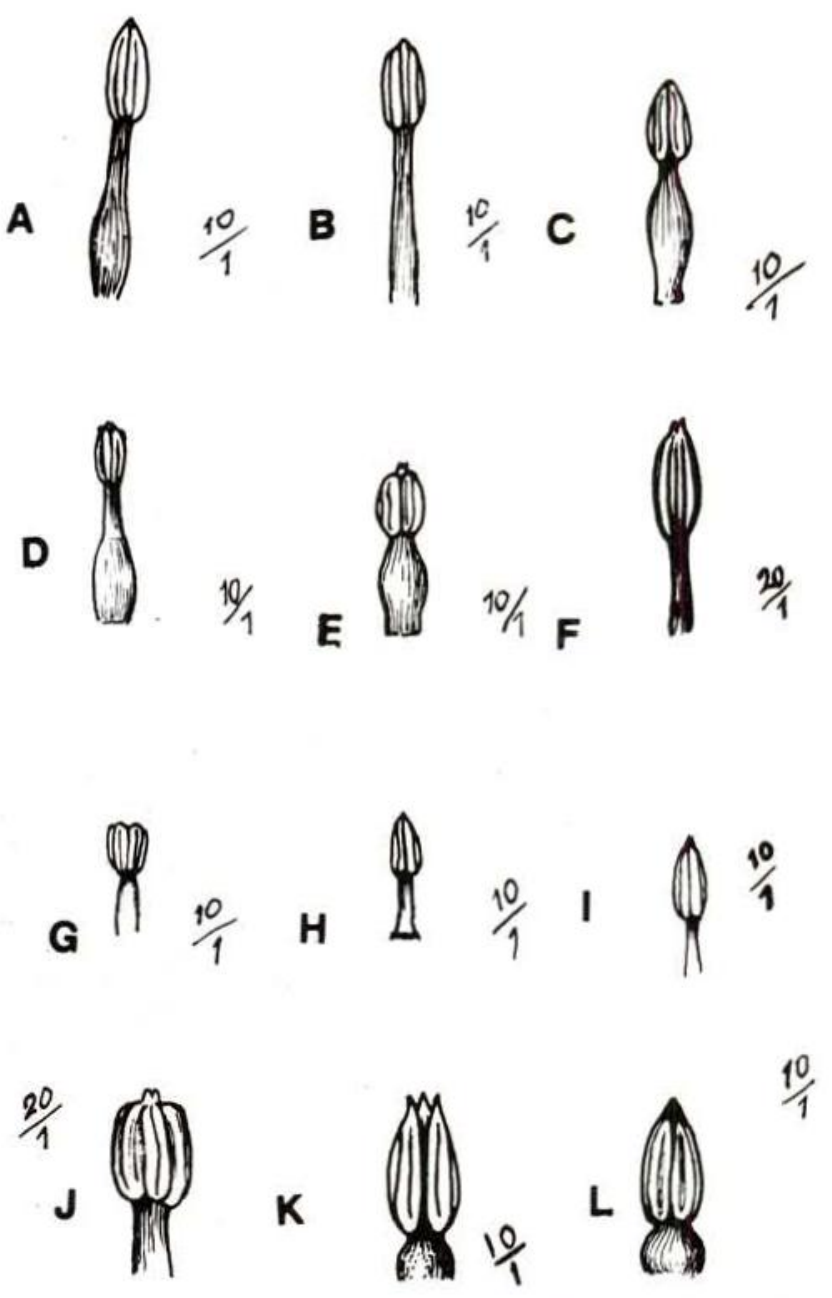

Fig. 3 - Alguns tipos característicos de androceu de Virola: A) V. venosa (Ducke RB 18630); B) V. carinata (Ducke RB 21203); C) V. parvifolia (Ducke RB 24553); D) V. albidiflora (Ducke RB 24563); E) V. calophylla (Ducke RB 18632); F) V. crebrinervia (Ducke RB 25311): G) V. duckei (Ducke RB 24563); H) V. minutiflora (Ducke RB 24559); I) V. decorticans (Ducke RB 25551); J) V. loretensis (Ducke RB 17983); K) V. divergens (Ducke 24550); L) V. sebifera (Ducke MG 11871).

Possui uma testa lisa, fina e quebradiça e um endosperma ruminado. O embrião é constituído de cotilédones suberetos, livres e escassamente conados. A germinação é criptocotilar, epígea, dicotiledonar, com os cotilédones peciolados bem acima do solo, envolvidos pelo espermoderma até o seu desprendimento, os quais separam o hipocótilo do epicótilo; folhas primárias (eófilas) pecioladas, supracotiledonares, simples, alternas, conduplicadas, exestipuladas, peninérveas, inteiras, ferrugíneo-tomentosas ou glabrescentes. Fig. 5 . 


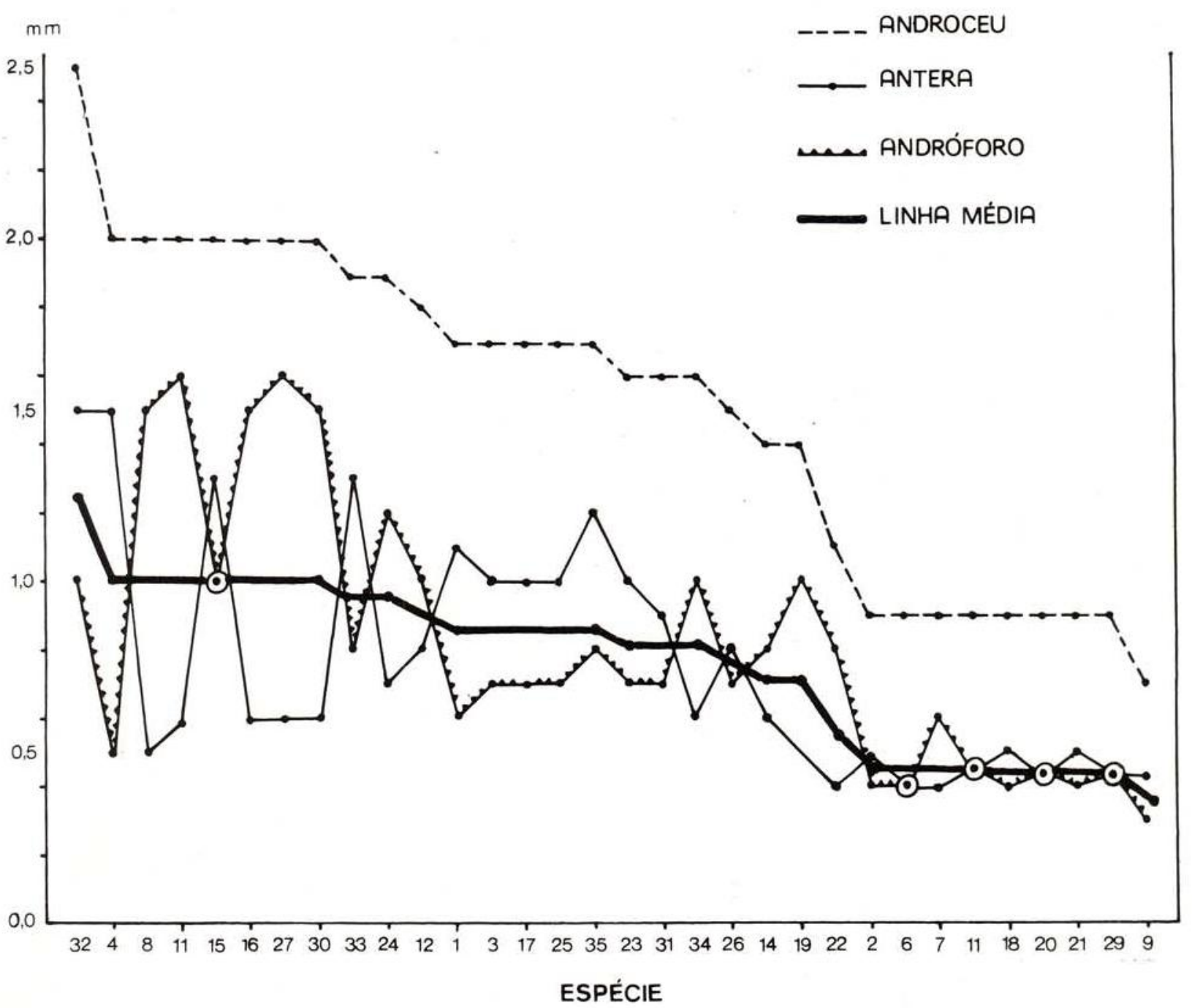

Fig. 4 - Altura comparativa entre androceu, antera e andróforo de 32 espécies de Virola. As espécies estăo dispostas por ordem decrescente de altura do androceu e cada número de referência corresponde ao mesmo da lista de espécies do Quadro 2.

Polem - Os grãos de polem de Miristicáceas do continente americano foram até agora muito pouco estudados. Os únicos trabalhos conhecidos, que tratam do assunto são os de Smith \& Wodehouse (1937), Veloso \& Barth (1962) e Erdtman (1966), sendo que destes estudos o mais importante é o dos primeiros autores citados, referente a 36 espécies dos 5 gêneros americanos, de cujo total, 17 só de Virola. Com base principalmente nesses trabalhos é que são descritas a seguir as principais características dos grãos de polem de Virola.

Grãos triangulares em vista lateral com arestas bem arredondadas. Nas outras posi- ções são mais ou menos ovais ou amplamente elipsoides. A forma triangular ou oval está relacionada com a condição higrométrica do polem. Quando o sulco é profundamente invaginado, pode tomar a forma de disco e quando é evaginado, pode-se apresentar sob a forma irregularmente globular ou mesmo esferoidal. São unissulcados ou monocolpados (Eames 1961) longitudinalmente em toda extensão do seu comprimento, localizando-se os sulcos numa das arestas do triângulo, nunca na parte proximal. Os sulcos são simples e de contornos um pouco irregulares. A exina é fina, uniformemente perfurada ou reticulada, exceto na região do sulco, em cuja região é geralmente 
fragmentada ou marcada por uma fenda longitudinal. A sexina é mais espessa que a nexina. A intina é delgada, exceto numa faixa estreita, longitudinai do lado ventral do grão subjacente ao suco, na qual é grandemente espessada e fortemente afundada no protoplasto. Segundo Smith \& Wodehouse (I.c. 1937), as dimensões do polem variam de 22 a $27,5 \mu \mathrm{m}$ de comprimento ou diâmetro. As medições dos grãos de polem de $V$. oleifera, segundo Veloso \& Barth (I.c., 1962), apresentam variações contorme o método empregado. Pelo de acetólise, o diâmetro foi de $29,03 \pm 0,43 \mu \mathrm{m}(26,34-36,08)$ $\mu \mathrm{m}$ e pelo método de Wodehouse, o diâmetro obtido foi de $24,47 \pm 0,33(22,96-27,88) \mu \mathrm{m}$. Fig. 6 e 7 .

Resumidamente, de acordo com a chave de identificação de Wodehouse e Smith (I.c. 1937), os grãos de pólem de Virola distinguemse dos demais gêneros americanos de Miristicáceas pelas seguintes diferenças:

1) - Sulco não bem definido superficialmente;

2) - Espessamento do sulco em faixa estreita;

3) - Grãos de 22-27 $\mu \mathrm{m}$ de comprimento;

4) - Exina perfurada ou reticulada; e

5) - Grãos de forma alongada ou globular.

Os grãos de pólem de Virola são essencialmente semelhantes interespecificamente, exceto na textura da exina. Ainda, de acordo com os autores acima citados, as variações encontradas são relativamente pequenas no polem das diferentes espécies e parecem ser para a maiơria sem significância filogenética.

ANATOMia DA MAdeira - Camadas de crescimento pouco distintas; quando definidas, apresentam-se com faixas estreitas de fibras mais ou menos achatadas radialmente e, freqüentemente, de paredes relativamente mais espessas ou, então, com parênquima terminalinicial. Vasos podem ser solitários, geminados (maioria) múltiplos e grupados, de forma circular, oval ou ovoide, de parede espessa, muito pequenos a médios, de muito poucos a moderadamente numerosos (até $15-18$ por $\mathrm{mm}^{2}$ ) ae diâmetro tangencial em geral médio, não ultrapassando $230 \mu \mathrm{m}$. Elementos vasculares variam de muito curtos a muito longos com predominância destes, podendo chegar até $2300 \mu \mathrm{m}$ de comprimento. Pontuações intervasculares areoladas, numerosíssimas, alternas, pequenas a grandes, abertura inclusa e curta, de alinhamento vertical, contorno ovalado ou elíptico e, às vezes, poligonal; fenda estreita, lenticular, de direção horizontal ou oblíqua. Pontuações radiovasculares com pares semi-areolados, diminutos a muito grandes, de contorno elíptico, ovalado, arredondado, alongado ou, às vezes. achatado radialmente. Placas de perfuração horizontal ou oblíqua, a maioria simples, às vezes escalariformes e foraminadas, com barras de espessura média; tiloses, às vezes, presentes. Parênquima axial paratraqueal escasso, reduzido a algumas células em contato com os raios ou próximas dos vasos; terminal-inicial formando faixas de 1 ou 2 células de largura, às vezes, presente; óleo-resina geralmente abundante. Parênquima radial 1-,2-

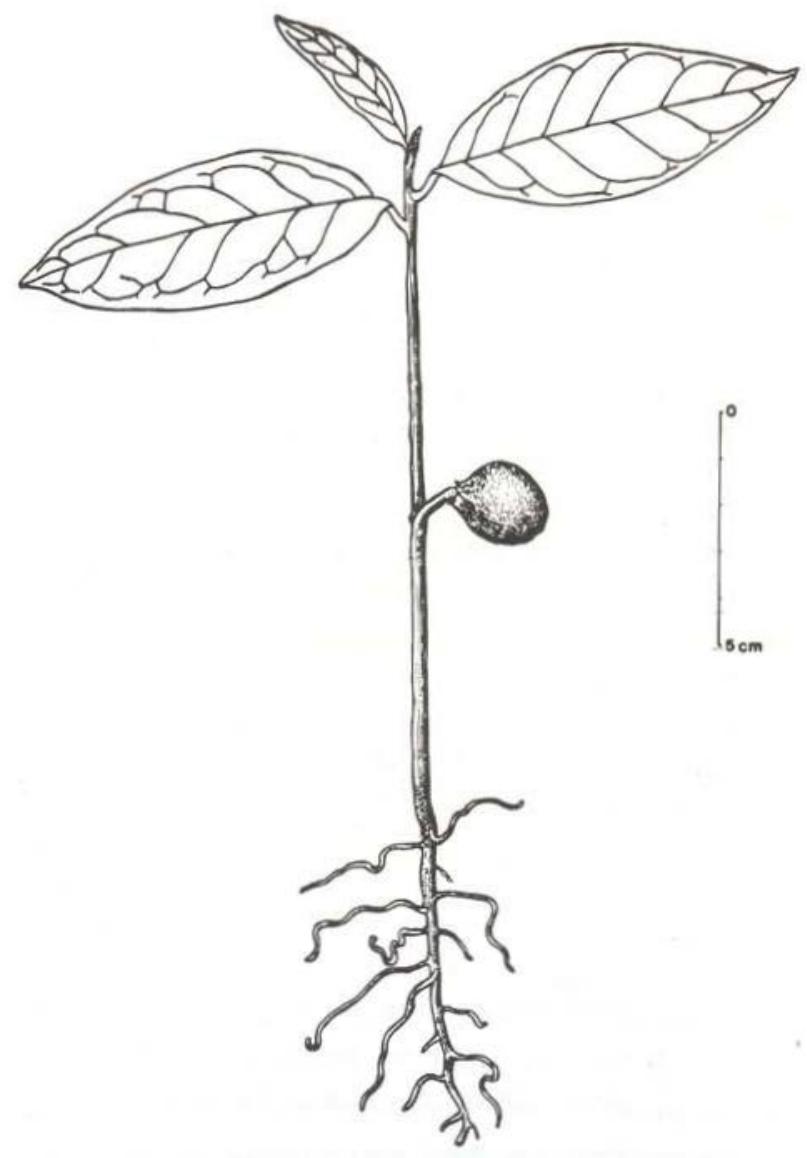

Fig. 5 - Plântula de Virola surinamensis (W. Rodrigues INPA 37127). 
e 3- seriado, às vezes até 3-,6-seriado, apresentando-se os 2-seriados como os mais freqüentes; extremamente baixos a baixos, cerca de $1000 \mu \mathrm{m}$ de altura, excepcionalmente acima de $2000 \mu \mathrm{m}$; geralmente heterogêneos (tipos 1,11-A e $B$ de Kribs), às vezes, quase homogêneos; de muito numerosos a numerosos, variando de 5 a 25 por $\mathrm{mm}^{2}$ (Honda, 1971) e de 2 a 43 células de altura, os 1-seriados até 15 células; células apicais de $2-15$ células altas e quadradas, formando muitas vezes expansões mais longas que a parte multisseriada; tubos taníferos muitas vezes presentes em raios ocasionais. Fibras em geral libriformes, homogêneas, de secção quadrangular a achatada, às vezes, irregularmente circular, oval, elíptica ou poligonal, dispostas em fileiras radiais, algumas septadas delimitando camadas de crescimento e distintas em secção radial, variando de muito curtas a muito longas, de comprimento entre 860 a $2400 u \mathrm{~m}$ e diâmetro de 15 a $33 \mu \mathrm{m}$; paredes delgadas de lumen grande a médio; pontuações numerosas nas paredes radiais, simples, lenticelares ou inconspicuamente areoladas, paralelas e ligeiramente obliquas às paredes das fibras. Madeira de cerne variável do castanho avermelhado claro ou escuro ao castanho claro uniforme, às vezes, com reflexos dourados ou amarelados, muitas vezes distinto do alburno castanho-claro; textura média a grosseira, grão regular, sem cheiro e gosto distintos, variando de leve a mole e moderadamente pesada e dura. Fig. 8 A-C.

Descrição baseada, principalmente, nos estudos anatômicos de Martin-Lavigne (1909), Garratt (1933a), Machado (1949), Mello (1950), Mainieri (1962), Metcalfe \& Chalk (1965), Pereira (1970) e Honda (1971).

Segundo Garratt (1933a), Virola se distingue dos demais gêneros conhecidos da América e África principalmente pelas seguintes diferenciações :

1) - Perfuração dos vasos predominantemente a quase exclusivamente simples $(30 \%$ ou mais de abertura) .

2) - Perfuraçöes reticuladas e escalariformes compostas aparentemente ausentes, estas últimas, quando, presentes, com 1-6 barras.
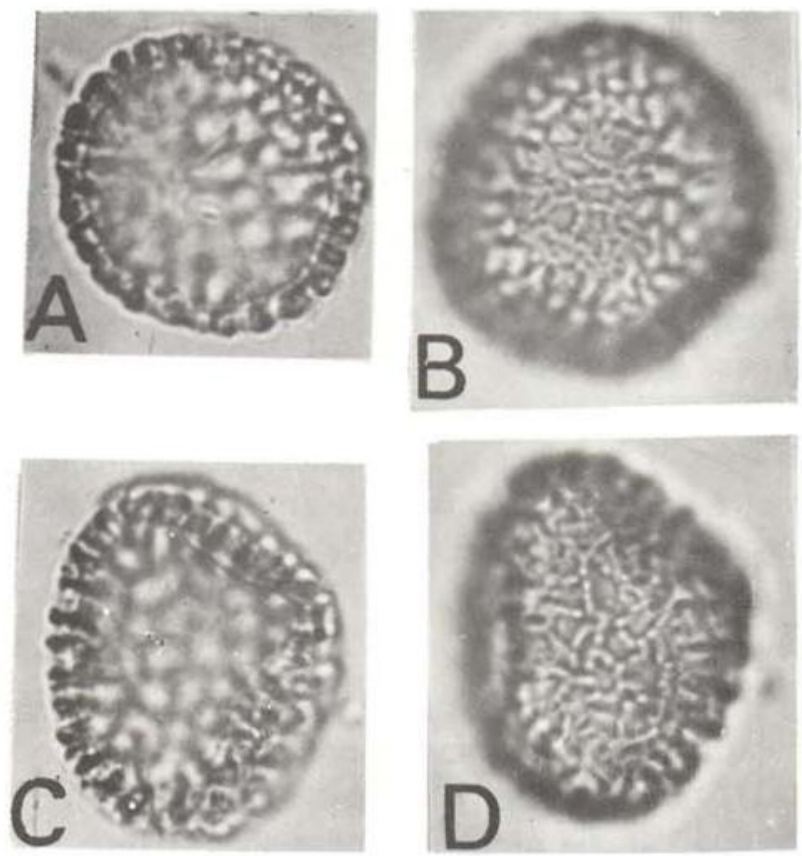

Fig. 6 - Grãos de polem de Virola venosa com exina reticulada (L. Carrera s.n., INPA), X 1000. A e B, vista polar; C e D, vista lateral.
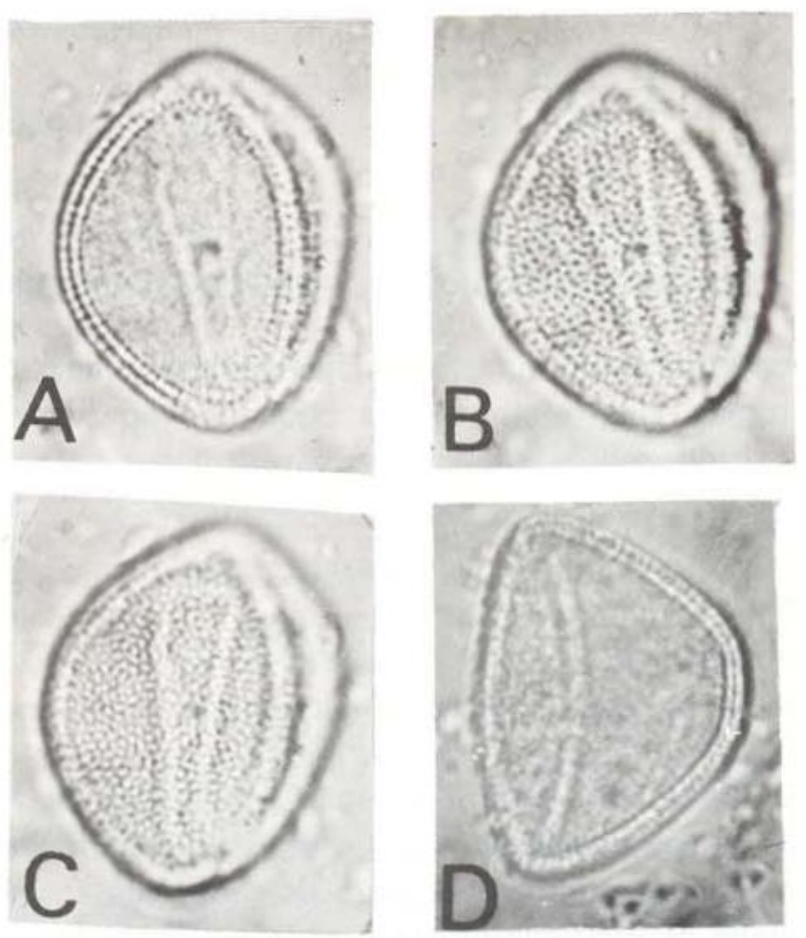

Fig. 7 - Grãos de polem de Virola surinamensis com exina perfurada (R. Siqueira s.n., MG 8781, INPA), $X$ 1000. A, B e C, vista equatorial; D, vista lateral, 


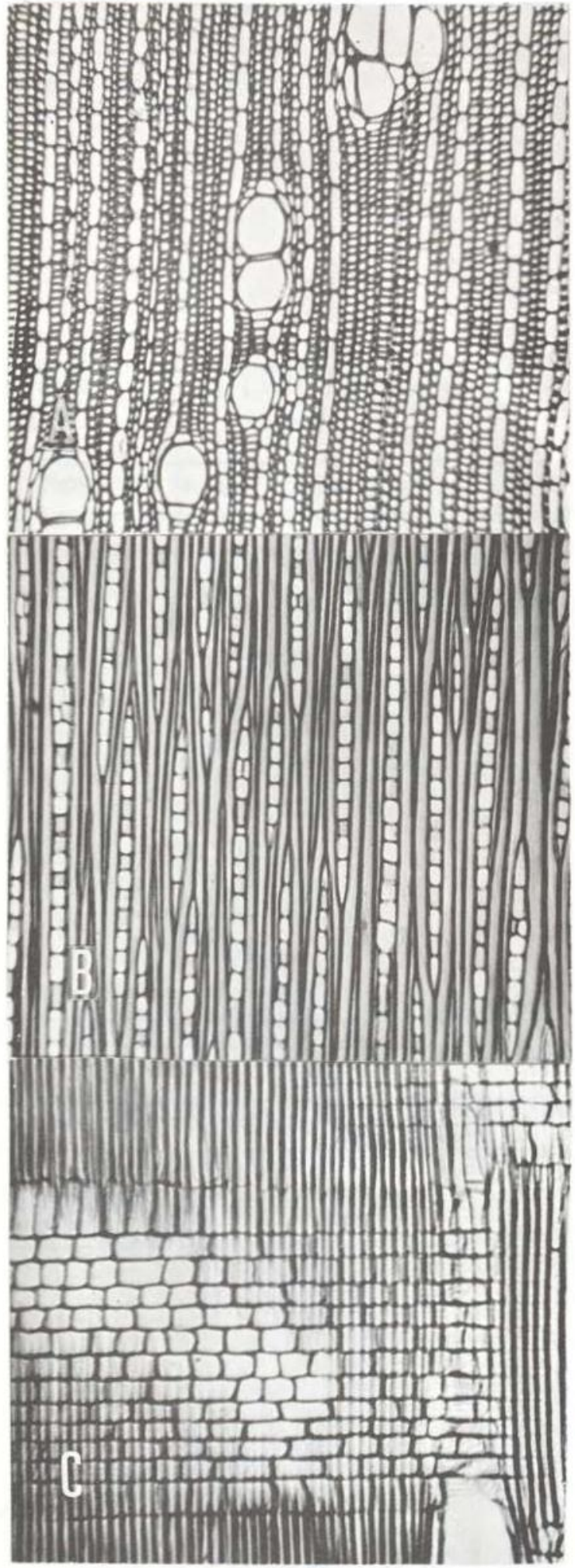

Fig. 8-Características anatômicas da madeira de Virola loretensis (lâmina INPA $n 0^{\circ} 285 A$ ). A, seção transversal (X 60); B, seção tangencial ( $X$ 60); C, seção radial $(X 60)$.
3) - Camadas de crescimento freqüentemente presentes, delimitadas por fibras lenhosas achatadas ou faltando inteiramente.

4) - Raios predominantemente unisseriados, às vezes, definidamente trisseriados e, em alguns casos, localmenmente tetra - a pentasseriados.

\section{OBSERVAÇÕES FENOLÓGICAS}

Observações fenológicas são muito importantes não só para os estudos botânicos como para a prática de Silvicultura. Dados a respeito no Brasil são, infelizmente, muito escassos, especialmente, sobre o gênero Virola. Dentre os raros trabalhos que tratam quase que exclusivamente deste assunto, sobressaem-se os de Araújo (1970), Pereira \& Pedrosa (1972) e Fonseca Filho apud Mendes Guimarães (1955). Algumas referências ocasionais sobre fenologia de Virola são também encontradas em Veloso (1947), Mello (1950), Reitz (1968) e Hatschbach (1972), Rodrigues (1972) e Lemos (1973). Infelizmente, estes dados disponiveis referem-se a muito poucas espécies (cerca de 6). razão pela qual este capítulo foi criado para que se pudessem tecer alguns comentários de ordem geral sobre a fenologia do gênero. Melhores dados sobre todas as espécies vão ser encontrados no tratamento sistemático, que se faz de cada uma delas.

Inicialmente, convém relembrar aqui o ób. vio valor do herbário como uma importante fonte de informação de dados fenológicos, quando não se dispõe de outros elementos. O quadro 3, apesar de baseado em muito poucas espécies e em dados muito esparsos, confirma isto, quando se comparam os dados coligidos de literatura com os de herbário.

De acordo com a observação acima, foram elaboradas as Fig. 9-20, fundamentadas nas 12 espécies mais importantes pelo número disponivel de exsicatas. Para confecção destas figuras, coleções botânicas feitas mais de uma vez num mesmo mês e ano, qualquer que fosse a localidade ou região de coleta, eram consideradas, para efeito de contagem de anos de cada fitofase, como uma única unidade. Desta 
Período de floração e frutificação de algumas espécies de Virola ocorrentes no Brasil, conforme dados de herbário.

A floração é indicada por traços interrompidos (- - - e a frutificação, por linha cheia (-

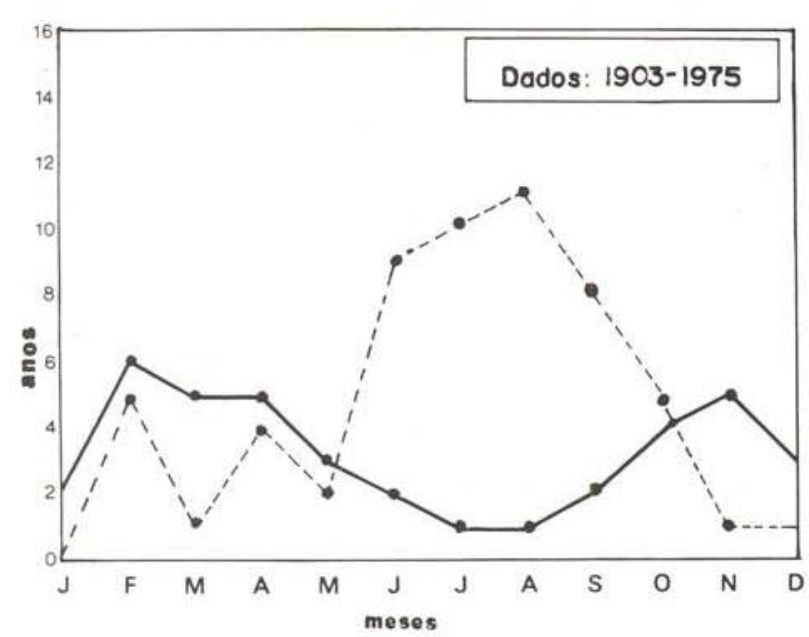

Fig. 9 - Virola calophylla Warb.

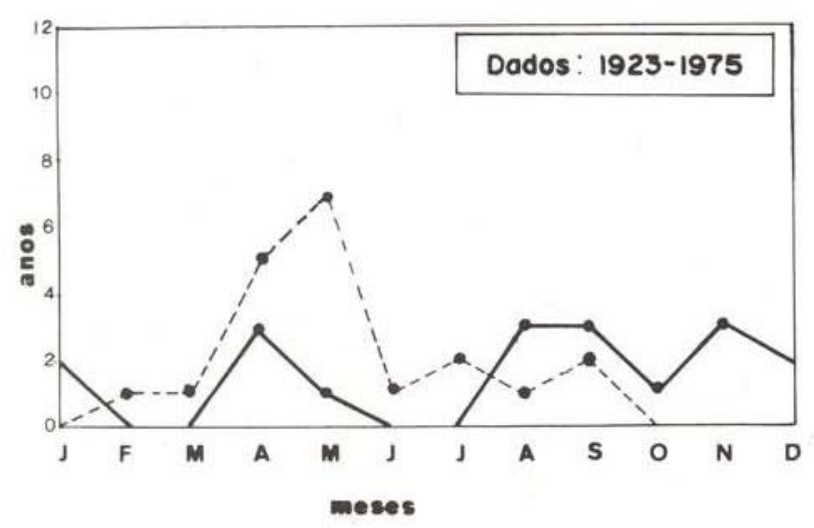

Fig. 11 - Virola divergens Ducke.

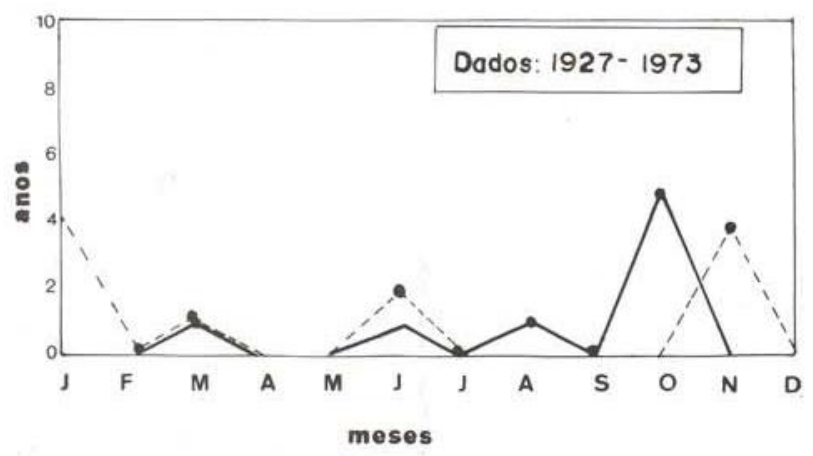

Fig. 13 - Virola gardneri (A. DC.) Warb.

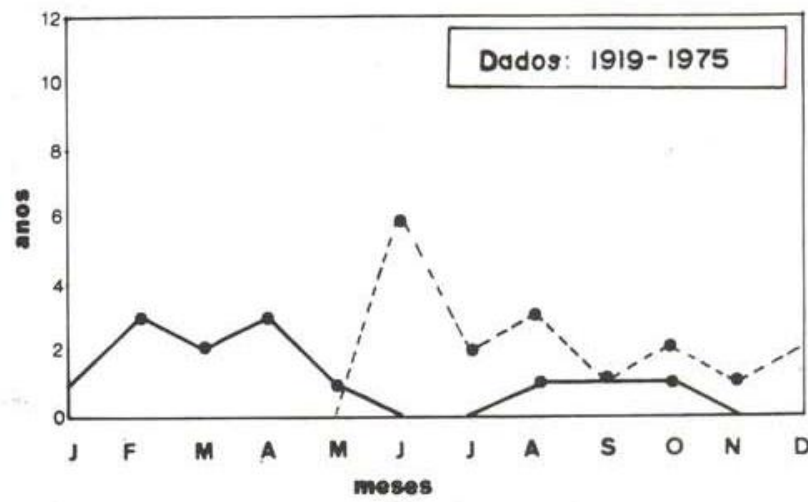

Fig. 10 - Virola carinata (Spr. ex Bth.) Warb.

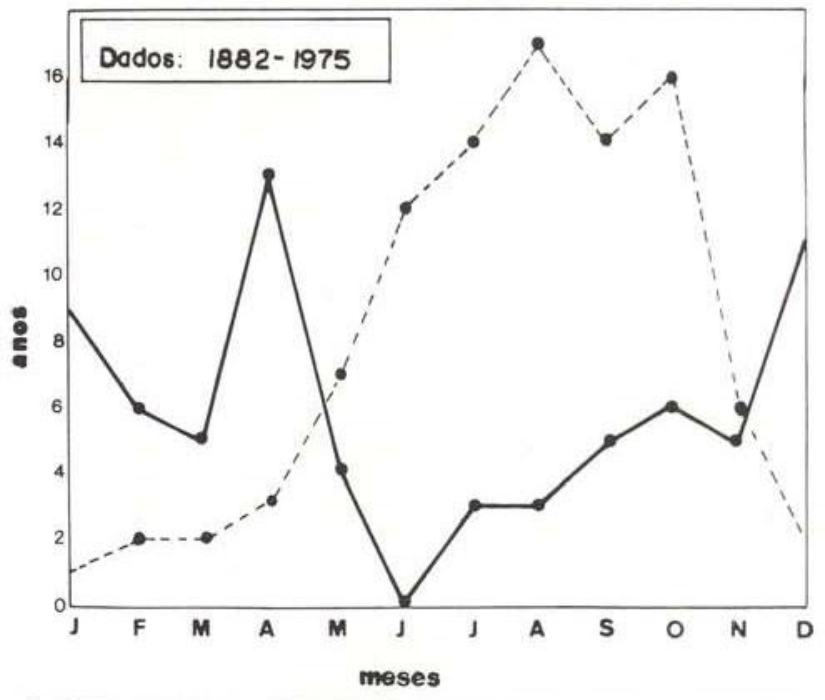

Fig. 12 - Virola elongata (Spr. ex Bth.) Warb.

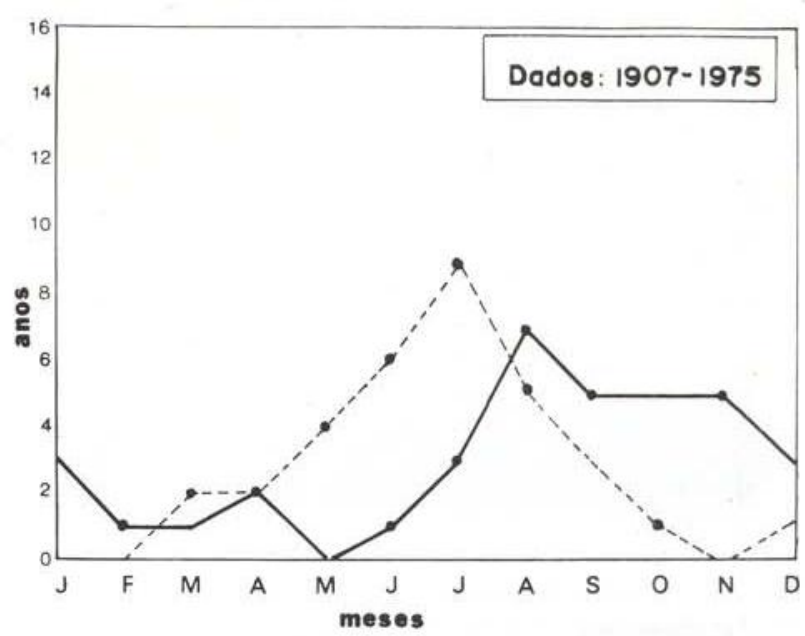

Fig. 14 - Virola michelii Heckel. 
Periodo de floração e frutificação de algumas sspécies de Virola ocorrentes no Brasil, conforme dados de herbário

A floração é indicada por traços interrompidos (_ - - ) e a frutificaçăo, por linha cheia (- - ).

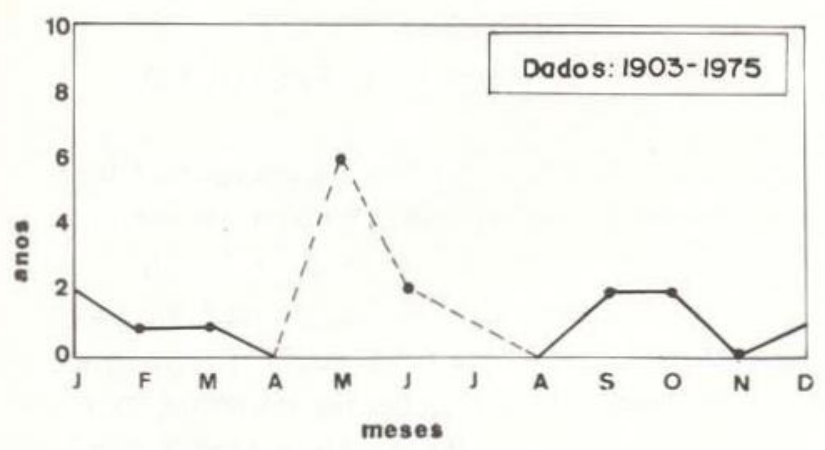

Fig. 15 - Virola multinervia Ducke.

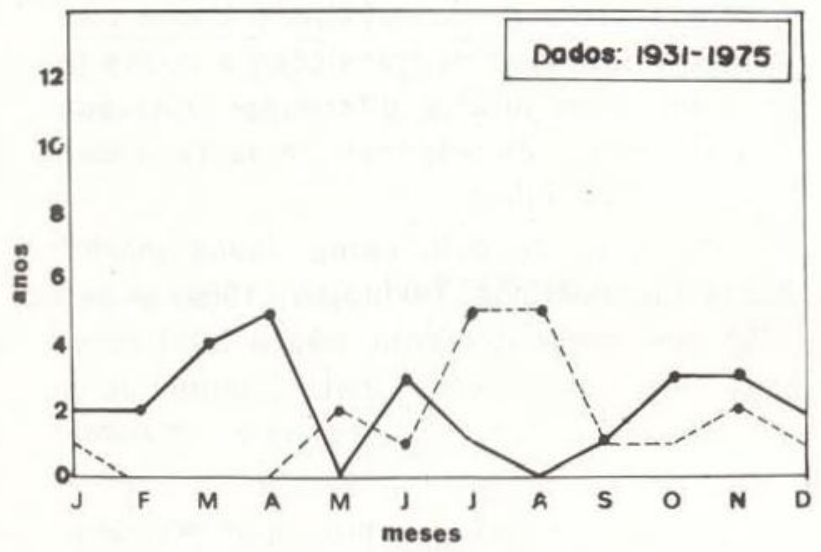

Fig. 17 - Virola pavonis (A. DC.) A. C. Smith.

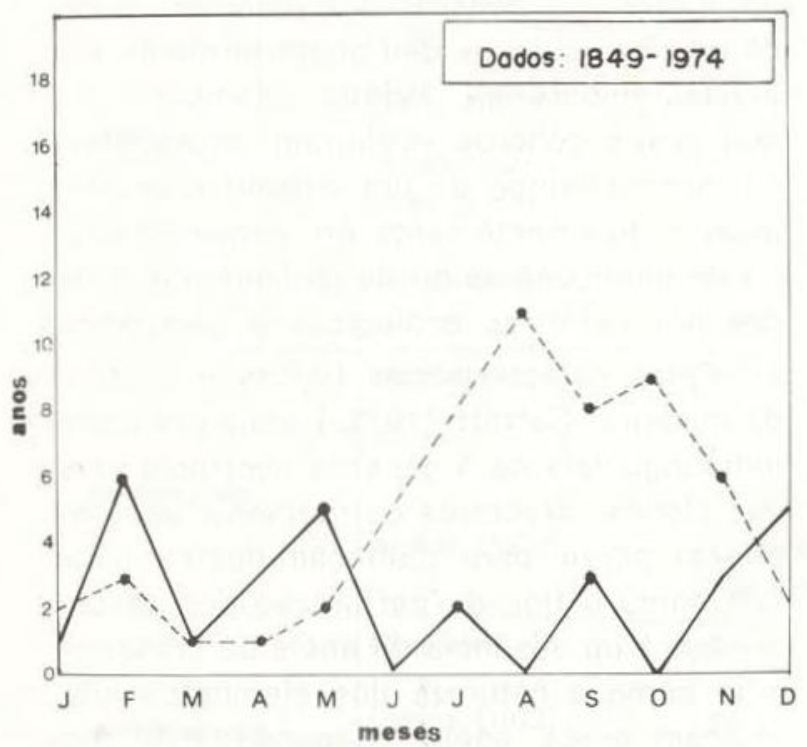

Fig. 19 - Virola surinamensis (Rol.) Warb.

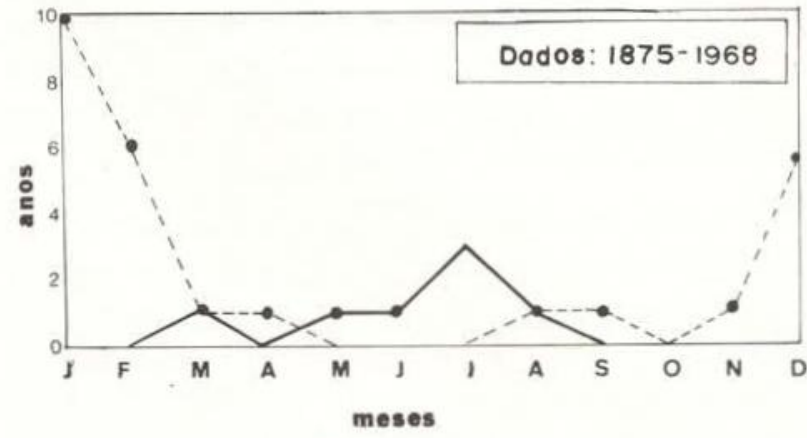

Fig. 16 - Virola oleifera (Schott) A. C. Smith.

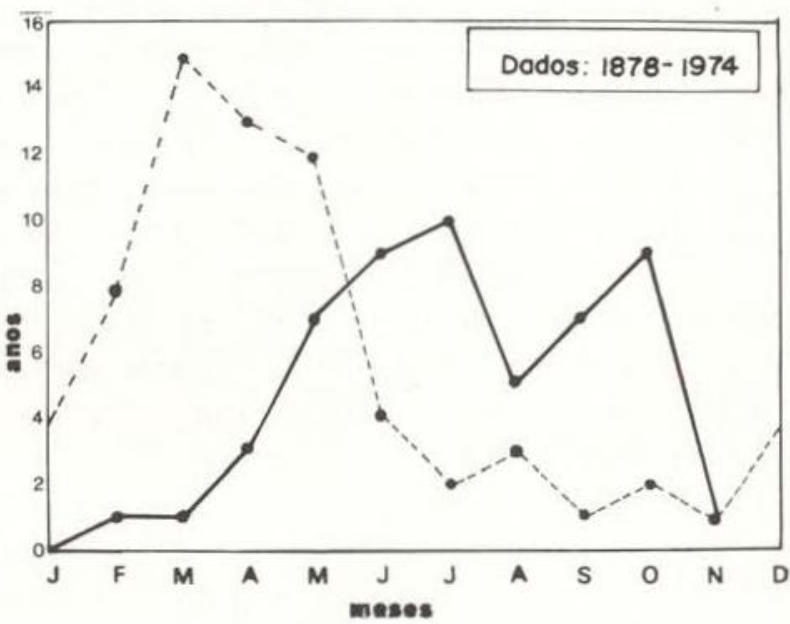

Fig. 18 - Virola sebifera Aublet.

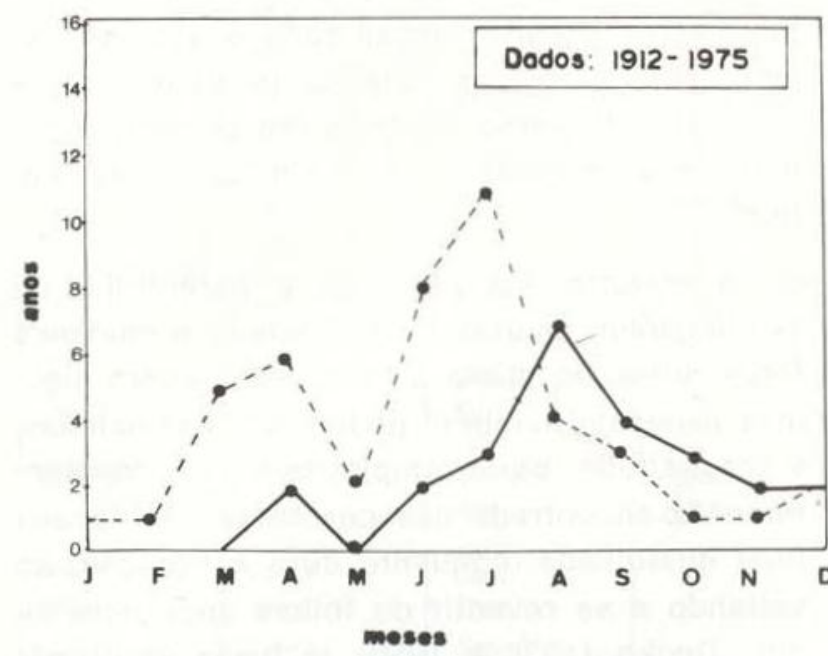

Fig. 20 - Virola venosa (Bth.) Warb. 
forma, a curva mensal de cada fitofase representa a somatória de anos contínuos ou des. contínuos dos períodos de floração e frutificação de todas as exsicatas compulsadas. Em geral, todas estas figuras foram elaboradas com dados de coleta de um período de mais de 40 anos, conforme se pode verificar nas anotações apostas em cada uma delas.

Como as figuras mostram claramente, em nenhum caso houve superposição dos principais picos de cada fitofase. Quando um pico cai o outro automaticamente se sobressai e assim sucessivamente. O mesmo acontece com as curvas de floração e frutificação, embora, às vezes, menos acentuadamente.

Para a maioria das espécies tipicamente amazônicas, a floração parece coincidir com a estação estival e a frutificação, com a época das chuvas. Com referência à $V$. divergens (fig. 11), V. michelii (fig. 14), V. multinervia (fig. 15) e V. venosa (fig. 20), espécies em geral muito mais abundantes dos arredores de Manaus do que de outra parte da Hiléia. no entanto, a maior freqüência de floração ocorre no final da estação chuvosa e a frutificação, em plena estiagem até parte da estação chuvosa. Para as espécies mais tipicamente extra-amazônicas, tais como V. oleifera (fig. 16) e V. sebifera (fig. 18), a floração coincide em geral com o verão e a frutificação, com a estação fria. V. gardneri (fig. 13), aparentemente, não tem uma estação bem definida para as duas fitofases. A frutificação é assinalada intermitentemente durante quase todo o ano. A floração parece ocorrer mais no fim da primavera até o fim do verão, embora em pleno inverno tenha sido encontrada também, às vezes, em flor.

A maioria das espécies é perenifolia ou semidecíciua, ocorrendo geralmente a mudança foliar antes do início da floração, porém algumas exceções também podem ser assinaladas. V. caducifolia, por exemplo, tem sido freqüentemente encontrada nas cercanias de Manaus toda desfolhada, enquanto dura a floração, só voltando a se revestir de folhas após este ciclo. Ducke (1936 e 1950) já hayia verificado este mesmo fenômeno em $V$. multicostata. $V$. flexuosa, conforme os exemplares de herbário deixam transparecer, parece que apresenta esta mesma tendência, pelo menos no início da fioração.

\section{RELAÇÕES GENÉRICAS E EVOLUÇÃO}

Não estão bem claras as relações filogenéticas tanto dos vários gêneros de Myristicaceae como também da própria família.

Esta pantropical família possui ao todo 16 gêneros reconhecidos, os quais, fitogeograficamente, formam 3 grupos de especiação muito distintos. O grupo da América tem 5 gêneros, o da Ásia, 4 e o da África e Madagascar, 7.

Segundo Engler \& Prantl apud Garratt (1933a), estes grupos fitogeográficos não se combinam através de transições e quase todos eles mostram nítidas diferenças, não apenas nas flores e inflorescência, mas também nos frutos e nas folhas.

Por falta de suficientes dados morfológicos e filogenéticos, Takhtajan (1969) é de opinião que, presentemente, não é fácil reconhecer, entre os gêneros desta familia, os mais primitivos. O mesmo acontece, obviamente. com os gêneros americanos.

Warburg (1897) admite que os gêneros neotropicais seguiram linhas distintas de de senvolvimento, sendo bem mais relacionados entre si do que qualquer outro do Velho Mundo, e que a monadelfia dos estames, encontrada nos 3 grupos, se deu posteriormente e independentemente na família. Também, sugere que esses gêneros evoluiram, provavelmente, ao mesmo tempo de um mesmo ancestral comum e divergentemente em conseqüência não só de mutações como de isolamentos provocados por barreiras ecológicas e geográficas

Pelas características físicas e anatômicas da madeira, Garratt (1933a) acha praticamente indistinguíveis os 5 gêneros neotropicais. Apenas alguns caracteres estritamente anatômicos podem servir para dịstinção destes gêneros, tais como o tipo de perfuração dos vasos e a presença ou ausência de anéis de crescimento, bem como a natureza dos elementos que demarcam estes anéis. Segundo este mesmo autor, também, raramente, é possível identificar espécies apenas pela madeira. 
A fitogeografia, possivelmente, não oferece subsídios para explicação sobre a evolução dos gêneros, porque quase todos eles estão bem representados em ambos os lados dos Andes, com exceção apenas de Iryanthera, o qual parece não ocorrer na região transandina, provavelmente por ter surgido depois do Terciáric, quando esta cordilheira se formou. Todos estes gêneros têm a Amazônia como o seu centro de distribuição geográfica.

QUADRO 3 - Quadro comparativo da fenologia de algumas espécies de Virola baseado em fontes bibliográficas e de herbário.

\begin{tabular}{|c|c|c|c|c|c|c|}
\hline \multirow{2}{*}{ Espécie } & \multirow{2}{*}{ Fonte de informação } & \multicolumn{2}{|c|}{ Observação } & \multicolumn{3}{|c|}{$\begin{array}{l}\text { Fitofase } \\
\text { (mês) }\end{array}$} \\
\hline & & $\begin{array}{l}\text { Locali- } \\
\text { dade }\end{array}$ & $\begin{array}{c}\text { Periodo } \\
\text { (ano) }\end{array}$ & Floração & $\begin{array}{l}\text { Frutifi- } \\
\text { caçäo }\end{array}$ & $\begin{array}{c}\text { Mudança } \\
\text { foliar }\end{array}$ \\
\hline $\begin{array}{l}\text { V. michelii }(=\mathrm{V} . \\
\text { melinonii) }\end{array}$ & $\begin{array}{l}\text { Herbário } \\
\text { Araújo (1970) }\end{array}$ & $\begin{array}{l}\text { Brasil } \\
\text { Amazonas: } \\
\text { Manaus }\end{array}$ & $\begin{array}{l}1907- \\
1945 \\
1962-68\end{array}$ & $\begin{array}{l}\text { Mar./ } \\
\text { Set. } \\
\text { Jul./ } \\
\text { Set. }\end{array}$ & $\begin{array}{l}\text { Jun./ } \\
\text { Abr. } \\
\text { Nov./ } \\
\text { Jan. }\end{array}$ & $\begin{array}{l}\text { Abr./ } \\
\text { Jul. } \\
-\end{array}$ \\
\hline $\begin{array}{l}\text { Virola sp. (prova- } \\
\text { velmente v. mi- } \\
\text { chelii }\end{array}$ & $\begin{array}{l}\text { Pereira \& Pe- } \\
\text { drosa (1972) }\end{array}$ & $\begin{array}{l}\text { Pará: } \\
\text { Curuá-Una }\end{array}$ & 10 anos & $\begin{array}{l}\text { Jul./ } \\
\text { Ago. }\end{array}$ & $\begin{array}{l}\text { Out./ } \\
\text { Dez. }\end{array}$ & $\begin{array}{l}\text { Parcial } \\
\text { (perene) }\end{array}$ \\
\hline V. gardneri & $\begin{array}{l}\text { Herbário } \\
\text { Mendes-Maga- } \\
\text { lhães (1955) }\end{array}$ & $\begin{array}{l}\text { Brasil } \\
\text { Minas } \\
\text { Gerais: } \\
\text { Beio Hori- } \\
\text { zonte }\end{array}$ & $\begin{array}{c}1927- \\
1973 \\
?\end{array}$ & $\begin{array}{l}\text { Nov. } \\
\text { Jan./ } \\
\text { Mar. e } \\
\text { Jun. } \\
-\end{array}$ & $\begin{array}{l}\text { Out./ } \\
\text { Jun. e } \\
\text { Ago. } \\
\text { Out. }\end{array}$ & $\begin{array}{l}- \\
-\end{array}$ \\
\hline V. officinalis & $\begin{array}{l}\text { Herbário } \\
\text { Veloso (1947) }\end{array}$ & $\begin{array}{l}\text { Brasil } \\
\text { (Bahia) } \\
\text { Bahia: } \\
\text { Ilhéus }\end{array}$ & $\begin{array}{l}1944 \\
1944\end{array}$ & $\begin{array}{l}\text { Set. } \\
\text { Set. }\end{array}$ & $\begin{array}{l}- \\
\text { Ago./ }\end{array}$ & $\begin{array}{l}- \\
-\end{array}$ \\
\hline V. oleifera & $\begin{array}{l}\text { Herbário } \\
\text { Hatschbach } \\
\text { (1972) } \\
\text { Mello (1950) } \\
\text { Mendes-Maga- } \\
\text { lhães (1955) } \\
\text { Reitz (1968) }\end{array}$ & $\begin{array}{l}\text { Rio Jan: } \\
\text { Itatiaia } \\
\text { Minas } \\
\text { Gerais: Belo } \\
\text { Horizonte } \\
\text { Sta. Cata- } \\
\text { rina }\end{array}$ & $\begin{array}{l}? \\
- \\
-\end{array}$ & $\begin{array}{l}\text { Ago./ } \\
\text { Abr. } \\
\text { Out./ } \\
\text { Nov. } \\
\text { Verão } \\
\text { Jan./ } \\
\text { Mar.) } \\
\text { (Jan./ } \\
\text { Abr. }\end{array}$ & $\begin{array}{l}\text { Mar./ } \\
\text { Ago. } \\
\text { Jan./ } \\
\text { Fev. } \\
\text { Inverno } \\
\text { (Jun./ } \\
\text { Set./ } \\
\text { Out./ } \\
\text { Dez. }\end{array}$ & $\begin{array}{l}- \\
- \\
- \\
\text { Semide- } \\
\text { cídua }\end{array}$ \\
\hline V. multicostata & $\begin{array}{l}\text { Herbário } \\
\text { Araújo (1970) }\end{array}$ & $\begin{array}{l}\text { Brasil } \\
\text { Amazonas: } \\
\text { Manaus }\end{array}$ & $\begin{array}{l}1913- \\
1974 \\
1962-68\end{array}$ & $\begin{array}{l}\text { Jul./ } \\
\text { Out./ } \\
\text { Dez. } \\
\\
\text { Ago./ } \\
\text { Nov. }\end{array}$ & $\begin{array}{l}\text { Mar. } \\
\text { Maio./ } \\
\text { Set.J } \\
\text { Out. } \\
\text { Fev./ } \\
\text { Mar./ }\end{array}$ & $\begin{array}{l}\text { Ago. } \\
\text { Jul./ }\end{array}$ \\
\hline V. surinamensis & $\begin{array}{l}\text { Herbário } \\
\text { Lemos (1973) } \\
\text { Rodrigues } \\
\text { (1972) }\end{array}$ & $\begin{array}{l}\text { Brasil } \\
\text { Pará } \\
\text { Pará }\end{array}$ & $\begin{array}{c}1849- \\
1974 \\
- \\
-\end{array}$ & $\begin{array}{l}\text { Jan./ } \\
\text { Dez. } \\
- \\
\text { Ago. } \\
\text { Nov./ }\end{array}$ & $\begin{array}{l}\text { Jan./ } \\
\text { Dez. } \\
\text { Fev./ } \\
\text { Maio. } \\
\text { Ian./ } \\
\text { Jul. }\end{array}$ & $\begin{array}{l}- \\
- \\
-\end{array}$ \\
\hline
\end{tabular}


A unissexualidade, na maioria dos gêneros, constitui um caráter evolutivo avançado na família. Em Iryanthera, no entanto, árvores monoicas foram freqüentemente observadas em várias espécies por Smith (1937), Ducke (1950) e pelo autor pessoalmente. Subtendese, portanto, que neste gênero deve estar havendo, provavelmente, um estágio evolutivo intermediário.

Muito poucos fósseis têm sido encontrados desta família (Berry, 1916, 1916, 1929 e Gothan \& Weyland, 1964). Isto tem dificultado sobremaneira, até hoje, a interpretação de sua filogênese.

Smith (I.c.) ressalta a importância da facies vegetativa dos gêneros neotropicais como um elemento valioso na caracterização de suas relações genéricas. As partes jovens da maioria das espécies, inclusive os ramos das inflorescências $e$, freqüentemente, as flores e foIhas, estäo relacionadas a pêlos muito diferenciados. Os de Virola e Osteophloem são mais comumente estrelados, embora o primeiro gênero os tenha também de outras formas, invariavelmente, ramificados livremente. Os outros gêneros neotropicais possuem pêlos pseudomalpiguiáceos, birramosos (ou aparentemente simples e ligados pelo meio). Destes últimos, Compsoneura é muito distinto quanto à venação foliar, androceu e frutos. Dialyanthera e Iryanthera têm aspectos muito semeIhantes, porém são imediatamente identificáveis pelos frutos, presença ou não de uma bractéola na base do perianto e pela vernação foliar. Osteophloem e Virola diferem nitidamente no fruto, androceu e na bractéola e folhagem.

Smith (I.c.), hipoteticamente, propõe que são os seguintes os caracteres diagnósticos essenciais dos gêneros americanos, na ordem de sua importância evolucionária: tipo de pubescência; vernação e venação foliares; tipo de ramificação da inflorescência; fruto; presença ou não de uma bractéola na flor; e forma do grão de polem e do androceu.

Pela estrutura do grão de polem, Smith \& Wodehouse (1937) crêem que, entre os gêneros neotropicais das Myristicaceae, Dialyanthera é o mais primitivo, por apresentar grãos unissulcados, sugestivos daqueles das famílias mais primitivas da ordem das Magnoiales, e que os demais gêneros apresentam, em especial, sulcos mais especializados nesta ordem de evolução: Virola, Osteophloem, Compsoneura e Iryanthera.

Diversos estudos vêm sendo publicados recentemente sobre sistemática bioquímica das Myristicaceae americanas, visando principalmente a dar a sua valiosa contribuição à solução de alguns problemas de taxonomia e filogenia desta importante família, convindo destacar, dentre outros, os trabalhos de Barata et al. (1976), Blair et al. (1969), Braz Filho et al. $(1973,1976 a, b, c)$, Cassady et al. (1971), Franca et al. (1974, 1975), Gottlieb et al. (1973, 1975a, b), Lima et al. (1975), Oliveira et al. (1973, 1976), Wallace et al. (1963). Assim, vários constituintes químicos foram ultimamente isolados e identificados nestas plantas tais como triptaminas, diarilpropanoides (virolanos, virolanois, lignanas e neolignanas). cromanonas, flavonóides (flavanas, isoflavonas e pterocarpanos), estilbenos, esteróides (sitosterol e stigmasterol) etc.

Estes estudos já começam a dar os seus primeiros resultados com o trabalho, e. g., de Gottlieb et al. (1973), publicado em Phytochemistry, no qual tentam agrupar algumas espécies de Virola em função da presença ou não de determinados compostos nas espécies analisadas. Os diarilpropanoides virolano [1-(2-hidrox?-4-methoxifenil)-3-(3,4-metilenedioxifenil)-propano] e virolanol [2-hidroxi-1-(2-hidroxi -4- metoxifenil)-3-(3,4-metilenedioxifenil) propano] foram, portanto, assinalados por eles em Virola multinervia, $V$. venosa, $V$. divergens, V. melinonii ( $=V$. michelii), V. pavonis, V. surinamensis e eram ausentes em $V$. calophylla, $V$. elongata, $V$. rufula $(=V$. elongata $)$ e V. multicostata.

Virolano foi posteriormente encontrado em V. caducifolia (Braz Filho et al., 1976a) e em Iryanthera coriacea (Lima et al. 1975 e Oliveira \& Shaat, 1976) .

Do ponto de vista filogenético, as Myristicaceae são colocadas pelos sistematas entre as famílias mais primitivas dos Angiosperınas vivos. Vários caracteres comprovam isto, e. g., nós trilacunares, folhas alternas, anteras ex- 
trorsas, flores hipóginas, polem monocolpado. endosperma abundante e ruminado, embrião pequeno etc. A presença, no entanto, de outros caracteres de plantas bem mais especializadas nãc deixa de ser surpreendente como, e. g., flores monoclamídeas e unissexuais, estames monadeltos e gineceu monocarpelar.

isto tem levado muitos filogenistas como, e. g., Bentham \& Hooker (1880), Bessey (1915). Engler \& Diels (1936), Wettstein (1944), Uphof (1959), Eames (1961), Melchior (1964), Hutchinson (1964, 1974), Thorne (1964), Cronquist (1968), Takhtajan (1969). Sauer \& Ehrendorfer (1970) etc. a proporem diferentes ordens para a família: Micrembriae, Polycarpicae, Ranales, Annonales, Laurales, Magnoliales etc.

Recentemente, Wilson \& Maculans (1967), estudando comparativamente a morfologia floral de 2 espécies de Myristicaceae (Myristica fragrans Van Houtt e M. malabarica Lam.) com as de Canellaceae, encontraram notável semeIhança no androceu das 2 famílias, sugerindo, portanto, uma possível afinidade entre elas.
Takhtajan (I. c.) abraça esta hipótese e acha, mesmo, que as Canellaceae, Annonaceae e Myristicaceae tiveram, possivelmente, uma origem comum.

Van de Wyk \& Canright (1956), contrapondo-se a Garratt (1933b), também supōem que, provavelmente, as Myristicaceae e Annonaceae sejam realmente afins pela anatomia comparada do caule jovem e madeira destas 2 familias.

Nos sistemas filogenéticos mais modernos, e.g., entre outros, Engler (I.c.), Cronquist (I.c.) e Takhtajan (I.c.), as Myristicaceae vêm sendo, geralmente, colocadas entre as Annonaceae e Canellaceae dentro da ordem das Magnoliales, na qual estão incluídas também as Magnoliaceae, Winteraceae, Degeneriaceae, Himantandraceae, Eupomatiaceae e outras, conforme o autor.

Embora a exata circunscrição das famílias desta ordem varie um pouco de autor para autor, no presente estudo nada foi encontrado de novidade que sugerisse outra posição sistemática para as Myristicaceae.

CHAVE PARA DETERMINAÇÃo DOS GÊNEROS AMERICANOS DE MYRISTICACEAE

Adaptação da Chave de A. S. Smith (1937) por Soukup (1966)

1. Nervuras terciárias subparalelas, quase perpendiculares à nervura mediana, sementes irregularmente manchadas de negro ou roxo, an-

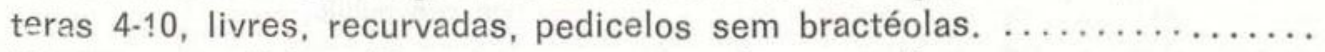

- Nervuras terciárias diferentes, sementes de cor uniforme. . ............... Compsoneura

2. Tricomas dos raminhos jovens, pecíolos e, às vezes, da página inferior das folhas novas birramificados, ou pelo menos com 1-2 ramos

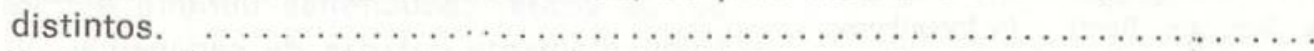

- Tricomas dos raminhos jovens, dos pecíolos e geralmente da página inferior das folhas, estrelados ou muito ramificados. . ..................

3. Folhas de vernação conduplicada, pedicelos sem bractéolas, anteras livres e divergentes, na única espécie brasileira conhecida. ............. Dialyanthers

- Folhas de vernação convoluia, pedicelos com bractéolas no ápice. anieras geralmente conadas dorsalmente, raro livres, fruto em geral transversalmente elipsoide, arilo brevemente laciniado ou subinteiro. . . Iryanthera

4. Folhas com ápice arredondado, pedicelos com bractéolas até o ápice. anteras 12-14, fruto transversalmente elipsoide, arilo obscuramente laciniado.

- Folhas geralmente com ápice agudo, pedicelos sem bractéolas, anteras geralmente $3(2-6)$, fruto elipsoide ou subgloboso, arilo profundamente laciniado. 


\section{TRATAMENTO SISTEMÁTICO}

Virola Aublet, Hist. PI. Guiane Fr. 2:904, tab. 345. 1775; Jussieu, Gen. PI.: 81. 1789; Warburg, Nova Acta Acad. Leop.-Carol. 68:127-128, tab. 1,5,6,7. 1897; Ooststroom, in Pulle, Fl. Surin. 2 (1):118. 1934; Lemée, Dict. Descr. Synon. Gen. PI. Phan. 6:875. 1935; Williams, Field Mus. Nat. Hist.-Bot. 15:134-135. 1936; Smith \& Wodehouse, Brittonia 2 (5) :454-455. 1937; Machado, Rodriguesia 24:53-78, est. 1-2, fig. 1-7. 1949; Lemée, FI. Guyane Franç. 1:620-621. 1952; Uphof, in Engl. \& Prantl, Nat. Pflanzenfam., $2^{\mathrm{a}}$ ed., $17^{a}$ (2):205-206, fig. 44 i,k,I. 1959; Ducke, Ann. Miss. Bot. Gard. 49:220-221. 1962; Hutchinson, Gen. Flower. PI. 1:151. 1964; Soukup, Biota 6 (48): 128-129. 1966; Reitz, in Reitz, FI. llustr. Catarinense: 4-5. 1968; Camargo, Inst. Ci. Nat. Bogotá 4:94. 1970; Hatschbach, Bol. Mus. Bot. Mun. Curitiba 4:1-2. 1972.

Myristica L. sens. lat. Swartz, Prod.: 96. 1788. Sebophora Necker, Elem. Bot. 2: 188.1790.

Myristica sect. Virola Endlicher, Enchiridion Bot. 419. 1841.

Myristica sect. Sychnoneura A.DC., Ann. Sci. Nat. 4 (4): 30. 1855; A. DC. in DC. Prodr. 14: 196. 1856; A. DC., in Mart., FI. Bras. 5 (1): 112. 1860.

Myristica sect. Virola A. DC. in DC., Prodr. 14: 194-195. 1856, pro parte excl. M. macrophylla Spr. ex Benth. (=Iryanthera macrophylla Warb.); A. DC. in Mart., FI. Bras. 5 (1): 109. 1860, pro parte; Baillon. Hist. PI. 2: 500-501. 1870; Bentham \& Hooker, Gen. PI. 3: 136. 1883, pro parte; Prantl in Engl. \& Prantl, Nat. Pflanzenfam., 3 (2): 42. 1891.

Myristica sect. Otoba A. DC. sens, lat. Bentham \& Hooker, Gen. PI. 3: 136. 1856, pro parte quoad Sect. Sychnoneura tantum.

Palala Rumpf sens. lat. Kuntze, Rev. Gen. PI. 2: 565. 1891, pro parte.

Virola sect. Oxianthera Warburg, Nova Acta Acad. Leop. Carol. 68: 163. 1897.

Virola sect. Amblyanthera Warburg, Nova Acta Acad. Leop. Carol. 68: 165, 1897.
Virola grupo Mollissimae Smith, Brittonia 2 (5): 455. 1937, nom. non rite public.

Virola grupo Sebiferae Smith, Brittonia 2 (5): 455. 1937, nom. non rite public.

Virola grupo Calophyllae Smith, Brittonia 2 (5): 455. 1937, nom. non rite public.

Virola grupo Rugulosae Smith, Brittonia 2 (5): 455. 1937, nom. non rite public.

Virola grupo Surinamenses Smith, Brittonia 2 (5): 455. 1937, nom. non rite public.

Virola grupo Subsessiles Smith, Brittonia 2 (5): 455. 1937, nom. non rite public.

Virola sect. Mollissimae Uphof, Nat. Pflanzenfam., 2.: ed., 17: (2): 206. 1959, nom. non rite public.

Virola sect. Sebiferae Uphof, Nat. Pflanzenfam., 2." ed., 17: (2): 206, 1959, nom. non rite public.

Virola sect. Calophyllae Uphof, Nat. Pflanzenfam., 2.' ed., 17.' (2): 206-207. 1959, nom. non rite public.

Virola sect. Rugulosae Uphof, Nat, Pflanzenfam, 2." ed., 17: (2): 207. 1959, nom. non rite public.

Virola sect. Surinamenses Uphof, Nat. Pflanzenfam, 2.' ed., 17:' (2): 207. 1959, nom. non rite public.

Virola sect. Subsessiles Uphof, Nat. Pflanzenfam., 2.: ed., 17.' (2): 208. 1959, nom. non rite public.

Árvores de muito pequenas a muito grandes, raramente arbustos, dióicas, perenifólias ou, às vezes, caducifólias durante a floração. freqüentemente dotadas de sapopemas ou raízes-escoras na base do tronco monopodial, oitotrópico; córtex geralmente liso, de espessura fina a mediana, de cuja parte interna exsuda um suco acastanhado ou avermelhado; os ramos principais, plagiotrópicos, verticilados, os ramos menores em geral finos $e$ subteretes, tomentosos ou puberulentos, quando muito novos, logo depois glabros. Folhas alternas, pecioladas; lâminas de textura submembranácea a coriácea, de margens inteiras ou um tanto onduladas e ligeiramente revolutas, comumente glabras na página superior e pubescentes ou freqüentemente glabrescentes na 
inferior; nervuras secundárias muito variáveis em número, anastomosadas junto às margens, às vezes, muito indistintamente. Inflorescências solitárias, axilares, amplamente paniculadas ou relativamente simples, racemiformes, pedunculadas, pubescentes a glabrescentes, as femininas em geral mais densas do que as masculinas; brácteas membranáceas, envolvendo um ou mais fascículos de flores, logo decíduas; bractéolas ausentes; flores, às vezes, únicas, mas geralmente em fascículos nas extremidades distais dos pedúnculos, pediceladas ou subsésseis; perianto das flores masculinas pequeno, em geral tenuemente carnoso e pubescente externamente, 3 (às vezes 4 . raro 5) - lobado; filetes conados formando um andróforo, anteras geralmente 3 (às vezes 4 ou 5 , raro 2 ou 6) conadas até o ápice ou distalmente divergentes (nunca separadas até a base), obtusas ou apiculadas, biloculares, abrindo-se por rimas extrorsas; perianto das flores femininas em geral um pouco maior e mais carnoso que os das flores masculinas, ovário unicarpelar, globoso ou elipsóide, tomentoso ou puberulento, estilete curto e grosso ou caracteristicamente nulo, estigma, em geral bilobulado, levemente partido; um só óvulo fixado na placentação basal; fruto globoso ou elipsóide, tanto glabro como pubescente ou tomentoso, baciforme, bivalvar, deiscente pela sutura ventral e dorsal, pericarpo freqüentemente lenhoso, arilo laciniado e muitas vezes distintamente espesso e ceroso, semente globosa ou elipsóide.

\section{Espécie-tipo: Virola sebifera Aubl.}

O nome do gênero tem origem no nome vulgar da espécie-tipo, usado pelos índios Sinemari da Guiana Francesa.

O presente autor não aceita nem as divisões do gênero propostas por Smith (I.C., 1937) nem as que haviam sido anteriormente sugeridas por De Candolle (I.c., 1855 e 1856) e Warburg (I.c., 1897). Os 6 grupos criados por Smith para Virola, que se distinguiam, principalmente, pelos caracteres muito instáveis e inseguros do indumento, nervação foliar e androceu, podem levar uma mesma espécie a mais de um grupo, como chegou a ocorrer em sua chave com $V$. urbaniana, $V$. divergens, $V$. loretensis e V. weberbaueri.

Uphof (I.c. 1959), aceitando integralmente as divisões feitas por Smith, passou simplesmente todos os seus grupos para seções, porém tanto um como o outro não cumpriram o Art. 36 do Código Internacional de Nomenclatura (1972), que exige que, a partir de 19 de janeiro de 1935, para se considerar validamente publicado, todo novo taxon deve vir acompanhado de diagnose latina. Da mesma forma, de acordo com o Art. 22 do referido Código, o autônimo de um dos taxa propostos deveria ser Virola e não Sebiferae.

Tentativas para agrupar as poucas espécies americanas, na época conhecidas, de Myristicaceae haviam sido feitas antes por Bentham (1853), firmando-se principalmente no androceu, o mesmo fazendo Ducke (1936) para as espécies amazônicas do gênero Virola, tomando como elementos principais de diferenciação os caracteres do fruto e do androceu, publicando ambos suas sinopses sem a preocupação de dar nomes a esses grupos.

Em verdade, a preocupação da maioria dos monografistas mais antigos do gênero foi realçar a importância do androceu para formar grupos. Este caráter só, com base nos conhecimentos atuais do gênero, não pode ser levado muito a sério, porquanto se sabe que, entre as espécies de Virola, existe toda a gama de correlação de tamanho de andróforo e antera, mesmo entre espécies evidentemente afins (Fig. 3 e 4), só servindo para caracterizar espécies, não grupos, ऽ mesmo acontecendo com a pilosidade, cuja instabilidade é muito mais evidente, inclusive dentro da própria espécie. O gênero Virola apresenta, portanto, uma unidade tal de caracteres semelhantes, que o torna muito complexo.

É possível que em futuro próximo, de posse de melhores dados botânicos, que os atuais, sobre muitas das espécies, presentemente, ainda, insuficientemente conhecidas, complementadas com os subsídios da morfologia, citologia, química etc., muitos desses grupos taxonômicos possam ser melhor evidenciados. No momento, parece impraticável qualquer tentativa neste sentido. 


\section{CHAVE PARA O RECONHECIMENTO DAS ESPÉCIES DE VIROLA OCORRENTES NO BRASIL}

1. Folhas tomentosas na página inferior com tricomas estrelado-estipitados ou dendríticos, persistentes ou tardiamente glabrescentes.

2. Nervuras secundárias pouco numerosas (15-30 pares ou menos), relativamente espaçadas (em média menos de 10 por $10 \mathrm{~cm}$ ), e em geral irregularmente arranjadas; perigônio fendido cerca de $1 / 3$ do seu comprimento.

3. Andróforo nitidamente menor que a antera apiculada.

4. Antera nitidamente divergente na metade distal.

5. Folha densa e uniformemente tomentosa com cheiro forte e característico, fortemente cordada a truncada na base; inflorescência masculina amplamente paniculada até cerca de $250 \mathrm{~mm}$ de comprimento; fruto pedicelado, subgloboso ou elipsóide de $15-30 \mathrm{~mm}$ de diâmetro.

\section{V. divergens}

5. Folha laxa e uniformemente tomentosa sem cheiro especial, arredondada a aguda na base; inflorescência masculina curtamente paniculada, até cerca de $40 \mathrm{~mm}$ de comprimento. Fruto desconhecido.

4. Antera concrescida até o ápice.

16. V. marlenei

6. Folha persistentemente rufotomentosa na página inferior; infrutescência curta até $180 \mathrm{~mm}$ de comprimento, 5-10 frutos por infrutescência; fruto densa e persistemente rufotomentoso (tricomas de $2-4 \mathrm{~mm}$ de comprimento), 11 a $25 \mathrm{~mm}$ de diâmetro.

19. V. mollissima

6. Folha uniformemente tomentosa na página inferior; infrutescência ampla, geralmente acima de $80 \mathrm{~mm}$ de comprimento, 10-30 frutos por infrutescência, deciduamente tomentosos (tricomas de $0,2-1,0 \mathrm{~mm}$ de comprimento).

30. V. sebifera

3. Andróforo um pouco maior que a antera ou subigual; fruto densa e persistentemente rufotomentoso (tricomas de $7-9 \mathrm{~mm}$ de comprimento), $13-22 \mathrm{~mm}$ de diâmetro.

14. V. loretensis

2. Nervuras secundárias numerosas (23-27 pares ou mais), relativamente densas (em média mais de 12 por $10 \mathrm{~cm}$ ), em geral retas e paralelas; perigônio fendido da metade até quase a base do seu comprimento.

7. Antera menor ou um pouco maior que o andróforo, concrescida até o ápice.

8. Fruto persistentemente denso-setuloso (tricomas de $1-2 \mathrm{~mm}$ de comprimento, articulados com numerosos apêndices laterais).

9. Folha glabra e nitidamente reticulada na página superior; andróforo maior que a antera.

21. V. multinervia

9. Folha pilosa com tricomas rígidos simples ou bifurcados de $0,5-1 \mathrm{~mm}$ de comprimento na página superior; reticulado obscuro; andróforo um pouco menor que a antera.

7. V. decorticans

8. Fruto deciduamente tomentoso ou glabrescente.

10. Folha até cerca de $420 \mathrm{~mm}$ de comprimento, $125 \mathrm{~mm}$ de largura, 19 pares de ner. vuras em média por $10 \mathrm{~cm}$, canescente-tomentosa na página inferior.

2. V. caducifolia 
10. Folha até cerca de $260 \mathrm{~mm}$ de comprimento, $100 \mathrm{~mm}$ de largura, $26-45$ pares de nervura secundária em média por $10 \mathrm{~cm}$, ferrugíneo-tomentosa na página inferior.

11. Folha papirácea ou submembranácea, $17-40 \mathrm{~mm}$ de largura, 45 pares de nervura em média por $10 \mathrm{~cm}$; raminhos flexuosos.

\section{V. flexuosa}

11. Folha coriácea ou cartácea, em geral mais de $40 \mathrm{~mm}$ de largura, 26-28 pares de nervura em média por $10 \mathrm{~cm}$; raminhos normais.

12. Folha relativamente curto-peciolada $(5-11 \mathrm{~mm}$ de comprimento), esparsamente estrigulosa na página superior, estreitamente cordada ou obtusa na base; vênulas terciárias pouco distintas na página superior.

13. V. guggenheimii

12. Folha relativamente longo-peciolada $(10-25 \mathrm{~mm}$ de comprimento), glabra na página superior, amplamente cordada ou arredondacia na base; vênulas terciárias distintas em ambas as páginas.

\section{V. polyneura}

10. Folha até cerca de $300 \mathrm{~mm}$ de comprimento, $100 \mathrm{~mm}$ de iargura, $12-17$ pares de nervura secundária em média por $10 \mathrm{~cm}$, ferrugíneo-tomentosa na página inferior.

13. Folha bolhosa, vênulas fortemente impressas na página superior, estreitamente cordada na base; flores masculinas densamente agrupadas, com pedicelos tênues nítidos.

\section{V. rugulosa}

13. Folha não bolhosa, arredondada ou ligeiramente cordada na base.

14. Flores masculinas sésseis; perianto de 2-3mm de comprimento, carnoso, com vênulas indistintas; androceu de 1,5-1,7mm de comprimento; andróforo duas vezes maior que a antera apiculada; fruto elipsóide.

$$
\text { 1. V. albidiflora }
$$

14. Flores masculinas visivelmente pediceladas; perigônio de $1,0-1,2 \mathrm{~mm}$ de comprimento, tenuemente carnoso, lóbulos com uma vênula central um tanto visivel; androceu de $0,6-0,7 \mathrm{~mm}$ de comprimento; andróforo levemente maior que a antera obtusa.

$$
\text { 9.v. duckei }
$$

7. Antera cerca de $1 \mathrm{~mm}$ de comprimento, visivelmente maior que o andróforo, nitidamente divergente na metade distal; $13-17$ pares de nervura secundária por $10 \mathrm{~cm}$ nas folhas.

34. V. urbaniana

1. Folhas adultas glabras ou tomentelas na página inferior com tricomas em geral séssil-estrelados ou raro estipitados, evanescentes.

15. Perigônio fendido cerca de $1 / 3$ do seu comprimento total; andróforo maior, menor ou subigual à antera.

16. Andróforo nitidamente menor que a antera; fruto deciduamente tomentoso a glabrescente.

17. Página inferior da folha com tricomas estipidados, freqüentemente evanescentes.

18. Folha coriácea; antera em geral 2-3 vezes maior que o andróforo; fruto em geral levemente elipsóide.

30. V. sebifera 
18. Folha submembranácea ou cartácea; antera cerca de 2 vezes maior que c andróforo ou apenas um pouco mais longa; fruto essencialmente globoso.

$$
\text { 10. V. elongata }
$$

17. Página inferior da folha com tricomas sésseis, freqüentemente glabrescente.

19. Folha adulta gradualmente atenuada no ápice; antera cerca de 2 vezes maior que o andróforo, com apículo fendido; fruto indistintamente carenado.

20. Folha geralmente oblonga ou oblongo-elíptica, obtusa ou subcordada na base; fruto subgloboso ou elipsóide, deciduamente tomentelo ou glabrescente.

\section{V. elongata}

20. Folha obovada ou elíptica, atenuada ou aguda na base; fruto subgloboso ou obovóide-elipsóide, estreitado em direção à base, persistentemente ferrugíneo-tomentoso.

22. V. obovata

19. Folha bruscamente aguda ou cuspidada no ápice; antera pelo menos 2 vezes maior que o andróforo, inteiramente concrescida, com apículo inteiro; fruto elipsóide, distintamente carenado.

27. V. peruviana

16. Andróforo maior que a antera ou subigual; fruto tomentelo ou puberulento.

21. Folha séssil ou subséssil (pecíolo geralmente menor que $2 \mathrm{~mm}$ de comprimento); inflorescência 1- ou 2-ramosa.

22. Fruto amplamente elipsóide, $14-21 \mathrm{~mm}$ de comprimento, $12-17 \mathrm{~mm}$ de Iargura, obtuso na base; folha de $35-80 \mathrm{~mm}$ de largura, vêriulas reticuladas, promínula em ambas as páginas; androceu cle cerca de $1,6 \mathrm{~mm}$ de comprimento.

31. V. sessilis

22. Fruto oblongo-elipsóide, $14-17 \mathrm{~mm}$ de comprimento, $7-9 \mathrm{~mm}$ de largura, arredondado ou truncado na base; folha de $25-45 \mathrm{~mm}$ de largura, vênulas obscuras; androceu de 2,2-2,5mm de comprimento.

\section{V. subsessilis}

21. Folha patentemente peciolada, discolor; página inferior densa e indistintamente puberulenta salpicada de pontuações ferrugíneas escamiformes; inflorescência livremente ramificada; andróforo geralmente estrangulado distalmente; fruto elipsóide, glabrescente, a princípio densa e indistintamente estrelado-tomentelo.

23. Folhas com nervuras esparsas $(4-6$ por $10 \mathrm{~cm})$, em geral separadas por mais de $1 \mathrm{~cm}$; margens da lâmina foliar não caracteristicamente paralela; inflorescência masculina sem brácteas patentes.

\section{V. calophylla}

23. Folhas com nervuras numerosas ( $16-30$ por $10 \mathrm{~cm}$ ) em geral 3 ou mais por $1 \mathrm{~cm}$; margem da lâmina foliar essencialmente paralela; inflorescência masculina com brácteas grandes.

\section{V. coelhoi}

15. Perigônio fendido da metade áé quase a base de seu comprimento total. Andróforo maior que a antera ou subigual. 
24. Nervuras secundárias das folhas pouco numerosas (até 18-32 pares) e relativamente espaçadas (menos de 18 pares em média por $10 \mathrm{~cm}$ ). Inflorescência pouco densa de flores de tamanho em geral regular.

25. Folha oblonga ou linear-oblonga de margens caracteristicamente paralelas, cerca de 4 vezes mais longa que larga.

26. Ramos jovens puberulentos; inflorescência masculina 1-ramosa, ramos laterais poucos e curtos; fruto ovóide-elipsóide, agudo ou cuspidado no ápice.

24. V. oleifera

26. Ramos jovens tomentelos; inflorescência masculina livremente ramosa; fruto subgloboso ou ovóide, geralmente apiculado no ápice.

\section{V. surinamensis}

25. Folha elíptica ou obovóide- ou elíptico-oblonga, de margens não caracteristicamente paralelas e geralmente cerca de 3 vezes mais longa que larga.

27. Inflorescência masculina 1- a 3-ramosa.

28. Folha amplamente elíptica, arredondada, subcordada ou obtusa na base.

29. Nervuras secundárias conspícuas em ambas as páginas; folha freqüentemente subcordada na base.

30. Inflorescência 2- ou 3- ramosa; andróforo subigual à antera, estreitado distalmente; folha arredondada ou levemente subcordada na base, freqüentemente emarginada no ápice.

15. V. malmei

30. Inflorescência simples geralmente; andróforo mais longo que a antera e não estreitado distalmente; folha truncada ou subcordada na base, subaguda ou cuspidada no ápice.

23. V. officinalis

29. Nervuras secundárias inconspícuas em ambas as páginas; folha largamente elíptica, obtusa ou arredondada na base, obtusa e ligeiramente emarginada no ápice; inflorescência 1- ou 2- ramosa.

25. V. parvifolia

28. Folha estreita, regular e simetricamente elíptica, atenuada ou cuneada na base, subaguda ou obtusamente curto-acuminada ou cuspidada no ápice.

31. Folha bruscamente atenuada e longamente decorrente no pecíolo (pecíolo estreitamente alado); nervuras secundárias um tanto irregulares; vênulas promínulas na página inferior; inflorescência geralmente 1-ramosa; fruto elipsóide ou subgloboso de 23-30 mm de comprimento, $15-24 \mathrm{~mm}$ de largura, arredondado e obtusamente apiculado no ápice.

12. V. gardneri

31. Folha cuneada ou gradualmente atenuada na base; pecíolo não alado; nervuras secundárias regulares; vênulas obscuras ou promínulas em ambas as páginas; inflorescência 1- a 3-ramosa. 
32. Folha glabra ou esparsamente puberulenta na página inferior e cuneada na base; vênulas finas notavelmente promínulas em ambas as páginas; inflorescência 2- ou 3- ramosa; fruto subgloboso ou elíptico, $130-190 \mathrm{~mm}$ de comprimento, $110-140 \mathrm{~mm}$ de largura, arredondado e apiculado no ápice, indistintamente carenado ou liso; pericarpo tênue, $0,7-1,5 \mathrm{~mm}$ de espessura.

\section{V. venosa}

32. Folha regular e persistentemente puberulenta na página inferior e atenuada em direção à base do pecíolo; vênulas em geral obscuras na página superior; inflorescência 1- ou 2- ramosa; fruto amplamente elipsóide, $250-400 \mathrm{~mm}$ de comprimento, $170-270 \mathrm{~mm}$ de largura, obtuso e levemente apiculado no ápice, nitidamente carenado de um lado; pericarpo lenhoso, $3-4 \mathrm{~mm}$ de espessura.

17. V. michelii

27. Inflorescência masculina livremente ramosa; folha oblongo-elíptica.

33. Raminhos jovens freqüentemente ferrugíneo-puberulentos; fruto oblongoelipsóide, $15-50 \mathrm{~mm}$ de comprimento, $12-35 \mathrm{~mm}$ de largura, nitidamente carenado, obtuso ou subagudo no ápice.

26. V. pavonis

33. Raminhos jovens em geral glabrescentes; fruto subgloboso, ovóide ou elípsóide, $15-25 \mathrm{~mm}$ de diâmetro, liso ou imperfeitamente impresso na sutura, arredondado ou obtusamente apiculado no ápice.

\section{V. carinata}

24. Nervuras secundárias das folhas relativamente numerosas (30-38 pares ou mais) e relativamente densas (em média mais de 22 por $10 \mathrm{~cm}$ ), em geral retas e paralelas; inflorescência densa com flores diminutas.

34. Nervuras secundárias 40-60 pares.

35. Folha elíptica ou oblongo-elíptica, 40-100mm de largura.

20. V. multicostata

35. Folha oblonga, estreitamente elíptica ou oblongo-lanceolada, $15-60 \mathrm{~mm}$ de largura.

36. Folha estreitamente oblongo-lanceolada, $100-280 \mathrm{~mm}$ de comprimento, caudado-acuminada no ápice, reticulado promínulo distinto em ambas as páginas.

6. V. crebrinervia

36. Folha oblonga ou estreitamente eliptica, $50-180 \mathrm{~mm}$ de comprimento, obtusa ou aguda no ápice, reticulado obscuro na página superior.

\section{V. flexuosa}

34. Nervuras secundárias das folhas 30-38 pares. Folha tenuemente coriácea, oblonga ou elíptico-oblonga, vênulas obscuras, esparsa e uniformemente tomentela na página inferior; fascículos florais com 50-100 flores muito pequenas.

18. V. minutiflora 
1. Virola albidiflora Ducke, Journ. Wash. Acad. Sci. 26 (6):259. 1936, pro parte; A.C. Smith \& Wodehouse, Brittonia 2 (5): 486. 1937; A. Ducke, Arq. Serv. Florest. 1 (1):27. 1939; A.C. Smith, Journ. Wash. Acad. Sci. 43 (7):204. 1953; J.C. Th. Uphof in Engl. \& Prantl, Nat. Pflanzenfam., 2. ${ }^{\circ}$ ed., 17a(2):207. 1959; H. Garcia-Barriga, Fl. Medicinal de Colombia. 1:349. 1974 (V. albiflora Ducke, sphalmate).

Virola kukachkana L. Williams, Fieldiana, Bot. 31 (2): 38. 1965, syn. nov. - Tipo: A. Arostegui V. 115, Peru, Loreto, Maynas. distrito Mazán, rio Mazán, Fundo "La Libertad", alt. 130m, 8 Ago. $1963 \mathrm{fl}$. (holótipo: $\mathrm{F}$; isótipos: GH, NY, US).

Arvore até $30 \mathrm{~m}$ de altura; raminho velho robusto, rugoso, nigrescente, glabro, os mais novos densamente ferrugíneo-tomentosos (tricomas pouco ramificados, $0,5-1 \mathrm{~mm}$ de comprimento). Pecíolo fortemente canaliculado, robusto, $2-4 \mathrm{~mm}$ de diâmetro, tomentoso como o raminho, glabrescente, $6-12 \mathrm{~mm}$ de comprimento. Lâmina foliar oblonga, $150-300 \mathrm{~mm}$ de comprimento, $50-85 \mathrm{~mm}$ de largura, arredondada ou estreitamente subcordada na base, subaguda ou obtusamente cuspidada no ápice, glabra na página superior, tomentela, às vezes, apenas sobre a nervura mediana (uniformemente tomentela quando nova), uniformemente tomentosa na página inferior (tricomas ferrugíneos, estipitados, pouco ramificados, irregularmente estrelados, $0,3-0,5 \mathrm{~mm}$ de comprimento); nervura mediana plana ou levemente imersa na página superior, muito proeminente na página inferior; 25-35 nervuras secundárias de cada lado, anastomosadas perto das margens, ligeiramente impressas na página superior, elevadas na inferior; vênulas obscuras ou ligeiramente impressas na página ventral. Inflorescência masculina amplamente paniculada, $100-150 \mathrm{~mm}$ de comprimento e quase o mesmo tanto de largura; pedúnculo mais ou menos achatado, 30-40 mm de comprimento, raminhos e flores densamente tomentelos (tricomas irregularmente ramificados desde a base, $0,1-0,2 \mathrm{~mm}$ de comprimento); brácteas ovais, 2-4mm de comprimento, densamente tomentelas, logo decíduas; 5-12 flores por fascículo, subsésseis; perianto delgado, carnoso, 2-3mm de comprimento, 3-4 lobado até próximo à base; lóbulos oblongos, obtusos ou arredondados; androceu 1,5-1,7mm de comprimentb; andróforo tênue, $1-1,1 \mathrm{~mm}$ de comprimento; 3 anteras, $\quad 0,5-0,6 \mathrm{~mm}$ de comprimento, soldadas em direção ao ápice, levemente apiculadas, apículos separados. Inflorescência feminina $50-90 \mathrm{~mm}$ de comprimento, semelhante à masculina, porém menos abundantemente ramificada; 3-8 flores por fascículo; pedicelos robustos $1-2 \mathrm{~mm}$ de comprimento; ovário elipsóide, densamente tomentelo, estigma séssil, partido. Infrutescência robusta, $80-120 \mathrm{~mm}$ de comprimento, ramos rugosos, puberulentos ou glabros; 4-8 frutos maduros por infrutescência, pedicelados (pedicelos muito espessos, 30-50mm de comprimento), elipsóides, carinados, $33-38 \mathrm{~mm}$ de comprimento, $21-25 \mathrm{~mm}$ de largura, glabros; pericarpo lenhoso, 4-6mm de espessura; arilo laciniado até quase a base; semente $25-27 \mathrm{~mm}$ de comprimento cerca de $12 \mathrm{~mm}$ de largura. Figs. 3D, 21 e 22.

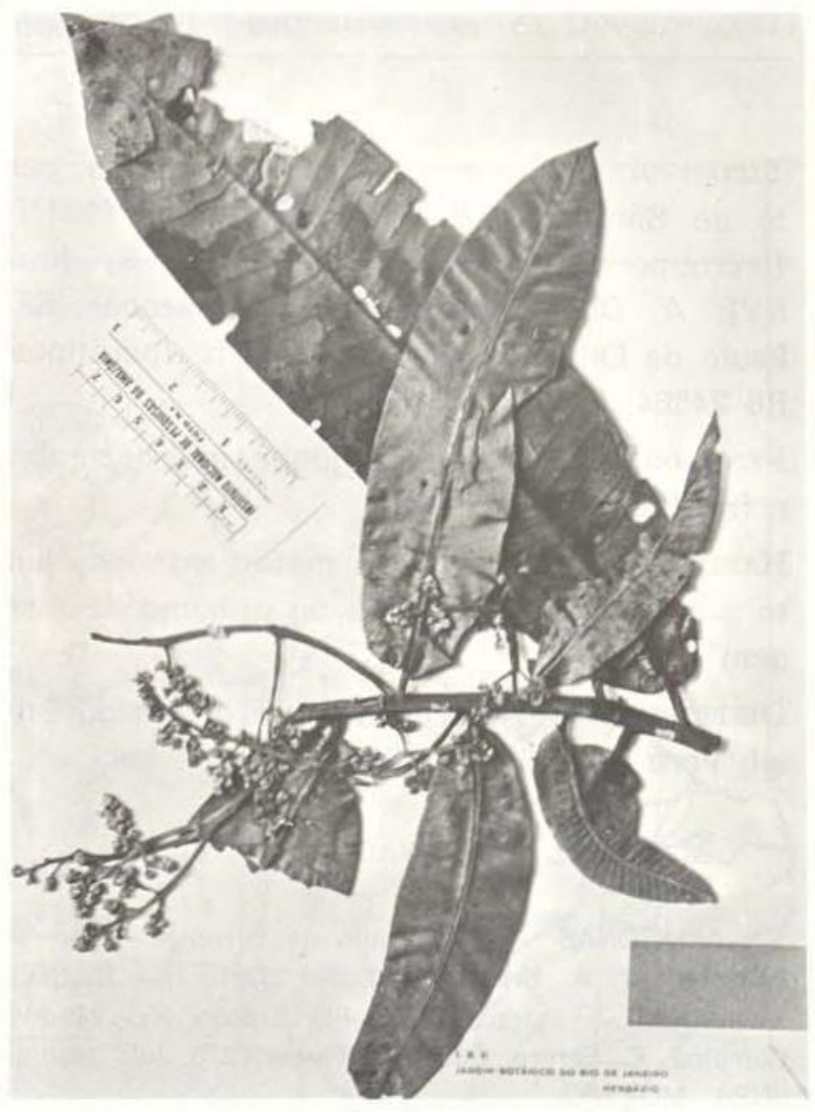

Fig. 21 - Virola albidiflora. A. Ducke s.n. (RB 24563, lectótipo). 


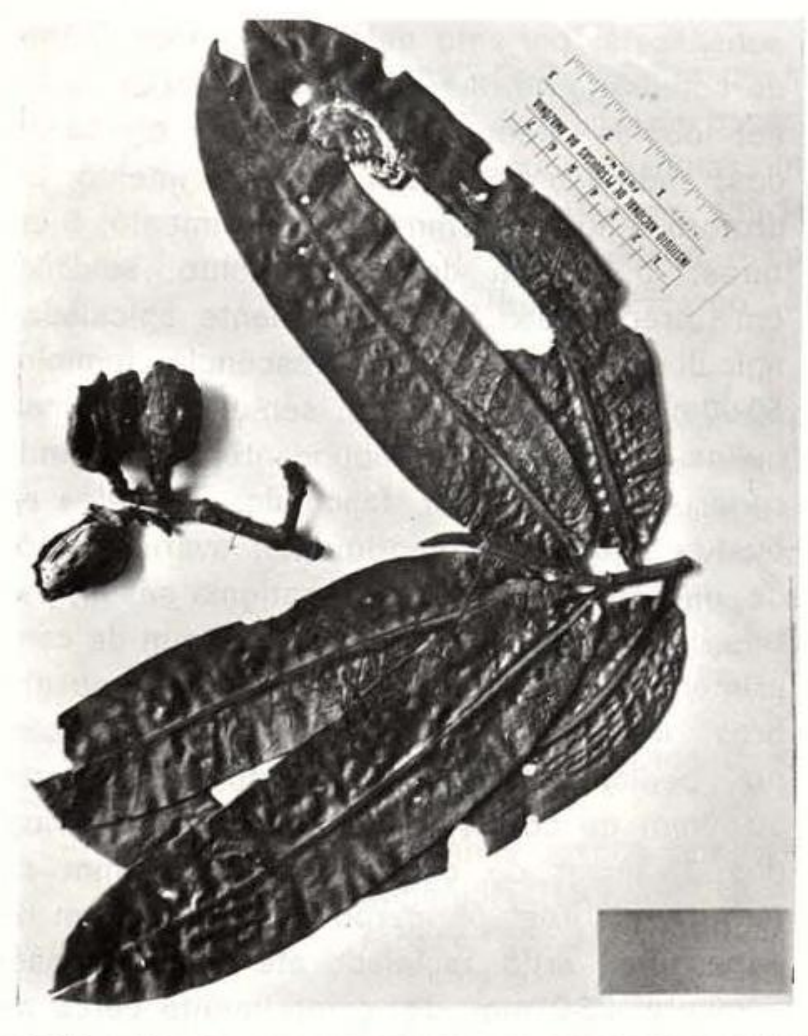

Fig. 22 - Virola albidiflora. A. Ducke s.n. (RB 24564 , parátipo)

Tipos: A. Ducke s.n., Brasil, Amazonas, perto de São Paulo de Olivença, 3 Out. $1931 \mathrm{fl}$. (lectótipo: RB 24563; isolectótipo: K; foto: NY); A. Ducke s.n., Brasil, Amazonas, São Paulo de Olivença, 25 Fev. 1932 fr. (parátipos: RB 24564, K, US).

Fenologia: Floresce de junho até dezembro e frutifica em fevereiro.

HABITAT: Geralmente em mata pantanosa junto a igapós de te:ra firme ou próximo de margem de rio.

Distribuição: Amazonas, Acre e fora do Brasil: Peru e Colômbia. Fig. 23.

\section{MATERIAL ADICIONAL EXAMINADO:}

AMAZONAS: - São Paulo de Olivença, perto de Palmares: B. A. Krukoff 8103. Set./Out. $1936 \mathrm{fl}$. (NY).

ACRE: - Estrada Abunã-Rio Branco, Km 242-246, Campina: E. Forero, Coêlho \& Farias 6370, Jul. $1968 \mathrm{fl}$. (INPA, MG, NY).

Próxima de V. duckei A.C. Smith, distingue-se desta facilmente tanto pelas flores co- mo pelos frutos, os quais nesta espécie são inteiramente glabros e apresentam valvas carnosas, que se enrolam ao abrir.

V. kukachkana, descrita por L. Williams, baseada em coleção de flores femininas, é reduzida a sinônimo por não apresentar diferença suficiente na parte vegetativa, que justificasse mantê-la como boa espécie.

2. Virola caducifolia W. Rodr., Ciência e Cultura, Suplemento, 29(7):559. 1977. Acta Amazonica 7(4): 459, fig. 1. 1977.

Arvore até $28 \mathrm{~m}$ de altura; tronco até cerca de $30 \mathrm{~cm}$ de diâmetro sem sapopema; ao cortar exsuda um suco aquoso vermelho; copa pequena, em geral de folhagem inteiramente decídua durante a floração; raminhos grossos, os do ano lateralmente achatados, estriados longitudinalmente, densamente ferrugíneo-tomentelos (tricomas irregularmente ramificados desde a base, tênues, $0,2-0,4 \mathrm{~mm}$ de comprimento), os mais velhos glabrescentes, muito grossos, acinzentados, rugosos com vestígios conspícuos de cicatrizes de folhas, casca friável, desprendendo-se comumente em pequeninas placas. Pecíolos grossos de $3-6 \mathrm{~mm}$ de diâmetro, $5-35 \mathrm{~mm}$ de comprimento, fortemente canaliculados, geralmente estriados longitudinalmente, tomentelos como os raminhos novos, continuando a princípio a nervura mediana. Lâmina foliar consistentemente coriácea, freqüentemente lanceolado-elíptica, às vezes ovado - ou obovado-elíptica, $100-420 \mathrm{~mm}$ de comprimento, $35-125 \mathrm{~mm}$ de largura, fortemente cordada na base, aguda ou cuspidada no ápice, lustrosa e glabra na página superior, tomentela por exceção, a princípio, apenas sobre a nervura mediana, depois glabra, página inferior densíssima e diminutamente canotomentela (tricomas séssil-estrelados, pálidos de cerca de $0,1 \mathrm{~mm}$ de comprimento, entremeados esparsamente com tricomas irregularmente ramificados, amarelados, de cerca de 0,3-0,4mm de comprimento); nervura mediana, na página superior, plana ou levemente imer$\mathrm{sa}$, bastante elevada na inferior; $48-60$ às vezes até 69 nervuras secundárias de cada lado, (12-21 por $10 \mathrm{~cm}$, média 17$)$ retas, paralelas, curvando-se e anastomosando-se junto às mar- 
gens, juntamente com as nervuras terciárias, levemente impressas na página superior, salientes na inferior; vênulas reticuladas inconspícuas na página superior e promínulas na inferior. Inflorescência masculina terminal, amplamente paniculada, densiflora, até $180 \mathrm{~mm}$ de comprimento e quase o mesmo de largura; pedúnculo amarelo-esverdeado, grosso, até cerca de $20 \mathrm{~mm}$ de comprimento com os raminhos densamente ferrugíneo-tomentoso (tricomas de $0,3-0,5 \mathrm{~mm}$ de comprimento); brácteas largamente ovadas, tomentelas até cerca de $10 \mathrm{~mm}$ de comprimento, logo decíduas; flores alvacentas ou cremes, levemente aromáticas, en fascículos densos de cerca de 3-5mm de diâmetro; 50-90 flores por fascículo; pedicelos $\mathrm{fi}$ nos até $1,5 \mathrm{~mm}$ de comprimento, estrigosos: perianto de $1,0-1,4 \mathrm{~mm}$ de comprimento, submembranáceo, infundibuliforme, estrigoso, trilobado até quase a base, lóbulos oblongos, obtusos com nervura mediana; androceu de 0,7-0,9mm de comprimento; andróforo delgado de $0,3-0,5 \mathrm{~mm}$ de comprimento; 3 anteras de cerca de $0,4 \mathrm{~mm}$ de comprimento, soldadas até o ápice, obtusas. Inflorescência feminina não vista. Infrutescência até $70 \mathrm{~mm}$ de comprimento; 1-7 frutos por infrutescência, pedicelados (pedicelos grossos de $3-4 \mathrm{~mm}$ de comprimento), elipsóides ou às vezes ovoides, $25-30 \mathrm{~mm}$ de comprimento, $13-25 \mathrm{~mm}$ de largura, arredondados e levemente apiculados no ápice, obtusos ou amplamente arredondados na base, na maturidade verde-escuros, quando frescos, depois de secos, enegrescidos, cobertos por tênue tomento ferrugíneo evanescente (tricomas de 0,2-0,5mm de comprimento com curtos apêndices laterais); pericarpo de $2-3 \mathrm{~mm}$ de espessura; arilo laciniado quase até a base, róseo. Semente de $22-24 \mathrm{~mm}$ de comprimento, $13 \mathrm{~mm}$ de largura, elipsóide, longitudinalmente sulcado pela pressão do arilo Fig. 24 .

TIPO: W. Rodrigues \& D. Coelho 9263, Brasil, Amazonas, estrada Manaus-Itacoatiara, Km. 120, 20 Nov. $1973 \mathrm{fl}$., amostra de madeira INPA X-5577 (holótipo: INPA).

Nomes vUlgares: Ucuuba-vermelha (ex Rodrigues 5505); ucuuba-da-mata (ex Oliveira 2697).

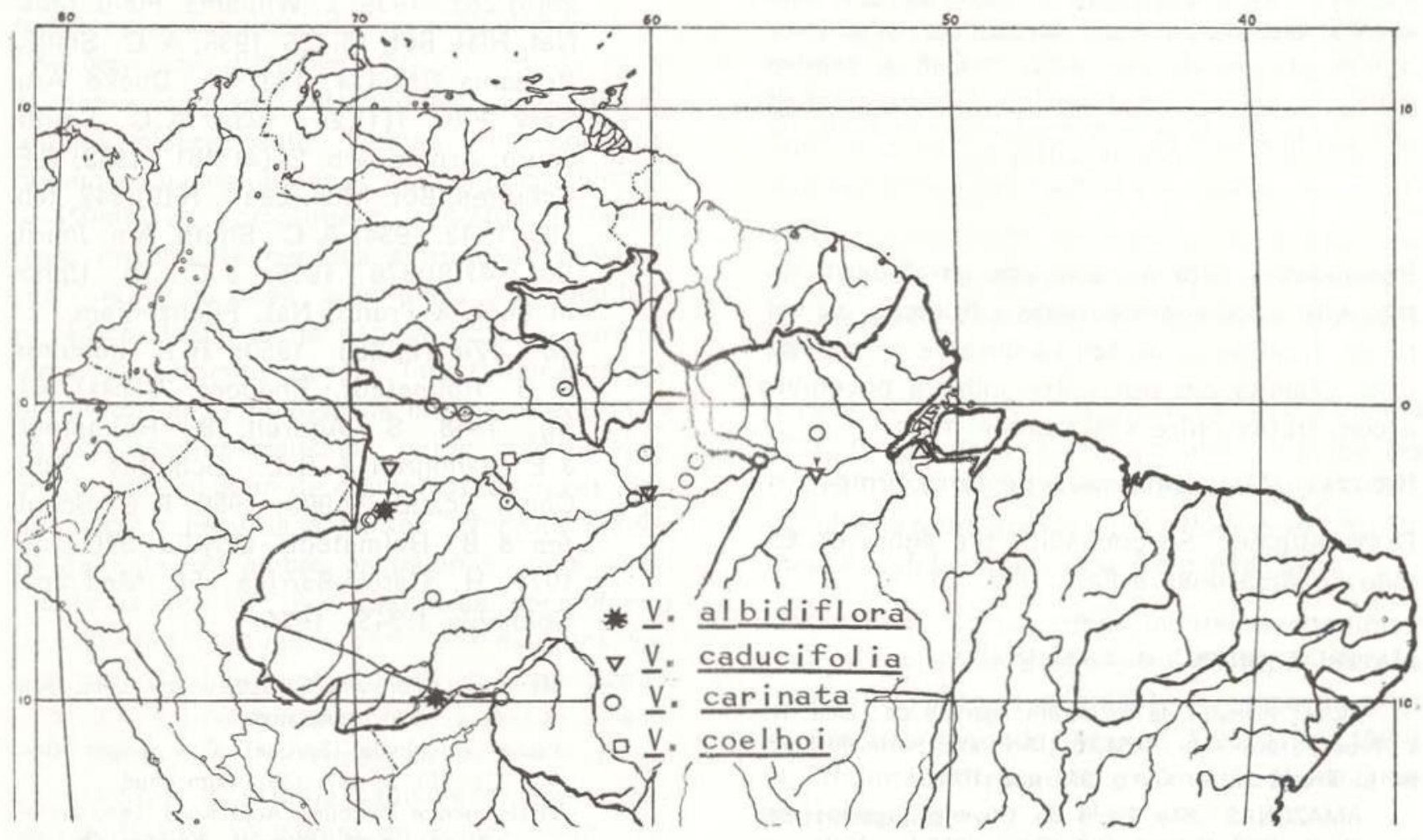

Fig. 23 - Distribuiçăo atual de Virola albidiflora, V. caducifolia, V. carinata e V. coelhoi no Brasil. 


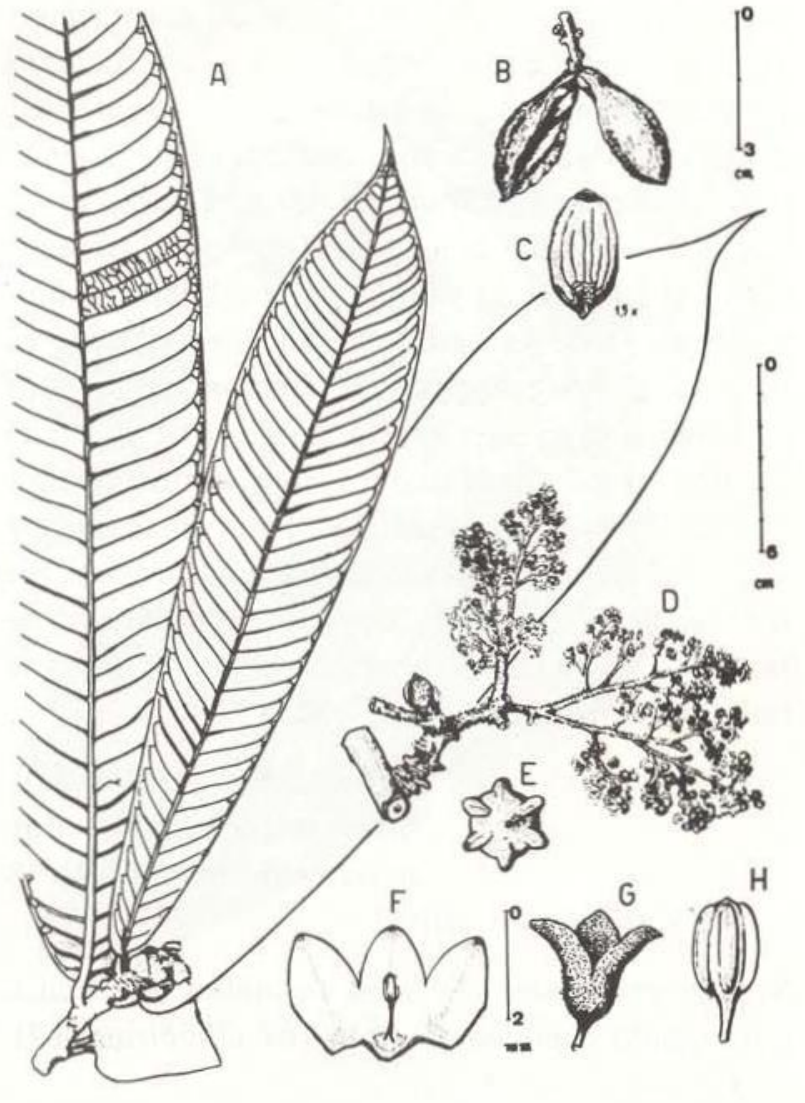

Fig. 24 - Virola caducifolia. A, hábito do ramo estéril (O. P. Monteiro 25); B e C (W. Rodrigues et al. 8700): B, fruto; C, semente com arilo; D-H (R. E. Schultes 24616): D, inflorescência masculina; $E$, antera vista de cima; F. secção do perianto mostrando o androceu; G. flor; $H$, antera.

Fenologia: Esta espécie em geral perde totalmente a folhagem durante a floração, só voltando a cobrir-se de folhas durante a frutificação. Colhida em flor entre julho e novembro e com frutos entre setembro e maio.

HaBitat: Mata amazônica de terra firme

Distribuição: Só conhecida até agora do Estado do Amazonas e Pará. Fig. 23.

\section{MATERIAL ADICIONAL EXAMINADO:}

PARA: Planalto de Santarém, igarapé da Lama: R. L. Froes, 31005, Ago. 1954 fl. (IAN, NY); Porto de Moz: R. L. Froes, 32174, Out. 1955 est. (IAN).

AMAZONAS: São Paulo de Olivença, igarapé Belém: B. A. Krukoff 8891, Out./Dez., 1936 fr. (NY); cercanias de Manaus: W. Rodrigues 8584, Set. $1963 \mathrm{fr}$. (INPA); W. Rodrigues 8583, Out. 1963 fr. (INPA); E.
Oliveira 2697, Out. $1963 \mathrm{fl}$. (IAN); W. Rodrigues 5505, Out. $1963 \mathrm{fl}$. (INPA); W. Rodrigues \& A. Loureiro 7070, Set. $1965 \mathrm{fl}$. (INPA); W. Rodrigues \& Osmarino 7911, Jun. 1966 est. (INPA); R. E. Schultes 24616, Jul/Ago. $1967 \mathrm{fl}$. (ECON, IAN, INPA); O. P. Monteiro 25, Nov. $1969 \mathrm{fl}$. (INPA); W. Rodrigues et al 8700, Fev. 1970 fr. (INPA, MG); R. E. Schultes \& W. Rodrigues 26127A, Abr. 1972 est. (ECON, INPA); D. Coelho s.n., Out. 1973 est. (INPA 42232); W. Rodrigues \& D. Coelho 9263. Nov. 1973 fl. (INPA); W. Rodrigues \& D. Coelho 9598, Maio $1975 \mathrm{fr}$. (INPA).

Muito próxima de $V$. multinervia, na forma da folha e inflorescência, distinguindo-se desta logo, no entanto, pela ausência de folhas durante a floração, fato este só observado antes em V. multicostata, segundo Ducke (1950). As folhas, no entanto, são mais rigidamente coriáceas, discolores, densa e diminutamente canotomentelas na página inferior e as inflorescências masculinas são geralmente apicais nos raminhos mais novos.

3. Virola calophylla Warburg, Nova Acta Acad. Leop.-Carol. 68:231. 1897; A.C. Smith, Bull. Torrey Bot. Club 58(2):96. 1931; A. Ducke, Journ. Wash. Acad. Sci. 26(6):263. 1936; L. Williams, Field. Mus. Nat. Hist. Bot. 15:135. 1936; A.C. Smith, Brittonia 2(5):474. 1937; A. Ducke, Arq. Serv. Flor. 1(1):26. 1939; A.C. Smith, Journ. Arnold Arb. 24(4):461. 1943; R.E. Schultes, Bot. Mus. Leafl. 16(9):242 tab. 39, 41, 42. 1954; A.C. Smith, Am. Journ. Bot. 43(8):576. 1956; J.C. Th. Uphof in Engl. \& Prantl, Nat. Pflanzenfam., 2." ed., 17a (2):206. 1959; R.E. Schultes \& B. Holmstedt, Rhodora 70(781):147, fig. 1968; S. Agurell, B. Holmstedt, J.E. Lindgren \& R.E. Schultes, Acta Chem. Scand. 23:903. 1969; R.E. Schultes \& B. Holmstedt, Lloydia 34(1):69. 1971; H. Garcia-Barriga. Fl. Medicinal Colombia 1:345. 1974.

Myristica calophylla Spruce, Journ. Linn. Soc. 5: 4. 1861, nom. nud.

Palala calophylla (Spruce) O. Kuntze, Rev. Gen. PI. 2: 567. 1891, nom. nud.

Virola incolor Warburg, Acta Acad. Leop.-Carol. 68: 232. 1897 Tipo: H. Karsten S.n., Colombia, Meta, Villavicencio, est. (holótipo: W, destruído; lectótipo: BM). 
Otoba incolor Karst. in Warburg, Nova Acta Acad. Leop.-Carol. 68: 232. 1897, pro syn.

Virola calophylloidea Markgraf, Repert. Sp. Nov. 19: 531. 1923; A. Ducke, Journ. Wash. Acad. Sci. 26 (6): 263. 1936; A. C. Smith, Brittonia 2 (5): 475. 1937; A. Ducke, Arq. Serv. Flor. 1 (1): 27. 1939; A. C. Smith, Am. Journ. Bot. 43 (8): 576. 1956; J. C. Th. Uphof in Engl. \& Prantl, Nat. Pflanzenfam., 2.' ed., 17.' (2): 207. 1959; R. E. Schultes \& B. Holmstedt, Rhodora 70 (781): 149, ilustr. 1968; R. E. Schultes \& B. Holmstedt, Lloydia 34 (1): 70, 1971; H. Garcia-Barriga, FI. Med. Colombia 1: 346. 1974, pro parte. Tipo: Ule 8846, Brasil, Amazonas, Manaus, Maio $1910 \mathrm{fl}$. (holótipo: B destruído; lectótipo: US; isótipos: K, L), syn. nov.

Virola lepidota A. C. Smith, Brittonia 2 (2): 152. 1936. Tipo: B. A. Krukoff 6889, Brasil, Amazonas, Humaitá, Livramento, rio Livramento, bacia do rio Madeira, 29 Out. 1934 fr. (holótipo: NY; isótipos: BM, F, S, U, US).

Arvoreta fina a árvore até $20 \mathrm{~m}$ de altura; raminhos muitas vezes rugosos, densamente canescentes ou ferrugíneo-puberulentos, (tricomas comumente muito pequenos, séssil-estrelados), glabrescentes. Pecíolo vulgarmente fortemente canaliculado ou sub-cilíndrico de 1,5-5,0mm de diâmetro, $7,0-20,0 \mathrm{~mm}$ de comprimento, rugoso, puberulento como os raminhos, glabrescente. Lâmina foliar coriácea, oblonga, ovado-oblonga ou elíptico-oblonga, $55-550 \mathrm{~mm}$ de comprimento, $18-240 \mathrm{~mm}$ de largura, fortemente cordada a truncada e às vezes obtusa na base, acuminada ou cuspidada no ápice, lustrosa na página superior, uniforme e densamente porém indistintamente puberulenta ou tomentosa na página inferior (tricomas séssil-estrelados, muito ramificados, cerca de $0,1-0,2 \mathrm{~mm}$ de diâmetro), às vezes com pontuações escuras esparsas. Nervura mediana saliente em ambas as páginas, mais fortemente na inferior; 8-27 nervuras secundárias de cada lado, curvadas perto das margens, impressas ou ligeiramente elevadas na página superior, salientes na inferior; vênulas obscuras, levemente impressas ou promínulas. Inflorescência masculina paniculada, ligeiramente ramificada, $10-300 \mathrm{~mm}$ de comprimento; pedúnculo até $70 \mathrm{~mm}$ de comprimento com raminhos e flores tenra e densamente tomentelos, castanho-escuros (tricomas séssil-estrelados, 5-8 ramificados, cerca de $0,1 \mathrm{~mm}$ de diâmetro); ebracteada; 2-13 flores por fascículo, pardoamareladas, levemente aromáticas; pedicelos finos, $0,5-1 \mathrm{~mm}$ de comprimento; perianto levemente carnoso, infundibuliforme, $1,0-1,5 \mathrm{~mm}$ de comprimento, tripartido até cerca de $1 / 3$ do comprimento, lóbulos arredondados ou obtusos; androceu $0,6-0,9 \mathrm{~mm}$ de comprimento; andróforo bastante carnoso, bruscamente estrangulado no ápice, $0,2-0,5 \mathrm{~mm}$ de comprimento; 3-6 anteras soldadas até o ápice, 0,2-0,4 $\mathrm{mm}$ de comprimento, obtusamente apiculadas no ápice. Inflorescência feminina em geral menor que a masculina; $2-5$ flores por fascículo; pedicelos grossos, $1,0-1,5 \mathrm{~mm}$ de comprimento; ovário subgloboso ou elipsóide inteira e tenramente ferrugíneo-puberulento; estígma subséssil, fortemente fendido, oblíquo. Infrutescência até $70 \mathrm{~mm}$ de comprimento; $1-35$ frutos por infrutescência, pedicelados (pedicelos grossos, $3-4 \mathrm{~mm}$ de comprimento) estreitamente elipsóides, obovóide-elipsóides ou subglobosos, $15-30 \mathrm{~mm}$ de comprimento, $8-18 \mathrm{~mm}$ de largura, levemente rugosos, levemente carinados, densamente tomentelos (tricomas séssilestrelados, castanhos ou ferrugíneos) glabrescentes; pericarpo $0,5-5,0 \mathrm{~mm}$ de espessura; arilo laranja-avermelhado ou escarlate, fendido até cerca da metade de seu comprimento total; semente elipsóide. Figs. 3,25.

Tipo: Spruce 3207, Venezuela, Amazonas, região do rio Cassiquiare, 1853-4 fl. (holótipo: $\mathrm{B}$, destruído; lectótipo: $\mathrm{K}$; isótipos: $\mathrm{BM}, \mathrm{GH}$, NY, P).

Nomes vUlgares: Ucuubarana (ex Oliveira 2704, Prance \& al. 1576); ucuuba; ucuhuba (ex Ducke 396); ucuuba-vermelha (ex Aluisio 59); ucuuba-da-folha-grande (ex Rodrigues 6872); massaranduba-branca (ex Berg P18530).

UTILIDADES: Certas tribos indígenas costumam usar a resina na preparação de rapé alucinogênico (Schultes I.c. 1954). A casca da árvore produz, segundo Agurell \& al. (I.c. 1969), $\mathrm{N}, \mathrm{N}$-dimetil-triptamina e 5-metoxi-N, N-dimetil-triptamina.

FENOLOGIA: A floração e frutificação têm sido observadas durante quase todo $o$ ano, regis- 
trando-se mais freqüentemente a floração entre junho e outubro, e a frutificação de outubro a maio. Fig. 9.

Habitat: Ocorre em geral na mata de terra firme, sendo ocasionalmente assinalada também em matas secundárias, mata de terra bai$\mathrm{xa}$, úmida, várzeas e às vezes também num tipo especial de vegetação amazônica sobre solo silicoso, conhecido regionalmente por "caatinga".

Distribuição: Acre, Amazonas, Mato Grosso, Pará, Território de Rondônia, e fora do Brasil: Bolívia, Colômbia, Equador, Guiana, Peru e Venezuela. Para a Guiana (Bacia do rio Kuyuwini: A. C. Smith 2628 (NY), Equador (Esmeraldas: C. Jativa \& C. Epling 1143 (NY)) e Bolívia (Pando: G.T. Prance \& al. 5863 (INPA, NY)), este é o primeiro registro de sua ocorrência nesses paises. Fig. 26.

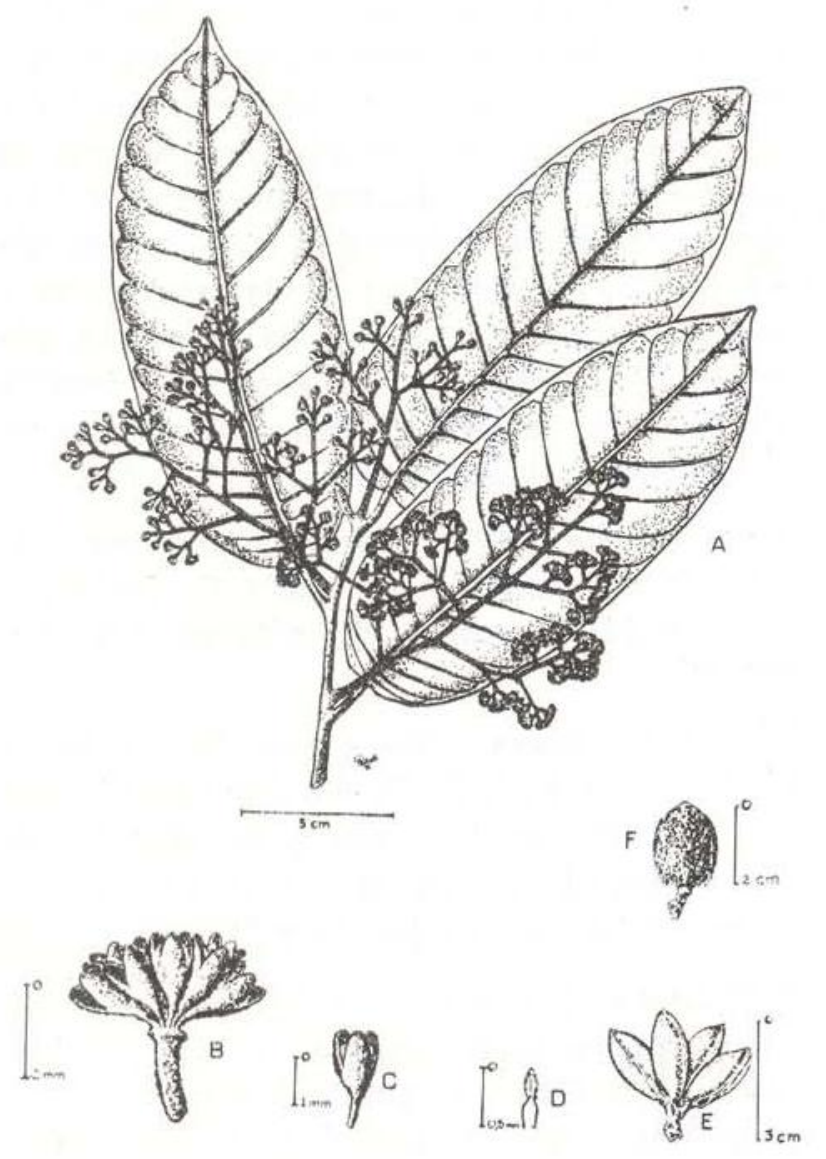

Fig. 25 - Virola calophylla. A-D (L. Coelho \& Osmarino 149): $A$, hábito do ramo florifero masculino; 8 , fasciculo floral: C, flor; D, androceu; E (A. Ducke 120), fruto: $F$ (G. Black \& Francisco 52-14640), fruto.

\section{MATERIAL ADICIONAL EXAMINADO:}

AMAZONAS: Rio Javari: Tabatinga: G. T. Prance et al. 16775, Jul. $1973 \mathrm{fl}$. (INPA, NY); ibid.: Palmeiras (long. $72^{\circ} 49^{\prime}$ W; lat. $5^{\circ} 8^{\prime} S$ ); G. T. Prance, Lleras et al. 16993, Ago. 1973 fl. (INPA, NY); ibid.: Estirão do Equador: G. T. Prance, Lleras et al. 17207. Ago. $1973 \mathrm{fl}$. (INPA, NY): ibid.: Seringal Santa Fé: J. Ramos s.n., Nov. 1975 fr. (INPA 54084); ibid.: Esperança: A. Ducka s.n., Fev. 1942 fl. (RB 53226, NY). Rio Solimões: São Paulo de Olivença: A. Ducke 396, Fev, 1932 fl. (GH, NY R): id. 1495, Abr. $1944 \mathrm{fr}$. (GH, IAN, NY, R); id. s.n. Fev. $1932 \mathrm{fr}$. (RB 24485); id. s.n., Out. 1931 fl. (RB 24494, F, INPA, NY, UB, US); id. s.n., Fev. 1937 fl. (RB 30139); R. L. Froes 20757, Abr. 1945 fr. (IAN, US); id 20908. Maio $1945 \mathrm{fr}$. (IAN, NY, US); id. 20925, Maio $1945 \mathrm{fr}$. (IAN. NY); id. 34792, Mar. 1945 fr. (IAN); Santo Antonio do Içá: R. L. Froes 34802, Mar. $1945 \mathrm{fr}$. (IAN): Fonte Boa: R. L. Froes 20612, Mar. $1945 \mathrm{fr}$. (IAN, NY). Bacia do rio Juruá: R. L. Froes 21640, sem data, fr. (IAN !, RB); rio Embira, tributário do rio Tarauacá (lat. $7^{\circ} 30^{\prime} \mathrm{S}$, long. $70^{\circ} 15^{\prime} \mathrm{W}$ ): B. A. Krukoff 4657 , Jun. $1933 \mathrm{fl}$ (NY); id. 4713, Jun. $1933 \mathrm{fl}$. (NY). Rio Tefé, Paxiubinha: R. L. Froes 26228, Jun. $1950 \mathrm{fl}$. (IAN, $\mathrm{RB})$. Bacia do rio Purus: rio Curuquetê tributário do rio Ituxi: G. T. Prance et al. 14312, Jul. 1971 fl. (INPA, NY); Cachoeira Ubim: A. Goeldi s.n., Jun. 1903 fl. (MG 3923, INPA): Boca do Acre: A. Ducke s.n., Abr. 1933 fl. (RB 24486). Manaus: J. Aluísio 59, Jul. 1968 fl. (INPA); C. C. Berg et al. P 18793, Set. 1973 fl. (INPA, NY); J. Chagas s.n., Fev. 1955 fr. (INPA 779): D. Coêlho s.n., Set. 1973 est. (INPA 42214): A. Ducke 20, Jul. 1942 fi. (GH, IAN, MG, R); id. 670, Fev. 1941 fr. (MG, R); id. 761. Jul. $1941 \mathrm{fl}$ ( (MG, R, RB); id. 1894, Ago, 1942 fl. (MG, R): id. s.n., Jun. 1932 fl. (RB 24539. INPA); id. s.n., Fev. 1933 fl. (RB 24540, US); id. s.n., Dez. 1942 fr. (IAN 120): A. P. Duarte \& L. Coêlho 9818, Jul. 1966 est. (INPA, RB); R. L. Froes 24922, Ago. 1949 fl. (IAN); J. M. Pires \& Black 937, Set. 1945 fl. (IAN); G. T. Prance et al. 2144, Set. $1966 \mathrm{fl}$. (INPA); id. 3079, Nov. $1966 \mathrm{fr}$. (INPA); id. 3639, Dez, $1966 \mathrm{fl}$. (INPA, NY, S, U, US, W); id. 3845, Dez, 1966 fr. (INPA); id. 18756, Ago. $1973 \mathrm{fl}$. (INPA); id. 21689, Ago. 1974 fl. (INPA); id. 22608, Set. $1974 \mathrm{fl}$. (INPA); W. Rodrigues \& J. Chagas 2291. Ago. $1961 \mathrm{fl}$. (INPA): W. Podrigues 5534, Set. $1963 \mathrm{fr}$. (INPA): W. Rodrigues \& Osmarino 6872, Fev, $1965 \mathrm{fr}$. (INPA, NY): W. Rodrigues \& Coêlho 8290, Jan. $1967 \mathrm{fr}$. (INPA); W. Rodrigues 8919. Ago. $1970 \mathrm{fl}$. (INPA); Id. 8935, Set. 1970 fl. (INPA); id. 9363, Jun. 1974 fl. (INPA): id. 9535 , Set. $1974 \mathrm{fl}$. (INPA); W. Rodrigues \& Ramos 9589. Mar. 1975 fr. (INPA); R. E. Schultes 24603, Jul/ Ago. $1967 \mathrm{fl}$. (ECON, IAN, INPA); id. 24611, Jul/Ago. 1967 fl. (ECON, IAN, INPA); J. A. Souza s.n., Ago. 1972 fl. (INPA 37125). Bacia do rio Madeira: rio Marimari: R. L. Froes 33715, Out. 1957 fr. (IAN); Humaitá: A. Ducke s.n., Jun. 1936 fl. (RB 30140). Bacia do rio Negro: Jauareté: R. L. Froes 21222, Out. 1945 fl. (IAN, NY); id. 21266, Out. $1945 \mathrm{fl}$. (IAN. NY). - rio Uaupés, Porto Cucurui: id. 22127. Abr. $1947 \mathrm{fr}$. (IAN): - rio !çana, Iraruca: G. A. Black 48-2569, Maio 1948 fr. (IAN); - rio 


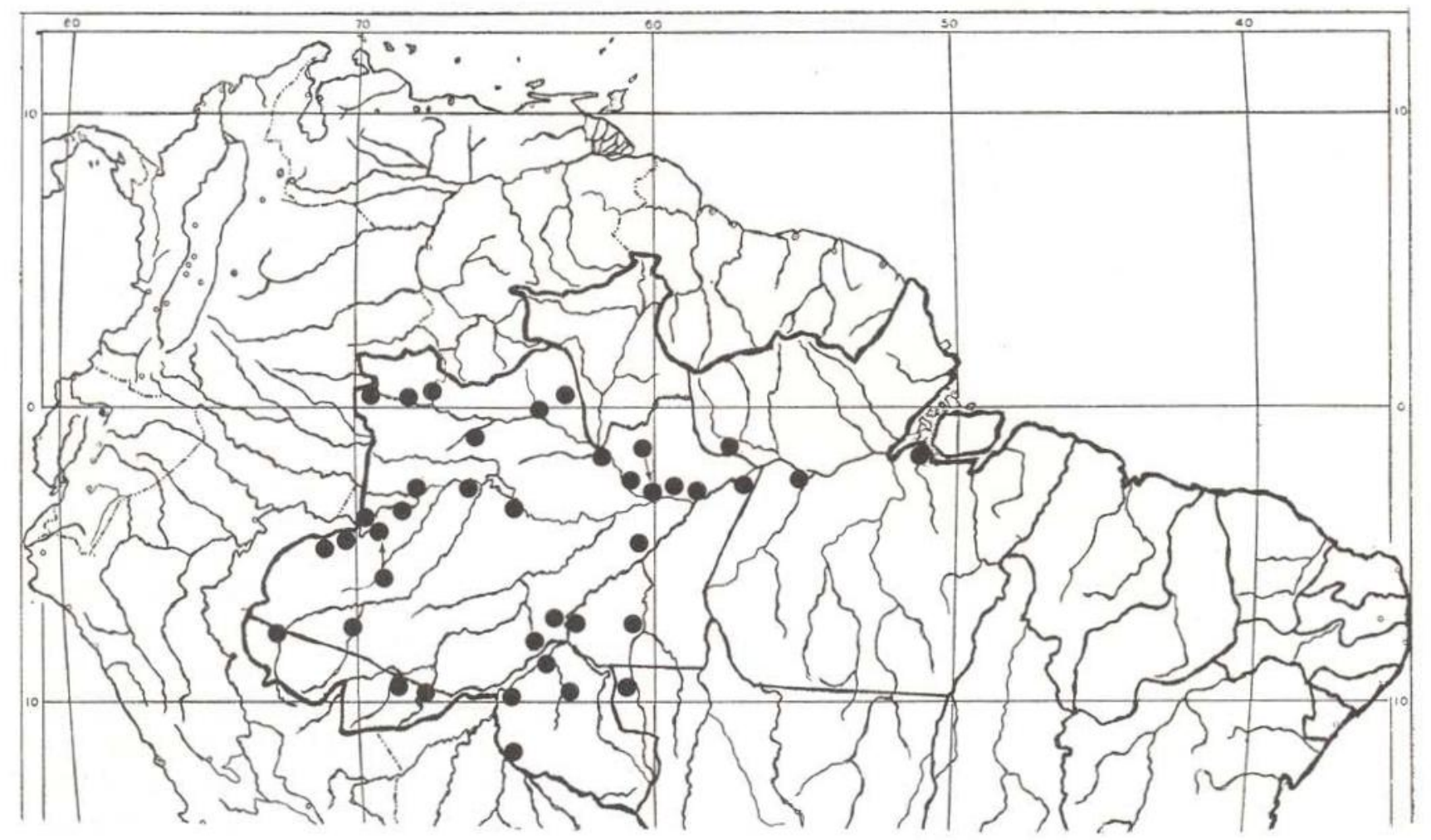

Fig. 26 - Distribuição atual de Virola calophylla no Brasil.

Içana, praia dos Patos: K. L. Froes 28063, Mar. 195? fr. (IAN); rio Cauaburi: R. E. Schultes 24570, Jul/Ago. 1967 fl. (ECON, IAN, INPA); Tapuruquara, rio Uneiuxi, tributário do rio Tea: G. T. Prance et al. 15565, Out. 1971 est. (INPA, NY); Tapuruquara: W. Rodrigues 829, Fev. 1959 fr. (INPA); - rio Demeni, Cuiufite: R. L. Froes \& Addison 28955, Out. 1952 fr. (IAN): - Airão: R. L. Froes 23255, Jun. 1948 fl. (IAN, SP); - rio Cuieiras: G. T. Prance et al. 14796, Set. $1971 \mathrm{fl}$. (NY); id. 14947, Set. $1971 \mathrm{fl}$. (INPA, NY); id. 14954, Set. 1971 fl. (INPA, NY); id. 17741 , Set. $1973 \mathrm{fl}$. (INPA); id 17790. Set. $1973 \mathrm{fl}$. (INPA); id. 17895, Set. $1973 \mathrm{fl}$. (INPA); id. 18002, Set. 1973 fl. (INPA); D. G. Campbell et al. P21821, Abr. 1974 fr. (INPA); id. P21883, Abr. 1974 fr. (INPA); - rio Araras: A. Loureiro et al. s.n., Abr. 1973 fl. (INPA 37712); id. s.n., Jul. 1973 fl. (INPA 39553). Estrada Manaus-ltacoatiara: Km 60: W. Rodrigues \& Lima 2226, Mar. 1961 fr. (INPA): - Km 64: L. Coêlho \& Osmarino 149, Fev. $1972 \mathrm{fl}$. (INPA); W. Rodrigues 4997, Mar. $1963 \mathrm{fr}$. (INPA): M. F. Silva 37, Jan. 1972 fr. (INPA): - Km 70: E. Oliveira 2704, Out. 1963 fl. (IAN); W. Rodrigues et al. 9080, Jun. 1973 fl. (INPA); $-\mathrm{Km}$ 122: W. Rodrigues 8902, Ago, 1970 fl. (INPA); - Km 133: T. D. Pennington \& Monteiro P22638, Set. 1974 fl. (INPA); W. Rodrigues \& Loureiro 9493, Jul. 1974 fl. (INPA); $-\mathrm{Km}$ 138: 0. Pires \& Lima 59, Jun. 1972 fl. (INPA); - Km 165: D. Coêlho s.n., Dez. 1974 fr. (INPA 47272); id. s.n., Dez. 1974, est. (INPA 47275): - Km 175: W. Rodrigues 9008
Fev. 1971 fr. (INPA); - Km 185: W. Rodrigues \& CoêTho 7269, Nov. 1965 fr. (INPA); - Km 204: G. T. Prance et al. 3779, Dez, 1966 fr. (INPA, NY, UB). Estrada Manaus-Porto Velho: L. Coêlho 143, Jan, 1972 fr. (INPA); entre rios Castanho e Tupana: G. T. Prance et al. 22777, Out. 1974 fr. (INPA): M. F. Silva et al. 157, Jul. 1972 fl. (INPA); id. 216, Jul. 1972 fr. (INPA); id. 249, Jul. 1972 fl. (INPA); id. 440, Jul. 1972 fr. (INPA); id. 623, Jul. 1972 fl. (INPA); id. 1013, Jul. 1972 fl. (INPA); entre rios Castanho e Araçá: M. F. Silva et al. 1003, Jul. 1972 fl. (INPA); - Km 240: E. Lleras et al. P19573, Nov. $1973 \mathrm{fr}$. (INPA); id. P19621, Nov. 1973 (INPA); $\mathrm{Km}$ 253-255 G. T. Prance et al. 20689, Mar. $1974 \mathrm{fl}$. (INPA); id. 20741, Mar. 1974 fl. (INPA); - Km 380-386: G. T. Prance et al. 22885, Out. $1974 \mathrm{fr}$. (INPA); id. 22920, Out. 1974 (INPA). Careiro, Lago do Castanha-Mirim: Byron et al. 921, Jun. 1973 fr. (INPA); Parintins, Lago José-Açu: A. Ducke s.n., Set. 1932 fl. (RB 24487).

ACRE: Cruzeiro do Sul: P. Maas et al. P12659, Abr. 1971 fl. (INPA, NY); id. P12718, Maio 1971 fl. (INPA, NY): id. P12788, Maio 1971 fl. (INPA, NY); G. T. Prance et al. 11800, Abr. $1971 \mathrm{fl}^{\circ}$ (INPA, NY); id. 12550 , Abr. 1971 fr. (INPA, NY): id. 12606, Abr. fr. (INPA, NY): id. 12618, Abr. 1971 fl. (INPA, NY). - Rio Macauã, tributário do rio Yaco (lat. $9^{\circ} 20^{\prime} \mathrm{S}$; long. $69^{\circ} \mathrm{W}$ ): B. A. Krukoff 5492, Ago. 1933 fr. (NY, RB). - Rio Acre: E. Ule 9376, Abr. 1911 fl. (L, MG). 
TERRITÓRIO DE RONDONIA: - Estrada Porto VeIho-Cuiabá: Santa Bárbara, Km 117: G. T. Prance et al. 6944, Ago. 1968 fl. (INPA, NY); id. 7013, Ago. $1968 \mathrm{fl}$. (INPA, NY); Ariquemes: G. T. Prance et al. 7033, Ago. $1968 \mathrm{fl}$. (INPA, NY). - Bacia do rio Madeira: rio Mutumparaná, Mutumparaná: G. T. Prance et al. 8775, Nov. $1968 \mathrm{fr}$. (INPA); id. 8838, Nov. 1968 fr. (NY). - Estrada de Ferro Madeira-Mamoré, $\mathrm{Km}$ 133: B. Maguire et al. 56666, Set. 1968 fr. (INPA, NY, RB); - Mutumparaná, Serra dos Três Irmãos: G. T. Prance et al. 5530 , Jul. 1968 fl. (INPA, NY). - Porto Velho: G. A. Black et al. 52-14640, Maio $1952 \mathrm{fr}$. (IAN); A. Ducke s.n., Jun. 1936 fl. e fr. (RB 3014); G. T. Prance et al. 8258, Nov, 1968 fl. (INPA). - Guajará-Mirim, Serra dos Pacaás-Novas, alt. $200-400 \mathrm{~m}$ : G. T. Prance et al. 6665, Ago. 1968 fl. (INPA, NY). - Ponto 26-SC-20-XD (Projeto RADAM): M. R. Cordeiro 680, Ago, 1975 fl. (IAN, INPA).

MATO GROSSO: - Rio Aripuanā, Cachoeira Dardanelos (long. $59^{\circ} 21^{\prime} \mathrm{W}$; lat. $10^{\circ} 12^{\prime} \mathrm{S}$ ): C. C. Berg et al. P18530, Out. 1973 fl. (NPA); M. R. Cordeiro 120, Jun. 1974 fl. (IAN, INPA); id. 199, Jun. 1974 fl. (IAN, INPA); P. Lisboa et al. 518, Set. 1975 fl. (INPA): G. T. Prance et al. 18355, Out. $1973 \mathrm{fl}$. (INPA).

PARÁ: - Faro: G. A. Black \& Ledoux 50-10672. Nov. 1950 fr. (IAN, UB, US), - Rio Tapajós, lugar Maria Luiza: A. Ducke s.n., Jul. 1923 fl. (RB 18632). - Santarém: igarapé da Lama: R. E. Froes 30982, Jul. $1954 \mathrm{fl}$. (IAN, US): Estrada do Palhăo: M. Silva \& Souza 2351, Ago. 1969 fl. (INPA). - Portel, rio Muirapiranga (long. $50^{\circ} 38^{\prime}-50^{\circ} 50^{\prime} \mathrm{W}$; lat. $\left.2^{\circ} 33^{\prime}-2^{\circ} 50^{\prime} \mathrm{S}\right)$ : G. T. Prance et al. 1576, Out. $1965 \mathrm{fl}$. (GH, IAN, NY, UB).

Embora Ducke (1936, I.c.) e Smith (1937, I.c.) admitissem a existência de bons caracteres para distinguir a presente espécie da $V$. calophylloidea, ambas não passam de sinônimos. As diferenças antes atribuídas a elas são em geral insignificantes e encontráveis tanto numa como na outra espécie, quando se examina vasta coleção. Morfologicamente, V. calophylla apresenta uma plasticidade fenotípica muito grande devido a sua grande dispersão. Possivelmente, esta espécie representa o que Steenis (1957) chama de "paramorfa", termo este que define todos os espécimes que desviam um ou mais caracteres da média das populações, resultantes de uma variação genotípica.

A coleção L. Coêlho \& Osmarino 149 diverge de todos os espécimes examinados principalmente pelos fascículos florais mais densos e pelas flores distintamente menores.

A coleção Ducke s.n. (RB. 30139), embora apresente flores muito maiores que as nor- mais desta espécie, à primeira vista, lemera $C$. peruviana, porém a diferença óbvia entre as duas espécies se nota logo nos caracteres do androceu.

4. Virola carinata (Spr. ex Benth.) Warburg, Nova Acta Acad. Leop.-Carol. 68:222, tab. 5, fig. 1-2 (sementes). 1897: A. Ducke, Journ. Acad. Sci. 26(6):258. 1936 pro parte excl. especim. RB 24501, 24504, MG 11265); A.C. Smith \& Wodehouse, Brittonia 2(5):505, fig. 9 i (fruto). 1937; A. Ducke, Bol. Técn. Inst. Agron. Norte 4:11. 1945; A.C. Smith, Contr. U.S. Nat. Herb. 29(8):329. 1950; A. Ducke, Bol. Técn. Inst. Agron. Norte 19:6. 1950; A.C. Smith, Am. Journ. Bot. 43(8):577. 1956; R.E. Schultes \& B. Holmstedt, Lloydia 34(1):70. 1971, pro parte; H. Garcia-Barriga, FI. Medicinal de Colombia 1:351. 1974; O.R. Gottlieb, J.G.S. Maia \& M.N.P.R. de Souza, Ciência e Cuitura 27(7):172. 1975.

Myristica carinata Spruce ex Bentham, Hook. Journ. Bot. 5: 2. 1853; A. De Candolle in DC., Prodr. 14: 198. 1856; A. De Candolle in Mart., FI. Bras. 5 (1): 117. 1860

Palala carinata (Benth.) O. Kuntze, Rev. Gen. PI. 2: 567. 1891, nom. illegit.

Myristica gracilis A. De Candolle, Ann. Sc. Nat. Sér. 4, Bot. 4: 30. 1855; A. DC. in DC., Prodr. 14: 198. 1856; A. DC. in Mart., FI. Bras. 5 (1): 117. 1860. Tipo: Spruce 1682, Brasil, Amazonas, Manaus $(=$ Barra), Out. $1851 \mathrm{fl}$. (holótipo: G-DC; isótipo: BM, C, GH, K, M, NY, P; B e W destruídos).

Virola carinata var. gracilis Warburg, Nova Acta Acad. Leop.-Carol. 68: 223. 1897.

Virola venosa var. martii Warburg, Nova Acta Acad. Leop.-Carol. 68: 226. 1897; J. C. Th. Uphof in Engl. \& Prantl, Nat. Pflanzenfam., 2." ed., 17: (2): 208. 1959. Tipo: Martius s.n., Brasil, Amazonas, rio Japurá, Jan. fr. (holótipo: M; fotos: F 19104, IAN, INPA],

Myristica hypoleuca Spruce, Journ. Linn. Soc. 5: 4. 1860, nom. nud. Origem do nome: Spruce 3206, Venezuela, rio Cassiquiare, Vasiva e Pacimoni, Dez. 1853 fl. (BM, C, GH, K, NY, P, RB). 
Palala hypoleuca (Spruce) Kuntze, Rev. Gen. PI. 2: 567. 1891, nom. nud.

Myristica pacimonensis Spruce ex Warburg, Nova Acta Acad. Leop.-Carol. 68: 218. 1897, como sinônimo de V. surinamensis. Origem do nome: Spruce 3362, Venezuela, margem do rio Pacimoni, Fev. 1845 fr. (BM, K, P).

Árvore mediana a grande até $30 \mathrm{~m}$ de altura e $1 \mathrm{~m}$ de diâmetro do tronco à altura do peito; raminho geralmente glabro e enegrecido às vezes levemente tomentelo. Pecíolo fortemente canaliculado, puberulento ou glabro, $1-3 \mathrm{~mm}$ de diâmetro e $30-100 \mathrm{~mm}$ de comprimento. Lâmina foliar coriácea ou finamente coriácea, estreitamente elíptica ou estreitamente oblonga ou obovado-oblonga, $90-220 \mathrm{~mm}$ de comprimento, $25-50 \mathrm{~mm}$ de largura (raramente até $60 \mathrm{~mm}$ ), arredondada, obtusa ou subaguda na base, obtusa, aguda ou cuspidada no ápice, dispersamente pálido-puberulenta na página inferior (tricomas séssil-estrelados, 4-6-ramificados, 0,1-0,2mm de diâmetro), logo giabrescente; nervura mediana pouco imersa na página superior, saliente na inferior; 15-28 nervuras secundárias de cada lado, ligeiramente impressas na página superior, elevadas na inferior; vênulas levemente impressas ou obscuras. Inflorescência masculina amplamente panicula$\mathrm{da}$, livremente ramificada, densiflora, 40-140 mm de comprimento e quase o mesmo tanto de largura; pedúnculo até $40 \mathrm{~mm}$ de comprimento, com raminhos e flores tenuemente pubescentes (tricomas palidamente séssil-estrelados, pouco ramificados, $0,1-0,2 \mathrm{~mm}$ de diâmetro), glabrescente; brácteas puberulentas, oblongas, $2-5 \mathrm{~mm}$ de comprimento, indistintas, logo decíduas; flores isoladas ou em fascículos de 2-10; pedicelos delgados, até $1,5 \mathrm{~mm}$ de comprimento; perianto carnoso de $1,5-2,5 \mathrm{~mm}$ de comprimento, 3-lobado quase até a base, lóbulos oblongos, obtusos; androceu de 1-2mm de comprimento; andróforo delgado, $0,6-1,5 \mathrm{~mm}$ de comprimento; 3 anteras, $0,4-0,5 \mathrm{~mm}$ de comprimento, soldadas até o ápice ou divergentes distalmente, obtusas ou subagudas. Inflorescência feminina ligeiramente mais curta que a masculina; 1-3 flores por fascículo; pedicelos grossos, até $2 \mathrm{~mm}$ de comprimento; ovário subgloboso, tenuemente puberulento, estilete gros- so e curto; estigma oblíquo, fendido. Infrutescência até $100 \mathrm{~mm}$ de comprimento, na maturidade glabra inteiramente; 4-12 frutos maduros por infrutescência, pedicelados (pedicelos grossos, $50-70 \mathrm{~mm}$ de comprimento), subglobosos, ovóides $15-25 \mathrm{~mm}$ de diâmetro, lisos ou às vezes levemente impressos nas suturas, arredondados ou obtusamente apiculados no ápice; pericarpo coriáceo, liso ou rugoso, 0,7-4mm de espessura; arilo fendido quase até à base; semente subglobosa ou ligeiramente elipsóide. Figs. 3B, 27, 28 e 33 .

Tipo: Spruce 1343, Amazonas, Manaus, 1850-51 fr. (holótipo, K; isótipos: BM, C, GH, M, P; fotos: F 1960, IAN).

Nomes vulgares: Ucuuba (ex Ducke 259); ucuuba-branca (ex Rodrigues 7407); ucuubabranca-do-baixio (ex Rodrigues 7251); ucuuba-do-baixio (ex Souza, INPA 37123). Segundo Schultes \& Holmstedt (I.c. 1971) a espécie é conhecida também pelos seguintes nomes indígenas: na-tzin-ñe-me (Barasana); bom-am (Maku); la-see-ñe-me-hoo (Makuna) e chee-van (Puinave).

UtiLIDADES: Segundo Schultes \& Holmstedt (l.c. 1971) V. carinata tem empregos medicinais vagos e difusos no alto rio Negro, o mais específico dos quais é no tratamento de "carate", uma doença que provoca a descoloração da pele. Gottlieb et al. (I.c. 1975) isolaram e identificaram uma neolignana nova nesta espécie denominada mootobaphenol.

Fenologia: A floração registrada vai de junho até dezembro, com predominância em junho, e a frutificação entre outubro e maio. Fig. 10.

Haвitat: Planta característica das matas alagadiças ao longo dos pequenos rios de água preta, igapós, restingas e pântanos, geralmente em solos muitos ácidos e pobres de sedimentos.

Distribuição: Estados do Amazonas, Pará e Território Federal de Rondônia e fora do Brasil: Venezuela e Colômbia. Fig. 23.

\section{MATERIAL ADICIONAL EXAMINADO:}

AMAZONAS: - São Paulo de Olivença: igarapé Belém: R. L. Froes 23753, Dez. 1948 fr. (IAN). - Rio Tefé: R. L. Froes 26195, Jun. 1950 fl. (IAN, RB); Lago 


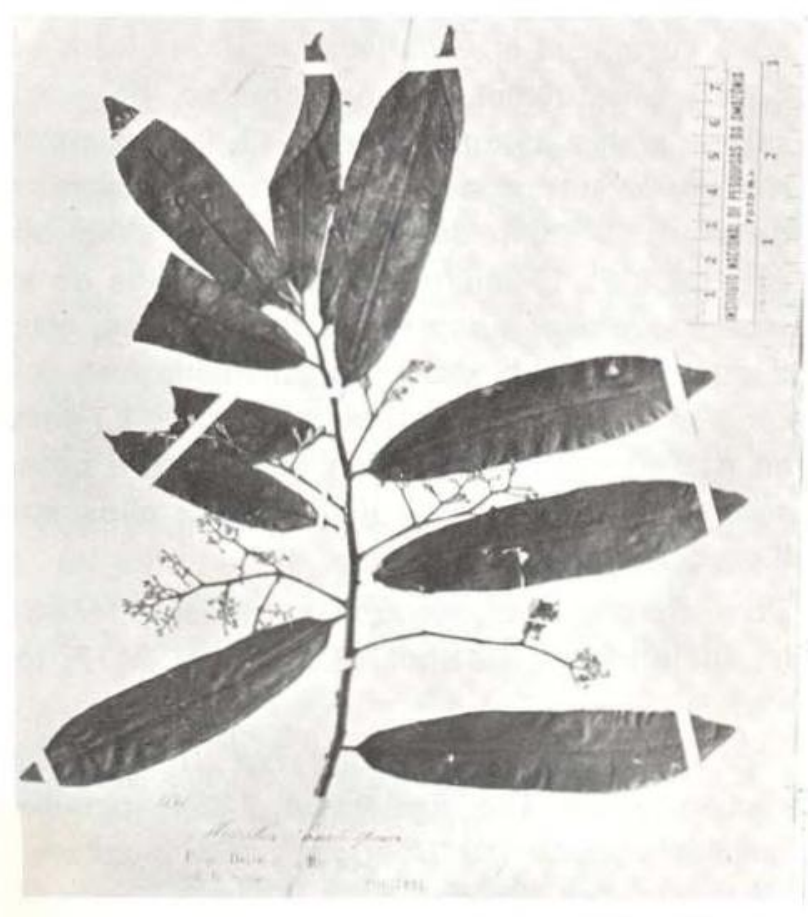

Fig. 27 - Virola carinata. R. Spruce 1682 (NY, ișótipo de Myristica gracilis).

de Tefé: E. Lleras et al. P 17486, Agô. 1973 fl. (INPA, NY). - Bacia do rio Negro: rio Papuri, tributário do rio Uaupés: R. L. Froes 21172, Out. 1945 fl. (IAN, NY); Uaupés: (long. $68^{\circ} \mathrm{W}$; lat. $1^{\circ} 28^{\prime} \mathrm{N}$ ): O. C. Nascimento et al. 104, Abr. 1975 fr. (IAN, INPA); perto do rio Curicuriari: M. F. Silva et al. 1715, Maio $1973 \mathrm{fr}$. (INPA); rio A:açá: R. L. Froes \& Addison 29147, Out. 1952 fr. (IAN). - Estrada Manaus-Caracaraí (BR 174), Km 185: G. T. Prance et al. 22699, Set. $1974 \mathrm{fl}$. (INPA, NY). Manaus: J. Aluísio 310, Dez. 1969 fl. (INPA); D. CoêIho s.n., Fev. $1974 \mathrm{fr}$. (INPA 46523): A. Ducke 259, Jul, $1936 \mathrm{fl}$. (IAN, MG, R.); id. 260, Jul. $1943 \mathrm{fl}$. (IAN, MG); id. 658, Mar. 1941 fr. (IAN, MG, R, RB); id. s.n., Nov. 1932 fl. (RB 24502); id. s.n., Jun. 1932 fl. (RB 24503); id. s.n., Ago. 1935 fl. (RB 30146); id. s.n., Jan. 1937 fr. (RB 37641); id. s.n. ou 1299, Mar. 1941 fr. (RB 50687, IAN, INPA); R. L. Froes 20467, Fev. 1945 fr. (IAN, NY); W. Rodrigues 9054, Jun. 1972 fl (INPA); id. 9544, Set. 1974 fl. (INPA); W. Rodrigues \& Monteiro 9591, Mar. $1975 \mathrm{fr}$. (INPA); R. E. Schultes \& Rodrigues 26181A, Abr. 1972 fr. (ECON, INPA); J. A. Souza s.n., Ago. 1972 fr. (INPA). - Estrada Manaus-Itacoatiara: $\mathrm{Km}$ 74: W. Rodrigues 7407 , Ago. 1965 est. (INPA); Km 118-135: O. P. Monteiro s.n., Ago. 1975 est. (INPA 50905). Km 165: W. Rodrigues 7251 , Out. $1965 \mathrm{fl}$. (INPA). - Estrada ManausPorto Velho: Km 328: W. Rodrigues \& Coêlho 9627, Jun. $1975 \mathrm{fl}$. (INPA). - Rio Urubu: Cachoeira de Iracema: R. L. Froes 25357, Set. $1949 \mathrm{fr}$. (IAN).

PARA: - Faro: A. Ducke s.n., Dez. 1919 fl. (RB 21203). - Santarém: R. L. Froes 30969 Jun. 1954 fl. (IAN); id. 31719, Abr. $1955 \mathrm{fr}$. (IAN); M Silva \& Souza 2285, Ago. $1969 \mathrm{fl}$. (INPA).
TERRITORIO DE RONDONIA: - Bacia do rio Madeira, entre Ribeirão e Abună: G. T. Prance et al. 6645, Jul. 1968 fl. (INPA, NY).

Esta espécie é difícil de separar-se de $V$. pavonis A.C. Smith quando não se dispõe de frutos. V. carinata Warb. prefere os pequenos cursos dágua ou igapós de água muito ácida e pobre de sedimentos. $V$. pavonis tem sido mais assinalada nas matas de terra firme, fora do alcance das águas. Ducke (I.c. 1950) acha fácil a separação de $V$. carinata de $V$. pavonis mesmo em estado estéril. Segundo ele, a presente espécie tem os raminhos novos dum verde luzidio e puro e suas folhas são relativamente glabras, enquanto $V$. pavonis apresenta raminhos cor de canela e folhas mais fortemente pilosas. Essas observaçōes infelizmente não têm sido confirmadas muitas vezes. A separação ou não das duas espécies vai depender, talvez, de muitas observaçöes de campo e não através de coleções de herhárin.

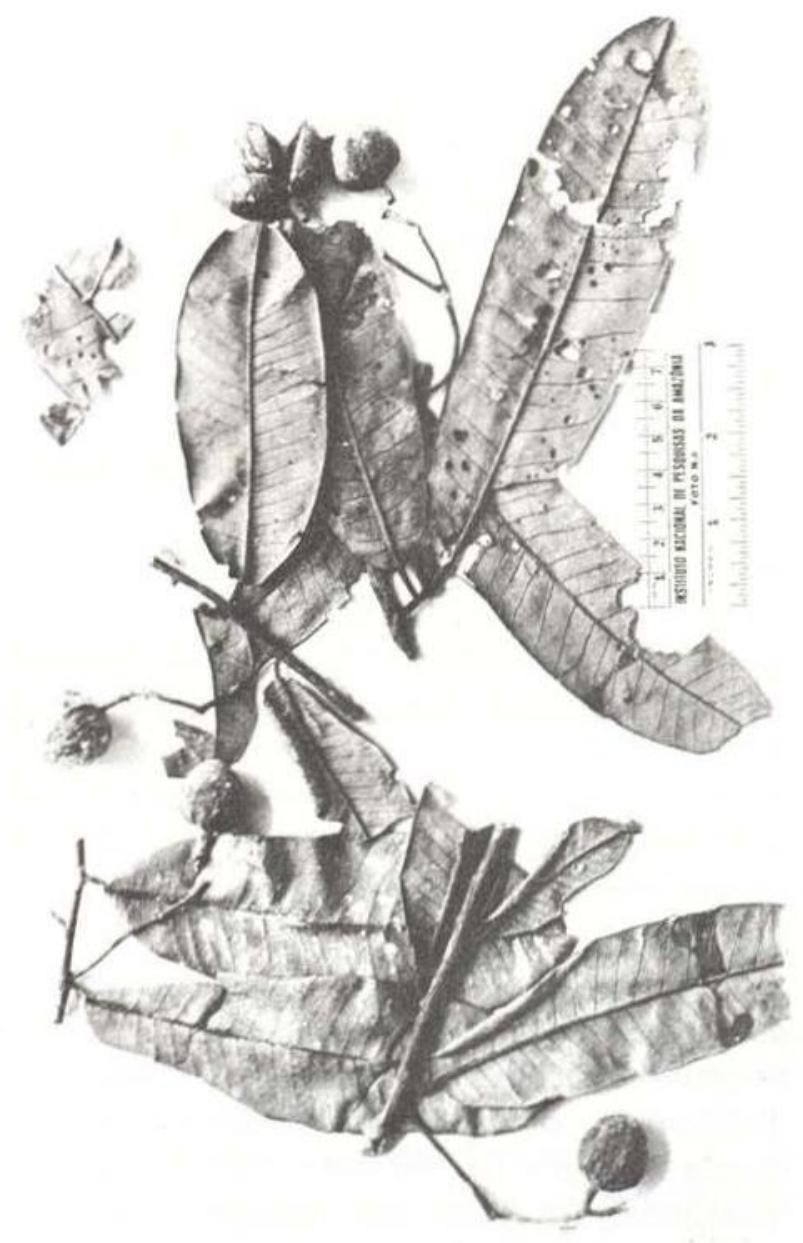

Fig. 28 - Virola carinata. A. Ducke s.n. (IAN 119). 
5. Virola coelhoi W. Rodr., Ciência e Cultura, Suplemento, 29(7):559. 1977; Acta Amazonica 7(4):462, fig. 2. 1977.

Arvore de $25 \mathrm{~m}$ de altura; tronco sem sapopema, de aproximadamente $25 \mathrm{~cm}$ de diâmetro à altura do peito; raminhos novos delgados, mais ou menos achatados lateralmente, com indumento densa, uniforme e microscopicamente castanho-puberulento como os pecíolos e pedúnculos (tricomas muito pequenos, séssil-estrelados), os mais velhos glabros e acinzentados. Pecíolos delgados, canaliculados, cerca de $1-2 \mathrm{~mm}$ de diâmetro, $4-12 \mathrm{~mm}$ de comprimento, rugosos, puberulentos como os raminhos jovens, depois glabrescentes. Lâmina foliar finamente coriácea, linear-oblonga ou obovado-oblonga, 33-230 $\mathrm{mm}$ de comprimento, $10-47 \mathrm{~mm}$ de largura, atenuada, aguda ou obtusa na base, obtusamente cuspidada, acuminada, subaguda ou obtusa no ápice, lustrosa e glabra na página superior, densa, uniforme, pálida e indistintamente puberulenta na página inferior (tricomas séssil-estrelados, cerca de $0,1-0,2 \mathrm{~mm}$ de diâmetro) esparsamente amarelo-punctuada na página inferior; nervura mediana imersa na página superior e elevada na inferior; 20-46 nervuras secundárias de cada lado (folhas adultas muito freqüentemente $16-21$ por $10 \mathrm{~cm}$, ou afastadas $3-11 \mathrm{~mm}$ entre si) levemente ascendentes, mais ou menos paralelas, anastomosadas junto às margens, levemente impressas ou promínulas na página superior, promínulas na inferior; vênulas reticuladas promínulas ou obscuras na página superior e indistintas geralmente na inferior. Inflorescência masculina e feminina não vistas, exceto uma inflorescência muito jovem e alguns restos de flores femininas ocasionalmente soltas, encontradas agarradas à exsicata. Flores robustamente pediceladas; ovário subgloboso, intensa e diminutamente ferrugíneo-puberulento; estígma subséssil obliquamente capitado e fendido. Infrutescência de $25-50 \mathrm{~mm}$ de comprimento, 1-2- ramificada, ferrugíneo-puberulenta, como os raminhos novos; $1-8$ frutos imaturos por infrutescência, amarelo-ferrugíneos, pedicelados (pedicelos grossos de mais ou menos $3-4 \mathrm{~mm}$ de diâmetro, $3-4 \mathrm{~mm}$ de comprimento), subglobosos, $7-17 \mathrm{~mm}$ de diâmetro, ar- redondados e curtamente estipitados na base (estipes grossos de 1-2mm de comprimento), arredondados no ápice, carinados em torno da sutura superior, diminutamente ferrugíneo-puberulentos ou séssil-estrelados, glabrescentes; pericarpo de 1-3mm de espessura; sementes não vistas. Fig. 29.

Trpo: D. Coelho s.n., Brasil, Amazonas, Mtunicípio de Tefé, Vila Nogueira, igarapé Manauă, 21 Out. 1975 fr. (holótipo: INPA 53124).

Fenologia: Colhida com inflorescências jovens em junho e com frutos imaturos entre outubro e dezembro.

Habitat: Mata de terra firme baixa, porém não alagável.

DistribUIÇÃo: Só conhecida da localidade típica no Município de Tefé, Estado do Amazonas. Fig. 23.

\section{MATERIAL ADICIONAL EXAMINADO:}

AMAZONAS: Tefé: Vila Nogueira: D. Coêlho 619 , Nov. 1975 fr. (INPA, amostra de madeira INPA X6200); Paxiubinha: R. L. Froes 26220, Jun. $1950 \mathrm{fl}$. (IAN, RB).

Espécie distinta das demais conhecidas pelas folhas menores e de cor branco-amarelada na página inferior. As inflorescências jovens encontradas na coleção Froes 26220 são muito semelhantes às de $V$. polyneura, porém mais delicadas. Os frutos lembram na forma e tamanho os da comum $V$. calophylla.

6. Virola crebrinervia Ducke, Journ. Wash. Acad. Sci. 26 (6) : 260. 1936; A.C. Smith \& Wodehouse, Brittonia 2 (5):481. 1937; A. Ducke, Arq. Ser. Florest. 1 (1):27. 1939; A.C. Smith, Brittonia 3 (2):340 1939; J.C. Th. Uphof in Engl. \& Prantl, Nat. Pflanzenfam., $2^{\text {a }}$ ed., $17^{a}$ (2) :207. 1959; descr. ampla.

Árvore até $25 \mathrm{~m}$ de altura; tronco cilíndrico, até $35 \mathrm{~cm}$ de diâmetro; raminho canescente- ou ferrugíneo-tomentoso, logo glabro. Pecíolo de 5-7-(14) $\mathrm{mm}$ de comprimento, mais ou menos robusto e profundamente canaliculado, tomentoso como os raminhos, os mais velhos mais 


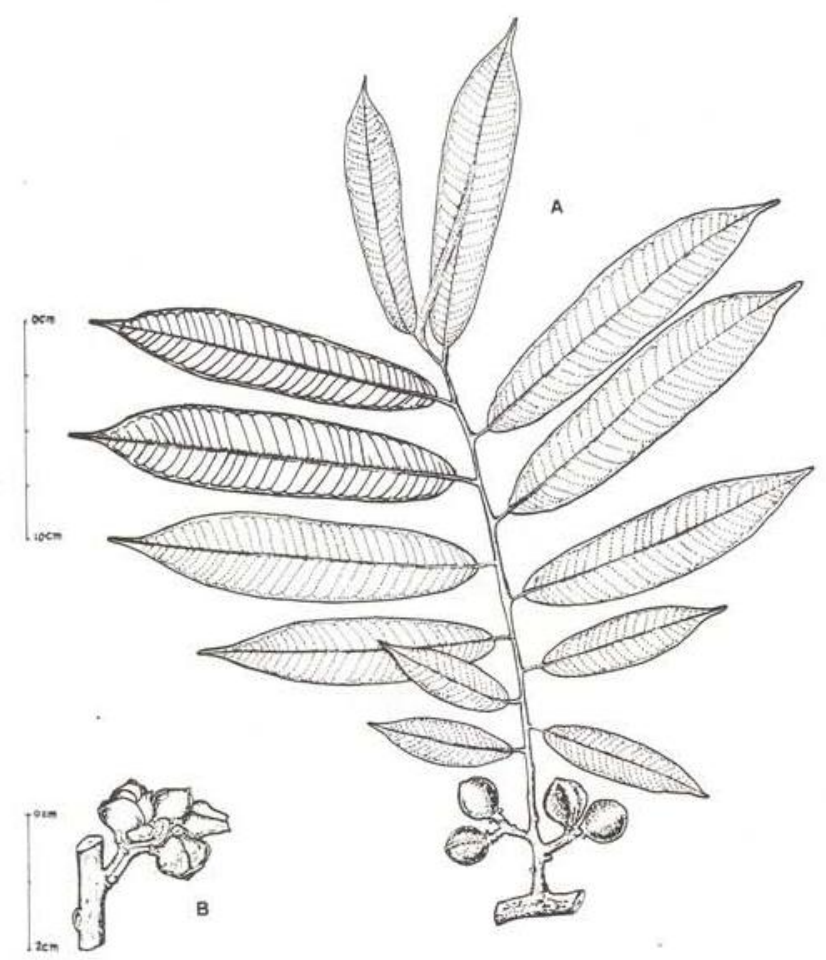

Fig. 29 - Virola coelhoi. A (D. Coelho s.n., INPA 53124), hábito do ramo florífero; B (R. L. Froes 26220), inflorescência jovem.

ou menos glabros. Lâmina foliar de 100-180(290) $\mathrm{mm}$ de comprimento, 22-30-(60) $\mathrm{mm}$ de largura, estreitamente oblongo-lanceolada, membranácea, margens subparalelas, distintamente cordada na base, agudamente caudado. acuminada no ápice, glabra em ambas as páginas, na superior fuscescente, na inferior ferrugínea; nervura mediana saliente e grossa na página inferior; 50-60 nervuras secundárias de cada lado, tênue e distintamente salientes na face inferior, perto das margens arcuado-anastomosadas; vênulas tenuemente reticuladas. Inflorescência masculina densiflora, axilar ou subterminal até $130 \mathrm{~mm}$ de comprimento, canoferrugíneo-tomentosa; brácteas densamente tomentosas, decíduas; densos fascículos florais de $3-5 \mathrm{~mm}$ de diâmetro; pedicelos finos até $1 \mathrm{~mm}$ de comprimento; perianto cơm cerca de $1,5 \mathrm{~mm}$ de comprimento, infundibuliforme. trífido até o meio, pardo-amarelado, tomentoso externamente; andróforo fino cerca de $0,8 \mathrm{~mm}$ de comprimento; 3 anteras soldadas até o ápice, subiguais ou ligeiramente mais curtas que 0 andróforo, glabras, com o conectivo curta- mente apicuiado. Inflorescência feminina subterminal de $40-50 \mathrm{~mm}$ de comprimento e quase o mesmo de largura, paniculada, 1-ramificada, ramos opostos, uniforme e densamente ferrugíneo-tomentosa; pedúnculo achatado, $16 \mathrm{~mm}$ de largura; 5-7 flores por fascículo; pedicelos grossos, $1,0-1,5 \mathrm{~mm}$ de comprimento; perianto de aproximadamente $1,5-1,8 \mathrm{~mm}$ de comprimento, $1,2 \mathrm{~mm}$ de largura, 3-lobado, cada lóbulo fendido até cerca da metade de seu comprimento total; ovário subgloboso, tenra e uniformemente ferrugíneo-tomentelo, cerca de $1 \mathrm{~mm}$ de comprimento; estigma subséssil, oblíquo e fendido. Infrutescência até $60 \mathrm{~mm}$ de comprimento, tenramente ferrugíneo-tomentosa; 3-5 frutos jovens por infrutescência, pedicelados (pedicelos grossos de 2,5-3mm de comprimento), elipsóide-obovoides, carinados, densamente ferrugíneo-tomentosos (tricomas inconspicuamente estrelados ou articulados com apêndices laterais). Figs. 3,60 .

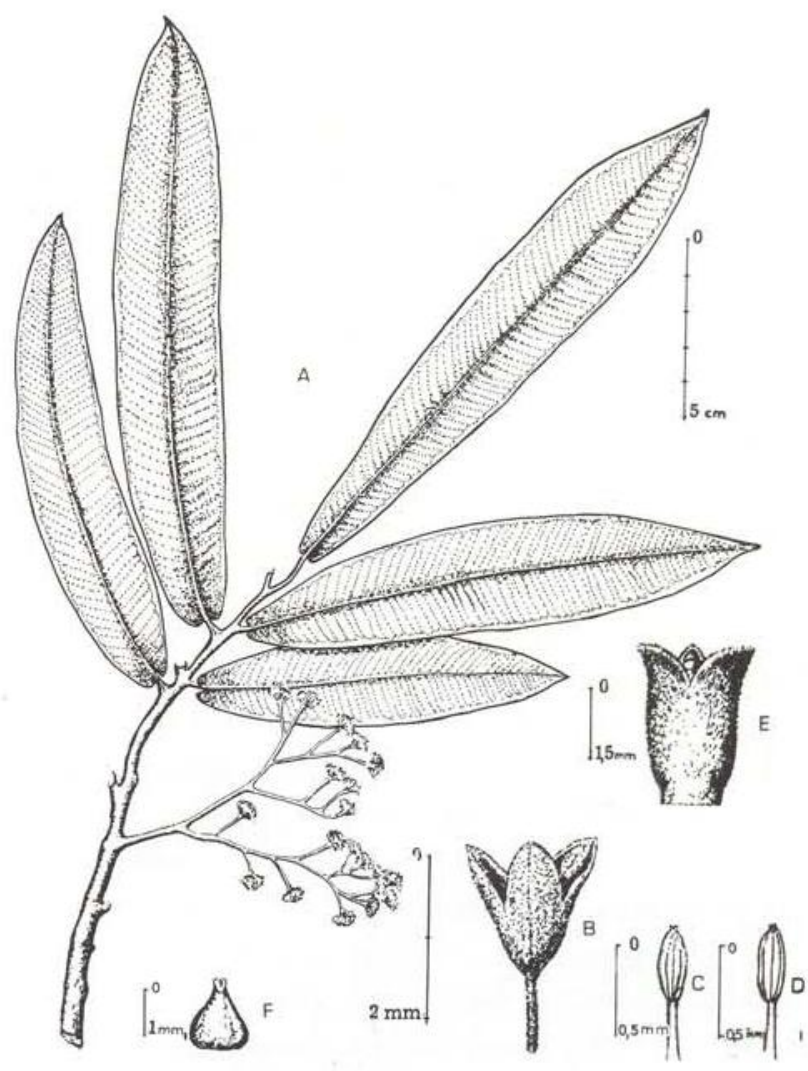

Fig. 30 - Virola crebrinervia. A-D (A. Ducke s.n., MG 17182): A, hábito do ramo florifero masculino; B, flor masculina; C e D, androceu; E-F (L. Williams \& Silva 18245): E, flor feminina; $E$, gineceu. 
Trpo: A. Ducke s.n., Brasil, Pará, Gurupá, mata de terra firme, 10 Ago. 1918 fl. (holótipo: MG 17182; isótipo: RB 25311).

Nome vUlgar: Ucuúba (ex Williams \& Silva 18245).

Fenologia: Colhida com flores entre agosto e novembro e com frutos imaturos em outubro.

HABITAT : Mata primária de terra firme.

Distribuição: Conhecida até hoje apenas da parte oriental do Pará. Fig. 31.

\section{MATERIAL ADICIONAL EXAMINADO :}

PARA: - Bacia do rio Xingu: Porto de Moz: Froes 32399, Nov. 1955 fl. (IAN). - Portel: L. Williams \& Silva 18245, Out. $1955 \mathrm{fl}$. e fr. (IAN, US).

A descrição da inflorescência feminina e frutos jovens foi baseada na coleção Williams \& Silva 18245, depositada no herbário do IAN.

Espécie muito próxima de V. flexuosa A.C. Smith, diferencia-se desta pela glabrescência dos raminhos, pecíolos e inf́lorescência masculina, e especialmente pelas folhas, as quais são longamente lanceoladas, estreitas e de margens paralelas, distintamente caudado-acuminadas no ápice, glabrescentes na página inferior e, também, pelo reticulado nitidamente promínulo em ambas as faces da folha.
7. Virola decorticans Ducke, Journ. Wash. Acad. Sci. 26 (6) :262. 1936; A.C. Smith \& Wodehouse, Brittonia 2 (5):478, 1937; A. Ducke, Arq. Ser. Florest. 1 (1):27. 1939; J.C. Th. Uphof in Engl. \& Prantl, Nat. Pflanzenfam., $2^{\mathrm{a}}$ ed., $17^{a}$ (2) :207. 1959.

Arvore mediana; raminho com casca fina. logo decídua, densamente rufovelutino, com tricomas irregularmente ramificados de cerca de $1 \mathrm{~mm}$ de comprimento. Pecíolo grosso, $5-7 \mathrm{~mm}$ de diâmetro, densamente rufovelutino, levemente canaliculado ou quase cilíndrico, $7-20 \mathrm{~mm}$ de comprimento. Lâmina foliar coriácea, amplamente elíptica ou obovado-elíptica, $250-600 \mathrm{~mm}$ de comprimento, $110-210 \mathrm{~mm}$ de largura, truncada, estreitamente cordada ou arredondada na base, cuspidada ou abruptamente caudado-acuminada no ápice, pilosa na página superior (tricomas rígidos, eretos, simples ou bifurcados, $0,5-1 \mathrm{~mm}$ de comprimento), página inferior tomentosa (tricomas estipitados, 0,8$1,3 \mathrm{~mm}$ de comprimento, estrelados ou irregularmente ramificados); nervura mediana em ambas as páginas rufovelutina, na inferior bastante grossa, na superior plana ou levemente impressa; 45-60 nervuras secundárias de cada lado, retas, paralelas, distintamente anastomo-

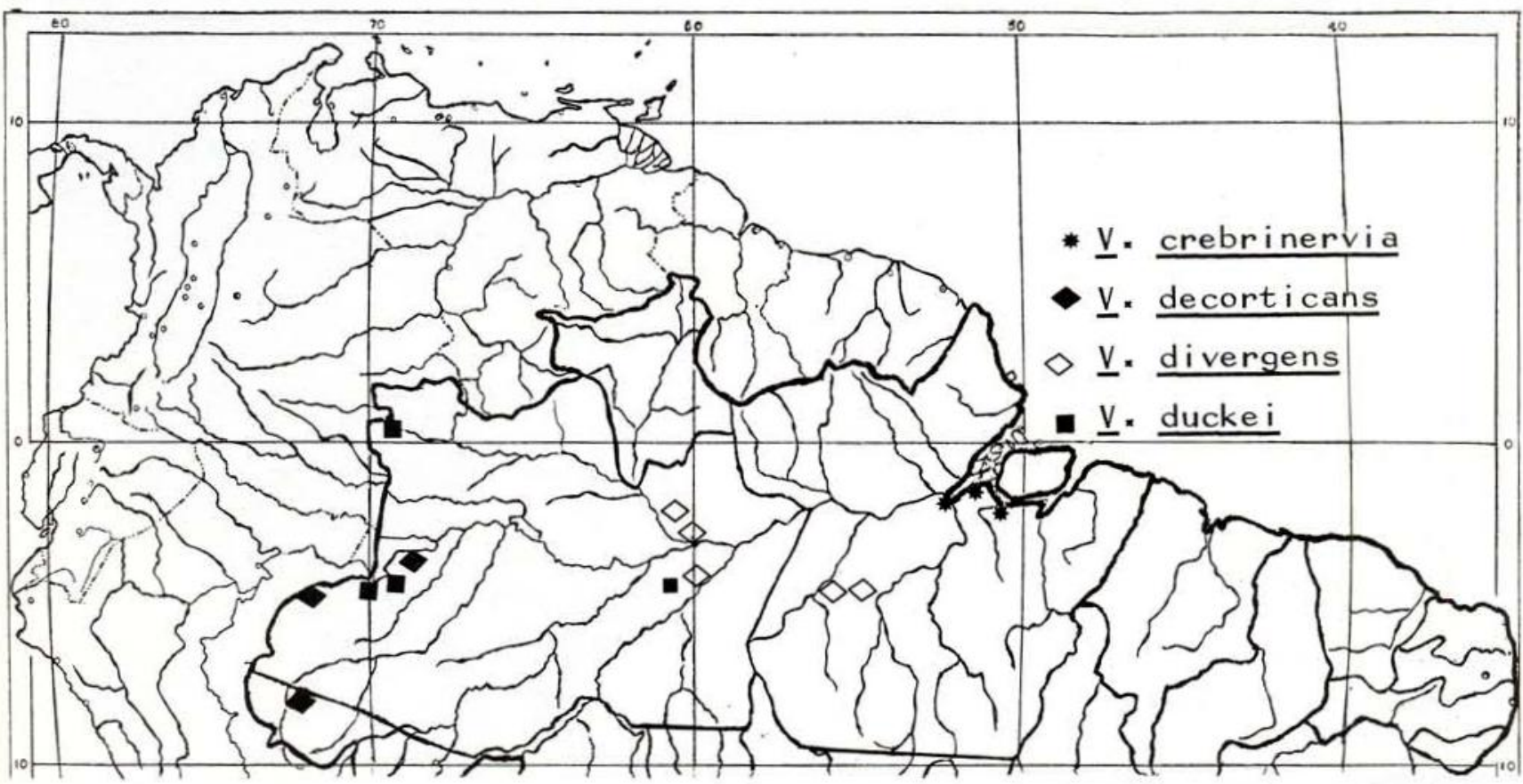

Fig. 31 - Distribuição atual de Virola crebrinervia, v. decorticans, v. divergens e V. duckei no Brasil. 
sadas perto das margens, planas ou levemente impressas na página superior, salientes na inferior; nervuras terciárias e reticulado inconspícuos ou ligeiramente impressos na parte superior, pouco elevados na inferior. Inflorescência masculina amplamente paniculada, livremente ramificada, densiflora, até $220 \mathrm{~mm}$ de comprimento e largura; pedúnculo grosso, até $40 \mathrm{~mm}$ de comprimento, com os raminhos densamente tomentosos (tricomas irregularmente ramificados, $1-1,5 \mathrm{~mm}$ de comprimento); brácteas distintas, persistentes, densamente rufotomentelas em ambas as faces, ovadas, $8.15 \mathrm{~mm}$ de comprimento; flores em fascículos densos. $6-10 \mathrm{~mm}$ de diâmetro, pedicelos delgados, até $3 \mathrm{~mm}$ de comprimento, densamente pilosos; perianto submembranáceo, $1,5-1,8 \mathrm{~mm}$ de comprimento, estrigoso na base e ápice, às vezes glabro, estreitamente infundibuliforme, trifido até quase a base, lóbulos oblongos, obtusos, com uma visível nervura mediana, esparsamente glandular-punctatos; androceu com cerca de $0,9 \mathrm{~mm}$ de comprimento, andróforo delgado, 0,3-0,4mm de comprimento, 3 anteras soldadas no ápice, $0,5-0,6 \mathrm{~mm}$ de comprimento, obtusas ou acuminadas sem ponta. Inflorescência feminina não vista. Infrutescência até $180 \mathrm{~mm}$ de comprimento, pouco ramificada, com casca decídua, densamente rufovelutina: $2-5$ frutos maduros por infrutescência, curto-pediculados, ovóide-elipsoides, $27-35 \mathrm{~mm}$ de comprimento, $170-220 \mathrm{~mm}$ de largura, estreitados em direção ao ápice, obtusos, arredondados na base, densa e persistentemente rufo-sub-hispido-velutinos (tricomas de $1-1,5 \mathrm{~mm}$ de comprimento, articulados, com numerosos apêndices laterais curtos). Figs. 3-32-33.

Tipos: A. Ducke s.n., Brasil, Amazonas, Săo Paulo de Olivença, mata perto do rio Jaratuba, terra firme baixa, 4 Nov. 1927 fr. (lectótipo: RB 19571; isolectótipos: K, US); L. Williams 3077, Peru, Loreto, Victoria, Ago./Set. $1929 \mathrm{fl}$. (parátipos: F, NY, US, frag. RB 25551).

Habitat: Ocorre geralmente em mata de terra firme, em lugares baixos.

Distribuição: Espécie conhecida apenas dos Estados do Amazonas e Acre, no Brasil e do Departamento de Loreto, no Peru. Fig. 31.

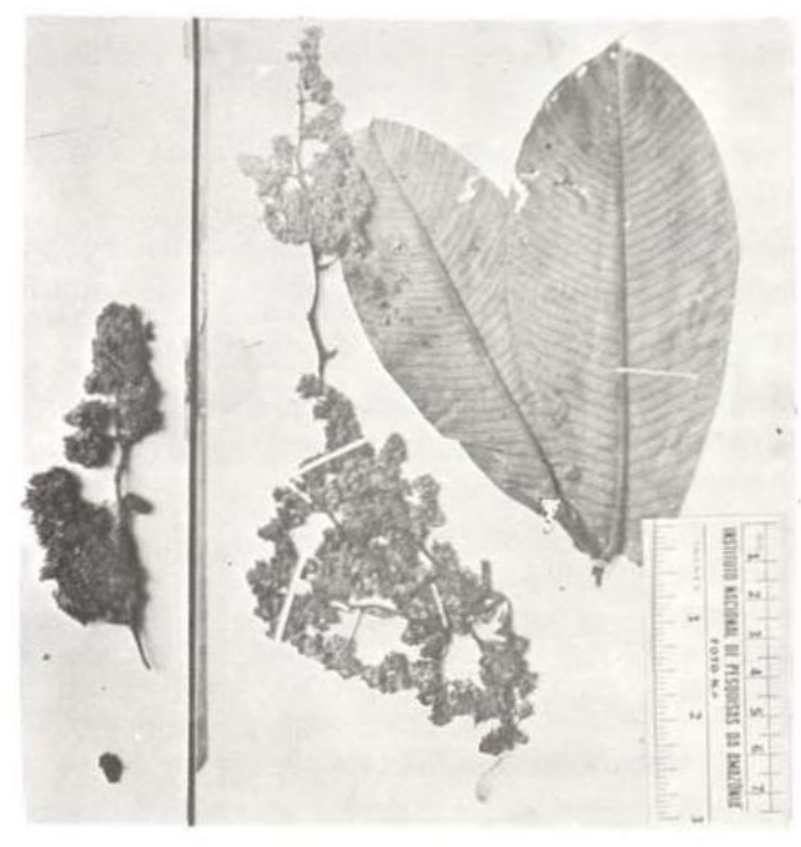

Fig. 32 - Virola decorticans. LI. Williams 3077 (RB, parátipo].

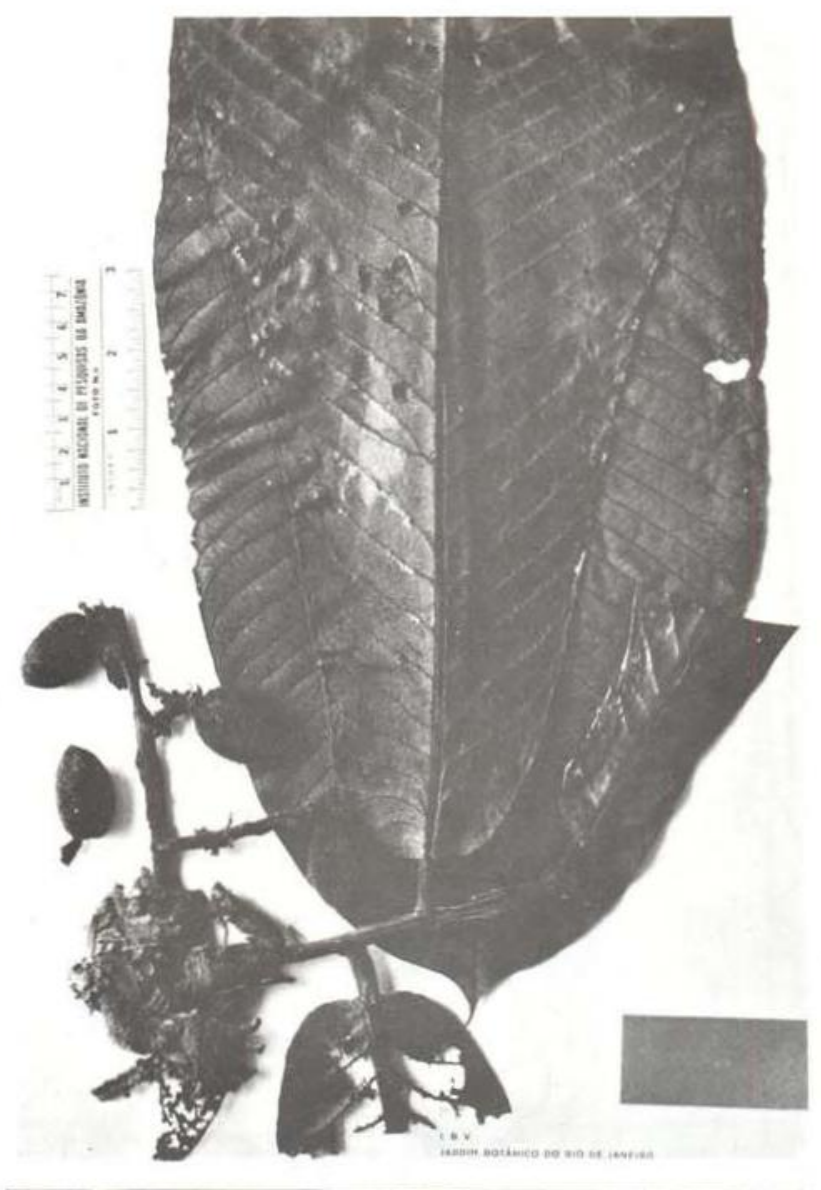

Fig. 33 - Virola decorticans. A. Ducke s.n. (RB 19571. lectótipo). 
MATERIAL ADICIONAL EXAMINADO:

AMAZONAS: - Rio Curuçá, afluente do rio Javari: J. Ramos s.n., Nov. 1975 est. (INPA 54140).

ACRE: - Cruzeiro do Sul: P. J. M. Maas et al. P12796, Maio 1971 fl. (INPA, NY).

Muitíssimo parecida com V. multinervia Ducke na inflorescência masculina e infrutescência, a principal diferença parece estar na face superior das folhas, que é pilosa e sem um reticulado distinto. Quando presente, este reticulacio é em geral ligeiramente imerso e não saliente como na espécie acima. V. multinervia Ducke costuma também soltar cascas nas pontas dos raminhos.

8. Virola divergens Ducke, Journ. Wash. Acad. Sci. 26 (6):255. 1936; A.C. Smith \& Wodehouse, Brittonia 2 (5):461. 1937; A. Ducke, Arq. Serv. Florest. 1 (1):25. 1939; J.C. Th. Uphof in Engl. \& Prantl, Nat. Pflanzenfam., $2^{a}$ ed., $17^{a}$ (2) :206. 1959; M. Honda, Acta Amaz. 1 (2):79, fig. 1-4. 1971.

Arvore até $25 \mathrm{~m}$ de altura; tronco até $1 \mathrm{~m}$ de diâmetro; raminho densamente tomentoso (tricomas irregularmente ramificados, 0,5-1 $\mathrm{mm}$ de comprimento) depois decíduo. Pecíolo subcilíndrico, grosso, 3-5 $\mathrm{mm}$ de diâmetro, $9-15 \mathrm{~mm}$ de comprimento, tomentoso como os raminhos. Lâmina foliar coriácea, oblonga, $80-450 \mathrm{~mm}$ de comprimento, $60-150 \mathrm{~mm}$ de largura, fortemente cordada a truncada na base, acuminada ou cuspidada no ápice, página superior glabra ou totomentela na nervura mediana, na inferior uniforme e densamente tomentosa (tricomas estipitados, irregularmente ramificados cerca de $0,5 \mathrm{~mm}$ de comprimento); nervura mediana elevada na face superior, muito saliente na inferior; $16-28$ nervuras secundárias de cada lado, ascendentes, arqueadas perto das margens, ligeiramente impressas ou promínulas na página superior, salientes na face inferior, as próximas da base freqüentemente recurvadas; vênulas promínulas ou obscuras. Inflorescência masculina amplamente paniculada, livremente ramificada, multiflora, até $250 \mathrm{~mm}$ de comprimento e largura; pedúnculo $50-80 \mathrm{~mm}$ de comprimento, com os rami- nhos bastante tomentelos (tricomas de $0,2-0,5 \mathrm{~mm}$, raramente até $0,8 \mathrm{~mm}$ de comprimento, irregularmente ramificados, muitas vezes com apêndices laterais); brácteas indistintas, logo decíduas; 3-8 flores dispostas em fascículos pequenos e laxos; pedicelos finos, $1-2 \mathrm{~mm}$ de comprimento; perianto densamente tomentelo (tricomas irregularmente ramificados de $0,2-0,4 \mathrm{~mm}$ de comprimento); perianto tenramente carnoso, $1,4-3,0 \mathrm{~mm}$ de comprimento, infundibuliforme, puberulento internamente, 3- ou 4- lobado até cerca de $1 / 3$ do seu comprimento, lóbulos deltóide-oblongos, obtusos; androceu $1,5-2,0 \mathrm{~mm}$ de comprimento, andróforo carnoso, túrgido na base, $0,1-0,5 \mathrm{~mm}$ de comprimento; $3-4$ anteras, $0,8-1,5 \mathrm{~mm}$ de comprimento, divergentes no ápice e cada uma encimada por um apículo tenro de $0,10-0,15 \mathrm{~mm}$ de comprimento. Inflorescência feminina 60-180 $\mathrm{mm}$ de comprimento tomentela como a inflorescência masculina; 2-5 flores por fascículo, curto-pediceladas; ovário subgloboso, fortemente tomentoso (tricomas $1,5-2,5 \mathrm{~mm}$ de comprimento, articulados, espinuloso-ramosos). Infrutescência até $90 \mathrm{~mm}$ de comprimento ou mais; 4-8 frutos por infrutescência, curto-pedicelados, subglobosos, $15-30 \mathrm{~mm}$ de diâmetro ou elipsóides de $30-40 \mathrm{~mm}$ de comprimento e 20-25mm de largura, densíssima e persistentemente rufo-subviloso-velutinos (tricomas como os do ovário, $3,0-4,5 \mathrm{~mm}$ de comprimento). Pericarpo coriáceo, 2-4 $\mathrm{mm}$ de espessura; arilo purpúreo, laciniado até quase a base; semente subglobosa, 10-12 mm de diâmetro ou elipsóide, 20-25mm de comprimento, 10-14mm de largura; testa distintamente sulcada. Figs. 3,34.

Trpos: A. Ducke s.n., Brasil, Amazonas, Manaus, 27 Abr. 1932 fl. (lectótipo: RB 24550; isolectótipos: K, P, S, U, US); A. Ducke s.n., ibid. 15 Maio $1932 \mathrm{fl}$. (síntipo: RB 24548, F, K, M, S, U, US); A. Ducke s.n., ibid., 2 Dez. 1932 fr. (síntipo: RB 24549, K, P, S, U, US); J. G. Kuhlmann 387, Brasil, Território de Rondônia, Porto Velho, rio Madeira, 8 Set. $1923 \mathrm{fl}$. (sínti. po: RB 24547, K, U, US).

Nomes vulgares: Ucuhuba (ex Costa 60). ucuuba (ex Ducke 11), ucuuba-vermelha (ex Coêlho, INPA 1842).

UtilidAdES: Segundo "Krukoff 1120", das sementes extrai-se óleo. 
FENOLOGIA: A floração tem sido observada com mais freqüência entre os meses de abril e julho, sendo que as primeiras florações começam em fevereiro e as últimas em setembro. A frutificação ocorre de agosto até maio do ano seguinte. Em Manaus, possível centro de dispersão da espécie, a frutificação começa geralmente em julho e termina em janeiro. Fig. 11 .

Distribuição: Acre, Amazonas e Pará. Fora do Brasil, como primeiro registro de ocorrência, aparece no Peru, perto de Iquitos, (ex $M$. Dias 54-A, sem data, fl. (INPA 48698, IAN)). Fig. 31.

Habitat : Planta heliófila, preferindo a borda da mata de terra firme.

\section{MATERIAL adicional EXAMinAdo :}

AMAZONAS: - Manaus: J. Aluísio s.n., Maio 1968 fl. (INPA 21213); id. 107, Ago. 1968 fr. (INPA); J. Chagas s.n., Dez. 1954 est. (INPA 364); id. s.n., Fev. $1955 \mathrm{fl}$. (INPA 786); id. s.n., Abr. 1955 fl. e fr. (INPA 951); L. Coêlho s.n., Maio 1956 fl. (INPA 3861); id. s.n., Out. 1975 fr. (INPA 53125); L. Coêlho s.n., Set. 1955 fr. (INPA 1842); A. Ducke 11, Nov. 1942 fr. (GH, IAN, MG, R); id. 174, Jul. 1943 fl. (GH, IAN, MG, R); id. 175, Jul. $1943 \mathrm{fl}$ (GH, MG, R); id. s.n., Nov. 1940 fr. (IAN 118); Francisco \& Coêlho s.n., Nov. 1955 fr. (INPA 2995); T. Guedes 44, Maio 1949 fl. (IAN); G. T. Prance et al. 2143, Set. $1966 \mathrm{fr}$. (F, INPA, NY, P. RB, S, U, US); id. 11436, Jan. 1971 fr. (INPA, NY); W. Rodrigues \& Coêlho 5212, Maio 1963 fl. (INPA); W. Rodrigues \& Loureiro 5835, Jun. 1964 fl. (INPA); W. Rodrigues \& Osmarino 6833, Jan. 1965 fr. (INPA); id. 6967, Jul. 1965 fl. (INPA); id. 8220, Ago. $1966 \mathrm{fr}$. (INPA); W. Rodrigues 8879, Maio $1970 \mathrm{fl}$. (INPA): W. Rodrigues \& Ramos 9593, Mar. 1975 fl. (INPA); R. E. Schultes \& Rodrigues 26115A, Abr. $1972 \mathrm{fl}$. e fr. (ECON, INPA); id. 26188A, Abr. 1972 est. (ECON, INP.A); E. Ule 8845, Abr. 1910 fl. ! (MG). - Estrada Manaus-Caracaraí: Km 148: G. T. Prance et al. 18120 , Set. 1973 fr. (INPA). - Baixo rio Negro, rio Araras: A. Loureiro et al. s.n., Abr. 1973 fl. (INPA 37740); id. s.n., Maio 1973 fl. (INPA 37933); id. s.n., Maio 1973 fr. (INPA 38093). - Estrada Manaus-Porto Velho: $\mathrm{Km}$ 129: W. Rodrigues \& Coêlho 9606, Jun. 1975 est. (iNPA); entre rios Castanho e Tupana: M. F. Silva et al. 251, Ago. $1972 \mathrm{fr}$. (INPA); Km 113: M. F. Silva et al. 266. Ago. 1972 fr. (INPA); entre rios Castanho e Araçá: M. F. Silva et al. 493, Ago. 1972 fl. (INPA).

PARA: - Fordlândia, rio Tapajós: R. M. da Costa $60,1931 \mathrm{fl}$. (NY). - Alto rio Cupari, plateau entre rios Xingu e Tapajós: B. A. Krukoff 1120, Set. $1931 \mathrm{fl}$. (GH, NY).
ACRE: - Cruzeiro do Sul: G. T. Prance et al. 12301, Abr. 1971 fr. (INPA, NY).

Espécie bastante distinta de todas as outras conhecidas, especialmente pelo forte aroma característico que desprende de toda planta depois de seca. Algumas vezes esse aroma pode ser notado também, particularmente, em $V$. elongata Warb., porém não tão pronunciadamente como nesta espécie. Muito próxima de $V$. sebifera Aubl., distingue-se pelo aroma acima mencionado como pela antera nitidamente divergente e fruto densissimamente rufo-aveludado.

9. Virola duckei A.C. Smith, Brittonia 2 (5): 478, fig. 8 I,m 1937; A. Ducke, Arq. Serv. Florest. 1 (1) :27. 1939; A. Ducke, Bol. Técn. Inst. Agron. Nort 4:11. 1945; J.C. Th. Uphof, in Engl. \& Prantl, Nat. Pflanzenfam., $2^{a}$ ed., $17^{a}$ (2):207. 1959.

Árvore até $35 \mathrm{~m}$ de altura; tronco até $52 \mathrm{~cm}$ de diâmetro, com casca um tanto lisa e sapopema na base até $2 \mathrm{~m}$ de altura; raminho grosso, densamente ferrugíneo-tomentoso (tricomas pouco ramificados, $0,5-1 \mathrm{~mm}$ de comprimento), glabrescente. Pecíolo fortemente canaliculado, $3-4 \mathrm{~mm}$ de diâmetro, $6-11 \mathrm{~mm}$ de comprimento, tomentoso como os raminhos. Lâmina foliar coriácea, opaca em ambas as faces, oblonga, $150-250 \mathrm{~mm}$ de comprimento, $50-80 \mathrm{~mm}$ de largura, amplamente obtusa ou subcordada na base, aguda no ápice, glabra na página superior, com exceção na nervura mediana que é tomentela, uniforme e persistentemente tomentosa na página inferior (tricomas dendríticos, estrelados ou irregularmente ramificados, $0,3-0,4 \mathrm{~mm}$ de comprimento); nervura mediana plana na face superior, saliente na inferior; 25-37 nervuras secundárias de cada lado, retas, fortemente impressas na página superior, elevadas na inferior; vênulas obscu. ras ou ligeiramente impressas na superior. Inflorescência masculina amplamente paniculada, multiflora, $150-200 \mathrm{~mm}$ de comprimento e quase o mesmo tanto de largura; pedúnculo $40-80 \mathrm{~mm}$ de comprimento com os raminhos densamente tomentosos (tricomas de 0,2-0,5 $\mathrm{mm}$ de comprimento); brácteas nulas; flores 


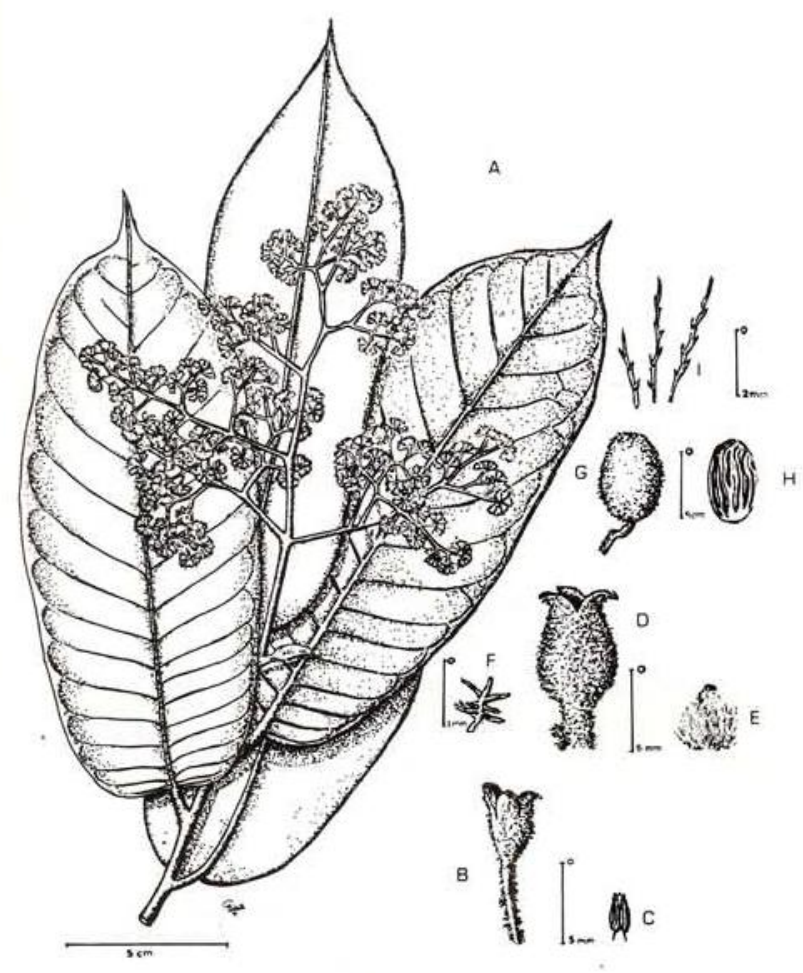

Fig. $34-$ Virola divergens. A-C (A. Loureiro et al. s.n., INPA 37933): A, hábito do ramo florífero masculino; B. flor masculina; C, androceu; D-F (A. Ducke 175): D, flor feminina; $E$, gineceu; $F$, tricoma da flor feminina;; $G$ e I (A. Ducke s.n., RB 24549): G, fruto; I, tricomas do fruto; H ( M. Dias 54-A): semente com arilo.

dispostas em fascículos densos de $4-7 \mathrm{~mm}$ de diâmetro, mais tarde divergentes, formando fascículos terminais de $3-27$ flores; pedicelo tênue $0,5-1,5 \mathrm{~mm}$ de comprimento; perianto levemente carnoso, alvacento, 1,0-1,2mm de comprimento, tomentelo externamente, trilobado quase até a base, lóbulos oblongos, obtusos com uma nervura mediana mais ou menos distinta; androceu $0,4-0,7 \mathrm{~mm}$ de comprimento; an. dróforo tênue cerca $0,2 \mathrm{~mm}$ comprimento; 3 anteras um pouco menores que o andróforo, obtusas, soldadas até o ápice ou levemente divergentes. Inflorescência feminina desconhecida. Infrutescência até $150 \mathrm{~mm}$ de comprimento; pedúnculo, $40-60 \mathrm{~mm}$ de comprimento, $3-5 \mathrm{~mm}$ de espessura, semicilíndrico ou achatado, juntamente com os raminhos, ferrugíneotomentoso, depois glabrescente e enegrecido; frutos novos ferrugíneo-tomentosos; $2-4$ frutos maduros por infrutescência, pedicelados (pedicelos grossos, $4-6 \mathrm{~mm}$ de comprimento), $25-30 \mathrm{~mm}$ de comprimento, cerca de $20 \mathrm{~mm}$ de largura, subobovado-elípticos, glabrescentes, apenas persistentemente ferrugíneo-tomentosos na base, levemente carinados, obtusos no ápice; pericarpo, $3-4 \mathrm{~mm}$ de espessura, duramente coriáceo, indeformável após a deiscência, enegrecido e ruguloso; semente espessa, elipsóide com arilo vermelho laciniado quase até a base. Figs. 3,35.

Trpo: A. Ducke s.n., Brasil, Amazonas, Manaus, mata do caminho de Marapatá, beira do Igapó. 31 Ago. $1931 \mathrm{fl}$. (holótipo: US 1615966; isótipos: RB 24562, K, P, S, U).

Nomes vulgares: Ucuúba (ex Ducke 1203); ucuuba-branca (ex Drees 07); ucuúba-silvestre (ex Fróes 20883).

UTHIDADES: Madeira branco-rosada podendo ser utilizada como sucedânea da "ucuuba-devárzea" (V. surinamensis).

HaBitat: Encontrada tanto em margens pantanosas ou alagadiças de rios e igapós, como também em matas pantanosas ou úmidas de

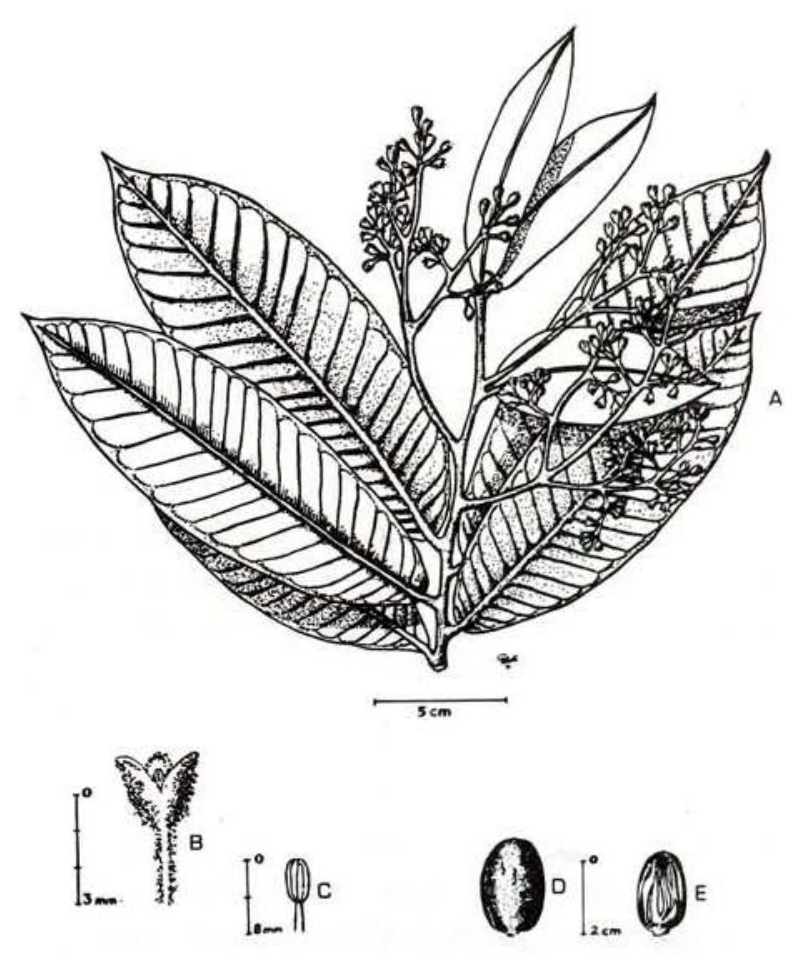

Fig. 35 - Virola duckei. A-C (M. F. Silva et al. 912): A, hábito do ramo florífero masculino; $\mathrm{B}$, flor masculina; C, androceu: D-E (A. Ducke 1203): D, fruto; E, semente com arilo. 
terra firme e em caatingas amazônicas (ex Fróes 21248); em geral em terrenos de baixa altitude.

Fenologia: A floração ocorre entre julho e novembro e a frutificação na estação chuvosa, começando em dezembro indo até maio.

DistribuiçÃo: Espécie pouco comum na Amazônia ocidental, chegando até o Departamento do Amazonas, província de Bagua, no Peru (ex coleção Wurdack 2259 (US)). Fig. 31.

\section{MATERIAL ADICIONAL EXAMINAdo :}

AMAZONAS: - Benjamin Constant: E. M. Drees 07. Out. $1956 \mathrm{fl}$. (IAN, INPA); Froes 20883, Maio 1945 fr. (IAN, NY). - Esperança, no estuário do Javari: Ducke 1057, Set. 1942 fl. (IAN, MG, NY, R, RB). Bacia do rio Negro: - Jauaretê: Froes 21248, Out. 1945 fl. (IAN, K, NY, SP, US); - rio Padauari: Froes 22685, Out. 1947 fr. (IAN, UB, US): - Manaus: D. Coêlho s.n., Nov. 1955 fl. (INPA 2948, IAN); Ducke 755. Jul. 1941 fl. (IAN, INPA, MG, R, RB); id. 1203. Dez. $1942 \mathrm{fr}$. novo, Mar. $1943 \mathrm{fr}$. maduro (GH, IAN, MG, R, RB). - Estrada Manaus-Porto Velho: entre rios Castanho e Tupana: M. F. Silva et al. 912, Jul. 1972 fl. (INPA).

Esta espécie se distingue de $V$. albidiflora Ducke não só pelas dimensões e estrutura das flores como pelo pericarpo do fruto, que não se enrola após abrir-se.

Muito próxima de $V$. rugulosa Warb. no aspecto geral, esta se distingue dela apenas pela lâmina foliar mais fortemente bolhosa e pelo reticulado bem mais acentuado. No mais são comparativamente idênticas .

A coleção Fróes 21248 diferencia-se do tipo pela forma mais glabra de toda a planta, folhas mais membranáceas com pilosidade mais densa na página inferior (tricomas em geral sésseis, raros curto-estipitados) e inflorescência acinzentada, não ferrugínea.

10. Virola elongata (Benth.) Warburg, Ber. Deutsch. Bot. Ges. 13:89. 1895, hipônimo; Warburg, Nova Acta Acad. Leop. Carol. 68:178. 1897; A.C. Smith \& R. Wodehouse, Brittonia 2 (5):470. 1937; A.C. Smith, Brittonia 3 (2):340. 1939, pro parte (excl. espec. Smith 2628); A. C. Smith, Contr. U.S. Nat. Herb. 29
(8) :327. 1950; A.C. Smith, Am. Journ. Bot. 43 (8):575. 1955; J.A. Duke, An. Missouri Bot. Gard. 49:225. 1962; R.E. Schultes \& B. Holmstedt, Lloydia 34 (1): 71. 1971; H. Garcia-Barriga, FI. Med. Colombia, Inst. Ciencias Nat., Bogotá, 1:352. 1974 .

Myristica elongata Bentham in Hook., Journ. Bot. \& Kew Misc., 5 (6): 5. 1853; A. De Candolle in DC., Prodr. 14: 196. 1856: A. De Candolle in Mart., FI. Bras. 5 (1): 113. 1860.

Palala elongata (Benth.) Kuntze, Rev. Gen. PI. 2: 567. 1891, nom. illegit.

Myristica cuspidata Spruce ex Bentham in Hook., Journ. Bot. \& Kew Misc. 5 (7): 5. 1853; A. De Candolle in DC., Prodr. 14: 195. 1856, pro parte: A. de Candolle in Mart., Fl. Bras. 5 (1): 111, tab. 41. 1860, pro parte. Tipo: Spruce 1794, Brasil, Amazonas, Barra (=Manaus), Set. 1851 fl. (holótipo: $\mathrm{K}$; isótipos: BM, GH, M. NY, P; B e W destruídos).

Palala cuspidata (Benth.) Kuntze, Rev. Gen. PI. 2: 567 . 1891, nom. illegit.

Virola cuspidata (Spr. ex Benth.) Warburg. Nova Acta Acad. Leop.-Carol. 68: 176. 1897; J. Huber, Bol. Mus. Goeldi 5 (2): 359. 1909; L. Williams, Field. Mus. Nat. Hist. - Bot. 15: 135. 1936; A. Ducke, Journ. Wash. Acad. Sci. 26 (6): 257. 1936; A. C. Smith \& R. Wodehouse, Brittonia 2 (5): 368. 1937; A. Ducke, Arch. Inst. Biol. Veg. 4 (1): 3. 1938; A. Ducke, Arq. Serv. Flor. 1 (1): 25. 1939; A. Ducke, Bol. Téc. Inst. Agron. Norte 19: 4. 1950; A. C. Smith, Contr. U.S. Nat. Herb. 29 (8): 327. 1950; A. C. Smith, Am. Journ. Bot. 43 (8): 575. 1956; G. E. Blair et al., Phytochem. 8: 497. 1969; R. E. Schultes \& B. Holmstedt, Lloydia 34 (1): 70.1971 ; G. M. Cassady et al., Lloydia 34: 161. 1971; INPA-Fitoquímica, Acta Amaz. 1 (3): 52. 1971: Braz Filho et al., Phytochem 12: 417. 1973.

Myristica punctata Spruce ex Bentham in Hook., Journ. Bot. \& Kew Misc. 5 (10): 6. 1853; A. De Candolle in DC., Prodr. 14: 196. 1856. A. De Candolle in DC., Prodr. 14: 696. 1957; A. De Candolle in Mart., FI. Bras. 5 (1): 112. 1860 Tipo: Spruce 1245 ou s.n., Barra (=Manaus), Dez.-Mar. 1850-1851 fr. (holótipo: K; isótipos: BM, C, G, GH, M, NY, P: B e W destruidos).

Palala punctada (Spr. ex Benth.) Kuntze, Rev, Gen. PI. 2: 567. 1891, nom. illegit. 
Virola elongata (Benth.) Warb. var, punctata (Epri ex Benthi) Warburg, Nova Acta Acad. Leop.-Carol. 68: 179, tab. 5, fig. 1-2. 1897.

Myristica theiodora Spruce ex Bentham in Hook., Journ. Bot. \& Kaw Miso, s (9): o. 1853: A. De Candolle in DC., Prodr. 14: 195. 1856; A. De Candolle in Mart., Fl. Bras. 5 (1): 110. 1860, pro parte, excepto tab. 40, fig. 2 ( $=$ V. sebifera); T. Peckolt \& G. Peckolt, Hist. PI. Med. Uteis Brasil: 1345. 1889, pro parte; M. Penna, Dic. Bras. P!. Med.: 271. 1946. Tipo: Spruce 1444 ou s.n., Brasil, Amazonas, Barra (=Manaus), Dez./Mar. 1850-1851 fr. (holótipo: K; isótipos: BM, M, NY, P; B e W destruídos).

Palala theiodora (Spr. ex Benth.) Kuntze, Rev. Gen. PI. 2: 568. 1891, nom. illegit.

Virola theiodora (Spr. ex Benth.) Warburg, Nova Acta Acad. Leop.-Carol. 68: 187, tab. 5, fig. 1-2. 1897; A. Ducke, Journ. Acad. Sci. 26 (6): 257. 1936; A. Ducke, Arch. Inst. Biol. Veg. 4 (1): 2. 1938. A. Ducke, Arq. Serv. FI. 1 (1): 26. 1936; R. E. Schultes \& B. Holmstedt, Rhodora $\mathbf{7 0}$ (781): 150, ilust. 1968; S. Agurell et al., Acta Chem. Scand. 23: 903. 1969; R. E. Schultes in II Simpósio Biol. Trop. Amaz.: 183. 1970; INPA-Fitoquímica, Acta Amaz. 1 (3): 49. 1971; R. E. Schultes \& B. Holmstedt, Lloydia 34 (1): 76, ilust. 1971; G. T. Prance, Acta Amaz. 2 (2): 7, fig. 11. 1972; J. G. S. Maia \& W. A. Rodrigues, Acta Amaz. 4 (1): 21. 1974.

Myristica membranacea A. De Candolle in DC., Prodr. 14: 196. 1856; A. De Candolle in Mart., FI. Bras. 5 (1): 111, 1860. Tipo: Poeppig 2647, Brasil, Amazonas, Ega (=Tefé), 1834 fl. (holótipo: G-DC, n.v.; isótipos: $F, P$, US; B e W destruídos).

Palala membranacea (Poepp.) Kuntze, Rev. Gen. PI. 2: 567. 1891, nom. illegit.

Virola cuspidata (Spr. ex Benth.) Warb. var. membranacea Warburg, Nova Acta Acad. Leop.-Carol. 68: 117. 1897; L. Williams, Field Mus. Nat. Hist., Bot. 15: 136. 1936.

Myristica cuspidata (Spr. ex Benth.) Warb. var. rufula A. De Candolle in DC., Prodr. 14: 696. 1857; A. De Candolle in Mart., Fl. Bras. 5 (1): 111. 1860. Tipo: Martius 28, Brasil, Amazonas, Coari, Nov. 1864 fl. (holótipo: $\mathrm{M}$; isótipo: $\mathrm{B}$ destruído).

Myristica rufula Mart. ex A. De Candolle in DC., Prodr. 14: 696. 1857, pro syn.

Virola rufula (A. DC.) Warburg, Nova Acta Acad. Leop.-Carol. 68: 181, tab. 5, fruto. 1897; A. Ducke, Journ. Wash. Acad. Sci. 26 (6): 256. 1936, pro parte; A. Ducke, Arch. Inst. Biol. Veg. 4 (1): 3. 1938; A.
Ducke, Arq. Serv. Fl. 1 (1): 26. 1939; S. Agurell et al,, Acta Chem. Scand, 23: 903, 1969; R. E. Schultes \& B. Holmstedt, Lloydia 34 (1): 73. 1971; INPA-Fitoquímica, Acta Amaz. 1 (3): 51. 1971.

Myristica uaupensis Spruce ox $A$. De Candol. le in DC., Prodr. 14: 696. 1857; A. De Candolle in Mart., FI. Bras. 5 (1): 112. 1860. Tipo: Spruce 2512, Brasil, Amazonas, rio Panuré - rio Uaupés, Out./Jan. 1852-1853 fl (holótipo: G-DC, n.v., isótipos (C, GH, K, M, NY, P; B e W destruídos).

Palala uaupensis (DC.) Kuntze, Rev. Gen. Pl. 2: 567. 1891. nom. illegit.

Myristica cuspidata Spr. ex Benth. var. globifera Spruce ex A. De Candolle in DC., Prodr. 14: 696. 1857; pro syn.

Virola elongata (Benth.) Warb. var. longicuspis Warburg, Nova Acta Acad. Leop.-Carol. 68: 179, tab. 5, fig. 1-3. 1897. Tipo: Spruce 3363, Venezuela, rio Cassiquiare, Vasiva e Pacimoni. Fev. 1854 fr. (holótipo: $\mathrm{K}$; isótipo: $\mathrm{P}$; $\mathrm{W}$ destruído).

Myristica longicuspis Spruce ex Warburg, Nova Acta Acad. Leop.-Carol. 68: 179. 1897, pro syn.

Virola elongata (Benth.) Warb. var. subcordata Warburg, Nova Acta Acad. Leop.-Carol. 68: 180. Tipo: Spruce, 3172, Venezuela, rio Cassiquiari, Vasiva e Pacimoni, 1853-54 fl. (holótipo: B, destruído; lectótipo: K; isótipos: C, G, NY, P, RB; W destruído).

Arbusto a árvore até cerca de $30 \mathrm{~m}$ de altura e tronco até $1 \mathrm{~m}$ de diâmetro; râmulo tomentelo, avermelhado (tricomas séssil-estrelados, $0,1-0,2 \mathrm{~mm}$ de diâmetro, e irregularmente ramificados, até $0,3 \mathrm{~mm}$ de comprimento) glabrescente. Pecíolo canaliculado ou subterete, $1-2,5 \mathrm{~mm}$ de diâmetro, $5-16 \mathrm{~mm}$ de comprimento, tomentelo como os râmulos. Lâmina foliar papirácea ou submembranácea, muitas vezes glandular-punctada, estreitamente oblonga a oblongo-elíptica, $120-350 \mathrm{~mm}$ de comprimento, $40-110 \mathrm{~mm}$ de largura, obtusa a subcordata na base (eventualmente aguda ou atenuada), longamente acuminada a aguda ou cuspidada no ápice, glabra e às vezes lustrosa na página superior, puberulenta ou tomentosa na inferior (tricomas séssil-estrelados, cerca de $0,1 \mathrm{~mm}$ de diâmetro, muitas vezes esparsos, ou dendríticos, 4-6-ramosos, 0,2-0,3mm de comprimento) glabrescente ou quase com o tempo; nervura mediana plana ou ligeiramente saliente na página superior, proeminente na inferior; 9-25 
nervuras secundárias de cada lado, em geral ascendentes e arqueadas, levemente impres. sas ou elevadas na página superior, salientes na inferior; vênulas promínulas ou obscuras. Inflorescência masculina paniculada, livremente ramificada, em geral multiflora, $40-220 \mathrm{~mm}$ de comprimento, $30-150 \mathrm{~mm}$ de largura; pedúnculo de $10-70 \mathrm{~mm}$ de comprimento, com os raminhos muitas vezes achatados e flores inteiramente tomentelas (tricomas estrelados ou com numerosos apêndices laterais, até $0,5 \mathrm{~mm}$ de comprimento), glabrescentes; brácteas oblongas, $2-3 \mathrm{~mm}$ de comprimento, indistintas e logo decíduas; flores dispostas laxamente, isoladas ou em fascícuios de 2-8, pedicelos até $3 \mathrm{~mm}$ de comprimento; perianto tenuemente carnoso, tomentelo, puberulento ou glabro internamente, infundibuliforme, $1,8-3 \mathrm{~mm}$ de comprimento (às vezes $1,5 \mathrm{~mm}$ de comprimento), 3- ou 4-lobado cerca de $1 / 3$ de seu comprimento, lóbulos obtusos; androceu 1-2mm de comprimento, andróforo mais ou menos carnoso, $0,25-0,6 \mathrm{~mm}$ de comprimento, anteras em geral 3 (freqüentemente 4 ou 5 , eventualmente 6 ). 0,6-1,6mm de comprimento, soldadas até o ápice ou indistintamente divergentes na metade distal, comumente apicuiadas, apículos comumente fendidos, $0,1-0,2 \mathrm{~mm}$ de comprimento. Inflorescência feminina até $70 \mathrm{~mm}$ de comprimento, tomentela como a masculina, logo glabra; flores isoladas ou em fascículos de 2-5, pedicelos crassos, $1-2 \mathrm{~mm}$ de comprimento: ovário subgloboso, densamente tomentelo (tricomas com cerca de $0,2-0,3 \mathrm{~mm}$ de comprimento, com numerosos apêndices laterais curtos). Infrutescência até $120 \mathrm{~mm}$ de comprimento, raminhos logo glabros, 5-20 frutos maduros por infrutescência, pedicelados (pedicelos finos 2-5mm de comprimento), elipsóides ou subglobosos, lisos ou levemente carinados, $11-21 \mathrm{~mm}$ de comprimento, $8-15 \mathrm{~mm}$ de largura, obtusos ou diminutamente apiculados no ápice, a príncípio densamente tomentelos como o ovário, logo glabrescentes; pericarpo $0,2-1,3 \mathrm{~mm}$ de espessura, arilo membranácea, laciniado até quase a base de seu comprimento total. Fig. 36 .

TrPo: Riedel s.n., Brasil, Amazonas, bacia do rio Madeira, Borba, Ago. $1828 \mathrm{fl}$. (holótipo: K; isótipos: BM, C, P, S; B destruído) .

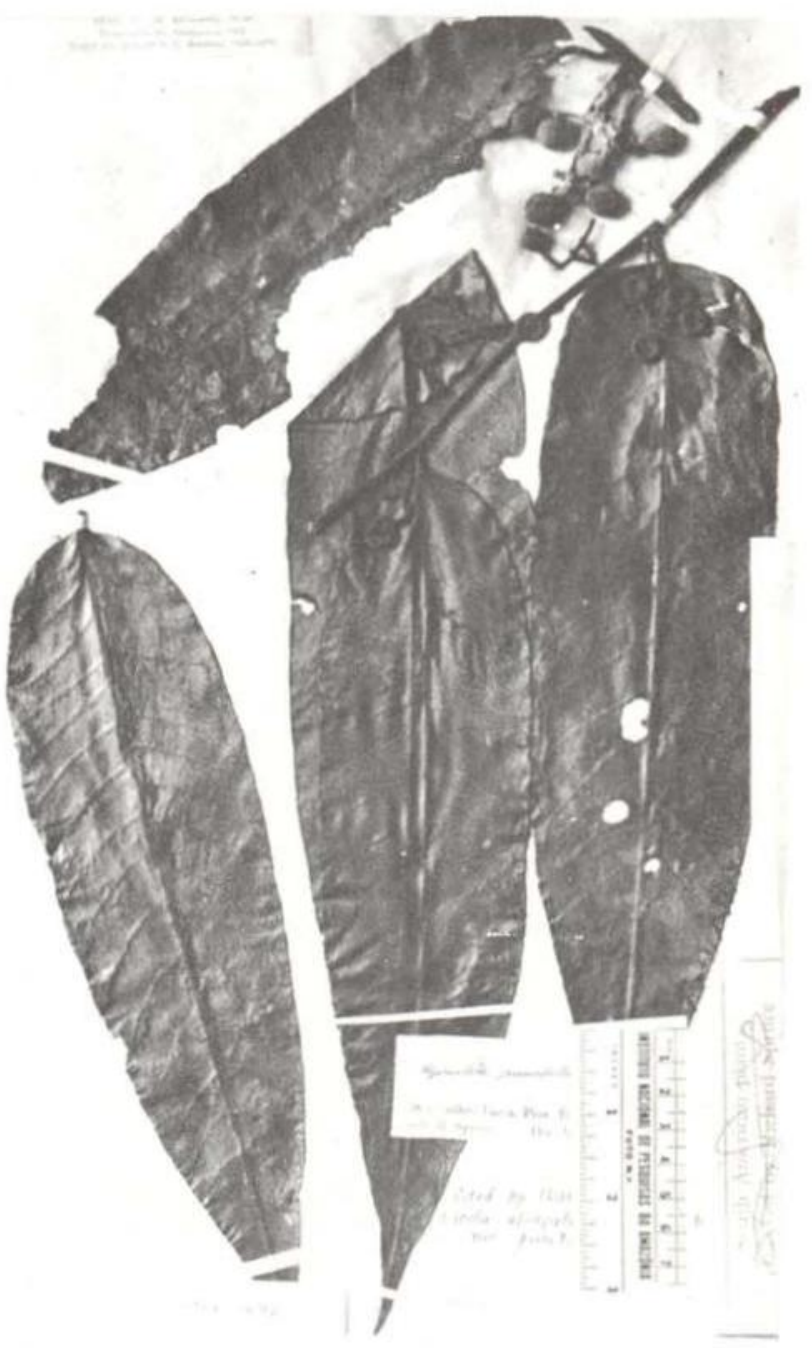

Fig. 36 - Virola elongata. R. Spruce s.n. (NY, isótipo de Myristica punctata).

Nomes vulgares: Aiooku (índios Mayongong, ex Prance et al. 21598); casseriv = casserivhcni (írdios Tukano); epená (índios Waiká, ex Schultes 24574); kawabo (índios Paumeri, ex Campbell et al. P-21253); mimba-branca (Black 47-2182); nyakuwana (ex Schultes 2426); paricá (ex Ducke RB 24498); saconadi (ex Prance et al. 20025); sacuná (Sanama, ex Prance et al. 21598); shomiá (Waiká, ex Prance et al. 10125); sikania (Waiká, ex Prance et al. 13636); tchakiana (Waiká, ex Prance et al. 10984); ucuuba; ucuúba-açu (ex Aluisio 147): ucuuba-branca (ex Krukoff 1455, ex Rodrigues \& Osmarino 8219): ucuuba-do-igapó (ex Chagas, INPA 2178); ucuuba-preta (ex Aluisio 30); 
ucuuba-vermelha (ex Coelho INPA 1644); ucuubinha (ex Rodrigues 744); uiqui (ex Ferreira INPA 6420).

Fenologia: Floresce e frutifica durante todo $\sigma$ ano, tendo os meses entre junho e outubro como os mais importantes para a floração e entre setembro e abril, para frutificação. Fig. 12.

UTILIDAdES: Dentre todas as espécies alucinogênicas do gênero, esta é a mais importante. Da resina que exsuda da casca diversas tribos do noroeste amazônico preparam um rapé que tomem em cerimônias especiais. Os consti. tuintes ativos principais contidos nesses rapés alucinogênicos são 5 metoxi $\mathrm{N}, \mathrm{N}$-dimetiltriptamina e N,N-dimetiltriptamina. A mesma resina costuma ser usada por algumas outras tribos para envenenamento de flechas. Diversos trabalhos recentes tratam desse assunto dentre eles Schultes (I.c. 1954), Schultes \& Holmstedt (I.c. 1971); Prance (I.c. 1970 e 1972); Maia \& Rodrigues (I.c. 1974) etc...

HabtтAt : Habita de preferência as margens alagáveis de rios e lagos, ocorrendo também nos campos e encostas de terra firme, em terrenos de baixa elevação, não sendo raro ocorrerem espécimes até a $800 \mathrm{~m}$ de aitura como na região do rio Auaris, no Território de Roraima (ex Prance et al. 9638). Nas margens de rios ou terrenos sujeitos à alagaçåo, seu porte é comumente arbustivo, enquanto na terra firme não é raro encontrarem-se árvores relativamente altas.

Distribuição: Largamente distribuída em toda a bacia amazônica desde a costa atlântica até a do Pacífico, ocorrendo na Bolívia, Colômbia, Equador, Guiana, Peru e Venezuela. Segundo Ducke (I.c. 1962), aparece também no Panamá. Fig. 37.

\section{MATERIAL ADicional EXAMinado:}

TERRITÓRIO DE RORAIMA: - Vizinhanças do rio Auati (lat. $4^{\circ} 3-6^{\prime} \mathrm{N}$; long. $64^{\circ} 22-25^{\prime} \mathrm{W}$ ): G. T. Prance et al. 9638, Fev. 1969 est. (INPA, NY); id. 9684, Fev. 1969 fl. (INPA, NY); id. 9864, Fev. 1969 fl. (INPA, NY); G. T. Prance, Dobzhansky \& Ramos 20025, Dez. 1973 est. (INPA); G. T. Prance et al. 21598, Jul. 1974 est. (INPA). Montanhas Maitá (lat. $3^{\circ} 15^{\prime} \mathrm{N}$; long. $63^{\circ}$ 28'W): G. T. Prance et al. 13636, Fev. $1971 \mathrm{fr}$. (INPA,
NY). Região do rio Uraricoera (lat. $3^{\circ} 33^{\prime} \mathrm{N}$; long. $63^{\circ}$ $11^{\prime}$ W): G. T. Prance et al. 10685, Fev. 1971, est. (INPA, NY). Região do rio Mucajaí. Posto Indígena de Mucajaí: G. T. Prance et al. 10984, Mar. 1971, est. (INPA, NY). Região do rio Catrimani, Serra do Aracá, Missão: J. M. Pires 15086, Fev. 1975, fl. (IAN, INPA). Serra dos Surucucus (lat. $2^{\circ} 42-47^{\prime} \mathrm{N}$; long. $63^{\circ} 33-35^{\prime} \mathrm{W}$ ): id. 101125, Fev. 1969, fl. (INPA, NY).

TERRITORIO DO AMAPÁ: - Região do rio Araguari: Campo 12 (lat. $1^{\circ} 11^{\prime} \mathrm{N}$; long. $52^{\circ} 8^{\prime} \mathrm{W}$ ): J. M. Pires, Rodrigues \& Irvine 51337, Set. 1961 fl. (IAN, MG, RB, NY).

AMAZONAS: - Tabatinga: ilha Aramaçá: G. T. Prance et al. 16791, Jul. 1973, fl. (INPA). Regiāo do rio Javari: Remate de Males: Ducke s.n., Jul. 1906, fr. (MG 7414); id. s.n., Ago. 1906, fl. \& fr. (MG 7459, INPA): - ibid.: Miraflor: E. Lleras et al. PI 6929, Jul. 1973, fr. (INP). São Paulo de Olivença: Ducke s.n., Out. 1931, fl. (RB 24495); id. s.n., Fav. 1932, fr. (RB 24496); id. s.n., Out. 1931, fl. (RB 24497); id. 530, Maio 1940, fl. (IAN); R. L. Froes 20928, Maio 1945 fl. (IAN. NY); id. 20930, Maio 1945, fl. (IAN, NY); id. 23816. Jan. 1945, fr. (IAN); id. 23821, Jan. 1948, fr. (IAN); id. 23910, Jan. $1949 \mathrm{fr}$. (IAN); id. 34817, Mar. 1945, fl. (IAN); id. 34837, Mar. 1945 fl. (IAN): B. A. Krukoff 8305, Set./Out. 1936, fr. (NY); id. 8689, Out./Dez. $1936 \mathrm{fr}$. (NY): id. 8787, Out./Dez. 1936, fr. (NY); id. 8917, Out./Dez. 1936 fl. (NY, US, RB); id. 8951, Out./ Dez. 1936, fr. (NY); id. B. S. Pena \& Silva 56, Ago. 1967 fr. (IAN). Santo Antonio do Içá: R. L. Frnes 2559i, Out. 1949, fl. (IAN); id. 25611, Out. 1949 fi. (IAN); id. 34799, Mar. 1945 fl. (IAN). Tonantins: Ducke 933. Nov. $1940 \mathrm{fl}$. (IAN, MG, NY, RB). Região do rio Jutaí: riozinho Juruema: R. L. Froes 21015, Jun. 1949, fi. (IAN, NY): - ibid.: sem localidade precisa: id. 34879, Maio 1945, fl. (IAN). Fonte Boa: Froes 20608, Mar. 1945, fr. (IAN, NY); id 20986, Maio 1945 fl. (IAN, NY); E. Lleras et al. P17449, Ago. 1973 fl. (INPA). Região do rio Juruá: Bonfim: E, Ule 5024, Dez. 1900 fr. (MG); Juruá-Mirim: id. 5638, Out. 1901 fl. (MG): Matupiri: Krukoff 4596, Maio 1933 fl. (NY): - estuário do rio Embira (lat. $7^{\circ} 30^{\prime} \mathrm{S}$; long. $70^{\circ} 15^{\prime} \mathrm{W}$ ): Krukoff 4794, Jun. 1933 fl. (NY); id. 4802, Jun. 1933 fl. (NY); id. 4910, Jun. 1933, fl. (NY); id. 4947, Jun. $1933 \mathrm{fl}$ (NY); Eirunepé, rio Gregório: Froes 21637, Out. 1946. fr. (IAN, RB). Boca do Acre: Prance et al. 2295, Set. 1966, fr. (INPA, NY). Região do rio Purus: Bom Lugar: A. Goeldi s.n., Jul. 1903, est. (MG 3938); Lábrea: D. G. Campbell et al. P21242, Jun. 1974 fl. (INPA); id. P 21253, Jun. 1974 est. (INPA); Prance et al. 8124, Out. 1968 fr. (INPA, NY); id. 8208, Nov. 1968 fr. (INPA, NY); id. 13753, Jun. 1971 fl. (INPA, NY); rio Curuquetê, afluente do rio Ituxi: Prance et al. 13994, Jul. 1971 fl. (INPA, NY); id. 14048, Jul. 1971 fl. (INPA, NY); id. 14081, Jul. 1971 fl. (INPA, NY); id. 14219, Jul. 1971 fl. (INPA); id. 14315, Jul. 1971 fl. (INPA, NY); id. 14384, Jul. 1971 fl. (INPA); id. 14385, Jul. 1971 fl. (INPA, NY); id. 14508, Jul. 1971fl. (INPA, NY). Tefé: G. A. Black 471504, Set. 1947 fl. (IAN); Byron, Coêlho \& Osmarino 604, Fev. 1972 fr. (INPA); id. 622, Mar. 


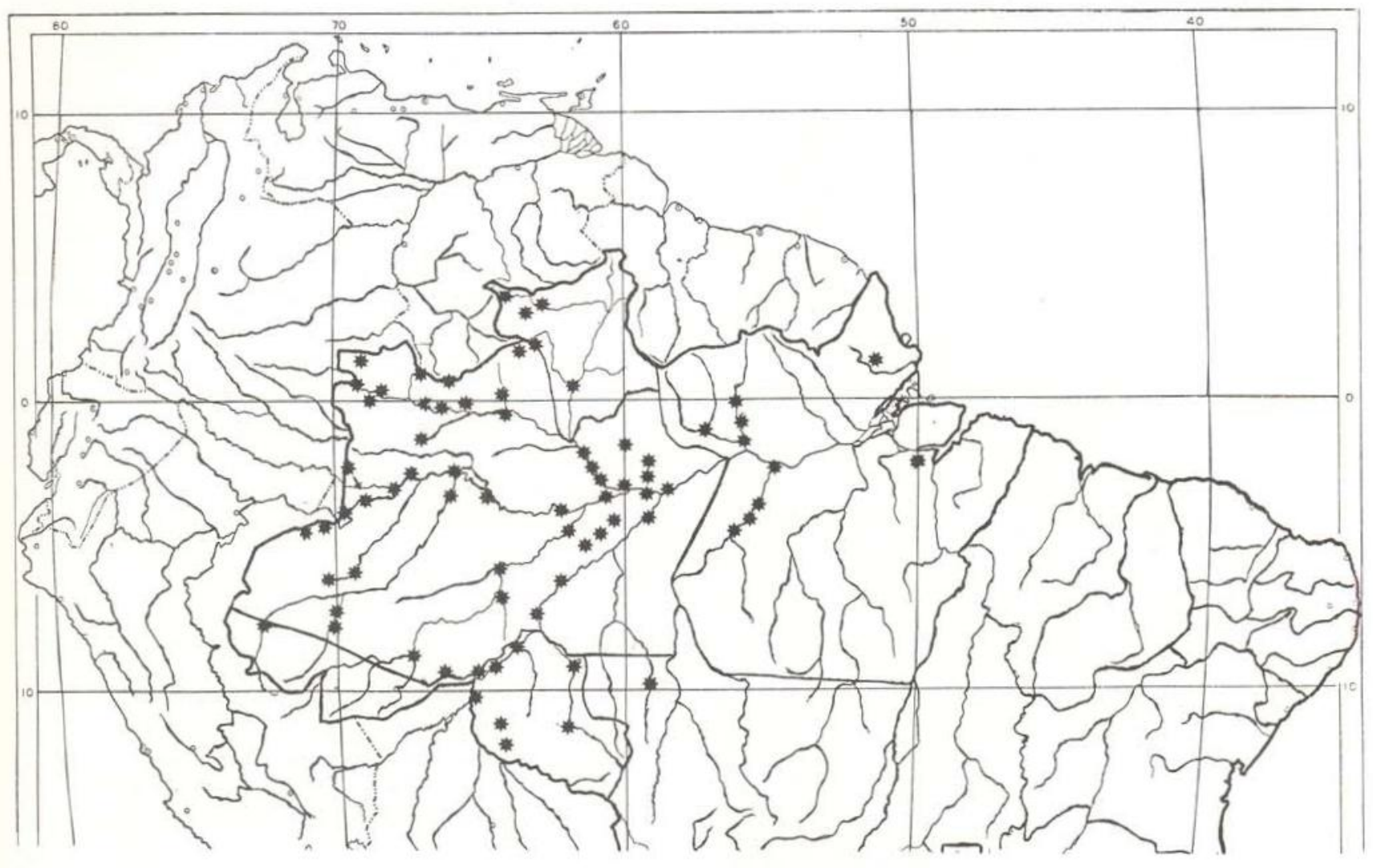

Fig. 37 - Distribuição atual de Virola elongata no Brasil.

1972 fl. (INPA); J. M. Pires 1321, Out. 1948 fr. (IAN); W. Rodrigues \& Coêlho 1409, Nov. 1959 fr. (INPA): id. 1413, Nov. 1959 est. (INPA); W. Rodrigues 2064, Jan. 1961 fl. (INPA). Codajás: E. Ferreira s.n., Abr. $1958 \mathrm{fl}$. (INPA 6420); Froes 26548, Set. 1950 fl. (IAN): M. Silva 1943, Set. 1968 fl. (MG). Regiảo do rio Manacapuru: acima do Repartimento: W. Rodrigues 420 , Abr. 1957 fr. (INPA). Bacia do rio Negro: Foz do rio Cuiari no rio Içana: Froes 28829, Out. $1952 \mathrm{fl}$. (IAN): - Cucuí: O. C. Nascimento, Pires \& Coradin 262, Maio 1975 fr. (IAN, INPA); Out. 1945 fl. \& fr. (IAN, NY); J. M. Pires \& Silva 7897, Jun. 1962 est. (IAN); Pari-Cachoeira, no rio Tiquié: C. Batista 2, Ago. 1967 fl (NY); J. M. Pires \& Silva 10905, Ago. $1967 \mathrm{fl}$. (IAN): rio Uaupés: E. Oliveira 2277, Out. $1962 \mathrm{fl}$. (IAN); São Gabriel da Cachoeira: Ducke s.n., Dez. 1929 fl. (RB 24498); J. M. Pires 786, Out. $1947 \mathrm{fl}$. (IAN); rio Maturacá, afluente do rio Cauaburi: J. A. Steyermark 104039, Out. 1970 est. (NY); R. B. Schultes 24574, Jul./Ago. 1967 est. (INPA); id. 24575, Jul./ Ago. 1967 est. (INPA); serra do Jacamim: Ducke s.n., Nov. 1936 fl. (RB 34619); cercanias da foz do rio Curicuriari, no rio Negro: A. Ducke s.n., Dez. 1931 fl. (RB 24466); id. s.n., Out. 1932 fl. (RB 24545); M. F. Silva, Machado \& Pires 1719, Maio $1973 \mathrm{fr}$. (INPA); rio Curicuriari: lugar Mirapara: Ducke s.n., Fev, 1936 fr. (RB
34615); rio Uneiuxi: $100-200 \mathrm{~km}$ acima da foz: Prance et al. 15486, Out. $191 \mathrm{fl}$. (NY, INPA); - Tapuruquara: P. Cavalcante 556, Fev. 1959 fr. (MG, INPA); Froes 22094, Abr. $1947 \mathrm{fr}$. (IAN); Prance et al. 15310, Out. 1971 fl. (INPA, NY); id. 15778, Out. $1971 \mathrm{fl}$. (INPA, NY); J. S. Rodrigues, Pires \& Silva 43, Fev. $1959 \mathrm{fr}$. (IAN): W. Rodrigues 839, Fev. $1959 \mathrm{fr}$. (INPA); - rio Padauari: Froes 22532, Jul. 1947 fl. (IAN): - entre Barcelos e rio Caurés: Prance et al. $15120 \mathrm{fl}$. (INPA, NY): - Barcelos: Ducke s.n., Jun. 1905 fl. (MG 7201, INPA): - vizinhança de Totobi no rio Demeni: Prance et al. 10399, Mar. $1969 \mathrm{fr}$. (INPA, NY): - entre ilha Jacaré e Airão: id. 15084, Out. 1971 fl. (INPA. NY): cercania da foz do rio Apuaú: W. Rodrigues 744 . Dez. $1958 \mathrm{fr}$. (INPA): foz do rio Araras: A. Loureiro et al. s.n., Abr. $1973 \mathrm{fl}$. (INPA, 37746); id. s.n., Abr. $1973 \mathrm{fr}$. (INPA 37853); id. s.n. Jul. $1973 \mathrm{fl}$. (INPA 39461): id. s.n. Jul. 1973 fl. (INPA 39473); id. s.n., Jul. $1973 \mathrm{fl}$. (INPA 39498); F. Mello, Pires \& Ramos s.n., Set. 1975 fl. (INPA 51802); rio Cueiras: L. CoêIho s.n., Abr. 1959 fr. (INPA 7243); O. Pires \& eq. Piatá 289, Out. $1972 \mathrm{fl}$. (INPA); G. Prance et al. 14945, Set. 1971 fl. (INPA, NY): id. 18005, Set. 1973 fl. (INPA); Uipiranga, baixo rio Negro Ducke s.n., Maio $1932 \mathrm{fl}$. (RB 24470). Cercanias de Manaus: J. Aluisio 30, Jun. $1968 \mathrm{fl}$. (INPA); id. 54, Jul. $1968 \mathrm{fl}$. 
(INPA); id. 147, Set. 1968 fl. (INPA); Chagas s.n. Out. 1954 fr. (INPA 196); id. s.n., Out. 1955 fl. (INPA 2178); Chagas \& Coelho s.n., Fev. 1956 fr. (INPA 3473); D. G. Campbell et al. P. 21893, Abr. 1974 fr. (INPA); D. Coêlho s.n., Set. 1973 st. (INPA 42227); id. s.n., Fev. 1974 st. (INPA 46533); L. Coêlho s.n., Jul. $1955 \mathrm{fl}$. (INPA 1403); id. s.n., Ago. 1955 fl. (INPA 1644); Ducke 254. Nov. 1942 fl. (MG); id. 422, Maio $1942 \mathrm{fr}$. (MG, IAN); id. 530, Jul. $1943 \mathrm{fl} .(\mathrm{MG}$, IAN); id. 583, Set. 1940 fl. (MG, IAN, RB); id. s.n., Nov. 1910 fl. (MG 11119); id. s.n., Abr. 1910 fr. (MG 11584); id. s.n., Out. 1912 fl. (MG 12.205, INPA); id. s.n., Jul. 1932 fl. (RB 24467); id. s.n., Abr. 1932 fr. (RB 24469); id. s.n., Maio 1932 fl. (RB 24541, INPA); id. s.n., Maio 1932 fl. (RB 24542); id. s.n., Jul. 1933 fl. (RB 24544); id. s.n., Jan. 1936 fr. \& Jun. 1973 fl. (RB 30150); Froes 20604, Mar. 1945 fr. (IAN); id. 25017. Ago. 1949 fl. (IAN); id. 29578, Abr. $1953 \mathrm{fr}$. (IAN); T. Guedes 57, Jun. 1948 fl. (IAN); F. Mello s.n.., Ago. 1956 fl. (INPA 4031, US); Mello \& Coêlho s.n., Set. 1956 fl. (INPA 4176); Prance et al. 2142, Set. $1966 \mathrm{fr}$. (INPA); id. 3875, Jan. $1967 \mathrm{fr}$. (INPA, PB); W. Rodrigues \& Lima 2311, Abr. $1961 \mathrm{fr}$. (INPA): Rodrigues \& Coêlho 2415, Abr. $1961 \mathrm{fr}$. (INPA); id. 8976 Maio 1961 fr. (INPA); Rodrigues 4534, Ago. 1963 fl. (iNPA, RB); Rodrigues \& Coêlho 5604, Dez. 1963 fr. (INPA); Rodrigues \& Loureiro 7119, Set. $1965 \mathrm{fl}$. (INPA); Rodrigues \& Osmarino 8219, Ago. $1966 \mathrm{HI}$. (INPA); id. 8232, Ago. $1966 \mathrm{fl}$. (INPA); Rodrigues 8917, Ago. 1970 fl. (INPA); id. 8934, Set. $1970 \mathrm{fl}$. (INPA); Rodrigues \& Coêlho 9435, Jul. 1974 fl. (INPA); R. E. Schultes 24595, Jul./Ago. 1967 fl. (INPA, IAN); id. 24608, Jul./Ago. 1967 fl. (INPA, IAN); id. 24612, Jul./Ago. 1967 fl. (INPA, IAN); id. 24615, Jul./Ago. $1967 \mathrm{fl}$. (INPA, IAN); Schwacke 571, $1877 \mathrm{fl}$. (RB); id. 3531, Jui. 1882 fl. (R, RB); M. Silva 934, Abr. $1967 \mathrm{fr}$. (INPA, MG, NY); M. F. Silva, Coêlho \& Pires 134, Maio 1972 fl. (INPA); J. A. Souza s.n., Maio 1972 fl. (INPA 35457); id. s.n., Ago. 1972 fl. (INPA 37124); Ule 8847, Ago. $1910 \mathrm{fl}$ (MG). Estrada Manaus-Caracaraí: Km 115-125: ?rance et al. 21633, Ago. 1974 fl. (INPA); W. C. Steward \& Ramos P. 19682, Dez. 1973 fr. (INPA). Estrada Manaus-Itacoatiara: Km 134: W. Rodrigues \& Monteiro 9373, Jun. $1974 \mathrm{fl}$. (INPA). Estrada ManausPorto Velho: rio Castanho: Mi. F. Silva et al. 285, Jul. 1972 fl. (INPA); id. 290, Jul. 1972 fr. (INPA); M. F. Silva et al. 470, Jul. 1972, (INPA); - Igapó-Açu, Km 150: Prance et al. 20558, Mar. 1974 fr. (INPA); Prance et al. 20565, Mar. $1974 \mathrm{fr}$. (INPA); id. 22815, Out. 1974 fl. (INPA); Rio Tupana, Km 160: D. G. Campbell et al. P. 20814, Mar. 1974 fr. (INPA); Km 235-240: E. Lleras, Holley \& Monteiro P 19642, Nov. $1973 \mathrm{fr}$. (INPA); id. P 19589. Nov. 1973 fr. (INPA); id. P 19668, Nov. $1973 \mathrm{fr}$. (INPA); $\mathrm{Km}$ 319: M. F. Silva et al, 279, Jul. $1972 \mathrm{fl}$. (INPA); Km 510, cercanias do rio Purusinho: Prance et al. 22991, Out. 1974 fl. (INPA). Carreiro: Byron et al. 923, Jun. 1973 fl. (INPA); L. Coêtho \& Coêlho 43, Abr. $1970 \mathrm{fr}$. (INPA); Ducke 2020. Out. 1946 fl. (IAN); id. 2021, Out. 1946 fl. (IAN, MG). Rio Urubu: Săo José das Pedras: Froes 25180, Set. 1949 fl. (IAN); - entre Tapatura e Cachoeira de Lin- doia: Froes 25212, Set. 1949 fl. (IAN, INPA); - Pedra Branca: Froes 25249, Set. 1949 f. (IAN): Cachoeira de Iracema: Froes 25368, Set. 1949 fl. (IAN); W. Rodrigues 339, Dez. $1956 \mathrm{fr}$. (INPA); - Sucuriju: Froes 25439, Set. 1949 fl. (IAN); - igarapé Sangana: Froes 25458, Out. 1949 fl. (IAN; - São Francisco: Froes 25485, Out. 1949 fl. (IAN); - Localidade imprecisa: Froes 25518, Out. 1949 fl. (IAN). Autaz-Mirim: A Loureiro, Pires \& Miranda s.i., Mar. 1973 fr. (INPA 37587); id. s.n., Mar. 1973 fr. (INPA 37634); id. s.n., Jun. 1973 fl. (INPA 38969); W. Rodrigues \& Meilo 7789 , Abr. $1966 \mathrm{fl}$. (INPA). Itacoatiara: Ducke s.n., Jul. 1913 fl. (MG 12486); J. G. Kuhlmann 108, Ago. 1923 fl. (RB); E. Oliveira 2815, Nov. 1963 fl. (IAN); Bacia do rio Madeira: Borba: W. Rodrigues 1589, Mar. 1960 fr. (INPA); - Humaitá: Ducke s.n., Jun. 1936 fl. (RB); Krukoff 6287, Set./Out. 1934 fl. (NY); Krukoff 6626, Out./Nov. 1934 fl. (NY); id. 6885, Out./ Nov. 1934 fl. (NY); Prance et al. 3257, Nov. 1966 fr. (INPA, NY); id. 3359, Nov. 1966 fl. (INPA, NY); id. 3488, Nov. 1966 fr. (INPA, NY); id. 3536, Dez. 1966 fr. (INPA, NY).

PARÁ: - Região do rio Trombetas: Repartimento: L. Barata s.n., Jan. $1973 \mathrm{fr}$. (INPA); - Estrada Perimetral Norte: L. Coêlho s.n., Dez. 1973 fr. (INPA). Rio Cuminá: Repartimento: M. Silva 1249, Jan. 1968 fr. (MG); - Lago do Castanho: Ducke s.n., Dez. 1906 fr. (MG 7922); - Cuminá-Mirim: Ducke s.n., Dez. 1910 fr. (MG 11472); id. s.n., Set. 1913 fl. \& fr. (MG 14838). Santarém: igarapé da Lama: Froes 30963, Jun. 1954 fl. (IAN); id. 30998, Jul. 1954 fl. (IAN); - Currupiru: Froes 31048, Ago. $1954 \mathrm{fl}$. (IAN, INPA); localidade imprecisa: Froes 31512, Jan. $1955 \mathrm{fr}$. (IAN); estrada do Palhăo: M. Silva \& Souza 2424, Ago. $1969 \mathrm{fl}$. (INPA, NY). Bacia do rio Tapajós: Goiana: Snethlage s.n., Dez. 1906 fr. (MG 8112); rio Cupari: Black 47-2182, Dez. 1947 fr. (IAN, INPA); Fordlândia: Capucho $391, \mathrm{~s} /$ data fr. (IAN); Itaituba: Ducke s.n., Ago. 1902 fl. (MG 2949); id. s.n., Jan. 1933 fr. (RB 24468). Entre rios Pacajá e Muirapiranga (lat. 2³3-50'S; long. 50'38-50'W): Prance, Pennington \& Silva 1477, Set. $1965 \mathrm{fr}$. (NY). Localidades imprecisas: J. M. Pires $7270, \mathrm{~s} /$ data est. (IAN); id. $7271, \mathrm{~s} /$ data fr. (IAN).

ACRE: - Cercanias de Cruzeiro do Sul: Prance et al. 2779, Out. $1966 \mathrm{fr}$. (INPA, NY); id. 2840, Out. $1966 \mathrm{fr}$. (INPA, NY); id. 12057, Abr. $1971 \mathrm{fl}$. (INPA, NY); id. 12308, Abr. $1971 \mathrm{fr}$. (NY); id. 12448, Abr. $1971 \mathrm{fl}$ (INPA, NY); W. C. Steward et al. P. 12875 Maio 1971 fl. (INPA, NY); id. P 12996, Maio $1971 \mathrm{fl}$. (INPA, NY); id. P13050, Maio 1971 fl. (INPA); id. P. 13114, Maio 1971 fl. (INPA, NY); id. P. 13205, Maio 1971 fl. (INPA, NY).

TERRITÓRIO DE RONDÔNIA: - Região do rio Machado: Tabajara: Krukoff 1590, Dez. 1931 fr. (NY). Cercanias de Porto Velho: Ducke s.n., Jun. $1936 \mathrm{fl}$. (RB 34617); id. s.n., Jun. 1936 fl. (RB 34618); Prance et al 8268, Nov. $1968 \mathrm{fr}$. (INPA, NY); J. F. Silva 208, Jun. 1952 fl. (IAN); id. 458, Ago. 1954 fl. (IAN). Região da estrada Porto Velho-Guajará-Mirim: Mutumparaná: Prance et al. 5438, Jul. $1968 \mathrm{fl}$. (INPA, NY); 
id. 5489, Jul. $1968 \mathrm{fl}$. (INPA, NY); id. 5542, Jul. 1968 fl. (INPA, NY); id. 5563, Jul. 1968 fl. (INPA, NY); id. 8825, Nov. $1968 \mathrm{fr}$. (INPA); id. 8838, Nov. $1968 \mathrm{fr}$. (INPA); id. 8841, Nov. 1968 fr. (NY); Abunã: Prance et al. 5843, Jul. $1968 \mathrm{fl}$. (INPA, NY, MG); Prance et al. 5990, Jul. $1968 \mathrm{fl}$. (INPA, MG, NY): - Ribeiräo e Guajará-Mirim: Prance et al. 6749, Ago. $1968 \mathrm{fl}$. (INPA, NY); - rio Bananeiras entre Guajará-Mirim e Abună: Prance et al. 6781, Ago. $1968 \mathrm{fl}$. (INPA, NY). Estrada Porto Velho-Cuiabá: entre Nova Vida e Rondônia: B. Maguire et al. 56777, Set. 1963 fl. (INPA, NY); cercanias de Santa Bárbara, no Km 117: Prance \& Ramos 6913. Ago. 1968 fl. (INPA, NY); id. 6997, Ago. 1968 fl. (INPA, NY). Rio Pacaás Novos, afluente do Mamoré: J. C. Kuhlmann 511, Set. 1923 fr. (RB); Prance et al. 6842, Ago. $1968 \mathrm{fl}$. (INPA, NY): - Rio Ouro Preto afluente do Pacaás Novos: J. C. Kuhlmann 499, Set. $1923 \mathrm{fr}$. (RB). Localidade imprecisa: J. F. Silva s.n., Ago. $1952 \mathrm{fr}$. (IAN).

MATO GROSSO: - Aripuanā (Cidade Cientifica Humboldt), lat. $10^{\circ} 12^{\prime}$ S; long. $59^{\circ} 21^{\prime} \mathrm{N}$ : C. C. Berg et al. P 18596, Out. $1973 \mathrm{fl}$. (INPA)

Espécie muito complexa, apresentando uma plasticiciade fenotípica muito grande, impossível, no presente, de se desdobrar em outras espécies ou variedades, razão pela qual são unidas provisoriamente num único taxon todas aquelas antes mantidas por Warburg (I.c. 1897), Ducke (I.c. 1936, 1938), Simith (I.c. 1937), Schultes \& Holmstedt (I.c. 1968) como espécies distintas, até que se consigam melhores elementos para separá-las.

O odor característico de alguns espécimes de terra firme, que, segundo Ducke, caracterizava $V$. theiodora Warb. das demais, também foi encontrado em espécimes de margens de rio, o mesmo acontecendo com a forma do fruto, que tanto pode ser alongado (elíptico) como sub-globoso em espécimes aparentemente idênticos.

Talvez algumas coleções da América Central e Venezuela de folhas glabrescentes, colocadas com certa reserva por Smith (I.c. 1937) em V. sebifera Aubl. devessem ser incluídas neste grupo para estudo posterior, incluindo além disso algumas formas de folhas de base estreita e aguda na base.

11. Virola flexuosa A. C. Smith, Brittonia 2 (2):151. 1936; A.C. Smith \& Wodehouse, Brittonia 2 (5):480, fig. 8 f-i. 1937; A. Ducke, Arq. Serv. Florest. 1 (1):27. 1939; A.C. Smith, Am. Journ. Bot. 43
(8):577. 1956; J.C. Th. Uphof in Engl \& Prantl, Nat. Pflanzenfam., $2^{\text {a }}$ ed., $17^{a}$ (2) :207. 1959; R.E. Schultes \& B. Holms tedt, Lloydia 34 (1):71. 1971; descr. am. pla.

Virola officinalis sensu $\mathrm{L}$ Williams in Field Mus. Nat. Hist.-Bot. 15: 138, non Warburg.

Árvore até cerca de $35 \mathrm{~m}$ de altura; tronco até $1 \mathrm{~m}$ de diâmetro; raminho com casca cinérea facilmente decídua, glabro, os mais novos distintamente flexuosos e densamente castanho-tomentelos (tricomas pouco ramificados, $0,1-0,2 \mathrm{~mm}$ de comprimento). Pecíolo canaliculado, densamente tomentoso, $1-1,5 \mathrm{~mm}$ de diâmetro, 2-8mm de comprimento. Lâmina foliar submembranácea oblonga ou estreitamente elíptica, $50-180 \mathrm{~mm}$ de comprimento, $17-40 \mathrm{~mm}$ de largura, cordada na base, obtusa ou aguda no ápice, glabra e lustrosa (quando fresca) na página superior ou às vezes tomentela na nervura mediana, opaca e tomentela na página inferior (tricomas sésseis ou dendriticos, curto-estipitados, estrelados, 4-8-ramificados, 0,2-0,3mm de diâmetro); nervura mediana impressa na página inferior; 40-60 nervuras secundárias de cada lado, retas, levemente impressas na página superior, elevadas na inferior; vênulas indistintas. Inflorescência masculina paniculada, densiflora, $40-90 \mathrm{~mm}$ de comprimento e quase o mesmo tanto de largura; peciúnculo normalmente cerca de $10 \mathrm{~mm}$ de comprimento, distintamente achatado, com raminhos densamente pardo-tomentelos; brácteas puberulentas, ovoides, cerca de $4 \mathrm{~mm}$ de comprimento, logo decíduas; flores verde-amareladas ou verde-alvacentas, dispostas em fascículos compactos de $3-6 \mathrm{~mm}$ de diâmetro e 10-15 flores por fascículo; pedicelos tênues, até $1 \mathrm{~mm}$ de comprimento; perianto submem. branáceo, 1,2-1,6mm de comprimento, esparsamente puberulento, 3-lobado quase até a base, lóbulos oblongos, obtusos, freqüentemente marcados por pontuações glandulares pretas, esparsas; androceu de $0,8-0,9 \mathrm{~mm}$ de comprimento; andróforo tênue; 3 anteras subiguais ao andróforo, soldadas até o ápice, obtusas ou obscuramente apiculadas. Inflorescência feminina desconhecida. Infrutescência compacta de $20-50 \mathrm{~mm}$ de comprimento, pedúnculo, ramos e pedicelos tenramente ferrugíneo-estrelado- 
tomentelos; pedúnculo até $10 \mathrm{~mm}$ de comprimento e $2-3 \mathrm{~mm}$ de diâmetro, mais ou menos achatado, 1-3-ramificado, pedicelos de $3-4 \mathrm{~mm}$ de comprimento; 1.9 frutos imaturos por infrutescência, elipsóide-obovóides até $15 \mathrm{~mm}$ de comprimento e $12 \mathrm{~mm}$ de largura, carinados. arredondados e levemente apiculados no ápice, obtusos ou arredondados na base, a principio abundante e uniformemente ferrugíneo-es. trelado-tomentelos mas depois presumivelmente glabrescentes. Fig. 38 .

TIPo : Krukoff 6732, Brasil, Amazonas, bacia do rio Madeira. Humaitá perto de Livramento, no rio Livramento, mata de terra firme, 12 Out. $6 \mathrm{Ncv} .1934 \mathrm{fl}$. (holótipo, NY; isótipos: RB 31528, BM, GH, S, U, US) .

Nome vUlgar: Ucuuba (ex Krukoff 6732).

UTILIDADE: Segundo Schultes \& Holmstedt (I.c. 1971), os indios Barasana da Colômbia usam a resina contra infecções dermatomicósicas.

Fenologia: Geralmente só floresce quando a copa apresenta folhagem inteiramente nova.

HaBrtat: Árvore aparentemente rara na mata de terra firme. Na Bolívia, no Departamento de Santa Cruz foi encontrada a $500 \mathrm{~m}$ de altura (ex Steinbach 3493).

Distribuição: Peru, Bolívia e Brasil amazônico. No Brasil, a sua ocorrência só é assinalada para o Estado do Amazonas. Fig. 40.

\section{MATERIAL ADICIONAL EXAMINADO :}

AMAZONAS: - Rio Juruá: Carauari: Seringal Santa Rosa D. Coêlho \& Aniceto s.n., Ago 1975 est. (INPA 52388. - Janauacá: Lago do Castanho: D. Coêlho s.n., Dez. 1974 fr. (INPA 47252).

A descrição do fruto foi baseada na coleção D. Coêlho s.n., (INPA 47252).

V. crebrinervia Ducke é a espécie mais próxima. Distingue-se dela especialmente por apresentar os raminhos mais jovens, pecíolos e inflorescências em geral cobertos de um denso tomento castanho-amarelado, e pelas folhas escassamente séssil-estrelado-tomentelas na página inferior e ápice obtuso ou agudo, não caudado-acuminado.
A recente coleção estéril de $D$. Coêlho \& Aniceto INPA 52388 foi colocada nesta espécie com certa reserva não só por se assemelhar com D. Coêlho INPA 47252 como ter sido coIhida na mesma região de dispersão desta espécie. Pela forma linear-lanceolada das folhas e glabrescência destas e dos raminhos mais novos, também lembra $V$. crebrinervia, só di. vergindo por não apresentar o reticulado promínulo e distinto nas folhas como em geral parece ocorrer nesta última. As verdadeiras delimitações provavelmente existentes entre elas só vão ser naturalmente possiveis de se definir quando se dispuser de maiores coleções de ambas as espécies.

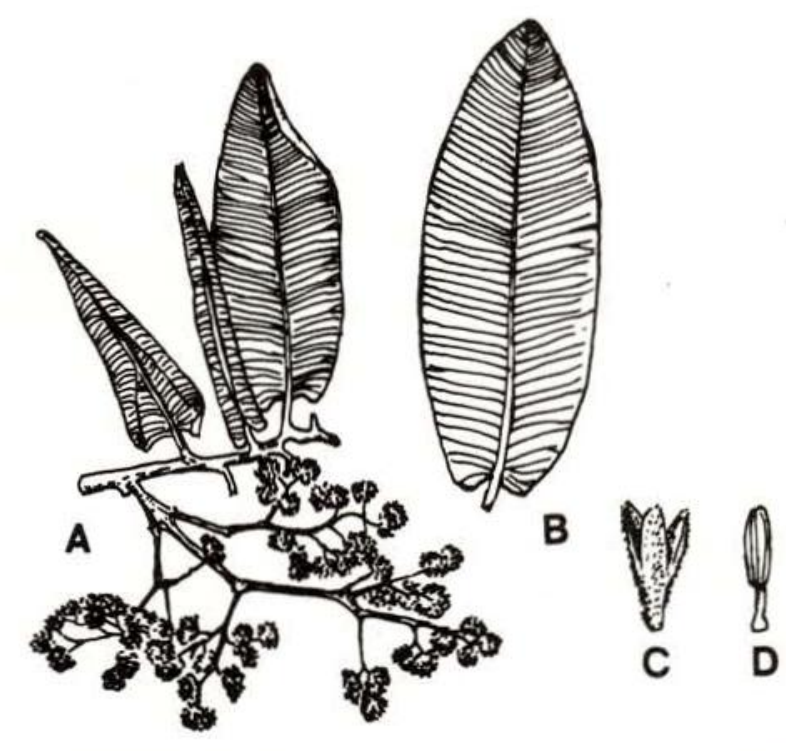

Fig. 38 - Virola flexuosa (segundo Smith \& Wodehouse, 1937): $A$, ramo florifero masculino $(x 1 / 2)$; $B$, folha ( $x$ 1/2); C, flor masculina ( $x$ 5); $D$, androceu $(x 10)$.

12. Virola gardneri (A. DC.) Warb., Nova Acta Acad. Leop.-Carol. 68:192, tab. 6. 1897; A.C. Smith \& Wodehouse, Brittonia 2 (5) :495. 1937; D. de A. Lima, Contr. Study Flora Pernambuco, Brasil 70. 1954; J.C. Th. Uphof in Engl. \& Prantl, Nat. Pflanzenfam., $2^{\text {a }}$ ed., $17^{a}$ (2) :207. 1959; A. Mattos Filho \& C.T. Rizzini, An. Bras. Econ. Florest. 19:1932. 1968; A.J. do Rego Pereira \& al., Bol. SUDENE (Recursos Naturais) 8:112. 1970; C.T. Rizzini, Árvores e madeiras úteis do Brasil: 185. 1971. 
Myristica gardneri A. De Candolle, in DC., Prodr. 14: 197. 1856; A. DC. in Martius, Fl. Bras. 5: 115. 1860.

Palala gardneri (DC.) O. Kuntze, Rev. Gen. PI. 2: 567. 1891, nom. illegit.

Myristica officinalis sensu Bentham, Hook. Journ. Bot. 5: 4. 1853, pro parte, (excl. specim. Schott s.n. et Martius 650) et sensu Mello Moraes, Phytografia: 84 1881, non Martius.

Myristica grandis $\mathrm{Fr}$. Allemão, Trabahos Socied. Vellosiana: 57. 1857, nom. nud. Origem do nome: $\mathbf{F r}$ Allemão s.n., Rio de Janeiro (BM).

Virola schwackei Warb., Nova Acta Acad. Leop.-Carol. 68: 180, tab. 7, fig. 1-2. 1897. Tipo: Schwacke s.n., Brasil, Minas Gerais, Rio Novo, fr. (holótipo: B, destruído).

Árvore até $35 \mathrm{~m}$ de altura; tronco até $120 \mathrm{~cm}$ de diâmetro; raminho tênue, estriado, castanho-puberulento quando novo, em seguida glabro e enegrecido. Pecíolo canaliculado, puberulento ou glabro, distalmente alado, $0,7-2 \mathrm{~mm}$ de diâmetro, $7-17 \mathrm{~mm}$ de comprimento. Lâmina foliar coriácea ou tenramente coriácea, oblonga, $80-160 \mathrm{~mm}$ de comprimento, $20-50 \mathrm{~mm}$ de largura (às vezes só 50 por $15 \mathrm{~mm}$, nos ramos floríferos), bruscamente atenuada na base e longamente decorrente no pecíolo, obtusa ou obtusamente curto-acuminada no ápice, lustrosa na página superior, glabra na inferior, quando nova esparsa e palidamente puberulenta (tricomas séssil-estrelados, $0,1-0,2 \mathrm{~mm}$ de diâmetro); nervura mediana plana ou levemente imersa na página superior, saliente na inferior; 11-16 nervuras secundárias de cada lado, muitas vezes um tanto irregulares, levemente elevadas na página superior, fortemente salientes na inferior; vênulas de modo geral levemente promínulas em ambas as faces. Inflorescência masculina estreita, comumente I-ramosa (raminhos inferiores às vezes pouco ramificados). $15-40 \mathrm{~cm}$ de comprimento; pedúnculo curto, muitas vezes mais ou menos achatado, raminhos e flores pardo-puberulentos (tricomas séssil-estrelados, $0,1-0,2 \mathrm{~mm}$ de diâmetro), ramos laterais distalmente túrgidos; brácteas indistintas, evanescentes; flores dispostas em 3-10 fascículos por inflorescência, 3-10 por fascículo; pedicelos tênues até $2 \mathrm{~mm}$ de comprimento; perianto tenramente carnoso, $1,8-2,3 \mathrm{~mm}$ de comprimento, trilobado quase até a base, lóbulos oblongos, obtusos; androceu de $1,5-1,8 \mathrm{~mm}$ de comprimento; andróforo tenramente carnoso, $0,6-0,8 \mathrm{~mm}$ de comprimento; 3 anteras de $0,7-1 \mathrm{~mm}$ de comprimento, soldadas até o ápice, obtusas. Inflorescência feminina quase do mesmo comprimento da masculina; 2-7 flores por fascículo; pedicelos grossos até $3 \mathrm{~mm}$ de comprimento; ovário elipsóide, tenuemente puberulento; estilete grosso até $0,7 \mathrm{~mm}$ de comprimento; estíma oblíquo, fendido. Infrutescência curta, simples, muitas vezes com apenas 1 fruto maduro; pedicelo curto, grosso; fruto elipsóide ou subglobosoelipsóide, $23-30 \mathrm{~mm}$ de comprimento, $15-24 \mathrm{~mm}$ de largura, arredondado ou obtusamente apiculado no ápice, curtamente estipitado na base, liso ou indistintamente carinado, muitas vezes enegrecido e glabro na maturidade; pericarpo rugoso de $1-2 \mathrm{~mm}$ de espessura; arilo fendido menos da metade de seu comprimento total; semente elipsóide. Fig. 39-58J.

TIPO: Gardner 5596, Brasil, Rio de Janeiro, 1841 fl. (holótipo: G-DC, n.v.; isótipos: BM, F, NY, P, R, US). Foto INPA (Herb. DC.) .

Nomes vulgares: Becuiba-açu (ex Rebouças, apud Warburg, I.c. 1897); becuiba-vermelha (ex Nunes 22534); bicuiba (ex Froes 33371); bicuiba-açu (fide Rebouças, I.c. 1897); bicuiba-da-folha-larga (fide Allemão, I.c. 1851); bicuiba-vermelha (ex Barros 43); bicuibuçu (Rebouças, apud Warburg, I.c. 1897); mucuhyba (ex Curran, apud Smith, I.c. 1937); pausangue (fide Warburg, I.c. 1897); urucuba (ex Lima 49-350) .

UTILIDADES : Dados sobre a anatomia da madeira e suas propriedades físico-mecânicas são apresentados por Pereira (I.c. 1970). A madeira avermelhada é empregada comumente em carpintaria, construções, canoas, taboados, assoalhos, vigamentos, telhas, mourões, réguas, persianas, caixotaria, etc...

O óleo que se extrai das sementes serve para fabricação de velas e para iluminação. Oswaldo G. Lima et al. (An. Soc. Biol. Pernambuco 13 (1):1-7, fig. 1-2. 1955) comprovaram que os extratos da amêndoa desta espécie tinham atividade antibacteriana contra germes grã-positivos e germes ácido-resistentes. 


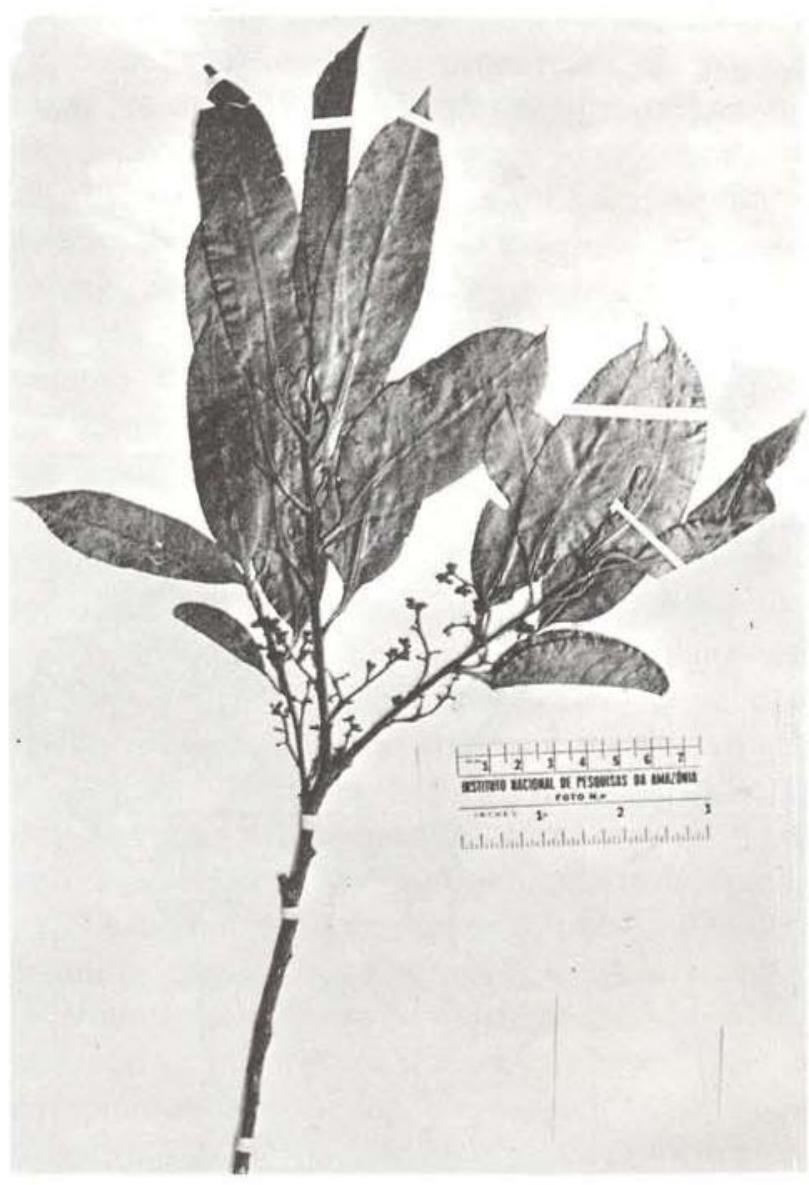

Fig. 39 - Virola gardneri. G. Gardner 5596. (NY, isótipo).

A manteiga ou óleo da bicuíba, segundo $M$. Moraes (I.c. 1881), é empregado em fricções nas doenças da pele, erisipelas, boubas, feridas frescas, feridas causadas por bichos de pé, cancro, dores uterinas, obstrução do baço e dores nervosas. Internamente, o cozimento feito das amêndoas é tido como excelente remédio para confortar o estômago debilitado, ventosidades, cansaço ou fadiga de caminho, mau hálito da boca, dores do ventre procedidas de resfriamento; conforta o cérebro e aju. da a memória; uma ou mesmo duas frutas comidas, tira o mau hálito e aclara a vista; em maior quantidade é venenosa. A resina que exsuda da casca da árvore ferida aplicada sobre ferimentos é, segundo Rizzini (I.c. 1971), anti-hemorrágico e cicatrizante poderoso.

Fenologia : Encontrada em flor nos meses de janeiro, março, junho e novembro e frutifican- do em março, junho, agosto e outubro, sendo possivelmente este último mês em que a frutificação ocorre cơm mais freqüência. Fig. 13.

Habitat : Cresce em mata de terra firme ou tabuleiro, tendo sido asinalada na Estação Biológica do Itatiaia a $700 \mathrm{~m}$ de altura (ex Barros 43).

Distribuição: Espécie exclusivamente brasileira, dispersando pela costa atlântica desde Pernambuco até o Rio de Janeiro. Fig. 40.

\section{MATERIAL ADICIONAL EXAMINADO :} (NY).

Sem localidade precisa: Riedel s.n., s/data fl.

PERNAMBUCO: - Cercanias de Recife: Ducke \& A. Lima 22, Nov. 1951 fl. (R); Ducke 2261, Out. 1944 fr. (IAN, MG, R, RB); C. G. Leal \& Octavio s.n., Jan. 1950 fl. (NY, RB); D. A. Lima 49-350, Out. 1949 fr. (IAN); id. 50-496, Jun. $1950 \mathrm{fl}$. (IAN, RB).

ALAGOAS: - Sem localidade precisa: A. M. Uchoa 36, s/data est. (RB).

BAHIA: - Bacia do rio Gongongi: W. M. Curran 46, Out./Nov. 1915 ! (US). - Ilhéus: J. Almeida \& Santos 213, Nov. $1968 \mathrm{fl}$. (CEPEC, INPA).

MINAS GERAIS: - Regiāo do rio Piracicaba, Reserva Florestal Estadual: R. L. Froes 33371, Ago. 1957 fr. (IAN). - Coronel Pacheco: Estação Experimental de Agua Limpa: E. P. Heringer 2511, Nov. 1946 fl. (SP); id. 2841, Nov. 1946 fl. (RB).

ESPIRITO SANTO: - Linhares: Rio Doce: J. G. Kuhlmann 436, Out. 1930 est. I (RB); J. Spada 168, Jan. $1973 \mathrm{fl}$. (INPA, RB).

RIO DE JANEIRO: - Rio de Janeiro: Horto Florestal: Antenor 628, Out. 1927 fr. (RB); Jardim Botânico (cultivada): A. Ducke s.n., Nov. 1934 fl. (RB 25105); Mata da Chácara do Fonseca: P. Ochioni s.n., Out. 1921 fr. (RB 21202). - Estado do Rio: Monte Sinai, G. Portela: G. M. Arinos 193, Jan. fl. (RB); Estação Biológica do Itatiaia: W. D. Barros 43, Out. $1940 \mathrm{fr}$. (RB); id. 559, Jan. 1942 fl. (RB); Posse, Avelar: G. M. Nunes 22534, Mar. $1928 \mathrm{fl}$. e fr. (NY, R, SP); Resende: J. G. Kuhlmann 629, Jun. 1927 fr. (RB).

Distingue-se da espécie mais próxima, $V$. oleifera A.C. Smith, pela folha oblonga, bruscamente atenuada na base e longamente decorrente no pecíolo e pelo fruto subgloboso ou elipsóide, arredondado ou obtusamente apiculado no ápice, liso ou indistintamente carinado. 


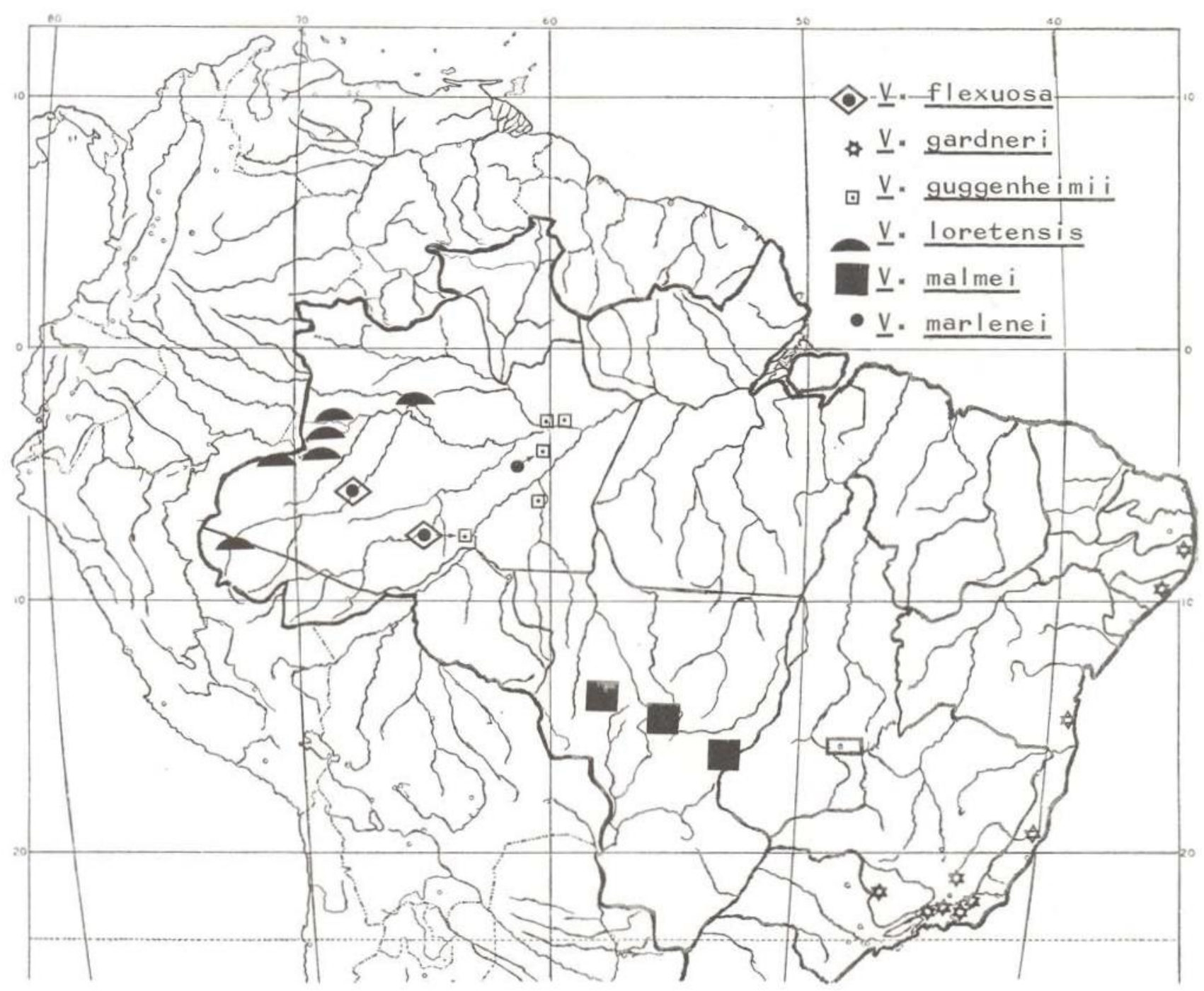

Fig. 40 - Distribuição atual de Virola flexuosa, V. gardneri, v. guggenheimii, V. loretensis, V. malmei e V. marlenei no Brasil.

13. Virola guggenheimii W. Rodr., Acta Amazonica, 7 (4): 464, fig. 3. 1977.

Arvore até $28 \mathrm{~m}$ de altura; tronco cilíndrico até $45 \mathrm{~cm}$ de diâmetro, sem sapopema; casca rugosa e fissurada longitudinalmente; lenho com exsudação avermelhada; raminhos do ano achatados lateralmente, cerca de $2-3 \mathrm{~mm}$ de espessura acima da infrutescência, rufotomentelos (tricomas irregularmente ramificados cerca de $0,2-0,3 \mathrm{~mm}$ de comprimento), os mais velhos glabrescentes e acinzentados com casca rugulosa e quebradiça. Pecíolo canaliculado, 2-3mm de espessura, 5-10-(-20) $\mathrm{mm}$ de comprimento, rufotomentelo como os raminhos no- vos, com a pilosidade se estendendo pela nervura mediana. Lâmina foliar coriácea, elíptica ou elíptico-oblonga, 50-220-(-255) mm de commento, 20-65-(-100) $\mathrm{mm}$ largura, cordada na base, aguda ou cuspidada no ápice, página superior esparsamente estrigulosa (tricomas rígidos, ramificados desde a base ou dendríticos, 0,2-0,4mm de comprimento), com o tempo glabrescente, nitídula, página inferior tomentosa (tricomas dendríticos, $0,2-0,3 \mathrm{~mm}$ de comprimento); nervura mediana plana ou ligeiramente imersa na página superior, muito saliente na inferior; 24-58 nervuras secundárias de cada lado, retas, paralelas, anastomosadas junto às margens, levemente imersas na 
página superior e elevadas na inferior; vênulas reticuladas obscuras ou promínulas na página superior e um tanto elevadas na superior. Inflorescência masculina amplamente paniculada, livremente ramificada, multiflora, densa e tenramente rufotomentosa (tricomas irregularmente ramificados, $0,1-0,2 \mathrm{~mm}$ de comprimento), até $140 \mathrm{~mm}$ de comprimento e quase o mesmo de largura; pedúnculc achatado, até ca. $25 \mathrm{~mm}$ de comprimento; brácteas oblongas, ca. $3 \mathrm{~mm}$ de comprimento, $1,5 \mathrm{~mm}$ de largura, logo decíduas; 11-53 flores por fasciculo, amareladas, fascículos pequenos e densos; pedicelos tinos até ca. $1,5 \mathrm{~mm}$ de comprimento; perianto tenuemente carnoso, ca. $1,0-1,5 \mathrm{~mm}$ de comprimento, infundibuliforme, 3-4-lobado até quase a base, lóbulos oblongos, obtusos; an droceu ca. $8 \mathrm{~mm}$ de comprimento; andróforo delgado ca. $0,3-0,4 \mathrm{~mm}$ de comprimento; 3-4 anteras soldadas freqüentemente até o ápice ca. $0,4-0,5 \mathrm{~mm}$ de comprimento, obtusas e curtamente apiculadas, apículos freqüentemente levemente divergente. Inflorescência feminina não vista. Infrutescência até cerca de $70 \mathrm{~mm}$ de comprimento; pedúnculo grosso, ferrugíneotomentelo como os raminhos novos: $1-4$ frutos maduros por infrutescência, pedicelados (pedicelos grossos até $3-5 \mathrm{~mm}$ de comprimento), elipsóides ou obovóides, $20-28 \mathrm{~mm}$ de comprimento e $15-20 \mathrm{~mm}$ de largura, arredondados e levemente apiculados no ápice, levemente carinados na sutura, obtusos a arredondados na base. glabrescentes, ferrugíneo-tomentosos apenas na base (tricomas dendríticos cerca de 0,5-1,0 $\mathrm{mm}$ de comprimento); pericarpo de 2-4mm de espessura; arilo róseo, laciniado até quase a base semente elipsóide. Fig. 41.

Tipo: O. P. Monteiro \& J. Ramos, 983, Brasil, Amazonas: estrada Manaus-Porto Velho, km 220, entre os rios Tupana e Igapó-Açu, mata de terra firme, flores amareladas, 28 abril $1976 \mathrm{fl}$. (holótipo: INPA 59445)

Fenologia: A floração se dá entre abril e maio e a frutificação, de julho a novembro.

Habitat : Mata de terra firme, solo argiloso,

Distribuição: Até agora só encontrada no centro da Amazônia brasileira. Fig. 40.

\section{MATERIAL ADICIONAL EXAMINADO :}

AMAZONAS: -- Estrada Manaus-Itacoatiara, Km 136: W. Rodrigues 9536, mata de terra firme, 17 Set. $1974 \mathrm{fr}$. e madeira INPA X-5865 (INPA); W. Rodrigues \& D. Coêlho, 9255, 20 Nov. 1973, est. (INPA). Estrada Manaus-Itacoatiara, Km 125: W. Rodrigues 9062, 24 Set. $1965 \mathrm{fr}$. (INPA); W. Rodrigues \& D. Coelho, 9065, 29 Mar. 1973, est. (INPA); W.Rodrigues \& D. Coelho, 9067. 29 Set. 1973, fr., plântulas e madeira INPA X-5370 (INPA); W. Rodrigues \& D. Coelho 9262, 20 Nov. 1973, fr. (INPA). Região do rio Madeira, rio Canumã: R. L. Froes 33645, 25 Out. 1957, est. (IAN). Estrada ManausPorto Velho, trecho entre os rios Castanho e Tupana: M. Silva et al. 196, 7 Jul. $1972 \mathrm{fr}$. (INPA).

Espécie próxima de Virola decorticans Ducke, da qual se distingue especialmente pelas folhas acentuadamente menores e um tanto persistente e esparsamente estrigulosas na página superior e pela glabrescência dos frutos, quando maduros.

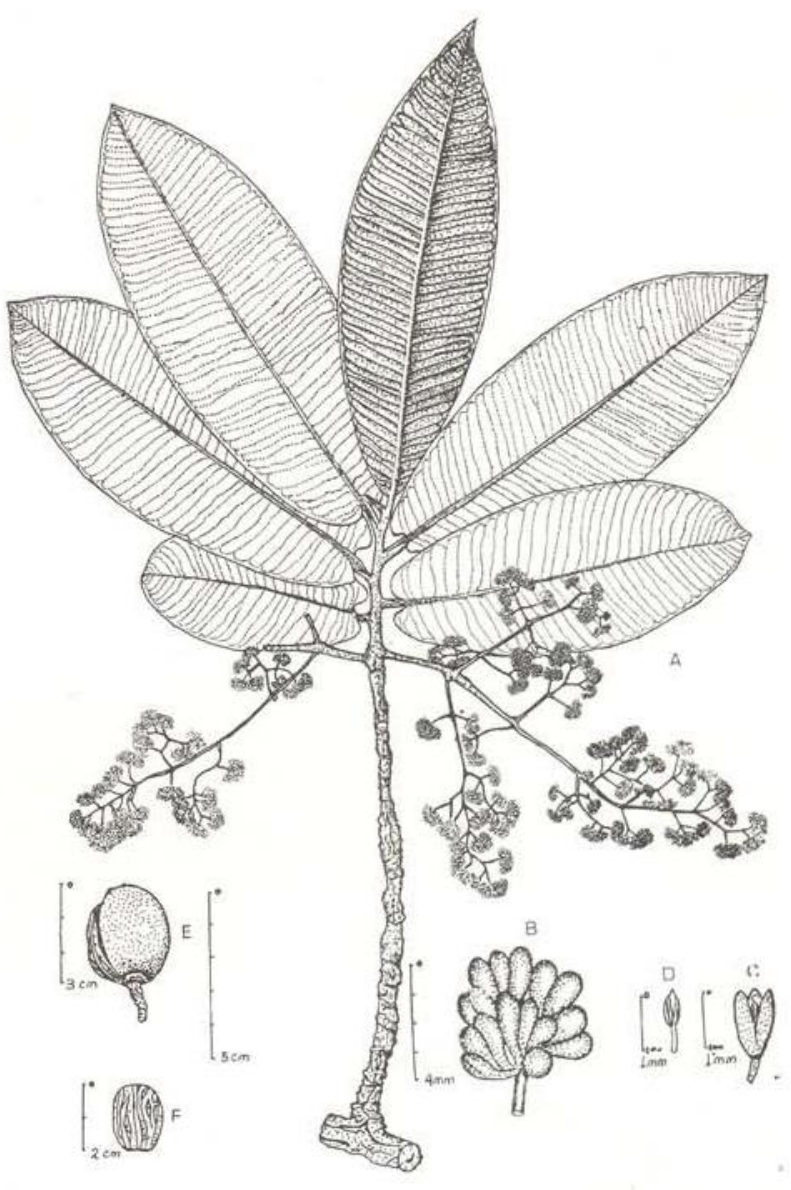

Fig. 41 - Virola guggenheimii A-D (O. P. Monteiro 983): A, hábito do ramo florifero masculino: B, fascícuculo floral; C, flor; D, androceu; E-F (W. Rodrigues 9536): $E$, fruto; $F$, semente com arilo. 
14. Virola loretensis A. C. Smith, Bull. Torrey Club 58 (2):95. 1931; A. Ducke, Journ. Wash. Acad. Sci. 26 (6):254. 1936; L. Williams, Field Mus. Nat. Hist.-Bot. 15:136. 1936; A. C. Smith \& R. Wodehouse, Brittonia 2 (5): 458, fig. 7 a-g. 1937; A. Ducke, Arq. Serv. Florest. 1 (1):24. 1939; J. C. Th. Uphof in Engl. \& Prantl, Nat. Pflanzenfam., $2^{\mathrm{a}}$ ed., $17^{a}$ (2): 206. 1959; R. E. Schultes \& B. Holmstedt, Lloydia 34 (1):71. 1971.

\section{Virola villosa Ducke, Bull. Mus. Hist. Nat. Pa- ris, 2." sér., 4 (6): 724. 1932; Arq. Jard. Bot. Rio de Janeiro 6: 11, 1933. Tipo: A. Ducke s.n., Peru, Iquitos, 27 Out. 1927 fr. (lectótipo: RB. 17983; isolectótipos: K, US); J. G. Kuhlmann 1485, Peru, Iqui- tos, 22 Fev. 1924 fr. (sintipos: RB 17984, S, U).}

Arbusto a arvoreta de $3-15 \mathrm{~m}$ de altura, bastante copada, tronco com cerca de $7-15 \mathrm{~cm}$ de diâmetro; raminhos densa e persistentemente tomentosos, tricomas ferrugíneos de $1,5-4 \mathrm{~mm}$ de comprimento, multicelulares, articulados, ramos laterais numerosos, esporoniformes ou ausentes. Pecíolo grosso, cilíndrico de $2,5-6 \mathrm{~mm}$ de diâmetro e $3-12 \mathrm{~mm}$ de comprimento, tomentoso como os raminhos. Lâmina foliar tenuemente coriácea ou papirácea, oblonga, oblongo-elíptica. ou estreitamente obovado-oblonga, $90-350 \mathrm{~mm}$ de comprimento, $30-130 \mathrm{~mm}$ de largura, cordada ou arredondada na base, gradualmente atenua. da na nervura mediana; página inferior densa ou esparsamente tomentosa (tricomas dendrí. ticos pediculados, cerca de $1 \mathrm{~mm}$ de comprimento, tricomas das nervuras geralmente com $2-3 \mathrm{~mm}$ de comprimento); nervura mediana quase plana ou mais ou menos saliente na página superior, muito saliente e forte na inferior: 15-26 nervuras secundárias de cada lado quase retas, arcuadas junto às margens, ligeiramente impressas na página superior, elevadas na inferior; vênulas fortemente reticuladas. promínulas em ambas as páginas ou obscuras. Inflorescência masculina amplamente panicula$\mathrm{da}$, livremente ramificada, multiflora, até $270 \mathrm{~mm}$ de comprimento e $150 \mathrm{~mm}$ de largura: pedúnculo de $40-120 \mathrm{~mm}$ de comprimento, tênue, com os raminhos densamente tomentosos (tricomas semelhantes aos dos raminhos vege- tativos); brácteas linear-lanceoladas, cerca de $3 \mathrm{~mm}$ de comprimento, densamente ferrugíneotomentosas, logo decíduas; flores amarelo-esverdeadas, isoladas ou dispostas em pequenos fascículos laxos; pedicelos tênues de $2-4 \mathrm{~mm}$ de comprimento, frouxamente tomentelos; perianto submembranáceo, infundibuliforme, $1,0-1,8 \mathrm{~mm}$ de comprimento, tomentelo externamente, (tricomas de aproximadamente $1 \mathrm{~mm}$ de comprimento, estrelados), 3-ou 4-lobado até quase a metade de seu comprimento, lóbulos deltoides, obtusos; androceu de $0,9-1,4 \mathrm{~mm}$ de comprimento; andróforo de $0,3-0,6 \mathrm{~mm}$ de comprimento; 3-4 anteras, soldadas até o ápice, $0,5-0,8 \mathrm{~mm}$ de comprimento, apiculadas no ápice, apículo simples ou fendido, com cerca de 0,1-0,2mm de comprimento. Inflorescência feminina comparativamente delgada, até $240 \mathrm{~mm}$ de comprimento, tomentosa como a inflorescência masculina; fascículos de 5-10 flores, subsésseis; ovário globoso, densamente tomentoso (tricomas até $1 \mathrm{~mm}$ de comprimento); estigma séssil. Infrutescência até $350 \mathrm{~mm}$ de comprimento e $150 \mathrm{~mm}$ de largura, pendente; 10-40 frutos por infrutescência, pedicelados (pedicelos grossos de $3.5 \mathrm{~mm}$ de comprimento), subglobosos, $13-18 \mathrm{~mm}$ de diâmetro, ou elipsóides, $18.24 \mathrm{~mm}$ de comprimento e $12-18 \mathrm{~mm}$ de largura, densa e persistentemente tomentosos (tricomas de $7-9 \mathrm{~mm}$ de comprimento, abundantemente articulados, apêndices laterais muito curtos ou ausentes); pericarpo frágil, geralmente menor que $0,5 \mathrm{~mm}$ de espes. sura. Fig. 3, 8A-C, 42-43.

Trpos : Killip \& Smith 27359, Peru, Loreto, cer. canias de lquitos, alt. 100m, 2-8 Ago. $1929 \mathrm{fl}$. (holótipo: NY; isótipos: F, US); Killip \& Smith 27026, Peru, Loreto, Iquitos fl. (parátipos: F, NY, US): Klug 1502, Peru, Loreto, perto de Iquitos, Mishuyacu Maio/Jun. $1930 \mathrm{fl}$. (parátipos: F, NY, US); Klug 1543, Peru, Loreto, perto de Iquitos, Mishuyacu Maio/Jun. 1930 (parátipos: F, NY, US); Killip \& Smith 29671, Peru, Loreto, Peña Blanca no rio Itaya 19 Set. 1929 (parátipos: F, NY, US) .

Nomes vUlgares: Ucuuba; ucuhuba.

DistribuIÇÃo: Ocorre nos Estados do Amazonas e Acre e fora do Brasil, no Peru e Colômbia. Fig. 40 . 


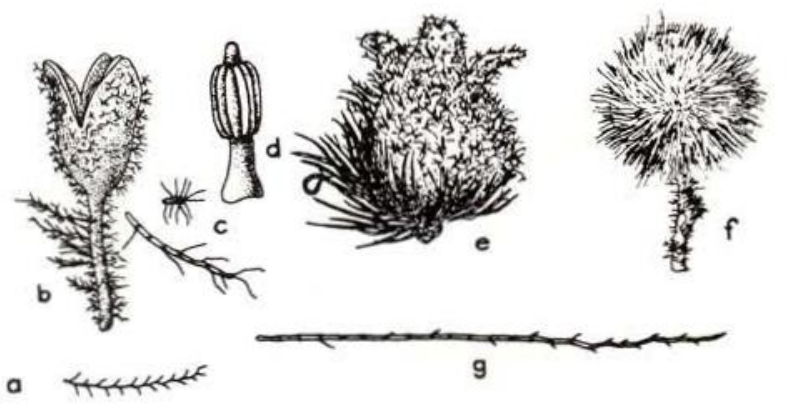

Fig. 42 - Virola loretensis (segundo Smith \& Wodehouse, 1937): $A$, pelo da face inferior da folha $(x 20)$; $B$, flor masculina $(x 10)$; C, pelos do pedicelo e perianto da flor masculina, muito aumentados; $D$, androceu ( $x$ 20); $E$, flor feminina $(x 10) ; F$, fruto $(x 1) ; G$, pelo do fruto $(x, 10)$.

Habitat : Planta freqüente nas matas de várzea e restingas, sendo encontrada também, muitas vezes nas matas de terra firme, em solo argiloso. Ocorre em geral em lugares de baixa altitude.

Fenologia: Floresce entre março e novembro; a frutificação tem início possivelmente em junho indo irregularmente até fevereiro.

\section{MATERIAL ADICIONAL EXAMINADO :}

AMAZONAS: - Esperança, foz do rio Javari: A. Ducke 882, Fev. 1942 fr. (IAN, MG, NY). Rio Javari: Palmeiras long. $72^{\circ} 49^{\prime} \mathrm{W}$; lat. $5^{\circ} 8^{\prime} 5$ ): G. T. Prance et al 17097, Jul. $1973 \mathrm{fl}$. (INPA, NY); rio Curuçá: J. Ramos s.n., Nov. 1975 fr. (INPA 54123); id. s.n., Nov. $1975 \mathrm{fl}$. (INPA 54127). Miraflor: G. T. Prance et al. 16921. Jul. 1973 fl. (INPA); G. T. Prance et al. 16922, Jul. 1973 fr. (INPA). - São Paulo de Olivença: R. L. Froes 20894, Maio $1945 \mathrm{fl}$. (IAN, K, NY, US). R. L. Froes 23820, Jan. 1949 fr. (IAN, RB, SP.); R. L. Froes 34789, Mar. 1945 fl. (IAN); B. A. Krukoff 8070, Set./ Out. $1936 \mathrm{fr}$. (GH, NY). Bacia do rio Içá: B. A. Krukoff 7850, Jun. 1936 fr. (NY) - Rio Japurá: A. Ducke s.n., Set. 1904 fl. (MG 6792); rio Japurá: (long. 67\% $11^{\prime} \mathrm{W}$; lat. $0^{\circ} 05^{\prime} \mathrm{S}$ ): O. C. Nascimento, Pires \& Coradin 152, Abr. $1975 \mathrm{fl}$. (IAN, INPA). Rio Jutaí (Projeto RADAM, Quadr. SB-19-XA): L. Coêlho, Mato \& Furtado, 349, Set. $1975 \mathrm{fr}$. (INPA).

ACRE: - Cruzeiro do Sul: G. T. Prance et al. 13324. Maio 1971 fl. (INPA, NY); id. 2805 Out. 1966 fr. (INPA, NY, U, R).

Espécie próxima de $V$. mollissima Warb., diferencia-se desta e das demais conhecidas pelo tipo característico de pilosidade da inflo- rescência e dos frutos. Da espécie acima citada também se distingue pela antera subigual ao andróforo em comprimento.

15. Virola malmei A.C. Smith, Brittonia 2 (5): 496. 1937, descr. ampla.

Virola glaziovii Warb. var. latifolia Malme, Ark. Bot. 26A (9): 29. 1935

Arbusto de $2 \mathrm{~m}$ a árvore de $10 \mathrm{~m}$ de altura; tronco de $10 \mathrm{~cm}$ de diâmetro; raminhos estriados, quando novos tomentelos (tricomas de cor amarelo-ouro, pouco ramificados desde a base até $0,5 \mathrm{~mm}$ de comprimento), logo glabros. Pecíolo canaliculado, rugoso, tomentelo ou glabro de $1,5-3 \mathrm{~mm}$ de diâmetro, $6-12 \mathrm{~mm}$ de comprimento. Lâmina foliar coriácea, oblonga ou elíptico-oblonga, $100-210 \mathrm{~mm}$ de comprimento, $40-70 \mathrm{~mm}$ de altura, arredondada ou ligeiramente subcordada na base, obtusa ou obtusamente cuspidada e muitas vezes ligeiramente emarginada no ápice, indistintamente puberulenta na página inferior (tricomas séssil-estrelados,

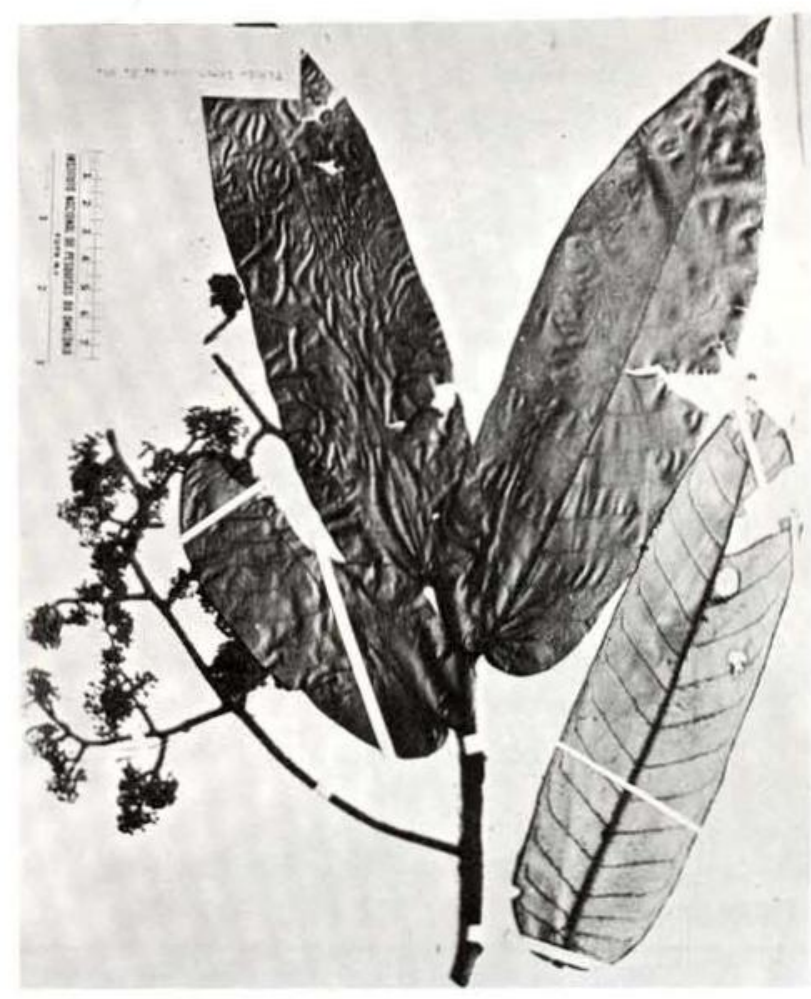

Fig. 43 - Virola loretensis. Killip \& Smith 27359 (NY. holótipo). 
amarelo-ouro, 2-5-ramificados com cerca de $0,2 \mathrm{~mm}$ de diâmetro), glabrescentes; nervura mediana quase plana na face superior, saliente na inferior; 14-20 nervuras secundárias de cada lado, levemente impressas na página superior, fortemente elevadas na inferior; vênulas obscuras ou levemente impressas. Inflorescência masculina paniculada, 2 (raro 3 ) vezes ramificadas, $70-150 \mathrm{~mm}$ de comprimento e quase o mesmo de largura; pedúnculo $15.55 \mathrm{~mm}$ de comprimento, muitas vezes ligeiramente achatado, com os raminhos e flores tomentelos ou puberulentos (tricomas amarelo-ouro, pouco ramificados desde a base, até $0,3 \mathrm{~mm}$ de comprimento); pedúnculos mais novos ligeiramente túrgidos no ápice; brácteas oblongas, puberulentas com aproximadamente $5 \mathrm{~mm}$ de comprimento, logo decíduas; fascículos de 8-25 flores cada; pedicelos tênues, até $3 \mathrm{~mm}$ de comprimento; perianto creme, carnoso, 2,5-3,0 mm de comprimento; perianto creme, carnoso, 2,5-3,0 mm de comprimento, trífido quase até a base, lobos oblongos, obtusos; androceu de aproximada.

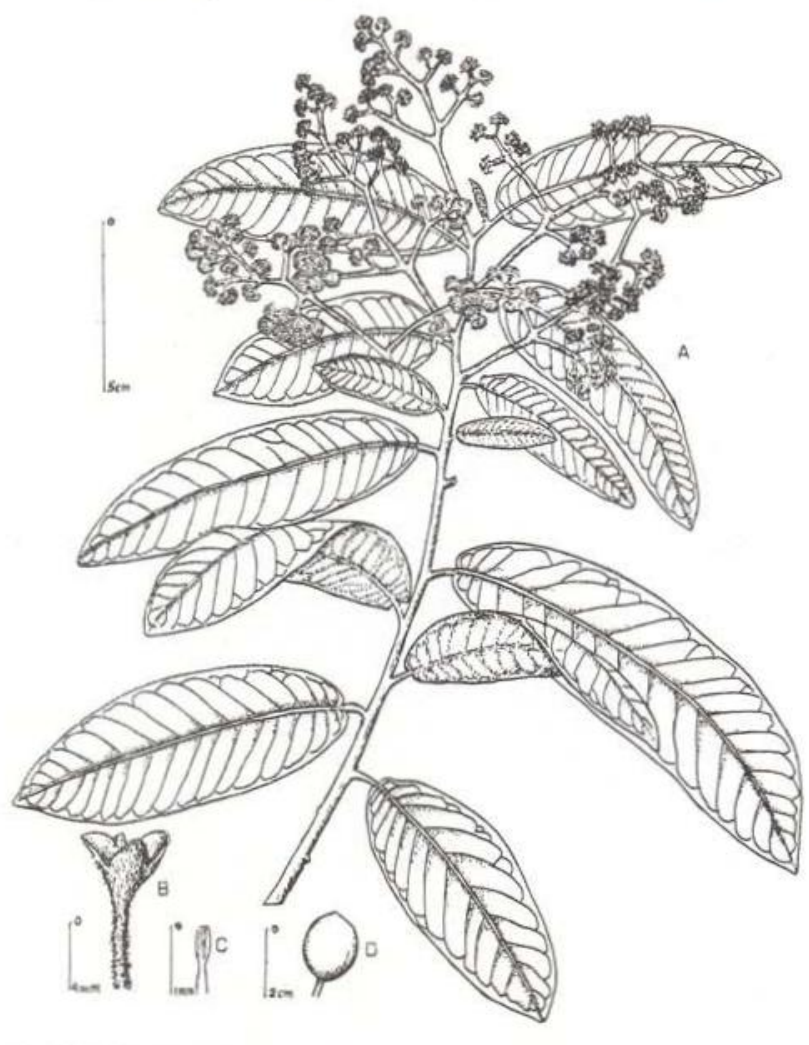

Fig. 44 - Virola malmei. A-C (B. Maguire et al. 56267): $A$, hábito do ramo florifero masculino; $B$, flor masculina; C, androceu; D (G. T. Prance, Lleras \& Coelho 19299), fruto. mente $2 \mathrm{~mm}$. de comprimento; andróforo carnoso de $1,0-1,3 \mathrm{~mm}$ de comprimento, contraído distalmente; 3 anteras de $0,6-1,9 \mathrm{~mm}$ de comprimento, soldadas até $\sigma$ ápice, obtusas. Inflorescência feminina não vista. Infrutescência de $45 \mathrm{~mm}$ de comprimento; pedúnculos tomentelos como os raminhos vegetativos, glabrescentes; frutos jovens 3 por infrutescência, verdes, glabros, pedicelados (pedicelos cerca de $4 \mathrm{~mm}$. de comprimento, $1,0-1,3 \mathrm{~mm}$ de diâmetro), ligeiramente carinados unilateralmente, $18-20 \mathrm{~mm}$ de comprimento, cerca de $15 \mathrm{~mm}$ de diâmetro, sem estipes distintos, ovado-elipsóides ou elipsóides, obtusos ou levemente apiculados no ápice, arredondados na base, pericarpo tênue, carnoso; sementes não vistas. Fig. 44.

TrPo: G. A. O. Malme 2033b, Brasil, Mato Grosso, Santana da Chapada: 6 Ago. $1902 \mathrm{fl}$. (holótipo: S; fotos: INPA, NY); id. $2033 \mathrm{fl}$. (parátipo: S); id. 2033a (parátipo: S).

HABITAT : Freqüente no cerrado, (ex Maguire et al. 56267) na estrada Brasília-Acre para Cuiabá, a $15-120 \mathrm{~km}$ acima do Alto Araguaia. Assinalada também para as matas paludosas de cabeceiras de rios e margens destes, até $300 \mathrm{~m}$ de altitude (ex Prance et al. 19299).

DISTRIBUição: Até hoje restrita apenas ao Estadó de Mato Grosso. Fig. 40.

\section{MATERIAL ADICIONAL EXAMINADO:}

MATO GROSSO: Estrada Buriti-Cuiabá: G. T. Prance, Lleras \& Coelho 19299, Out. 1973 fr. (INPA). Estrada Brasília-Acre: $15-120 \mathrm{Km}$ do Alto Araguaia em direção à Cuiabá: B. Maguire \& al. 56267, Ago. 1963 fl. (INPA, NY, RB).

A descrição da infrutescência foi baseada na coleção Prance et al. 19299.

Esta espécie difere das outras afins por apresentar folhas elípticas, ápice obtuso ou obtuso-cuspidado, base arredondada ou levemente subcordada. Distingue-se, também, de sua espécie mais próxima, $V$. surinamensis Warb., pelas folhas mais largas, inflorescência 2- ou 3-ramosa, perianto mais comprido e carnoso, e anteras mais longas, sustentadas por um andróforo estreitado distalmente. Os frutos são inteiramente glabros e elipsóides e constituídos de um pericarpo delgado. 
16. Virola marlenei W. Rodr., Ciência e Cuitura, Suplemento, 29 (7):559. 1977; Acta Amazonica 7 (4): 467 fig. 4. 1977.

Arbusto ou arvoreta de $4-6 \mathrm{~m}$ de altura; raminho densa e tenuemente rufotomentoso (tricomas de cerca de $0,2-0,4 \mathrm{~mm}$ de comprimento, com muitas ramificações esporoniformes). Peciolo cerca de $2-3 \mathrm{~mm}$ de espessura, $6-11 \mathrm{~mm}$ de comprimento, rufotomentoso como os raminhos, canaliculado. Lâmina foliar coriácea, obovado-oblonga ou elíptica, $95-270 \mathrm{~mm}$ de comprimento, $35-85 \mathrm{~mm}$ de largura, na base arredondada, atenuada ou estreitada em direção ao pecíolo, geralmente acuminada no ápice, margens levemente revolutas, glabra e mais ou menos lustrosa na página superior, página inferior esparsamente pilosa com tricomas dendríticos de cerca de $0,2-0,3 \mathrm{~mm}$ de comprimento; nervura mediana saliente em ambas as faces, mais fortemente na inferior; $12-18$ nervuras secundárias de cada lado, curvadas antes das margens, anastomosadas, ligeiramente imersas ou promínulas na página superior, salientes na inferior; vênulas estreitamente reticuladas, promínulas ou obscuras na face superior. Inflorescência masculina curtamente paniculada, laxiflora, cerca de $20-40 \mathrm{~mm}$ de comprimento e quase o mesmo tanto de largu-

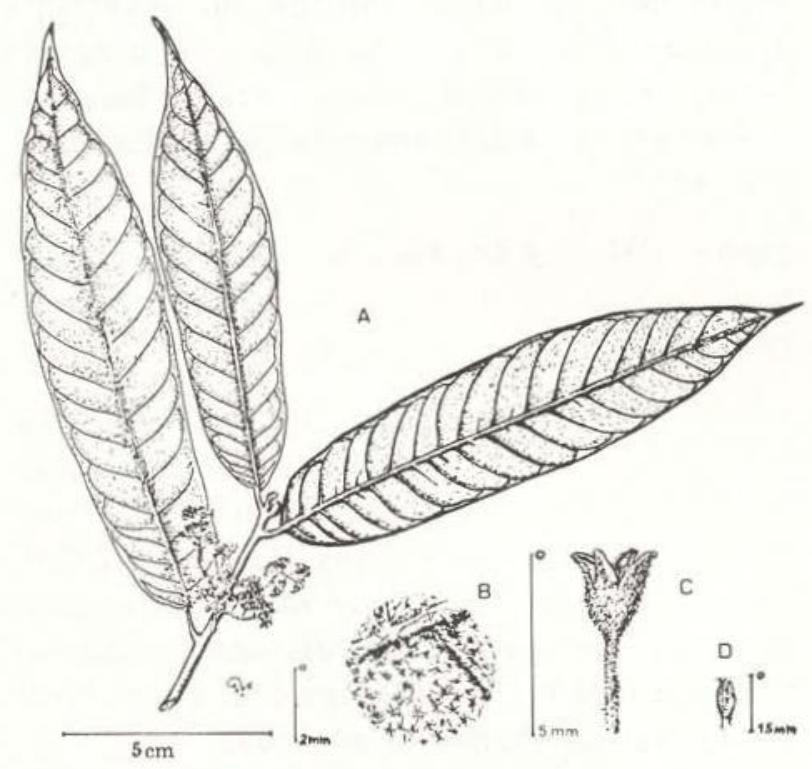

Fig. 45 - Virola marlenei. A-D (M. F. Silva et al. 753): $A$, hábito do ramo florífero masculino; $B$, visto da face inferior da folha, ampliada; C. flor masculina; D, androceu. ra, rufotomentosa como os raminhos vegetativos, curtamente pedunculada, pedúnculo tênue; flores ferrugíneas dispostas em fascículos frouxos; pedicelos tênues de cerca de $1,0-2,5 \mathrm{~mm}$ de comprimento (tricomas séssil-estrelados, diminutos cerca de $0,1-0,3 \mathrm{~mm}$ de diâmetro, e tricomas esparsos, articulados e irregularmente ramificados, de cerca de $0,2-0,3 \mathrm{~mm}$ de comprimento); perianto coriáceo, infundibuliforme, cerca de $1,8-2,2 \mathrm{~mm}$ de comprimento, rufotomentelo externamente (tricomas séssil-estrelados, diminutos, cerca de $0,1-0,2 \mathrm{~mm}$ de diâmetro, não persistentes), constricto na base, trilobado um pouco além da metade de seu comprimento total, lóbulos deltóides, agudos; androceu de $0,1-1,3 \mathrm{~mm}$ de comprimento; andróforo de $0.2-0,3 \mathrm{~mm}$ de comprimento, carnoso, estreitado em direção ao ápice; 3 anteras de 0,7-1,0mm de comprimento, divergentes no ápice, cada uma curtamente encimada por um apículo de cerca de $0,1 \mathrm{~mm}$ de comprimento. Inflorescência feminina e infrutescência não vistas. Fig. 45.

Trpo: M. F. Silva et al. 753, Brasil, Amazonas: Estrada Manaus-Porto Velho, entre os rios Castanho e Tupana. Arvoreta de $6 \mathrm{~m}$. de altura; mata de terra firme, solo argiloso úmido; flores ferrugíneas, 14 Jul. 1972 (holótipo: INPA 36844) .

Fenologia : Observada florescendo em julho. Habitat : Mata baixa de terra firme.

Distribuição: Somente conhecida do Estado do Amazonas. Fig. 40.

Difere de V. divergens Ducke e de V. loretensis Smith principalmente por apresentar foIhas obovadas, basalmente arredondadas ou atenuadas, e pelas inflorescências comparativamente bem menores, revestidas de um indumento tenuemente rufotomentoso. Também distingue-se da última espécie citada pelas anteras nitidamente divergentes no ápice.

17. Virola michelii Heckel, Ānn. Mus. Colon. Marseille 6: 118, fig. 24a-d (semente). 1898; C. Pesce, Oleaginosas da Amazônia: 64. 1941 (V. micheli Heckel, sphalmate).

Myristica melinonii Benoist, Bull. Mus. Hist. Nat. Paris. 30: 104. 1924. Tipos: Meli- 
non s.n., Guiana Francesa, Maroni, 1863 fl. (lectótipo: $P$; isolectótipo: $F$; $B$, destruído); Martin 8, G. Francesa, Caiena, s/ data (parátipo: $\mathrm{P} ; \mathrm{B}$. destruído); Benoist 666, G. Francesa, Charvein, 27 Jan. 1914 (parátipo: P): Benoist 1010, G. Francesa, Saint-Jean-du-Maroni, 26 Mar. $1914 \mathrm{fl}$. (parátipo: P); Benoist 1125, G. Francesa, Saint-Jean-du-Maroni, 26 Abr. 1914 (parátipo: P); Sagot s.n., G. Francesa, Acarouany, 1858 ! (parátipo: P).

Virola melinonii (Ben.) A. C. Smith, Brittonia 2 (5): 502, fig. 9e, f. 1937; Van Ooststroom, in Pulle, Fl. Surin 2 (1): 474 1939; A. Ducke, Bol. Técn. Inst. Agron. Norte 4: 11. 1945; A. Ducke, Bol. Técn. Inst. Agron. Norte 19: 7. 1950; P. Bena, Essences forestiéres de Guyane 29, figs. 1.4. 1960; J. C. Lindeman \& A. M. W. Mennega, Meded. Bot. Mus. Herb. Rijkuniv. Utrecht 200: 244, pl. 69, fig. M 1-3. 1963; V. C. Araujo, Publ. INPA, sér. Pesq. Florest, 4: 13. 1970. syn. nov.

Virola gardneri sensu Heckel in Ann. Mus. Colon. Marseille 5 (2): 138, fig: (ramo florifero e fruto), 1907 et sensu J. Cordemoy in Ann. Mus. Colon. Marseille 5 (2): 150, fig. 2 (anatomia do ramo), 1907, non Warburg:

Virola venosa sensu Van Ooststroom in Pulle, Fl. Surin. 2: 121. 1934, non Warburg.

Arvore até cerca de $30 \mathrm{~m}$ de altura; tronco até cerca de $50 \mathrm{~cm}$ de diâmetro à altura do peito; raminhos estriados, quando novos pardo-puberulentos, passando a glabros e enegrescidos ou cinéreos com a idade. Pecíolo fortemente canaliculado, essencialmente glabro, $1-2 \mathrm{~mm}$ de diâmetro, $4-10 \mathrm{~mm}$ de comprimento. Lâmina foliar cartácea, estreitamente elíptica ou oblongo-ou obovado-elíptica, $90-180 \mathrm{~mm}$ de comprimento; $25-60 \mathrm{~mm}$ de largura, atenuada ou aguda na base, subaguda ou subotusamente cuspidada no ápice, puberulenta na página inferior (tricomas pardacentos, séssil-estrelados, 4-6 ramificados, cerca de $0,1 \mathrm{~mm}$ de diâmetro, esparsa e uniformemente distribuídos, persistentes); nervura mediana levemente imersa ou quase plana na página superior, saliente na inferior; 13-22 nervuras secundárias de cada lado, em geral levemente ascendentes, planas ou fortemente impressas na página superior, elevadas na inferior; vênulas normalmente obscuras, raras vezes planas ou promínulas. Inflorescência masculina 1-ou 2-ramosa, $20-90 \mathrm{~mm}$ de comprimento, uniformemente ferrugíneo- ou pardacento-puberulentas (tricomas séssil-estrelados, muito pequenos, logo decíduos nos raminhos, persistentes nas flores); pedúnculo até $25 \mathrm{~mm}$ de comprimento, levemente achatado; brácteas oblongas, puberulentas, $3-5 \mathrm{~mm}$ de comprimento, logo decíduas; 5-15 flores por fascículo; os pedúnculos mais novos ligeiramente tủrgidos distalmente; pedicelos tênues, até $3 \mathrm{~mm}$ de comprimento; perianto carnoso, 2,0-3,5mm de comprimento, 3-lobado quase até a base com os lóbulos oblongos e obtusos; androceu, $1,5-1,7 \mathrm{~mm}$ de comprimento; andróforo tênue, $0,8-1 \mathrm{~mm}$ de comprimento; 3 anteras, $0,5-0,7 \mathrm{~mm}$ de comprimento, soldadas até o ápice, obtusas. Inflorescência feminina mais compacta do que a masculina; fascículo com 2-4 flores; pedicelos grossos; estigma levemente oblíquo. Infrutescência de $40-60 \mathrm{~mm}$ de comprimento, uniforme e inteiramente pardopuberulenta (tricomas ramificados desde a base), os raminhos passando a glabrescentes com a idade; frutos persistentemente puberulentos, 1-4 maduros por infrutescência, pedicelados, (pedicelos grossos de $3-9 \mathrm{~mm}$ de comprimento), elipsóides, na maturidade com 25-40 $\mathrm{mm}$ de comprimento, $17-27 \mathrm{~mm}$ de largura, nitidamente carinados de um lado e muitas vezes lisos do outro, arredondados ou curtamente estipitados na base, obtusos ou levemente apiculados no ápice; pericarpo lenhoso de $3-4 \mathrm{~mm}$ de espessura; arilo vermelho laciniado quase até a base; semente elipsóide, lisa. Fig. 46.

TiPo: Hayes \& Michel s.n., Guiana Francesa, Saint-Laurent-du-Maroni, 1898, sementes (holótipo: MARS, n.v.).

Nomes vulgares : Ucuúba-da-Guiana (fide Pesce, I.c. 1941 sob o sinônimo de Virola micheli Heckel); ucuuba-preta (ex Aluísio 232, Oliveira 4103); ucuuba-branca (ex Rodrigues 2999); "ucuúba-da-mata" (ex Oliveira 3975); ucuúbada-terra-firme (ex Silva 1378); ucuubarana (ex Camargo IAN-9, Silva 18); ucuuba; cigari (Waica-Mucajaí, ex Prance et al. 11035) .

UTILIDADES: A madeira tem uso em construção de interiores, podendo ser utilizada também em compensado. Segundo Heckel (I.c. 1898) e Pesce (I.C. 1941), a semente produz 
óleo ou sebo similar ao da "ucuúba-de-várzea" (V. surinamensis).

Fenologia : Segundo Araújo (I.c. 1970), em Manaus, esta espécie, embora perenifolia, renova suas folhas entre abril e julho, floresce de juiho a setembro e frutifica entre novembro e janeiro. De acordo com a coleção de herbário disponível, sua floração ocorre entre abril e dezembro, sendo bem mais marcante entre maio e agosto, a frutificação se dá durante todo o ano, notadamente entre agosto e janeiro. Fig. 14.

Habitat : Planta relativamente freqüente na mata de terra firme. No Museu Emílio Goeldi, ẹm Belém, há um espécime de grande porte, em cultivo.

DistribuiçÃo: Amazonas, Maranhão, Pará e Território do Amapá e Roraima. Fora do Brasil, estende-se até a Guiana Francesa e Suriname. Fig. 47.

\section{MATERIAL ADICIONAL EXAMINADO :}

TERRITORIO DE RORAIMA: - Serra da Lua $\left(2^{\circ}\right.$ $\left.25-29^{\prime} \mathrm{N} ; 50^{\circ} 11-14^{\prime} \mathrm{W}\right)$ : G. T. Prance et al. 9384, Jan $1969 \mathrm{fr}$. (INPA, NY). - Rio Mucajai: G. T. Prance et al. 11035, Mar. $1971 \mathrm{fr}$. (NPA, NY).

TERRITORIO DO AMAPA: - Rio Oiapoque: R. L. Froes 26659, Out. 1950 fl. (IAN). - Clevelândia: J. M. Pires 7737, Ago. 1960 est. (IAN): id 7738, Ago. 1960 est. (IAN). - Rio Araquari: J. M. Pires, Rodrigues \& Irwine 50526, Ago. $1961 \mathrm{fl}$. (IAN, MG, NY): id. 50556, Ago. 1961 fl. (IAN, MG, NY, RB); id. 50769, Set. $1961 \mathrm{fl}$. (IAN, MG, NY): id. 50958, Set. $196 i \mathrm{fr}$. (IAN. MG, NY). - Serra do Navio: W. Rodrigues 2999, Jun. 1961 est. (INPA); id. 3000, Jun. 1961 est. (INPA). - Amapá: G. A. Black \& Lobato 50-9603. Abr. 1950 est. (IAN); R. L. Froes \& Black 27696. Jul. 1951 fl. (IAN).

AMAZONAS: - Reserva Florestal Ducke, perto de Manaus: J. Aluísio 232, Out. $1968 \mathrm{fr}$. (INPA): id. 233, Out. $1968 \mathrm{fr}$. (INPA); id. s.n., Jul. 1968 fl. (INPA 21288): W. Rodrigues 5326, Jul. 1963 fl. (INPA): W. Rodrigues \& Coelho 5610, Dez. 1963 fl. (INPA); W. Rodrigues \& Osmarino 6968, Jul. 1965 fl. (INPA); W. Rodrigues \& Loureiro 7152, Set. 1965 fr. (INPA); W. Rodrigues \& Coelho 7839, Maio 1966 est. (INPA); W. Rodrigues \& Osmarino 8171. Jul. 1966 est. (INPA); id. 8207. Jul. 1966 fl. (INPA); id. 8210, Ago. 1966 fl. (INPA): id. 8216, Ago. 1966 fl. (INPA); W. Rodrigues 9597. Abr. $1975 \mathrm{fr}$. (INPA); R. E. Schultes \& Rodrigues 26153 A (ECON, INPA); J. A. Souza s.n.. Abr. 1952 fr. (INPA 49.028).

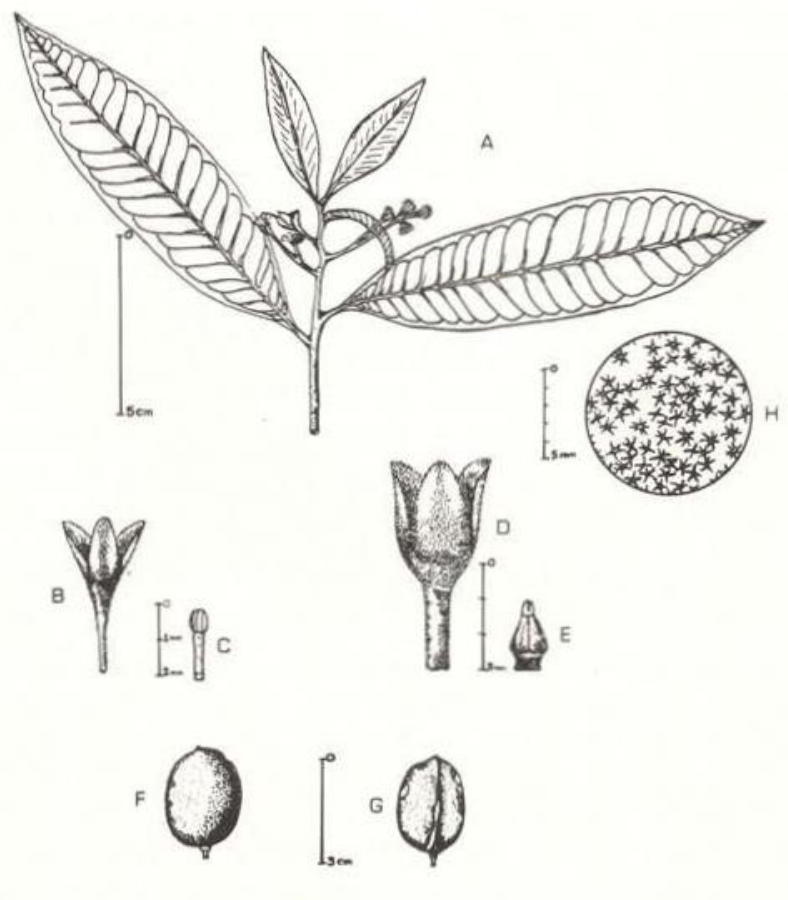

Fig. 46 - Virola michelii. A-C e $\mathrm{H}$ (A. Ducke s.n., BR 19569): A, hábito do ramo florifero masculino; B, flor masculina; C, androceu; D, flor feminina; E, gineceu; F-G (R. L. Froes 34693): F, fruto visto de frente; G, fruto visto de lado: $H$, face inferior da folha, ampliada.

PARA: - Rio Paru do Oeste, entre os igarapés Cuminá-Mirim e Ariranha: A. Ducke s.n., Dez. 1910 fr. (MG 11265). - Regiāo de Santarém: P. Cavalcante \& Silva 1593, Dez. 1966 fr. (IAN, MG); R. L. Froes 30813. Jun. $1954 \mathrm{fl}$. (IAN); id. 31003. Ago. $1954 \mathrm{fr}$. (INPA, NY): id. Ago, 1954 fl. (IAN, INPA): id. 31052, Ago. $1954 \mathrm{fr}$. (IAN); id. 31254 , Out. $1954 \mathrm{fr}$. (IAN): M. Silva \& Souza 2411, Ago. $1969 \mathrm{fl}$. (INPA): id 2433, Ago. 1969 fr. (INPA). - Bacia do rio Tapajós, Fordlândia: Capucho 594, Maio $1933 \mathrm{fl}$. (IAN): - Estrada Santarêm-Belterra: Km 72: Argemiro 072-34-01. Ago. $1974 \mathrm{fr}$. INPA 49569): $\mathrm{Km}$ 79: Raimundo 079-34-02, Ago. 1974 est. (INPA 49570). - Regiāo do rio Jari, serra do Monte Dourado: E. Oliveira 3551. Nov. $1967 \mathrm{fr}$. (IAN): id. 3683, Nov. $1967 \mathrm{fr}$. (IAN, NY): id. 3975, Jan. 1968 fr. (IAN, NY); id. 4018, Jan. $1968 \mathrm{fr}$. (IAN, NY); id. 4103, Fev. $1968 \mathrm{fr}$. (IAN, NY); id. 4825, Set. $1968 \mathrm{fl}$. (IAN, NY); N. T. Silva 1221, Out. $1968 \mathrm{fr}$. (IAN, INPA, NY); estrada entre Piläo e Repartimento: id. 1378 , Nov. 1968 fr. (IAN, INPA). - Regiăo do Xingu: Porto de Moz: R. L. Froes 32215, Out. $1955 \mathrm{fr}$. (IAN); id. 32268, Nov. $1955 \mathrm{fr}$. (IAN): id. 32494, Nov. 1955 fr. (IAN); id. 32511. Dez. $1955 \mathrm{fr}$. (IAN). - Belém: F. C. Camargo s.n., Jun. $1944 \mathrm{fl}$. (IAN 9, NY); P. Cavalcante 363. Maio $1958 \mathrm{fl}$. (MG): A Ducke 1233. Jun. $1943 \mathrm{fl}$. (NY); id. 1268, Jun. $1943 \mathrm{fl}$. (IAN, MG); id. 1268. Maio $1943 \mathrm{fl}$. (MG, NY); id. 1650, Out. 1944 fr. (IAN, MG, NY); id. s.n., Jul 1914 fl. (MG 15349, 
INPA); E. Oliveira 2584, Set. $1963 \mathrm{fr}$. (IAN); J. M. Pires \& Black 668, Nov. $1945 \mathrm{fr}$. (IAN); J. M. Pires 6816, Jun. $1968 \mathrm{fl}$. (IAN); id. 7028, Jul. $1959 \mathrm{fr}$. (IAN); id. 7093, Ago. $1958 \mathrm{fr}$. (IAN); J. M. Pires \& Silva 11.229, Set. $1967 \mathrm{fr}$. (IAN); id. 11283, Jun. $1967 \mathrm{fl}$. (IAN); id. 11880, Jul. 1968 fl. (IAN); G. T. Prance \& Pennington 1259 (L.S. 158), Ago. 1965 fr. (NY); A. Silva 18, Jan. $1944 \mathrm{fr}$. (IAN, NY); id. 314, Jul. $1944 \mathrm{fl}$. (IAN, NY); id. 320, Nov. 1944 fr. (IAN); N. T. Silva 13, Jul. $1947 \mathrm{fr}$. (IAN, INPA); id. 14, Jul. $1947 \mathrm{fl}$ (IAN, INPA). - Região do rio Tocantins: Remansão: R. L. Froes 23594, Out. $1948 \mathrm{fr}$. (IAN). Rio Itacaiúnas, serra Buritirana $\left(50^{\circ} 15^{\prime} \mathrm{W}-5^{\circ} 30^{\prime} \mathrm{S}\right)$ : J. M. Pires \& Belém 12221, Jun. $1970 \mathrm{fr}$. (IAN); id. 12260, Jun. $1970 \mathrm{fl}$. (IAN); id. 13058, Set. 1970 est. (IAN). Rodovia Belém-Brasília: Km 100: N. T. Silva 601, Jul. $1960 \mathrm{fr}$. (IAN); - Km 203: E. Oliveira 846, Maio 1960 fl. (IAN); Km 338: id. 1030, Ago. 1960 fr. (IAN); entre Paragominas e Gurupi (Km 161-250): G. T. Pran. ce \& Silva 58937, Ago. $1964 \mathrm{fr}$. (NY). - Bragança: A. Ducke s.n., Ago. 1926 fl. (RB 19569). - Peixe-Boi: A. Goeldi s.n., Set. 1907 fl. (MG 8314). - Região de São José do Piriá, igarapé Piritoró: R. L. Froes 34693. Set. $1958 \mathrm{fr}$. (IAN). - Sem localidade definida: J. M. Pires 7272 , s/data est. (IAN); id. 7273 , s/data est. (IAN).

MARANHÃO: - Rio Maracaçumé: R. L. Froes 34450, Jul. 1958 fl. (IAN).
Heckel em 1898 descreve e ilustra uma nova espécie a que denominou $V$. micheli (sic), baseando-se para tanto em sementes que recebeu da Guiana Francesa para estudo químico. Muito embora a descrição esteja em francês, isto não invalida o seu novo taxon de acordo com o Art. 36 do Código Internacional de Nomenclatura 1972, que considera válido o taxon descrito e publicado antes de $1^{\circ}$ de janeiro de 1935, mesmo que a descrição ou diagnose original não esteja transcrita em latim. Segundo Heckel, o tipo de sua espécie estava exposto na vitrine 170, 174 do Museu Colonial de Marselha. Caso estas não existam mais, de acordo com Art. 9 do referido Código, têm-se que considerar as ilustrações de Heckel como tipo.

Comparando as descrições apresentadas, mais as ilustrações das sementes de V. michelii com as de V. melinonii, verificou-se que ambas coincidem em forma e tamanho, cabendo neste caso, por questão de prioridade, aceitar a primeira como válida, reduzindo, por conseqüência, a segunda a sinônimo.

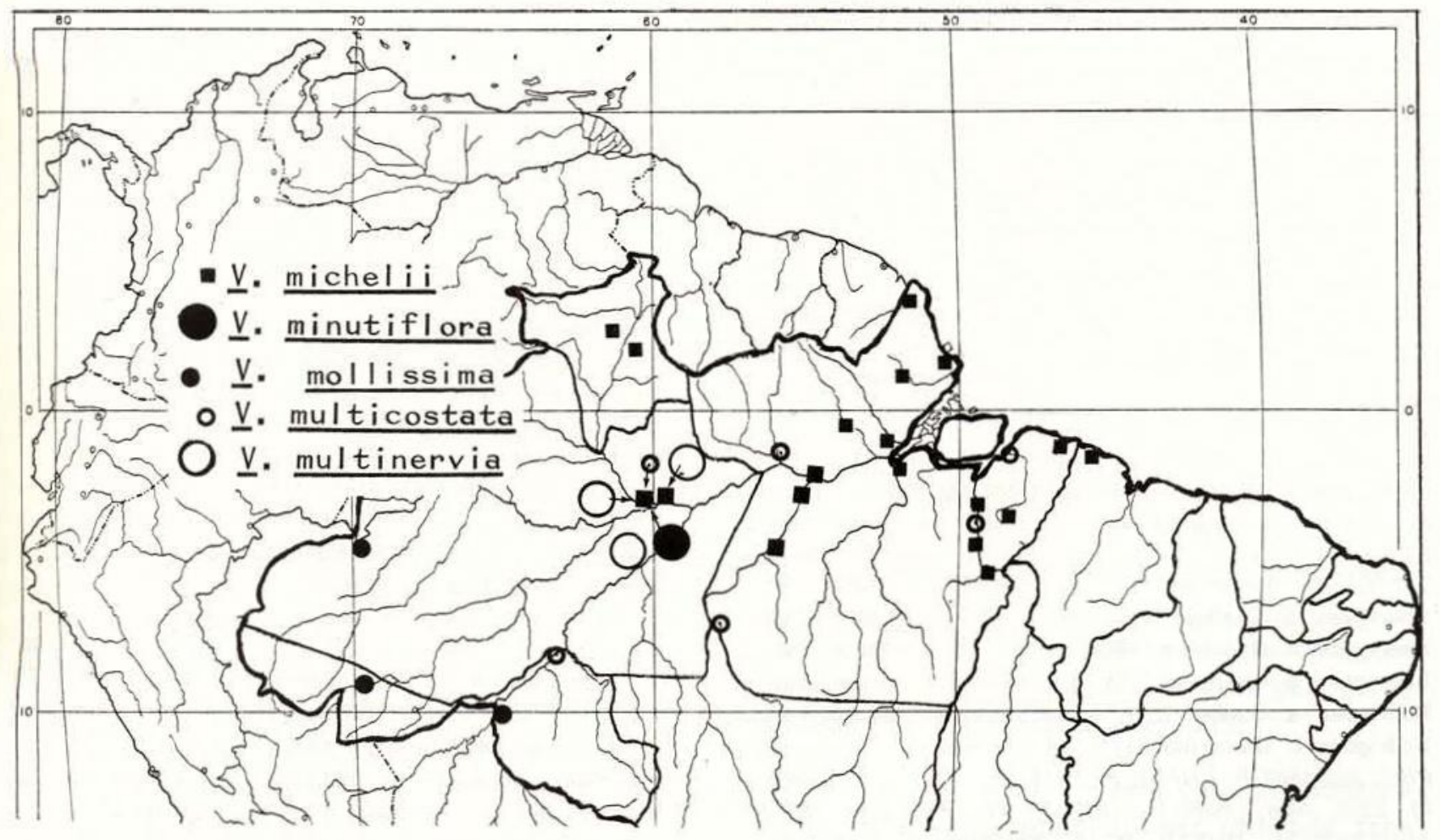

Fig. 47 - Distribuiçăo atual de Virola spp. no Brasil. 
Fato interessante a observar foi que Heckel em seu trabalho afirmava que completaria pos. teriormente a descrição de sua nova espécie tão logo dispusesse de material bơtânico mais completo, o que realmente não chegou a ocorrer, conforme uma publicação sua posterior (I.c. 1907), em que ilustra a mesma espécie sob a identificação errada de $V$. gardneri, sem fazer referência alguma à sua nova espécie. Smith (I.c. 1937), também, ao fazer a nova combinação de $V$. melinonii, evidentemente desconhecia o trabalho de Heckel, haja vista não o haver citado siquer em sua revisão.

Esta espécie tem sido muito confundida com V. venosa Warb., Distingue-se desta principalmente pela ausência em geral de um reticulado distinto em ambas as faces da folha, lâmina foliar comumente atenuada em direção à base do pecíolo, nervuras secundárias menos numerosas e mais afastadas entre si, indumento persistente e mais ou menos uniformemente distribuído na face inferior da folha, além dos outros caracteres já referidos por Smith (I.c. 1937) .

Segundo Ducke (I.c. 1945), sua área geográfica de ocorrência conhecida abrangia antes apenas a faixa litorânea da Hiléia das Guianas até o Pará. Com o presente registro para os Estados do Maranhão e Amazonas, Território do Amapá e Roraima, sua área de dispersão na Amazonia fica deste modo bastante ampliada.

18. Virola minutiflora Ducke, Journ. Wash. Acad. Sci. 26 (6):259. 1936; A.C. Smith \& Wodehouse, Brittonia 2 (5):484, 1937; A. Ducke, Arq. Serv. Florest., 1 (1):27. 1939; J.C. Th. Uphof in Engl. \& Prantl., Nat. Pflanzenfam., $2^{\text {a }}$ ed., $17^{\mathrm{a}}(2): 207$. 1959; descr. ampla..

Arvore mediana; raminho rugoso-estriado, os mais novos tenuemente rufopuberulento, passando a glabrescente com a idade. Pecíolo levemente canaliculado, tênue, $1,0-1,5 \mathrm{~mm}$ de diâmetro, 6-18mm de comprimento, rugoso, logo glabro. Lâmina foliar tenuemente coriácea, oblonga ou elíptico-oblonga, $50-210 \mathrm{~mm}$ de comprimento, $15-80 \mathrm{~mm}$ de largura, arredondada ou subcordada na base, aguda no ápice, in- distintamente pálido-puberulenta na página inferior (tricomas séssil-estrelados, 4-6-ramificados, cerca de $0,1 \mathrm{~mm}$ de diâmetro); nervura mediana quase plana na parte superior, saliente na inferior; 25-38 nervuras secundárias de cada lado, ligeiramente impressas na página superior, paralelas, retas, ascendentes, anastomosadas junto às margens, elevadas na inferior, evanescentes perto das margens; vênulas obscuras. Inflorescência masculina paniculada, densiflora, 30-60 mm de comprimento, paucirramosa; pedúnculo curto, com os raminhos densamente tomentelos (tricomas pouco ramificados, cerca de $0,2 \mathrm{~mm}$ de comprimento); brácteas submembranáceas, deltóide-ovadas, agudas, puberulentas, 4-6mm de comprimento, logo glabras; fascículos florais compactos de $4-7 \mathrm{~mm}$ de diâmetro, 50-100 flores verde-pardacentas ou ferrugíneas por fascículo; pedicelos finos até $1 \mathrm{~mm}$ de comprimento; perianto membranáceo, infundibuliforme, levemente puberulento externamente, $1,5-1,8 \mathrm{~mm}$ de comprimento, trilobado quase até a base, lóbulos oblongos, obtusos; androceu de 0,8-0,9mm de comprimento; and́óforo delgado; 3 anteras, ligeiramente mais curtas que o andróforo, soldadas até o ápice, obtusas. Inflorescência feminina não vista. Frutos maduros, $17-20 \mathrm{~mm}$ de comprimento, $10-16 \mathrm{~mm}$ de largura, pedicelados (pedicelos grossos, $3-4 \mathrm{~mm}$ de comprimento, $3 \mathrm{~mm}$ de diâmetro), elipsóides ou elipsóide - ovoides, arredondados e levemente apiculados no ápice, arredondados a truncados na base, levemente carinados, tenramente ferrugíneo-estrelado-tomentelos, glabrescentes; pericarpo duro. cerca de $2-3 \mathrm{~mm}$ de espessura, levemente rugoso externamente. Sementes não vistas. Fig. 3-48.

Tipos: A. Ducke s.n., Brasil, Amazonas, Manaus, Cachoeira Grande, mata de terra firme, 8 Ago. 1929 fl. (lectótipo: RB 24559; isolectótipo: K): A. Ducke s.n., Brasil, Amazonas, Manaus, picada da Villa Belisário (atual rua Maj. Gabriel), mata de terra firme, alta, 31 Aga. $1931 \mathrm{fl}$. (síntipo: RB 24560, K, US) .

Nome vulgar: Ucuúba (ex Ducke RB 30138).

Fenologia : Coletada em flor em julho e agosto, com frutos em dezembro e abril. 
Habitat : Mata de terra firme em terreno de baixa altitude.

DistribUição: Até hoje só conhecida das redondezas de Manaus, no Estado do Amazonas. Fig. 47.

\section{MATERIAL ADICIONAL EXAMINADO :}

AMAZONAS: - Manaus: A. Ducke s.n., Jul. 1936 fl. (RB 30138; INPA, US); A. Loureiro et al. s.n., Abr. $1973 \mathrm{fr}$. velho (INPA 37702); W. Rodrigues 9265, Dez. $1973 \mathrm{fr}$. velho (INPA); R. E. Schultes \& Rodrigues 26105 A, Abr. 1972 est. (ECON, INPA).

A descrição do fruto foi baseada nas coleçōes de Rodrigues 9265 e Loureiro et al. INPA 37702. Distingue-se das outras espécies afins de nervação numerosa pela inflorescência menor, escassez relativa de tomento nos raminhos mais desenvolvidos como nas folhas e pela dimensão diminuta das flores, estas sŏ comparáveis com as de V. micrantha A. C. Smith, espécie próxima, só conhecida da Colômbia.

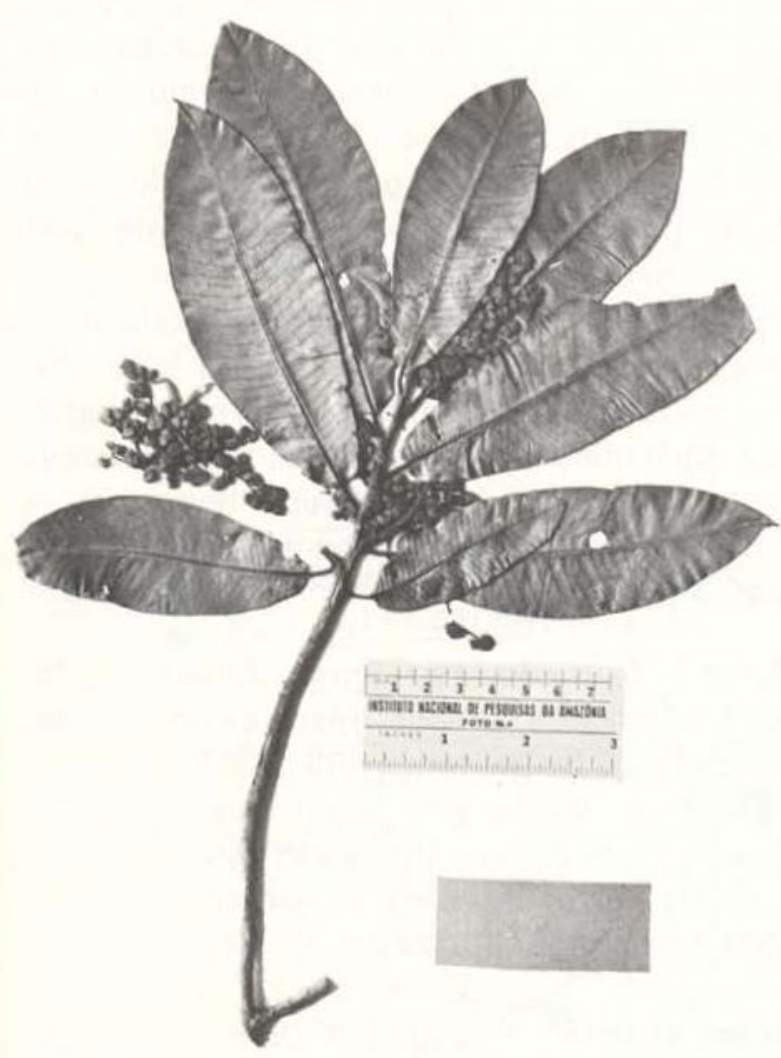

Fig. 48 - Virola minutiflora. A. Ducke s.n. (RB 24559, lectótipo).
19. Virola mollissima (Poepp. ex A.DC.) Warburg, Nova Acta Acad. Leop.-Carol. 68:167. 1897; A.C. Smith, Bull. Torrey Bot. Club. 58(2):95. 1931; A. Ducke, Journ. Wash. Acad. Sci, 26(6):254 . 1936; L. Williams, Field Mus. Nat. Hist. Bot. 15:137. 1936; A.C. Smith \& Wodehouse, Brittonia 2(5):460. 1937; J.C. Th. Uphof in Engl. \& Prantl, Nat. Pflanzenfam., 2." ed., 17a(2):206. 1959.

Myristica mollíssima Poeppig ex A. De Candolle in DC., Prodr. 14: 696. 1856; A. DC. in Mart., Fl. Bras. 5 (1): 113. 1860.

Palala mollissima (Poepp.) O. Kuntze, Rev. Gen. PI. 2: 567. 1891, nom. illegit.

Arvore até $20 \mathrm{~m}$ de altura; tronco até $35 \mathrm{~cm}$ de diâmetro; raminhos grossos, persistentemente tomentosos (tricomas ferrugíneos de 1-2mm de comprimento, multicelulares, articulados, apêndices laterais visivelmente calcariformes). Pecíolo grosso, cilíndrico de $3.8 \mathrm{~mm}$ de diâmetro, $8-21 \mathrm{~mm}$ de comprimento, tomentoso como os raminhos. Lâmina foliar tenuemente coriácea, oblonga ou obovado-obionga, $250-380 \mathrm{~mm}$ de comprimento, $80-190 \mathrm{~mm}$ de largura, fortemente cordada a arredondada na base, longamente acuminada ou bruscamente acuminada no ápice, página superior glabra ou deciduamente tomentosa na nervura mediana, página inferior densamente rufotomentosa (tricomas dendríticos, articulados de $1-1,5 \mathrm{~mm}$ de comprimento, com numerosos apêndices laterais, os das nervuras principais geralmente um tanto maiores); nervura mediana saliente em ambas as faces, muito distinta na página inferior; 15-30 nervuras secundárias de cada lado, quase retas, ligeiramente impressas ou promínulas na página superior, salientes na inferior, as próximas da base muitas vezes arqueadas; vênulas reticuladas, promínulas ou obscuras. Inflorescência masculina paniculada, livremente ramificada, densiflora, até $250 \mathrm{~mm}$ de comprimento e $180 \mathrm{~mm}$ de largura; pedúnculo de $30-80 \mathrm{~mm}$ de comprimento, com os raminhos densamente tomentosos com tricomas semeIhantes aos dos raminhos vegetativos; brácteas ovoides de aproximadamente $6 \mathrm{~mm}$ de comprimento, densamente tomentelas, logo decíduas; flores isoladas ou em fascículos laxi- 
floros, de 2-5 flores; pedicelos até $3 \mathrm{~mm}$ de comprimento, tomentelos; perianto tenuemente carnoso, infundibuliforme de $1,7-2,2 \mathrm{~mm}$ de comprimento, densamente tomentelo externamente, trífido cerca de $1 / 3$ do comprimento total, lóbulos obtusos; androceu de $1,1-1,4 \mathrm{~mm}$ de comprimento; andróforo de $0,2-0,5 \mathrm{~mm}$ de comprimento; 3 anteras soldadas até o ápice, cerca de $0,7-0,9 \mathrm{~mm}$ de comprimento, apiculadas no ápice, o apículo com cerca de $1 \mathrm{~mm}$ de comprimento, único ou fendido. Inflorescência feminina não vista. Infrutescência de aproximadamente $40-80 \mathrm{~mm}$ de comprimento e $5-10$ frutos por infrutescência, curto-pedicelados, subglobosos de $11-14 \mathrm{~mm}$ de diâmetro ou elipsoides de $30-35 \mathrm{~mm}$ de comprimento e $20-25 \mathrm{~mm}$ de largura, denso e persistentemente tomentosos (tricomas de $2-4 \mathrm{~mm}$ de comprimento, e ramo principal flexuoso, articulado com numerosos apêndices laterais curtos); pericarpo até cerca de 2,0mm de espessura. Fig. 49.

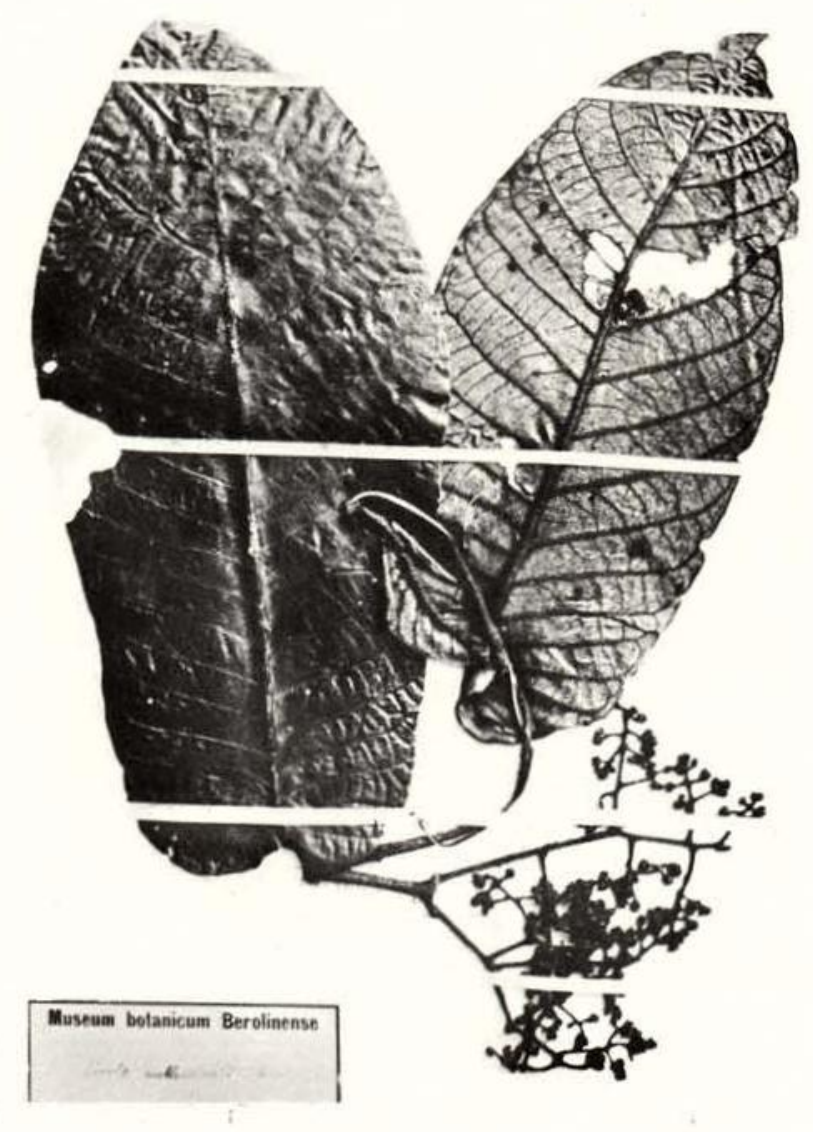

Fig. 49 - Virola mollissima. Poeppig 2195 (reprodução da foto F 1964, NY).
TrPo: Poeppig 2195, Peru, Loreto, perto de Yurimaguas, baixo rio Huallaga, $1839 \mathrm{fl}$. (holótipo presumivelmente $\mathrm{W}$, destruído; isótipo: $\mathrm{B}$ destruído; fotótipo: F 1964, GH, IAN, NY, US); Tessman 3473, Peru, Middle Ucayali, Yarina cocha, s/data fl. (neótipo: NY).

Fenologia: Frutificação entre setembro e novembro.

HaBitat: Mata de terra firme, às vezes em lugares baixos e úmidos.

Distribuição: Ocorre no Acre, Amazonas e Território de Rondônia e fora do Brasil, no Peru oriental, adjacente ao território brasileiro. Fig. 47.

\section{MATERIAL ADICIONAL EXAMINADO:}

AMAZONAS: - Esperança, perto da boca do rio Javari: A. Ducke 1775, Out. $1945 \mathrm{fr}$. (GH, IAN, MG, NY, R, RB, US).

ACRE: - Sena Madureira, estrada Sena Madureira-Rio Branco, Km 7: G. T. Prance et al. 7665, Set. $1968 \mathrm{fr}$. (INPA, NY, U).

TERRITORIO DE RONDONIA: - Bacia do rlo Madeira, vizinhanças das minas de São Lourenço, $65^{\circ} 6^{\prime} \mathrm{W}$, 9'33'S: G. T. Prance, W. A. Rodrigues, Ramos \& Farias 8950, Nov. 1968, fr. (GH, INPA, NY, R, US).

Um neótipo é escolhido devido a coleção típica, guardada nos herbários de Berlim, Viena e possivelmente Leipzig, ter sido destruída durante a segunda Guerra Mundial.

A primeira vista, esta espécie é muito semelhante em tudo à $V$. divergens Ducke, da qual logo se separa pela ausência do odor penetrante e característico desse último taxon e pela antera não divergente no ápice. De V. Ioretensis Smith também se distingue pela antera 2-3 vezes maior do que o andróforo, pela infrutescência muito mais curta e com pedúnculo muito mais forte, e pelos frutos com pilosidade bem mais curta e em geral não eriçada.

20. Virola multicostata Ducke, Journ. Wash. Acad. Sci. 26(6):261. 1930; (exceto a descrição do fruto, espécime Krukoff 6817: V. multinervia); A.C. Smith \& Wodehouse, Brittonia 2(5):479. 1937; A. Ducke, Arq. Serv. Florest. 1(1):27. 1939, pro parte (excl. specim. Krukoff 
6817); A.C. Smith, Brittonia 3(2):340. 1939, pro parte (excl. specim. Krukoff 6817); A. Ducke, Bol. Técn. Inst. Agron. Norte 19:6. 1950; J.C. Th. Uphof in Engl. \& Prantl, Nat. Pflanzenfam., $2^{\text {a }}$ ed., 17a(2):207. 1959; V.C. Araujo, Publ. INPA, Pesq. Florest. 4:15. 1970.

Arvore até $50 \mathrm{~m}$ de altura; tronco até cerca de $70 \mathrm{~cm}$ de diâmetro; raminho canotomentelo (tricomas pouco ramificados, de aproximadamente $1 \mathrm{~mm}$ de comprimento), logo glabro. Peciolo fortemente canaliculado, $2-4 \mathrm{~mm}$ de diâmetro, $10-12 \mathrm{~mm}$ de comprimento, glabro. Lâmina foliar elíptica ou oblongo-elíptica, $200-280 \mathrm{~mm}$ de comprimento, $40-100 \mathrm{~mm}$ de largura, arredor!. dada a subcordada na base, subaguda ou obtusamente cuspidada no ápice, glabra em ambas as faces; nervura mediana plana ou levemente imersa na página superior, promínula na inferior; 50-60 nervuras secundárias de cada lado. 16-27 nervuras por $10 \mathrm{~cm}$ de comprimento (mé. dia 22) retas, paralelas, ligeiramente impressas na face superior, ou promínulas em ambas as faces, elevadas na inferior; vênulas reticuladas, obscuras ou promínulas em ambas as páginas. Inflorescência masculina paniculada, densiflora, aproximadamente $150 \mathrm{~mm}$ de comprimento, ramos densamente tomentelos; fascículos florais compactos de $3-5 \mathrm{~mm}$ de diâmetro; pedicelos tênues, até $1 \mathrm{~mm}$ de comprimento; perianto de aproximadamente $1 \mathrm{~mm}$ de comprimento, densamente canotomentelo externamente, 3-lobado além da metade de seu comprimento total; andróforo nue; 3 anteras, subiguais ao andróforo, soldadas, levemente apiculadas no ápice. Inflorescência feminina de $45-85 \mathrm{~mm}$ de comprimento, pouco ramificada, canotomentela como a inflorescência masculina; pedúnculo achatado de $12-17 \mathrm{~mm}$ de comprimento; flores simples ou em pequenos fascículos, 2,0-2,5mm de comprimento; ovário ovóide ou cônico, subagudo no ápice, densa e diminutamente ferrugíneo-tomentelo; estigma subséssil, enegrecido, obliquo, grande. Infrutescência de $100 \mathrm{~mm}$ de comprimento; pedúnculo de $10-15 \mathrm{~mm}$ de comprimento, nitidamente achatado e robusto com os raminhos glabrescentes; 4-10 frutos maduros por infrutescência, pedicelados (pedicelos de $2-5 \mathrm{~mm}$ de com- primento), elipsóides ou ovóides, lisos ou carinados, de $20-35 \mathrm{~mm}$ de comprimento, $18-25 \mathrm{~mm}$ de largura, apiculados no ápice, curtamente estipitados (estipe cerca de $2 \mathrm{~mm}$ de altura). glabros; pericarpo rígido de $2-5 \mathrm{~mm}$ de espessura; semente com arilo róseo pálido, laciniado até quase a base. Fig. 50-51.

Tipo: A. Ducke s.n., Brasil, Pará, Rio Branco de Óbidos, Castanhal Grande, 27 Dez. 1913 fl. (holótipo: RB 24972 ex MG 15257; isótipo: MG 15257).

Nomes vUlgares: "Ucuuba-de-terra-firme" (ex Rodrigues \& Osmarino 8465).

Utilidades: Segundo Pires 4036, o tronco, quando cortado, exsuda gotinhas avermelhadas. A casca produz seiva aquosa abundante com cheiro balsâmico.

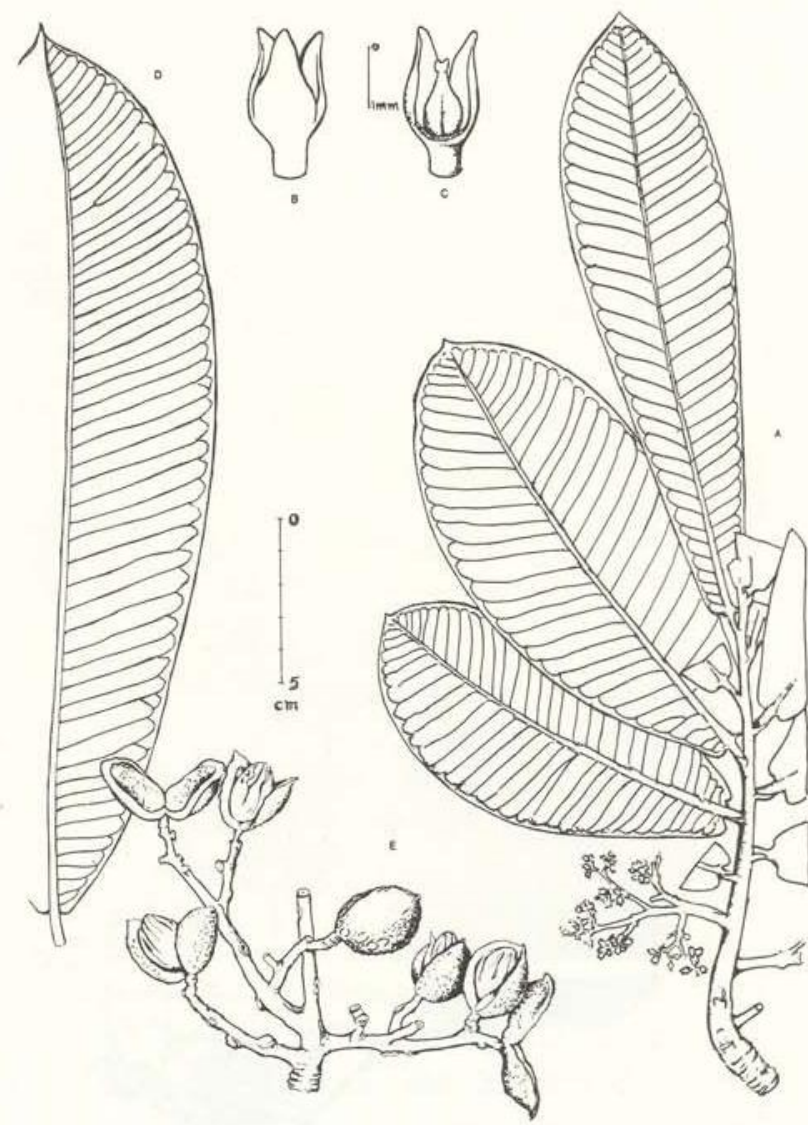

Fig. 50 - Virola multicostata. A-C (W. Rodrigues \& Osmarino 6986): A, hábito do ramo florífero feminino; B,

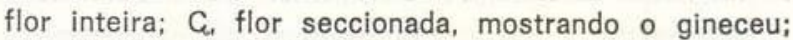
D-E (W. Rodrigues \& Osmarino 8465): D, folha; E, infrutescência. 


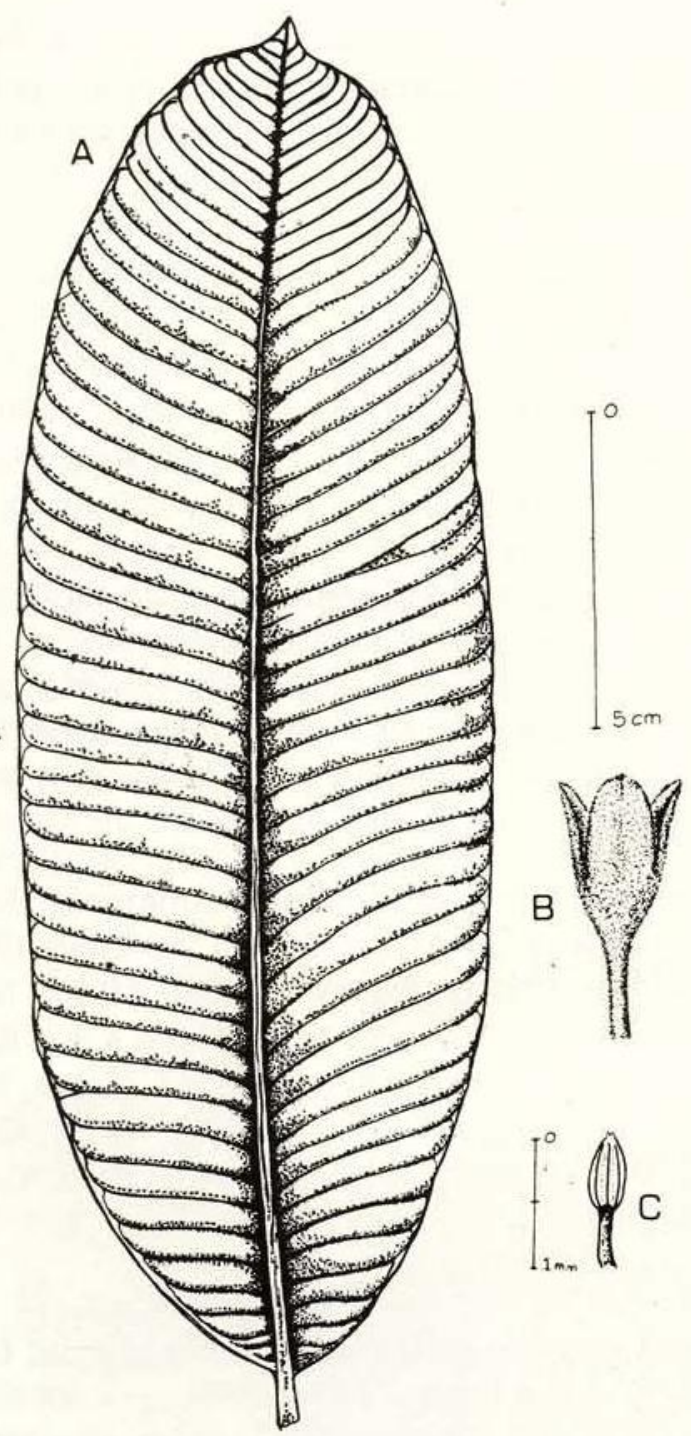

Fig. 51 - Virola multicostata. (A. Ducke s.n., RB 24972): A, folha, B, flor masculina; C, androceu.

Fenologia: Segundo observações de Ducke (I.c. 1936 e 1950), a espécie, geralmente, renova totalmente suas folhas durante a floração, isto é, entre julho e dezembro. A frutificação dá-se entre outubro e julho. Em Manaus, segundo observações de Araujo (I.c. 1970), ela é semicaducifolia em julho ou agosto, antecedendo a floração, que se dá entre agosto e novembro e a frutificação, em fevereiro e março.

HABITAT: Mata amazônica típica de terra firme.

DISTRIBUIÇÃo: Só conhecida até agora apenas da Amazônia brasileira. Fig. 47.

\section{MATERIAL ADICIONAL EXAMINADO:}

AMAZONAS: - Manaus: W. Rodrigues \& Osmarino 6986, Jul. 1965 fl. (INPA); W. Rodrigues \& CoêIho 7871. Maio 1966 est. (INPA); W. Rodrigues \& Osmarino 8465, Mar. $1968 \mathrm{fr}$. (INPA); J. Aluísio 278, Maio $1969 \mathrm{fr}$. (INPA); estrada Manaus-Porto Velho Km 175: G. T. Prance et al 22798, Out. $1974 \mathrm{fr}$. (INPA, NY); Município de Borba, rio Madeira: L. Coêlho s.n., Ago. 1973 est. (INPA 39601).

TERRITORIO DE RONDONIA: - Calama, no rio Madeira: Krukoff 1310, Nov. 1931 fr. (NY).

PARA: - Alto Tapajós, Vila Nova, perto de Cachoeira do Chacorão: J. M. Pires 4036, Jan. 1952 fr. (IAN). Breu Branco, rio Tocantins: R. L. Froes 23563, Set. 1948 fl. (IAN).

Afim de $V$. multinervia Ducke pelo grande número de nervuras secundárias, diverge pelas folhas menores e glabras nas duas faces, vênulas reticuladas e escassamente distintas, e pelos frutos inteiramente glabros, quando maduros. Os espécimes dos arredores de Manaus divergem do tipo pela folha geralmente lustrosa na face superior e, muito especialmente, pelo fino reticulado distinto em ambas as páginas.

21. Virola multinervia Ducke, Journ. Wash. Acad. Sci. 26(6):261. 1936; A.C. Smith \& Wodehouse, Brittonia 2(5):477. 1937; pro parte (excl. specim. Krukoff 8891); A. Ducke, Arq. Serv. Florest. 1(1):27. 1939; A. Ducke, Arq. Serv. Florest. 1(1):27. 1939; pro parte (excl. specim. Krukoff 1310); A.C. Smith, Brittonia 3(2):340. 1939; pro parte (excl. specim. Krukoff 1310); J.C. Uphof in Engl. \& Prantl, Nat. Pflanzenfam., 2." ed., 17a(2):207. 1959; S. Agurell et al., Acta Chem. Scand. 23:903. 1969; R. E. Schultes \& B. Holmstedt, Lloydia 34(1):72. 1971; M. Honda, Acta Amazonica 1(2):81. fig. 5-7. 1971; R. Braz Filho et al., Phytochem. 12:417. 1973; O.R. Gottlieb et al., Phytochem. 12:1830. 1973; O.R. Gottlieb, J.G.S. Maia \& S.L. Pinho, Ciência e Cultura 27(7). 1972. 1975; A.B. de Oliveira et al., Ciência e Cultura 25(6):173. 1973. 
Arvore até cerca de $35 \mathrm{~m}$ de altura; tronco até cerca de $45 \mathrm{~cm}$ de diâmetro; raminho robusto, com casca rugosa e enegrecida, glabro (os mais novos geralmente angulosos) densamente ferrugíneo-tomentoso (tricomas irregularmente ramificados desde a base ou com apêndices laterais curtos, até $1 \mathrm{~mm}$ de comprimento). Pecíolo grosso de $4-5 \mathrm{~mm}$ de diâmetro e $4-15 \mathrm{~mm}$ de comprimento, canaliculado, tomentoso como os raminhos novos, continuando na nervura mediana. Lâmina foliar coriácea, lanceolada, obovado ou ovado-elíptica, $250-450 \mathrm{~mm}$ de comprimento e $80-160 \mathrm{~mm}$ de largura, arredondada a subcordada na base, aguda ou cuspidada no ápice, muitas vezes I:geiramente ondulada nas margens, glabra ou tomentela na página superior sobre a nervura mediana, no lado inferior tomentoso (tricomas dendríticos, irregularmente ramificados, $0,3-0,5 \mathrm{~mm}$ de comprimento); nervura mediana na página superior plana ou ligeiramente imersa, muito saliente na página inferior; $40-60$ nervuras secundárias de cada lado, retas, paralelas, nitidamente anastomosadas perto das margens, planas ou levemente impressas na página superior, salientes na inferior; vênulas fina e nitidamente reticuladas e promínulas em ambas as faces. Inflorescência masculina amplamente paniculada, densiflora, $150-200 \mathrm{~mm}$ de comprimento e quase o mesmo tanto de largura; pedúnculo de $30-50 \mathrm{~mm}$ de comprimento, com raminhos densamente tomentosos (tricomas de $0,3-0,5 \mathrm{~mm}$ de comprimento); brácteas tomentelas até $5 \mathrm{~mm}$ de comprimento, logo decíduas; flores alvas quando frescas, depois de secas pardo-escuras, em fascículos densos de 3-5mm de diâmetro; 20-25 flores por fascículo; pedicelos finos de $1-2 \mathrm{~mm}$ de comprimento, esparsamente estrigosos; perianto de 1,2-1,5mm de comprimento, submembranáceo, longamente infundibuliforme, estrigoso, distalmente, às vezes glabro, trífico quase até a base, lóbulos oblongos e obtusos com nervura mediana nítida; androceu de aproximadamente $0,9 \mathrm{~mm}$ de comprimento; andróforo fino; 3 anteras ligeiramente mais curtas que o andróforo, soldadas até o ápice, obtusas. Inflorescência feminina robusta, quase tão ampla quanto a inflorescência masculina, toda densamente tomentosa (incluindo as flores); $3-8$ flores por fascículo geralmente denso; pedicelos até $2 \mathrm{~mm}$ de comprimento; ovário subgloboso, densamente tomentelo (tricomas geralmente bifurcados de aproximadamente $0,3 \mathrm{~mm}$ de comprimento), estilete em redor de $0,5 \mathrm{~mm}$ de comprimento; estígma fendido. Infrutescência até $150 \mathrm{~mm}$ de comprimento; 3-15 frutos por infrutescência, verde-escuros, pedicelados (pedicelos grossos até $4 \mathrm{~mm}$ de comprimento), elipsóides ou obovóides, $20-30 \mathrm{~mm}$ de comprimento, 15-25mm de largura, arredondados e levemente apiculados no ápice, obtusos na base, densa e persistentemente rufo-setulosos (tricomas retos de $1-2 \mathrm{~mm}$ de comprimento, articulados, com alguns apêndices laterais curtos); pericarpo de $1,5-4 \mathrm{~mm}$ de espessura; arilo laciniado quase até a base, vermelho. Fig. 52-53.

Trpos: A. Ducke s.n., Brasil, Amazonas, Manaus, estrada do Aleixo, km 10, 15 maio 1932 fl., 9 Dez. 1932 fr. (lectótipo: RB 24555; isolectótipos: F, K, P,U, US); A. Ducke s.n., Brasil, Amazonas, Manaus, estrada do Aleixo, km 5, 16 Maio $1933 \mathrm{fl}$. (parátipo: RB 24556, GH, K, S, U, US); J. G. Kuhlmman 1409, Peru, Yurimaguas, baixo rio Huallaga, 15 Fev. 1924 fr. (parátipo: RB 24557, K).

NOMES vULGARES: Ucuuba-da-folha-grande (ex Chagas INPA 1341, ex Rodrigues \& Coelho 7558); ucuuba-da-folha-peluda (ex Aluisio 275); ucuuba-vermelha (ex Loureiro INPA 16452).

UTILIDADES: Sem aplicação conhecida.

$\mathrm{O}$ estudo anatômico da madeira foi realizado por Honda (I.c. 1971).

Segundo Braz Filho et al. (I.c. 1973), esta espécie possui os alcalóides $\mathrm{N}, \mathrm{N}$-dimetil-triptamina na casca da árvore e 5-metoxi-N, N-dimetil-triptamina na raiz, em tão diminutas quantidades que poderiam ser consideradas ausentes em comparação com outras importantes espécies alucinogênicas tais como $V$. elongata (Spr. ex Benth.) Warb. e V. calophylla Warb. Na madeira, foram encontrados, ao lado de sitosterol e stigmasterol, mais dois novos constituintes cristalinos denominados pelos autores acima referidos como virolano e virolanol. 
Do ponto de vista quimiotaxonômico, Gottlieb et al. (I.c. 1973) encontraram esses dois novos diarilpropanos também em madeira de V. venosa (Benth.) Warb., apresentando relações filogenéticas inexplicáveis, visto que do ponto de vista morfológico as duas espécies são aparentemente bem distintas. Em nota prévia publicada recentemente por Gottlieb, Maia \& Pinho em Ciência e Cultura (I.c. 1975), da madeira de $V$. multinervia foi isolado também um diidroxi-dimetoxi-derivado relacionado com um constituinte de Iryanthera coriacea Ducke, pertencente à mesma família botânica.

HABItAT: Ocorre em geral na planície amazônica em matas de terra firme, chegando a $400 \mathrm{~m}$ de altura no Departamento de San Martin, Peru, conforme dados da coleção Schunke 3586 (F, INPA, NY).

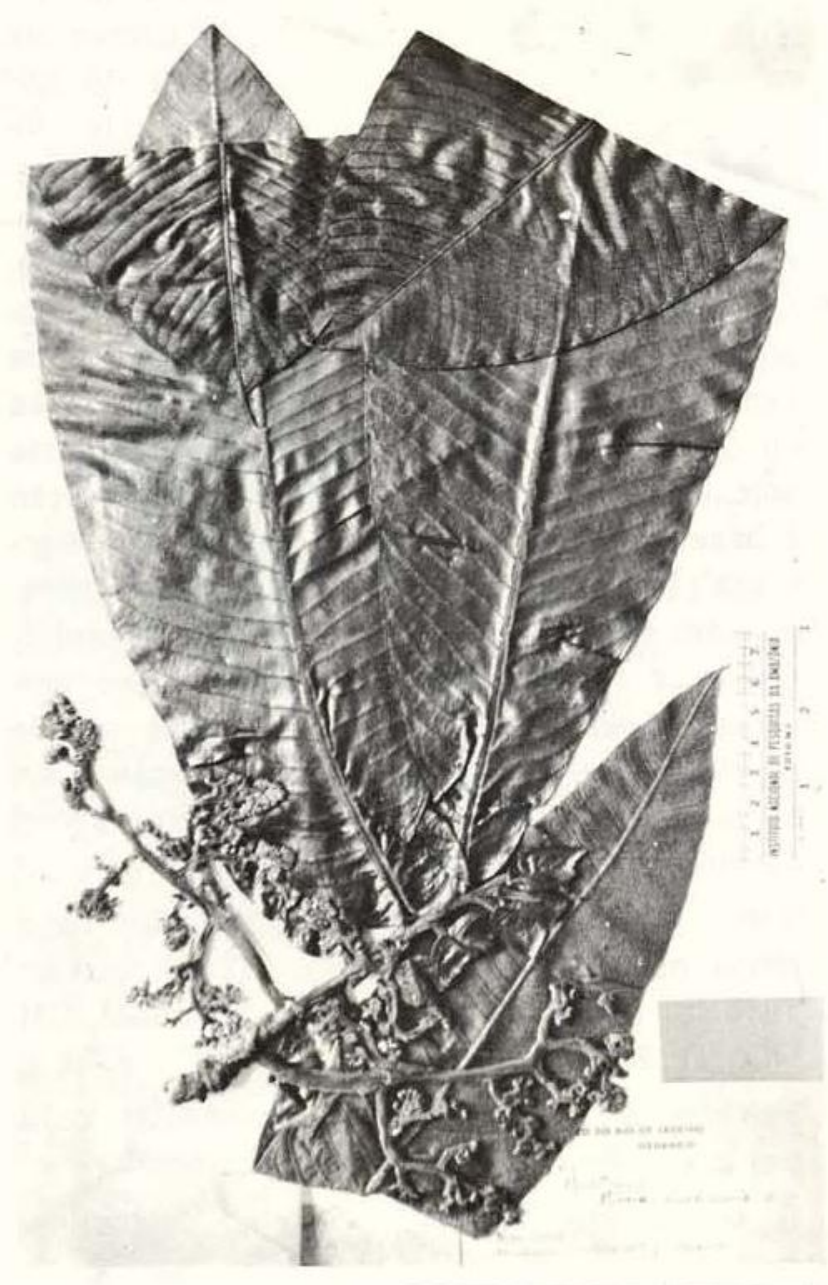

Fig. 52 - Virola multinervia A. Ducke s.n. (RB 24555, lectótipo).

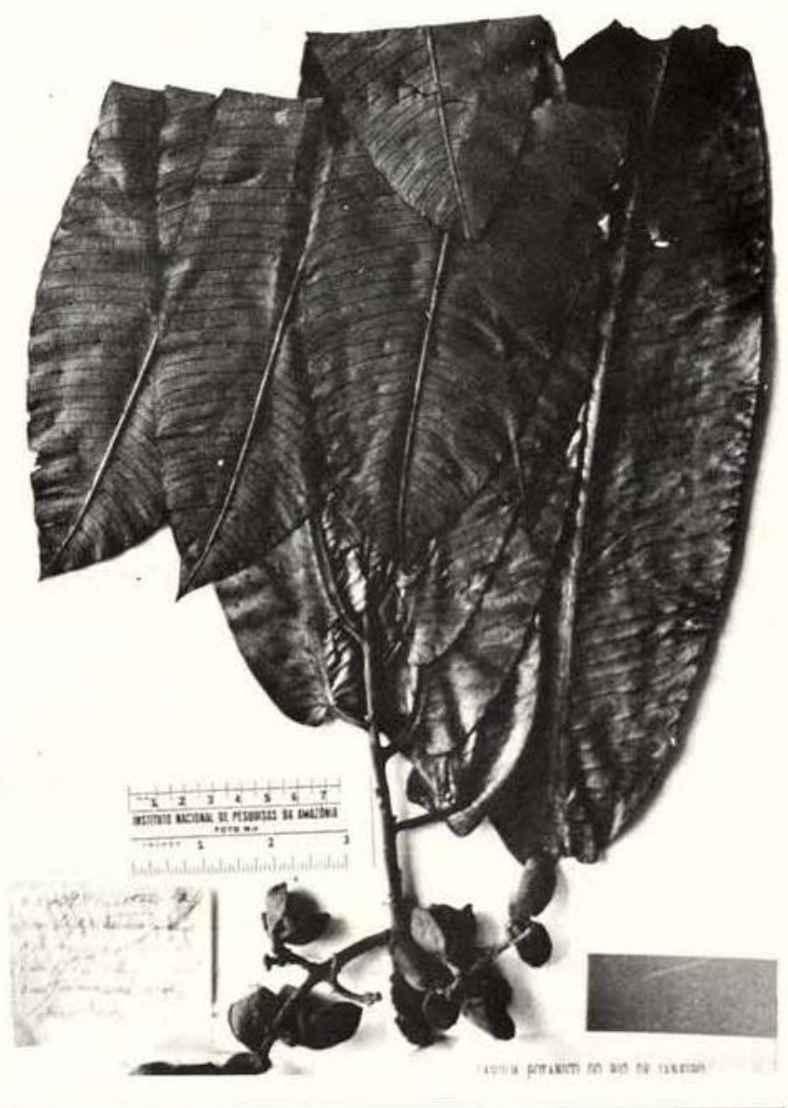

Fig. 53 - Virola multinervia. J.G. Kuhlmann 1409 (RB, parátipo).

Fenologia: A floração tem sido registrada de maio a julho com predominância em maio, e a frutificação de setembro a março do ano segुuinte. Fig." 15.

DistriBuição: Até hoje só conhecida da Amazônia Central até o Peru adjacente. Fig. 47.

\section{ESPÉCIMES ADICIONAIS EXAMINADOS:}

AMAZONAS: - Manaus: Aluísio 275, Maio 1969 fl. (INPA); Chagas s.n., Jan. 1955 est. (INPA 800); id. s.n., Jul. 1955 fl. (INPA 1341); L. Coêlho \& Coêlho s.n., Fev. 1968 est. (INPA 21157); Ducke 100, Jul. 1932 fl. (F, Y); id. 701, Maio 1941 fl. (GH, IAN, MG, R, SP); id. 2215, Jan. 1949 fr. (IA.N, GM, R); A. Goeldi s.n., Maio $1903 \mathrm{fl}$. (INPA, MG); T. Guedes 61, Jun. $1949 \mathrm{fl}$. (IAN); A. Loureiro s.n., Out. 1965 fr. (INPA 16452); Osmarino 01, Out. $1969 \mathrm{fr}$. (INPA); W. Rodrigues \& Coêlho 7558, Mar. 1966 fr. (INPA): id. 8293, Jan. 1967 fr. (INPA); W. Rodrigues \& Ramos 9633, Set. $1975 \mathrm{fr}$. (INPA); R. E. Schultes 24614, Jul./Ago. 1967 est. (INPA): Schultes \& Rodrigues 26151-A, Abr. 1972 est. (INPA); Schwacke 526, Jul. 1882 est. (R). - Estrada Manaus-Porto Velho: - Km 294: W. Rodrigues \& Coê- 
Iho 9617, Jun. $1975 \mathrm{fl}$. (INPA). Humaitá, rio Livramento: B. A. Krukoff 6847, Out. $1934 \mathrm{fr}$. (GH, IAN, NY, RB, S. U, US). - Estrada Manaus-Itacoatiara: entre os Km 135-150: A. Loureiro et al. s.n., Maio 1972 fl. (INPA 35764); O. Pires \& Coêlho 167, Set. 1972 fr. (INPA).

Muito próxima de $V$. decorticans Ducke e $V$. caducifolia W. Rodr. pelo grande número de nervuras secundárias e tamanho das folhas. difere delas principalmente pelo reticulado distinto e promínulo na página superior das foIhas. Da primeira também diverge especialmente pela ausência de pilosidade na página superior das folhas e da segunda, pela falta de um indumento canescente, denso e unifürme na página inferior e também pelo revestimento rufoferrugíneo dos frutos.

A coleção Krukoff 6847 , de certo modo já discutida por Ducke (I.c. 1939) e Smith (I.c. 1939), embora diferindo do tipo por apresentar folhas e frutos menores, deve ser considerada apenas como uma variação extrema da espécie e não como um novo taxon, visto que tem todas as características da espécie típica.

22. Virola obovata Ducke, Bol. Técn. Inst. Agron. Norte 4:12. 1945; A. Ducke, Bol. Técn. Inst. Agron. Norte 19:5. 1950; A.C. Smith, Journ. Wash. Acad. Sci. 43(7):203. 1953; descr. ampla.

Arvore delgada até $6 \mathrm{~m}$ de altura; raminho subcilíndrico ou levemente achatado, estriado ou não, densamente ferrugíneo-tomentoso (tricomas irregularmente ramificados, tênues) logo glabrescence. Pecíolo canaliculado ou subcilíndrico, 2,5-3,5mm de diâmetro; 10-20mm de comprimento, tomentoso como os raminhos, depois glabrescente. Lâmina foliar coriácea, obovada ou elíptica, $125-370 \mathrm{~mm}$ de comprimento, $40-120 \mathrm{~mm}$ de largura, atenuada a aguda na base, geralmente longamente acuminada, às vezes arredondada no ápice, glabra e lustrosa na página superior, puberulenta na inferior (tricomas séssil-estrelados, escassos, 0,2-0,3mm de diâmetro, e outros irregularmente ramificados até cerca de $0,3 \mathrm{~mm}$ de comprimento, muitíssimo esparsos), glabrescente; nervura mediana saliente em ambas as faces, mais fortemente na inferior; 14-17 nervuras secundárias de cada lado, curvadas antes das margens, anastomosadas, ligeiramente elevadas na página superior e salientes na inferior; nervuras terciárias transversais indistintas em ambas as páginas ou ligeiramente impressas na superior. Inflorescência masculina amplamente paniculada, 2-3-ramificada, $120-140 \mathrm{~mm}$ de comprimento, ebracteada; pedúnculo de $15-40 \mathrm{~mm}$ de comprimento, 2-4mm de diâmetro, juntamente com os raminhos e flores, densamente ferrugíneo-tomentoso (tricomas irregularmente ramificados, $0,2-0,5 \mathrm{~mm}$ de comprimento); $2-8$ flores por fascículo; pedicelo fino de $1,5-3,0 \mathrm{~mm}$ de comprimento; perianto finamente carnoso, infundibuliforme, densamente tomentelo externamente, $1,6-2,0 \mathrm{~mm}$ de comprimento, 3-4-lobado até cerca de $1 / 3$ do seu comprimento; !óbulos obtusos; androceu de 1,0-1,1 $\mathrm{mm}$ de comprimento; andróforo densamente carnoso, estreitado em direção ao ápice, bem mais curto que a antera, $0,3-0,4 \mathrm{~mm}$ de comprimento; $3-4$ anteras soldadas até 0 ápice, $0,7-0,8 \mathrm{~mm}$ de comprimento, obtusamente apiculadas no ápice. Inflorescência feminina desconhecida. Infrutescência até $50 \mathrm{~mm}$ de comprimento, curtamente pedunculada; 1-7 frutos por infrutescência, subsésseis ou curto-pedicelados (pedicelos até $3 \mathrm{~mm}$ de comprimento), obovóide-elipsóides, na maturidade até cerca de $25 \mathrm{~mm}$ de comprimento, $10 \mathrm{~mm}$ de largura, arredondados no ápice e na base, ou, às vezes, ligeiramente apiculados no ápice e estreitados em direção à base, densa e tenuemente ferrugíneo-tomentosos (tricomas irregularmente ramificados, marrom escuros, $0,4-2,0 \mathrm{~mm}$ de comprimento); pericarpo tenuemente coriáceo a lenhoso, cerca de 1-3mm de espessura; sementes obovóide-elipsóides, estreitando-se em direção à base obtusa, $13-22 \mathrm{~mm}$ de comprimento, $6-8 \mathrm{~mm}$ de largura; arilo escarlate. Fig. 54-55.

TrPo: A. Ducke 1509, Brasil, Amazonas, Esperança, na desembocadura do rio Javari, 24 Mar. $1944 \mathrm{fr}$. (holótipo: RB 50695; isótipos: GH, $M G, N Y, R$, US)

Fenologia: Observada florescendo em outubro e com frutos de novembro a março.

Habitat: Mata de terra firme ou de restinga de solo arenoso e úmido.

DistribuIÇÃo: Amazônia brasileira e colombiana. Fig. 56. 


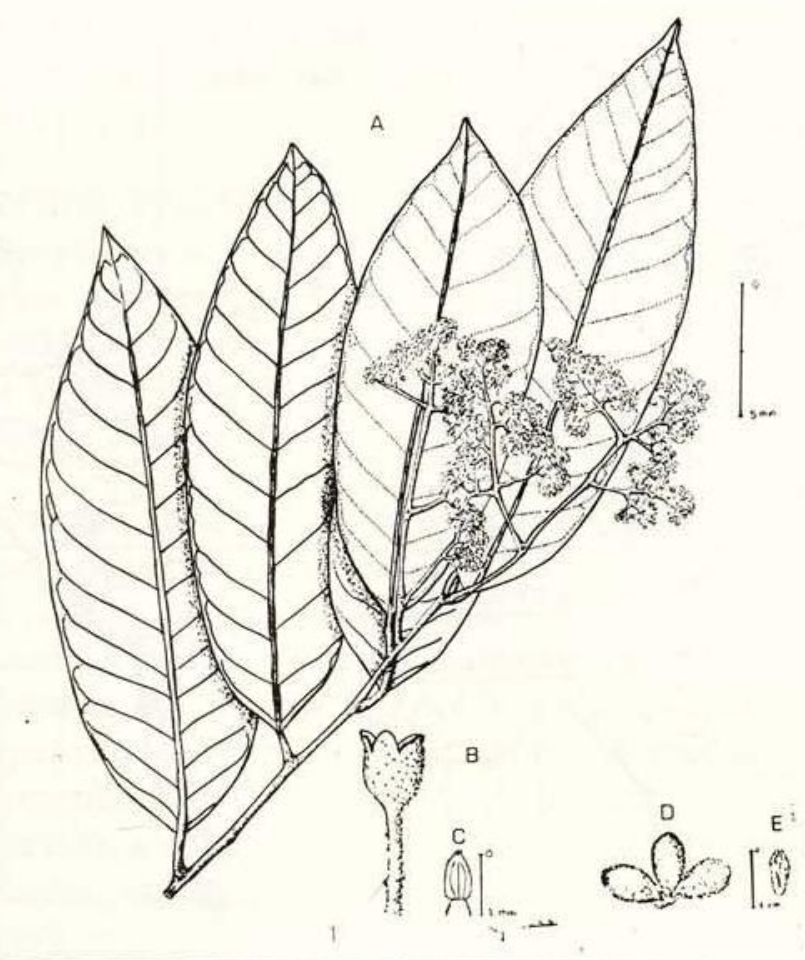

Fig. 54 - Virola obovata. A-C (R. L. Froes 25555): A, hábito do ramo florífero masculino; B. flor masculina; C, androceu; D-E (R. L. Froes 23746): D, frutos; E, semente com arilo

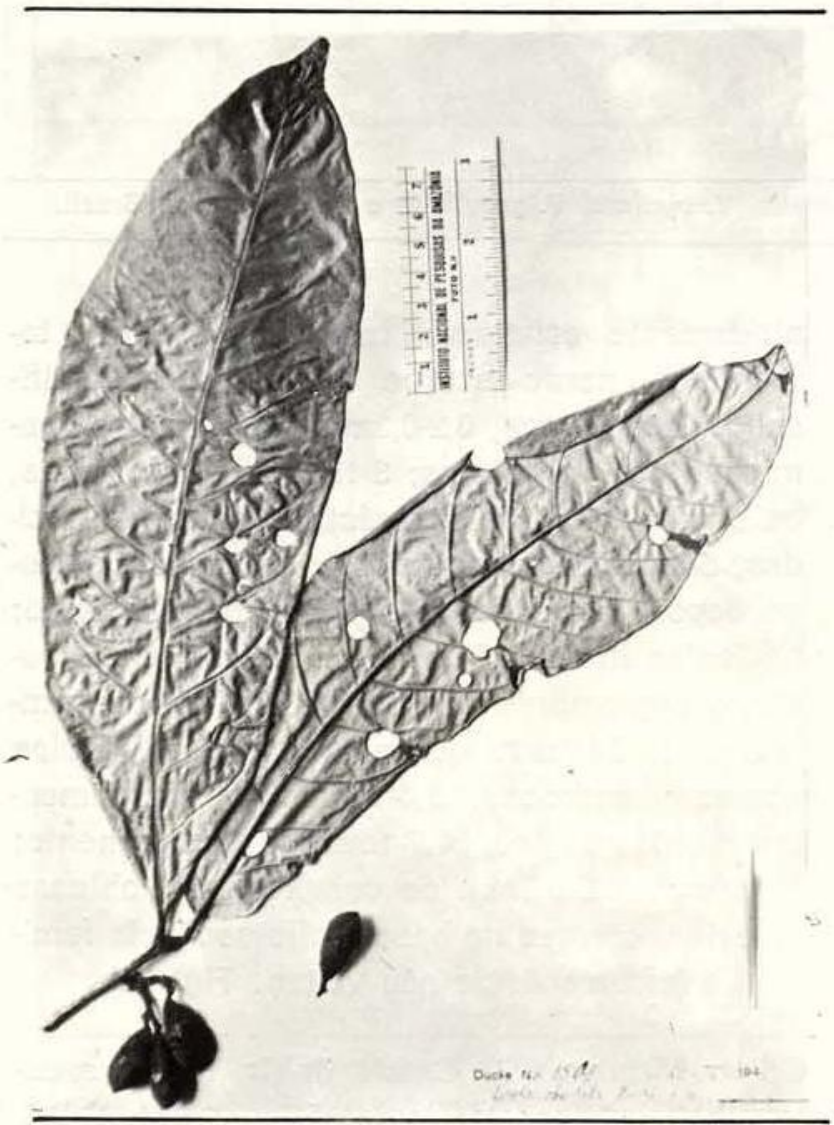

Fig. 55 - Virola obcvata. A. Ducke 1509 (NY, Isótipo).

\section{MATERIAL ADICIONAL EXAMINADO:}

AMAZONAS: - São Paulo de Olivença, alto igarapé Belém: R. L. Froes 23746, Dez. 1948 fr. (IAN, US). Rio Tonantins: R. L. Froes 25555, Out. $1949 \mathrm{fl}$. (IAN, UB, US). Estrada Humaitá-Lábrea: entre os rios Ipixuna e Itaparama, Km 83: G. T. Prance, B. S. Pena \& J. F. Ramos 3269, Nov. 1966 fr. (INPA, NY).

A descrição da inflorescência masculina, aqui apresentada pela primeira vez, foi baseada na coleção Fróes 25555. Distingue-se de V. calophylla Warb., especialmente, por apresentar folhas agudas e frutos persistentemente tomentosos com tricomas mais longos, providos de apêndices laterais esporoniformes.

23. Virola officinalis Warburg, Ber. Pharm. Gess.: 225. 1892, hipônimo; O. Warburg, Nova Acta Acad. Leop.-Carol. 68:228. 1897; A.C. Smith \& Wodehouse, Brittonia $2(5): 482$. 1937; H.P. Veloso, Mem. Inst. Oswaldo Cruz 44(2):251. 1947; J.C. Th. Uphof in Engl. \& Prantl, Nat. Pflanzenfam., 2." ed., 17a(2):207. 1959; Metcalf \& Chalk, Anat. Dicot. 2:1133. 1965; A. Mattos Filho \& C.T. Rizzini, Anuário Bras. Econ. Florest. 19:132. 1968; C.T. Rizzini, Arvores e madeiras úteis do Brasil: 186. 1971.

Myristica officinalis Martius in Spix \& Martlus, Reise in Brasilien 2: 543.1828 (1966), pro parte (excl. fruct.); Spix \& Martius, Viagem pelo Brasil, 2: 204. 1938, pro parte (excl. fruct.): Bentham, Hook. Journ. Bot. 5: 3. 1853, pro parte (excl. fruct. et specim. Gardner et Schott); A. De Candolle in DC., Prodr. 14: 197 et 697. 1856, pro parte (excl. fruct.); A. De Candolle in Mart., Fl. Bras. 5 (1): 116, tab. 44 (excl. fruct. et folia infra medio rami floriferi). 1860; M. J. Caminhoá, Com. Bot. Geral e Méd. 3: 2322. 1884; M. Penna, Dicionário bras. plantas medicinais: 271. 1946, pro parte (excl. fruct.); A. I. de Menezes, Flora da Bahia. 264: 39 et 237. 1949; non L.f. (17781).

Arvore de 20-25m de altura; tronco até $60-80 \mathrm{~cm}$ de diâmetro (Rizzini, I.c. 1971); raminho fino a robusto, densamente rufotomentoso quando novo, achatado unilateralmente (tricomas ferrugíneos, pouco ramificados, até $0,5 \mathrm{~mm}$ 


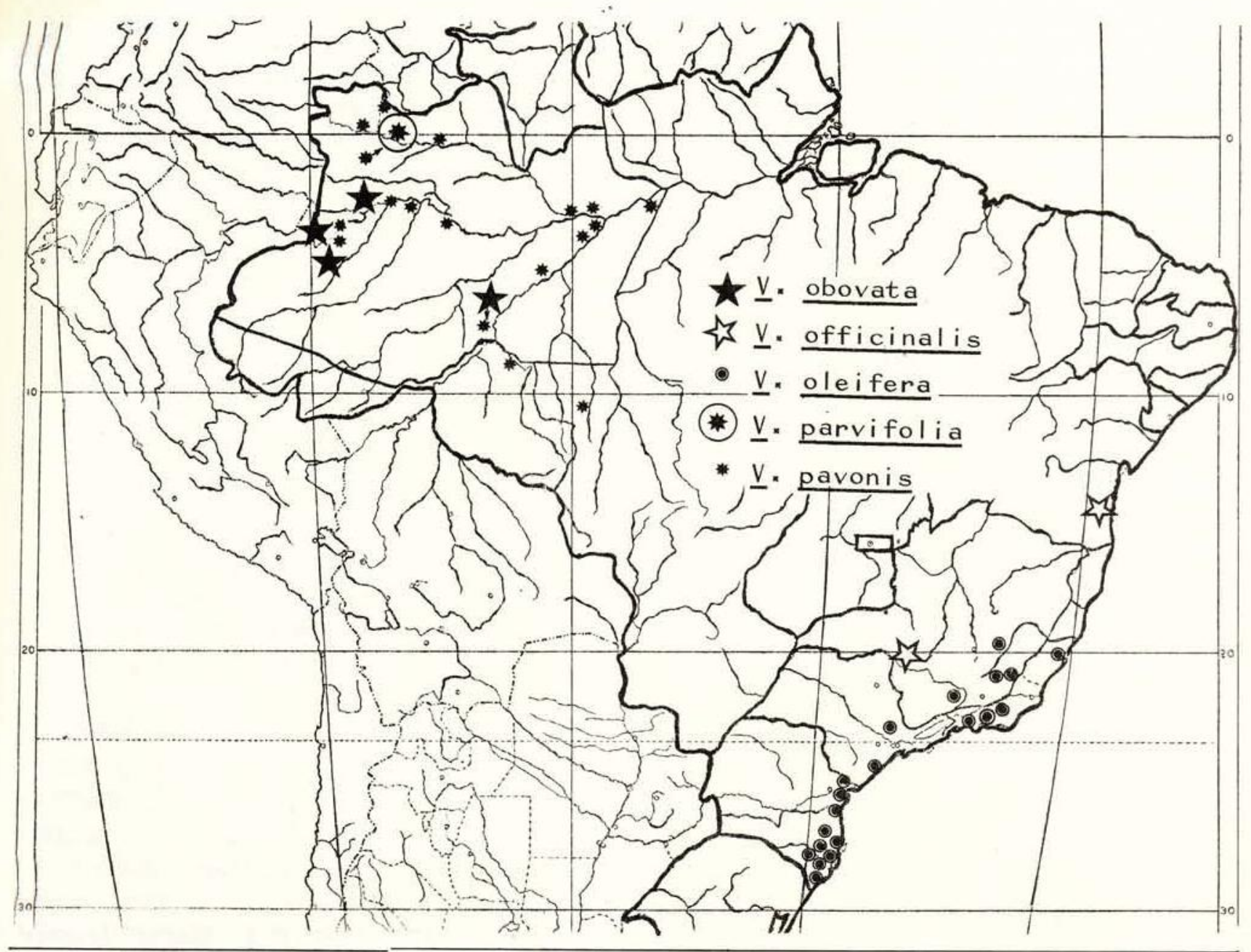

Fig. 56 - Distribuição atual de Virola obovata, V. officinalis, V. oleifera, V. parvifolia e V. pavonis no Brasil.

de comprimento), logo glabro. Pecíolo rasamente canaliculado, $1,5-3 \mathrm{~mm}$ de diâmetro, $5-11 \mathrm{~mm}$ de comprimento, tomentoso como os raminhos. Lâmina foliar cartácea ou coriácea, oblonga, elíptica ou obovado-elíptica, $80-220 \mathrm{~mm}$ de comprimento, $25-70 \mathrm{~mm}$ de largura, truncada ou levemente cordada na base, subaguda ou cuspidada no ápice, ferrugíneo-tomentela na página inferior (tricomas geralmente sésseis, porém, às vezes, curto-estipitados, 3-5ramificados, $0,2-0,4 \mathrm{~mm}$ de diâmetro); nervura mediana levemente impressa na página superior, saliente na inferior; 18-32 nervuras secundárias de cada lado, retas, ligeiramente impressas na página superior, elevadas na inferior, anastomosadas junto às margens; vênulas obscuras. Inflorescência masculina rufotomentosa, 1-ramificada, $30-130 \mathrm{~mm}$ de comprimento; pedúnculo $10-35 \mathrm{~mm}$ de comprimento, nitidamente achatado; raminhos e flores tomentelos, pardo-escuros (tricomas 3-8-ramificados, irregulares, $0,2-0,3 \mathrm{~mm}$ de diâmetro), raminhos poucos, curtos; 3-15 fascículos florais, os do ápice sésseis; brácteas oblongas, agudas, $5-8 \mathrm{~mm}$ de comprimento, puberulentas, logo depois decíduas; 8-20 flores por fascículo; pedicelos finos, até $2 \mathrm{~mm}$ de comprimento; perianto tenuemente carnoso $2,0-2,3 \mathrm{~mm}$ de comprimento, 3-lobado quase até a base, lóbulos obtusos; androceu, $1,4-1,6 \mathrm{~mm}$ de comprimento; andróforo fino, $0,7-1 \mathrm{~mm}$ de comprimento; 3 anteras, $0,5-0,7 \mathrm{~mm}$ de comprimento, obtusas no ápice, cônicas na base. Inflorescência feminina e infrutescência não vistas. Fig. 57.

TIPo: Martius 650, Brasil, Bahia, Ilhéus s/data! fl. (lectótipo: $\mathrm{M}$; isolectótipos: BM, G-DC, GH, K, L, P; B e W destruídos; fotos: F 7439, 
IAN, M, NY); Martius 927, Minas Gerais, Presídio São João Batista, s/data fl. (parátipo: M, n.v.).

Nomes vulgares: Bicuíba (ex Veloso 1080); bicuíba-branca (ex Santos 1107). Todos os nomes a seguir citados por Martius (I.c. 1828 , 1938) deveriam provavelmente ser atribuídos a $V$. oleifera e não a esta espécie: bicuíba-redonda, noz-moscada-do Brasil e vicuíba.

UTILIDADES: As aplicações medicinais podem ser ocasionalmente idênticas às atribuídas à $V$. oleifera Smith e V. gardneri Warb. com as quais a espécie durante muito tempo foi confundida na literatura, porém nada se sabe a respeito. Produz resina vermelha. A madeira, segundo Rizzini (I.c. 1971), é moderadamente pesada e dura; bastante durável e fácil de trabalhar, embora tida como inferior a de $V$. gardneri.

Habitat: Segundo Veloso (I.c. 1947), é uma espécie própria das áreas ensolaradas de capoeira, podendo ser encontrada nas comunida-

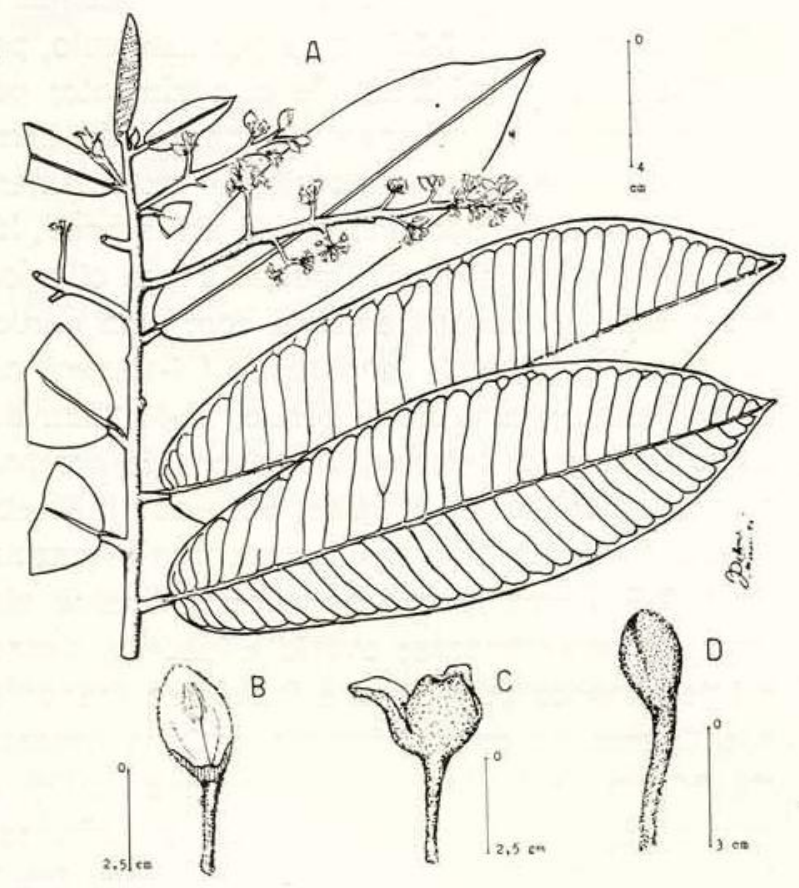

Fig. 57 - Virola officinalis. (H. Veloso 1080): A, háblto do ramo florífero; 3 , flor seccionada, mostrando o androceu; C, flor inteiro; D, flor em botão. des subclimax e quasiclimax, atingindo seu máximo na associes Lecythis-Brosimum e nas associações climácicas.

Distribuição: Até hoje só conhecida do Sul da Bahia, muito embora Warburg (I.c. 1897) a cite também para Minas Gerais. Fig. 56.

\section{MATERIAL ADICIONAL EXAMINADO:}

BAHIA: -. Ilhéus: H. Veloso 1080, Set. $1944 \mathrm{fl}$. (INPA, R). Belmonte: Estação Experimental: T. S. Santos 1107, Set. $1970 \mathrm{fl}$. (CEPLAC, INPA).

$V$. officinalis distingue-se das outras próximas, especialmente, pela inflorescência simples, 1-ramificada, tipo de inflorescência essa também encontrável em algumas outras espécies tais como $V$. oleifera Smith.

24. Virola oleifera (Schott) A.C. Smith, Brittonia $2(5): 488$. 1937; J.C. Th. Uphof in Engl. \& Prantl, Nat. Pflanzenfam., 2." ed., 17a(2):207. 1959; H.P. Veloso \& O.M. Barth, Mem. Inst. Oswaldo Cruz $60(1): 83$, fig. 28 a-d; tab. 2, figs. 17-19. 1962; P.R. Reitz in R. Reitz, Flora llustr. Catarinense, MIRI: 5 , fig. 5, fig. 1-2. 1968; C.T. Rizzini, Arvores e Madeiras Úteis do Brasil: 186-187. 1971. G. Hatschbach, Bol. Mus. Bot. Municipal Curitiba 4:2, fig. 1. 1972.

Myristica oleifera Schott, Isis Oken 12-13: 1050. 1823.

Myristica bicuhyba Schott, In C. Sprengel, Syst. Veg. 4 (2): 409. 1827; Brandes, Ann. Pharm. 7: 52. 1833; S. L. Endlicher in Enchiridium Bot.: 421. 1841; C.F.P. Martius, Systema materia medica veg.: 68. 1854; A. De Candolle in DC., Prodromus 14: 197. 1856; T. Peckolt, Arch. Pharm., 2. Reich, 107: 158 e 285; ibid. 108: 14. 1861; H. Wawra, Bot. Ergebn., Reise Bras. Maxim.: 66, tab. 57. 1866; M. J. Caminhoá, Comp. Bot. Geral e Med. 3: 2322. 1884; Nördlinger, Ueber das Bicuhyba - Fett, Ber. Chem. Ges.: 2617. 1885; T. Peckolt \& G. Peckolt, História das plantas med. e úteis Brasil.: 1349. 1889; Arata, Ann. Depart. Nac. Hyg. 401. 1891; F. C. Hoehne, M. Kuhlmann \& O. Handro, Jard. Bot. S. Paulo: 408. 1941; C. Mainieri, Madeiras brasileiras: 16, 1 fig., 1970. 
Virola bicuhyba (Schott) Warburg, Ber. Pharm. Ges.: 225, 1892, hipônimo; O. Warburg, Ber. Deutsch. Bot. Ges. 13: 92. 1895; Nova Acta Acad. Leop.-Carol. 68: 194, tab. 6, fig. 1,5 e 6. 1897; E. T. Fonseca, Indicador de Madeiras e plantas úteis Brasil: 57. 1922; O. X. de Brito Machado, Rodrig. 24: 53, estampa 1-2. 1949; E. C. Mello, Bol. Serv. Florest. Parque Nac. Itatiaia 2: 35, 3 figs. 1950; Inst. Pesq. Tecnol. S. Paulo 31: 195-196. R. E. Schultes \& B. Holmstedt, Lloydia, 34 (1): 69. 1971.

Virola sebifera sensu Velloso, FI. Flum. 5 (1-4): 401; tab. 30. 1881, non Aublet.

Virola bicuhyba var. schenckii Warburg, Ber. Pharm. Ges.: 228, fig. 13. 1892, hipônimo; O. Warburg, Nova Acta Acad. Leop.Carol.68: 206, tab. 6, fig. 2-4. 1897. Tipo: Fr. Müller s.n., Brasil, Santa Catarina, Itajai, s/data fl. (síntipo: R 61015, K); Schenck 287, Brasil, Santa Catarina, Blumenau, s/data fr. (síntipo: B, destruido).

Virola oleifera var. schenckii (Warburg) Uphof in Engl. \& Prantl., Nat. Pflanzenfam. 2." ed., 17: (2): 207. 1959.

Palala bicuhyba (Schott) Kuntze, Rev. Gen. PI. 2: 567. 1891, nom. illegit.

Virola araujovii Warburg, Nova Acta Acad. Leop.-Carol. 68: 208, tab. 7, fig. 1-3. 1897. Tipo: Araújo 9892, Brasil, Minas Gerais, Rio Novo, Set. 1889 est. (holótipo: B, destruído; lectótipo: R 61012).

Myristica officinalis sensu J. Saldanha da Gama Filho, Configuração e descrição de todos os órgãos fundamentais das principais madeiras de cerne e brancas da província do Rio de Janeiro 1: 58 , figs. 1-4 (excl. figs. 5-8). 1865; sensu J. de Almeida Pinto, Diccionário de Bot. Bras.: 76, fig. 10, 1873 quoad folia tantum.; sensu J. B. Spix \& C. F. P. Martius, Reise in Bras. 2: 543,1828 pro parte quoad fruct.; sensu Spix \& Martius, Viagem pelo Brasil 2: 204. 1938; sensu Bentham, Hook. Kew Journ. Bot. 5: 3, pro parte quoad fruct. 1853; A. De Candolle in DC., Prodr. 14: 197 et 697. 1856 pro parte quoad fruct.; A. De Candolle, in Mart., FI. Bras. 5 (1): 116, tab. 44. 1860, pro parte quoad fruct, et folia infra media rami floriferi; e sensu $M$. Penna, Dicionário bras. pl. med. 271. 1946; non L.f. nec Martius.

Árvore até $35 \mathrm{~cm}$. de altura e $105 \mathrm{~cm}$. (Reitz, I.c. 1968) de diâmetro de tronco; raminho estriado, os novos inteiramente cinéreo-puberu- lento, passando mais tarde a glabro e enegrecido. Pecíolo levemente canaliculado, distalmente alado, com indumento igual ao dos raminhos, $0,8-2 \mathrm{~mm}$ de diâmetro e $7-15 \mathrm{~mm}$ de comprimento. Lâmina foliar finamente coriácea ou papirácea, linear-oblonga ou oblongolanceolada, margens paralelas, $110-230 \mathrm{~mm}$ de comprimento, $20-40 \mathrm{~mm}$ de largura (raramente até $55 \mathrm{~mm}$ ), atenuada e aguda na base, aguda ou cuspidada no ápice, palidamente puberulenta na página inferior (tricomas séssil-estrelados, 4-6-ramificados, cerca de $0,2 \mathrm{~mm}$ de diâmetro); nervura mediana levemente impressa na face superior, saliente na inferior; 23-35 nervuras secundárias de cada lado, muitas vezes irregulares e levemente impressas na página superior, promínulas ou planas na inferior; vênulas obscuras ou levemente impressas na página superior. Inflorescência masculina estreita, 1-ramificada, $20-80 \mathrm{~mm}$ de comprimento; pedúnculo curto, estriado, com os raminhos cinéreo-puberulentos, glabrescentes, os raminhos laterais curtos, distalmente túrgidos; brácteas oblongas, puberulentas, $3-5 \mathrm{~mm}$ de comprimento, logo decíduas; flores dispostas em fascículos compactos (3-8 fascículos por inflorescência, os distais freqüentemente sésseis na raque), 7-25 flores por fascículo, pedicelos tênues, até $2 \mathrm{~mm}$ de comprimento; perianto finamente carnoso, $1,8-2,5 \mathrm{~mm}$ de comprimento, levemente puberulento externamente ou subglabro, 3-lobado quase até a base, lóbulos oblongos, obtusos, muitas vezes ciliados nas margens, freqüentemente com uma nervura mediana visível; androceu $1,4-1,9 \mathrm{~mm}$ de comprimento; andróforo tênue, $0,4-0,7 \mathrm{~mm}$ de comprimento; 3 anteras, $0,8-1,2 \mathrm{~mm}$ de comprimento, soldadas até o ápice, obtusas. Inflorescência feminina algo mais curta que a masculina; 2-5 flores por fascículo; pedicelos até $2 \mathrm{~mm}$ de comprimento; ovário elipsóide, densa e inteiramente puberulento (tricomas menores que $0,1 \mathrm{~mm}$ de comprimento); estilete grosso, até $0,7 \mathrm{~mm}$ de comprimento; estigma obliquamente capitado, levemente fendido. Infrutescência até $90 \mathrm{~mm}$ de comprimento, glabra inteiramente na maturidade; 3-6 frutos maduros por infrutescência, pedicelados (pedicelos de 6-8 $\mathrm{mm}$ de comprimento) ovóide-elipsóides, 28-30 $\mathrm{mm}$ de comprimento, $16-20 \mathrm{~mm}$ de largura, agu- 
dos ou cuspidados no ápice, curtamente estipitados na base, nitidamente carinados, em particular distalmente; pericarpo rugoso, cerca de $1 \mathrm{~mm}$ de espessura; arilo lacionado apenas no terço superior, poucos lóbulos comparativamente largos, formanda uma ponta subaguda; semente ovóide-elipsóide, $22-24 \mathrm{~mm}$ de comprimento, $13-19 \mathrm{~mm}$ de largura. Fig. 58A-1.

TIPO: Schott 4559, Brasil, Rio de Janeiro, s/data fl. (holótipo: W, destruído; lectótipo: $\mathrm{M}$; isolectótipo: US).

Nomes vUlgares: Arvore-de-sebo (fide Fonseca, I.c. 1922); avinhoz (fide Mainieri, I.c. 1970); baraúga (fide Fonseca I.c. 1922); bicuíba; bicuíba-açu (ex Nunes 57) bicuíba (becuíba)-branca (fide Rizzini, I.c. 1971); bicuíba-caa-mirim (fide Peckolt \& Peckolt, I.c. 1889); bicuiba-redonda (fide Martius I.c. 1828, 1938); bicuíva (fide Reitz, l.c. 1968) bicuíba-vermeIha-da-miúda (ex Kuhlmann 630); bicuva (id.); bocuba (id.); bucuíba (ex Froes 33385); bucuba (fide Reitz I.c. 1968); bucuúva (fide Fonseca, I.c. 1922); candeia-de-caboclo (id.); diquiúba (ex Mexia 4699); moscadeira-do-Brasil (fide Peckolt \& Peckolt, I.c. 1889); noz-moscada-doBrasil, (fide Martius sub $M$. officinalis, I.c. 1828, 1938); ocuba (fide Fonseca, I.c. 1922) pau-sangue (Velloso, apud Warburg I.c., 1897); pau-sangue-bicuiba (Riedel, apud Warburg I.c. 1897); piquibuçu=piquibussu (fide Schott I.c. Schott I.c. 1827); ucuuba (fide Fonseca, I.c. 1922); ucuuba-da-mata (fide Fonseca, I.c. 1922); ucuuba-vermelha (fide Fonseca I.c. 1922); urucuba (fide Fonseca, I.c. 1922).

UTILIDADES: Do gênero, é uma das espécies mais conhecidas no Brasil meridional pelas suas variadas aplicações folclóricas e grande dispersão. Muitos dos empregos medicinais populares atribuídos a outras bicuíbas (em particular V. officinalis), possivelmente, Ihe per. tence, devido em grande parte não só à confusão causada por Martius em admitir essas duas espécies como uma única como também, fato digno de menção, terem sido ilustradas juntas na Flora Brasiliensis sob o binômio de Myristica officinalis.

$\mathrm{O}$ estudo anatômico da madeira foi feito por Machado (I.c., 1949) e Mello (I.c. 1950) e o teste físico-mecânico pelo IPT de São Paulo

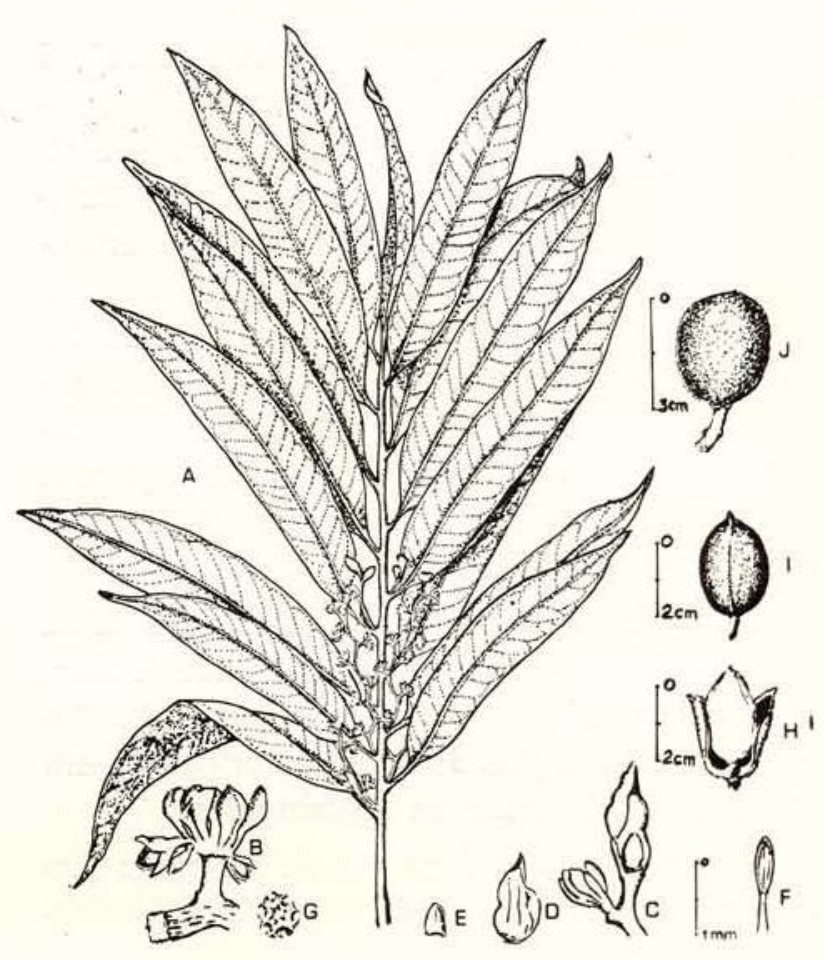

Fig. 58 - A-I, Virola oleifera. A-E (recoplado de Wawra, 1866): A, hábito do ramo florífero fasculino; $B$, farcículo floral; $C$, extremidade distal de uma inflorescência jovem; D, bráctea; $E$, tépala; $F$ (Saldanha 8752 ), androceu; G, antera seccionada transversalmente; H (M. Barreto 1560), fruto aberto, mostrando a semente; I (R. Reitz \& Klein 8825), fruto fechado, mostrando a carena. J. Virola gardneri: fruto.

(I.c. 1956). Com referência à germinação de sementes, esses dados podem ser encontrados em Müller (I.c. 1887). Quanto à análise química da semente e aplicações medicinais da bicuíba, Peckolt \& Peckolt (I.c. 1889), Warburg (I.c. 1897) e Fonseca (l.c. 1922) fornecem dados extensivos a respeito. De modo sucinto, são dadas a seguir algumas das possíveis aplicações indicadas para a presente espécie. A madeira é própria para construção civil e naval, assoalhos, canoas, carpintaria, marcenaria, caixões funerários, persianas e venezianas, pontes, ripas, vigas etc. servindo também como ótima lenha. Pode ser empregada para laminados e produção de papel. O óleo ou sebo que se extrai das amêndoas é medicinalmente usada contra dores reumáticas, asma, tumores nas articulações e vermes intestinais, mau hálito da boca, flatulência, acessos asmáticos, moléstias da pele, erisipelas e hemorroides. $\mathrm{O}$ suco resinoso que escorre da casca, quando 
ferida, conhecida por "sangue-de-bicuíba", é utilizado topicamente contra hemorroides, hemorragia dos mamilos e cólicas. Auxilia a cicatrização de úlceras e feridas crônicas. Combate as hemoptises, diarréias e qualquer hemorragia. Devido a sua adstringência, é usada como hemostática. Como homeopatia, é muito útil nas cólicas do estômago e intestinais e como tônico e restaurador das forças. É estimulante cerebral da memória e da inteligência. Produz uma manteiga tida como sucedânea da "manteiga-de-cacau".

Segundo Machado (I.c. 1949), a bicuíba tem substâncias realmente curativas contra bronquites catarrais, pneumatoses do aparelho digestivo, enteralgias de diversas origens e em alguns casos de miosites reumatoides.

A semente pega fogo, dando luz muito clara, sendo muito usada em saboaria e fabricação de velas.

Fenologta: Florece de agosto a abril seguinte, com predominância entre dezembro e fevereiro. A frutificação ocorre entre março e agosto com ligeira predominância em julho. Fig. 16.

HABITAT: Ocorre com regular distribuição na mata pluvial da vertente atlântica, nas encostas litorânias dos morros, e mais raramente na planície litorânea, sem preferência de solo. A maior altitude até então registrada de ocorrência da espécie foi $780 \mathrm{~m}$ sobre o nível do mar, no Parque Nacional de Itatiaia, Rio de Janeiro (ex Barros 607). Segundo Machado (I.c. 1949) a espécie tem desenvolvimento médio melhor nas regiões mais elevadas.

Distribuição: Conhecida apenas do Brasil meridional desde Minas Gerais, Espírito Santo, Rio de Janeiro até o extremo nordeste do Rio Grande do Sul (fide Reitz, I.c. 1968). Fig. 56.

\section{MATERIAL ADICIONAL EXAMINADO:}

MINAS GERAIS: - Coronel Fabriano: R. L. Froes 33385, Ago. 1957 fr. (IAN). - Viçosa L. G. Kuhlmann 2135, Dez. 1935 fl. (NY, US); M. Magalhães 83, Nov. $1961 \mathrm{fl}$. (INPA, VIC); - Tombos: M. Barreto 1560, Jul. 1935 fr. (BHMG, NY); - Agua Limpa: Estação Experimental: E. P. Heringer \& Gomes 2759, (Set. $1968 \mathrm{fl}$.
(RB, UB); E. P. Heringer 2797, Ago. 1950 fl. (RB). Coronel Pacheco: Estaçăo Experimental: E. P. Heringer 2227, Jan. $1946 \mathrm{fl}$. (SP). Alto Macaé: Glaziou 20464, Fev. 1893 (NY).

ESPIRITO SANTO: - Santa Tereza: G. Dolcolmo 12, Jan. 1954 (RB).

RIO DE JANEIRO: Rio de Janeiro: Glaziou 799, Set. 1893 (C, P); J. G. Kuhlmann 630, Dez. 1927 fl. (RB); C. Lage s.n., Ja. 1937 fl. (RB, 120358, NY); D. Machado 3852, Dez. 1941 fl. Mar. 1942 fr. (RB); P. Ochioni 247, Jan. 1945 fl. (RB); P. Rosa 142, Jan. 1934, fl. (RB). Estado do Rio: Terezópolis: H. P. Veloso s.n., Fev. 1943 fl. INPA, R.) - Parque Nacional de Itatiaia: W. D. de Barros 607, Fev. $1942 \mathrm{fl}$. (RB); - Macaé: Ducke 32, 1934 (R).

SÃO PAULO: - Serra da Mantiqueira: J. Saldanha 8752 Jan. 1885 fl. (R). S. Paulo: O. Handro s.n., Jan. $1937 \mathrm{fl}$ (SP 37597); M. Kuhlmann 2815, Fev. fl. (SP). Iguape: Brade 7960, Dez. 1917 fl. (RB).

PARANA: - Serra da Prata: P. Dusén 15313, Jul. 1914 fr. (M, NY). - Antonina: Lindeman, Hatschbach \& Haas 13535, Jan. 1966 (MBM, U). Guanabara: G. Hatschbach 3478, Dez. 1956 fl. (MBM, US).

SANTA CATARINA: - Luiz Alves: Reitz \& Klein 2672, Fev. 1956 fl. (HBR, NY); Itajaí: Fr. Müller s.n., s/data (K, R 61015); R. Klein 1421, Jun. 1955 fr. (HBR, NY); Reitz \& Klein 2006, Jul. 1954 fr. (HBR, NY). Blumenau: R. Klein 1104, Jan. 1955 fl. (HBR, NY); R. Reitz \& Klein 9623, Abr. 1960 fl. (HBR, SP). Brusque: R. Klein 139, Jan. 1950 fl. (HBR, NY); H. P. Veloso 42, Out. 1949 fl. (RB). - Ibirama: A. Gevieski 106, Jan. $1954 \mathrm{fl}$. (HBR, NY). - Rio do Sul: Reitz \& Klein 8825, Maio $1959 \mathrm{fr}$. (HBR, NY). Vidal Ramos: Reitz \& Klein 6552, Mar. 1958 fl. (HBR, NY). - Palhoça: Reitz \& Klein 2545, Jan. 1956 fl. (HBR, NY). - Criciúma: Y. Mexia 4699, Maio 1930 est. (NY).

SEM LOCALIDADE DEFINIDA: Riedel s.n. s/data fl. (NY).

Afim à $V$. gardneri Warb., diferencia-se, principalmente, desta não só pela folha linearoblonga ou oblongo-lanceolada, de margens paralelas, como pelo fruto ovóide-elipsóide agudo ou fortemente cuspidado no ápice e distintamente carinado.

25. Virola parvifolia Ducke, Journ. Wash. Acad. Sci. 26(6):264. 1936; A.C. Smith \& Wodehouse, Brittonia 2(5):497. 1937; A. Ducke, Arq. Serv. Florest. 1(1):27. 1939; J.C. Th. Uphof in Engl. \& Prantl, Nat. Pflanzenfam., 2. ${ }^{\mathrm{a}}$ ed., 17a(2):207. 1959.

Arvoreta; raminho estriado, rugoso-tuberculado, tênue, puberulento quando novo, pas- 
sando mais tarde a glabro e enegrescido. Pecíolo mais ou menos canaliculado, glabro, tuberculado, $1-2 \mathrm{~mm}$ de diâmetro, $6-14 \mathrm{~mm}$ de comprimento. Lâmina foliar coriácea largamente elíptica, $50-110 \mathrm{~mm}$ de comprimento, $30-50 \mathrm{~mm}$ de largura, obtusa ou arredondada na base, obtusa e ligeiramente emarginada no ápice, glabra, margens tenuemente revolutas, nítida na página superior e opaca na inferior, em ambas as faces densa e tenuemente tuberculato-granuladas vistas sob lente; nervura mediana levemente impressa na página superior, saliente na inferior; 12-16 nervuras secundárias de cada lado, paralelas, ligeiramente impressas na face superior, levemente elevadas ou obscuras na página inferior, evanescentes perto das margens; vênulas obscuras. Inflorescência masculina comparativamente simples, geralmente 2-ramificada, paniculada, nas axilas superiores, $80-120 \mathrm{~mm}$ de comprimento; pedúnculo fino, $30-60 \mathrm{~mm}$ de comprimento, com os raminhos glabros ou esparsamente puberulentos, os últimos pedúnculos distalmente túrgidos; brácteas puberulentas, $3-5 \mathrm{~mm}$ de comprimento, logo decíduas; 5-15 flores nos fascículos mais novos; pedicelos finos até $2 \mathrm{~mm}$ de comprimento; perianto finamente carnoso, 2,0-2,4 mm de comprimento, ligeiramente ferrugíneo-puberulento externamente, infundibuliforme, trilobado quase até a base, lóbulos oblongos, obtusos; androceu $1,6-1,7 \mathrm{~mm}$ de comprimento; andróforo tênue, carnoso, um tanto túrgido na parte mediana, cerca de $1 \mathrm{~mm}$ de comprimento; 3 anteras, $0,6-0,7 \mathrm{~mm}$ de comprimento, soldadas até o ápice, obtusas. Inflorescência feminina e infrutescência não vistas. Fig. 3C-59.

TIPO: A. Ducke s.n., Brasil, Amazonas, alto rio Negro, Camanaus, 12 Out. 1932 fl. (holótipo: RB 24553; isótipos: $\mathrm{K}, \mathrm{P}, \mathrm{U}, \mathrm{US}$ ).

Distribuição: Espécie própria das pseudocaatingas baixas amazônicas do rio Negro sobre solo humo-silicoso, até hoje só conhecida pela coleção típica. Fig. 56.

Afim à $V$. venosa Warb. pela inflorescência, afasta-se pelas folhas, que são bem distintas.
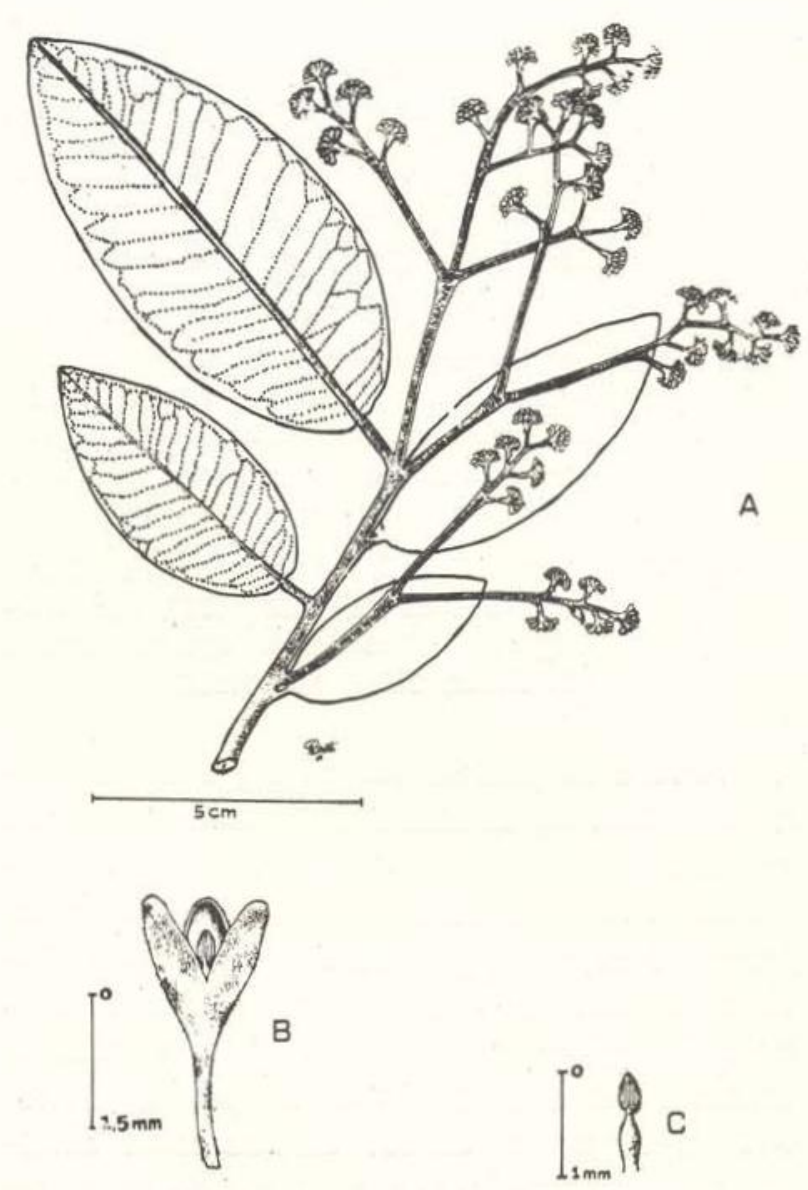

Fig. 59 - Virola parvifolia (A. Ducke s.n., RB 24553). A, hábito do ramo florifero $\mathrm{B}$, flor masculina; C, androceu.

25. Virola pavonis (A.DC.) A.C. Smith. Brittonia 2(5):504, fig. 9 g, h. 1937; A. Ducke, Arq. Serv. Florest. 1(1):28. 1939; A. Ducke, Bol. Técn. Inst. Agron. Norte 19:6. 1950; A.C. Smith, Contr. U.S. Nat. Herb. 29(8):329. 1950; J.C. Th. Uphof in Engl. \& Prantl, Nat. Pflanzenfam., 2. ${ }^{a}$ ed., 17a(2):208.. 1959; R.E. Schultes \& B. Holmstedt, Lloydia 34(1):73. 1971 .

Myristica pavonis A. De Candolle in DC., Prodr. 14: 697. 1856; A. De Candolle in Mart., Fl. Bras. 5 (1): 118. 1860.

Palala pavonii (A. DC.) Kuntze, Rev. Gen. PI. 2: 567. 1891, nom. illegit.

Myristica venosa (Benth.) Warb. var. pavonis Warburg, Nova Acta Acad. Leop.-Carol. 68: 225, tam. 7, fig. 1-2. 1897; J. C. Th. Uphof in Engl. \& Prantl, Nat. Pflanzenfam., 2.' ed. 17* (2): 208. 1959. 
Virola elliptica A. C. Smith, Bull. Torrey Club 60: 351. 1933; A. Ducke, Journ. Wash. Acad. Sci. 26 (6): 258. 1936. Tipo: Krukroff 1333, Brasil, Território de Rondônia, perto de Tabajara, alto rio Machado, Nov./Dez. 1931 fr. (holótipo: NY; isótipos: BM, GH, K, M, P, S, U, US).

Myristica balsamica Poepp. ex Warburg, Nova Acta Acad. Leop.-Carol. 68: 226. 1897, pro syn. Origem do nome: Poeppig 2048, Peru, Maynas alto, Mission de Tocache (rio Huallaga) fr. ( $P$; $B$ e $W$ destruidos).

Virola carinata sensu Ducke, Journ. Wash. Acad. Sci. 26 (6): 258. 1936, non Warburg, pro parte (excl. specim. Ducke, RB. 24502, 24503, MG 11265).

Arvore de porte mediano até $25 \mathrm{~m}$ de altura por $80 \mathrm{~cm}$ de diâmetro de tronco; raminhos estriados, os mais novos densa e uniformemente ferrugíneo-tomentelos ou puberulentos, passando depois a glabros e enegrescidos. Pecíolo fortemente canaliculado, rugoso, a princípio ferrugíneo-tomentelo como os raminhos, depois glabrescente, $1-2 \mathrm{~mm}$ de diâmetro, 4-13mm de comprimento. Lâmina foliar coriácea ou finamente coriácea, oblongo-elíptica ou obovado-elíptica, $80-210 \mathrm{~mm}$ de comprimento, 20-65 mm de largura, atenuada, aguda, obtusa, ou raramente arredondada na base, obtusamente cuspidada, subaguda, obtusa ou arredondada no ápice, a princípio densamente ferrugíneo-tomentela depois esparsamente pálido-puberulenta na página inferior (tricomas séssil-estrelados, 4-6-ramificados, 0,1-0,2mm de diâmetro), às vezes glabrescente; nervura mediana levemente imersa ou quase plana na página superior, saliente na inferior; $15-20$ nervuras secundárias de cada lado, impressas na página superior, elevadas na inferior, desordenadas ou ligeiramente ascendentes; vênulas planas ou levemente impressas. Inflorescência masculina amplamente paniculada, multiflora, livremente ramificada, $70-150 \mathrm{~mm}$ de comprimento e quase o mesmo de largura, a princípio densamente ferrugíneo ou pardo-puberulenta, os raminhos mais ou menos achatados e logo glabros; floies persistentemente puberulentas; pedúnculo de $20-40 \mathrm{~mm}$ de comprimento; brácteas oblongas, puberulentas, 4-7mm de comprimento, logo decíduas; fascículos mais novos com 3-8 flores; pedicelos tênues até $2 \mathrm{~mm}$ de comprimento; perianto carnoso, 1,5-2,0mm de comprimento, 3-lobado mais que a metade do seu comprimento total, lóbulos ovado-oblongos, obtusos; androceu $1,1-1,5 \mathrm{~mm}$ de comprimento; andróforo tênue, $0,7-0,8 \mathrm{~mm}$ de comprimento; 3 anteras, 0,4-0,7mm de comprimento, soldadas até o ápice ou levemente divergentes, obtusas. Inflorescência feminina, $50-160 \mathrm{~mm}$ de comprimento, livremente ramificada; pedúnculo até $45 \mathrm{~mm}$ de comprimento; 2-8 flores por fascículo; pedicelos grossos, 2-4mm de comprimento; ovário subgloboso ou elipsóide, densa e inteiramente castanho-puberulento; estigma fortemente partido. Infrutescência esparsamente puberulenta ou inteiramente glabra; frutos maduros normalmente poucos, pedicelados (pedicelo grosso, $4-7 \mathrm{~mm}$ de comprimento), elipsóides, $15-50 \mathrm{~mm}$ de comprimento, $12-35 \mathrm{~mm}$ de largura, em geral nitidamente carinados, obtusos ou subagudos no ápice; pericarpo coriáceo, rugoso, lenhoso, 2-7mm de espessura; arilo laciniado quase até a base; semente elipsóide, longitudinalmente sulcada pela pressão do arilo. Fig. 60-61.

TrPo: Ruiz \& Pavon s.n., Peru, Chicoplaya, $1798 \mathrm{fl}$. e fr. (holótipo: G-DC, n.v.; isótipos: BM, F, B destruído; fotos: $F$ 8539, IAN).

Nomes vUlgares: Ucuuba; ucuhuba; ucuubabranca-do-baixo (ex Aluísio 48) .

UTILIDADES: A madeira pode ser usada como sucedânea da ucuuba-da-várzea ( $V$. surinamensis) na confecção de laminados, compensados ou convertidas em tábuas para construção civil.

Frnologia: Tem sido colhida com flores nos meses de maio a janeiro, com mais freqüência entre julho e setembro e com frutos na estação chuvosa, de outubro a junho, sendo o mês de abril mais marcante. Fig. 17.

HaвiтAт: Ocorre muito comumente nas matas de terra firme, às vezes nas pseudocaatingas amazônicas sobre solo arenoso, menos freqüentemente nas matas pantanosas ou igapós de terra firme e em pequenos cursos d'água

Distribuição: Peru, Colômbia, Venezuela e no Brasil: Amazonas, Mato Grosso e Território de Rondônia. Fig. 56 . 


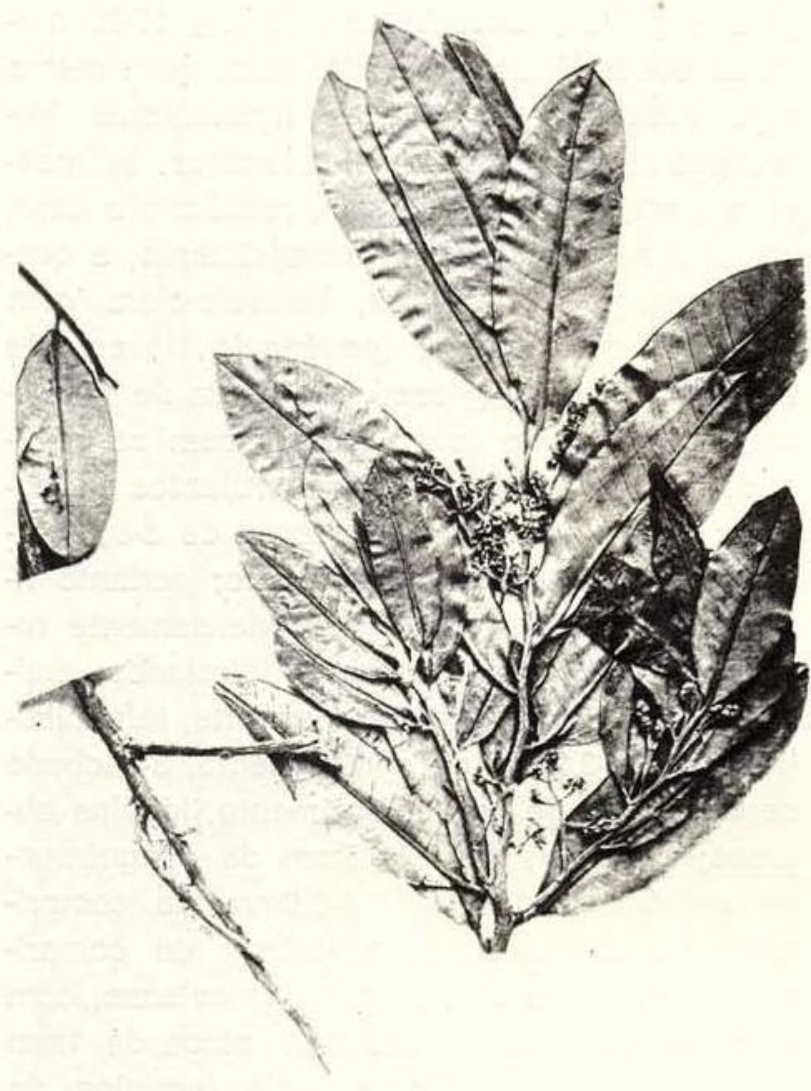

Fig. 60 - Virola pavonis. Pavon s.n. (reprodução da foto $F$ 8539, IAN).

\section{MATERIAL ADICIONAL EXAMINADO:}

AMAZONAS: - São Paulo de Olivença: A. Ducke 1059, Out. $1942 \mathrm{fl}$. (IAN, INPA, MG, NY, R, RB); id. s.n., Fev. 1932 fr. (RB 24504); id. s.n., Maio 1940 fl. (RB 53228); R. L. Froes 20766, Abr. 1945 fr. (IAN); id. 20716, Abr. 1945 fr. (IAN); id. 23972, Jan. 1949 fr. (IAN); rio Jundiatuba: J. Ramos s.n., Dez. 1975 fr. (INPA 54144); - Tonantins: A. Ducke 1496, Fev. 1944 fr. (IAN, MG, NY, R, RB, US); id. s.n., Fev. 1944 tr. (RB 53227. -- Fonte Boa: R. L. Froes 20629, Abr 1945 fr. (IAN, NY). - Tefé: D. Coêlho s.n., Nov. 1975 fr. (INPA 53738); E. Lleras et al P16579, Jul. $1973 \mathrm{fl}$. (INPA, NY). - Bacia do rio Negro - rio Uaupés: J. M. Pires et al. 7477, Fev. 1959 est. (IAN); id. 7478, Fev. 1959 est. (IAN); - Rodovia Perimetral Norte: O. C. Nascimento et al. 5 Abr. $1975 \mathrm{fr}$. (IAN, INPA); - São Gabriel da Cachoeira: O. C. Nascimento et al. 51. Abr. 1975 fr. (IAN, INPA); - Rio Içana: R. L. Froes 21400, Nov. 1945 fl. (IAN, NY); id. 22231, Abr. 1947 fr. (IAN); id. 22268, Abr. 1947 fr. (IAN, NY); id. 28148, Abr. $1952 \mathrm{fr}$. (IAN); - Tapuruquara: G. T. Prance et al. 15633, Out. $1971 \mathrm{fr}$. (INPA, NY); - Manaus: J. Aluísio 48, Jul. 1968 fl. (INPA); J. Chagas s.n., Dez. 1954 est. (INPA 363); D. Coêlho s.n., Dez. 1974 fl. (INPA 47280); id. s.n., Dez. 1974 fl. (INPA 47282); L Coêlho s.n., Jun. 1973 fr. (INPA 37128); id. s.n., Mar. 1957 fr. (INPA 5160); A. Ducke 1147,
Mar. 1941 fr. (IAN, MG, RB); id. 1299, Jul. 1943 fl. (IAN, MG, R, RB, RB); id. 1305, Ago. 1943 fl. (IAN, MG, R); id. s.n., Jun. $1933 \mathrm{fr}$. (RB 24501); id. s.n., Ago. 1935 fl. (RB 30145); id. s.n., Maio 1941 fl. (IAN 117); E. Ferreira s.n. Fev. 1957 est. (INPA 5055); R. L. Froes 24978, Ago. 1949 fl. (IAN); M. Freitas \& .Coêlho 19, Jun. $1970 \mathrm{fl}$. (INPA); F. Melo s.n., Jul. 1955 fl. (INPA 1307); J. M. Pires \& Coêlho s.n., Nov. $1962 \mathrm{fl}$.(INPA 13245);W. Rodrigues \& Osmarino 5999, Ago. 1964 fl. (INPA). - Estrada Manaus-Itacoatiara $\mathrm{Km}$ 133-134: A. Loureiro et al. s.n., Mar. 1975 fr. (INPA 48301); T. D. Pennington \& Monteiro P 22636, Set. 1974 fl. (INPA); Km 156: W. Rodrigues \& Coelho 9049, Maio 1972 est. (INPA); W. Rodrigues \& Montelro 9113, Ago. 1973 fl. (INPA); Km 165: D. Coêlho s.n., Dez. 1974 est. (INPA 47274); Km 182: A. Loureiro et al. s.n., Abr. 1975 fr. (INPA 48416). - Autaz-Mirim: A. Loureiro et al. s.n., Mar. 1973 fr. (INPA 37639); id. s.n., Jun. 1973 fr. (INPA 38954). - Estrada ManausPorto Velho - rio Castanho: M. F. Silva et al 339, Jul. $1972 \mathrm{fr}$. (INPA); - entre rios Castanho e Tupana: M. F. Silva et al. 926, Jul. 1972 fl. (INPA); id. 948, Jul. $1972 \mathrm{fl}$. (INPA); - entre rios Castanho e Araçá: M. F. Silva et al. 558, Jul. 1972 fl. (INPA); Km 190: G. T. Prance et al. 22810, Out. $1974 \mathrm{fr}$. (INPA). Humaitá: B. A. Krukoff 7172, Nov. 1934 fr. (NY); id. 7179, Nov. 1934 fr. (NY). - Parintins: A. Ducke s.n., Jan 1936 fl. (RB 30142); id. s.n., Jan. 1936 fr. (RB 30143).

TERRITÓRIO DE RONDÔNIA: - Região do rio Machado, perto de Tabajara: B. A. Krukoff 1496, Nov./Dez. 1931 fr. (NY).

MATO GROSSO: - Rio Aripuanã, salto dos Dardanelos: C. C. Berg et al. P18545, Out. 1973 fr. (INPA).

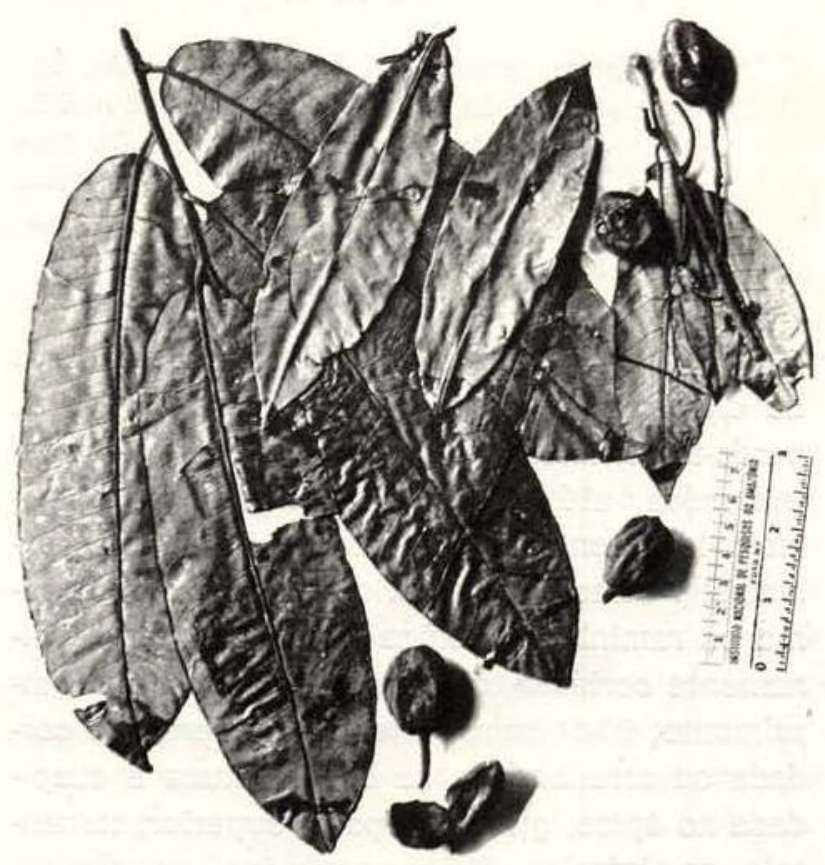

Fig. 61 - Virola pavonis. A. Ducke 1147 (IAN). 
Pelas folhas e inflorescências é praticamente impossivel distinguir esta espécie de V. carinata Warb., a não ser pelos frutos, aparentemente distintos. Segundo Ducke (I.c. 1950), V. pavonis Smith, é facilmente separável de $V$. carinata pelos seus raminhos cor de canela e folhas mais fortemente pilosas, fato este verificável em muitas das exsicatas examinadas, porém, infelizmente, com muitas exceções. Digno de nota também é a sua preferência pelas terras altas, longe dos cursos d'água ou alagadiços, onde a outra espécie parece não ocorrer normalmente.

27. Virola peruviana (A.DC.) Warburg, Nova Acta Acad. Leop.-Carol. 68:188. 1897; A. Ducke, Journ. Wash. Acad. Sci. 26(6):256. 1936; A.C. Smith \& Wodehouse, Brittonia, 2(5):472. 1937; A. Ducke, Arq. Serv. Florest. 1(1):26. 1939; A.C: Smith, Journ. Arnold Arb. 24(4):460. 1943; A.C. Smith, Am. Journ. Bot. 43(8):576. 1956; J.C. Th. Uphof in Engl. \& Prantl, Nat. Pflanzenfam., 2. ${ }^{a}$ ed., 17a(2):206. 1959; R.E. Schultes \& B. Holmstedt, Lloydia 34(1): 73. 1971; H. Garcia-Barriga, FI. Med. Colombia 1:347. 1974.

Myristica peruviana A. De Candolle, An. Sci. Nat. 4: 30. 1855; A. De Candolle in DC., Prodr. 14: 196 e 696. 1856; A. De Candolle in Mart., FI. Bras. 5 (1): 113. 1860.

Palala peruviana (DC.) Kuntze, Rev. Gen. PI. 2: 567. 1891, nom. illegit.

Arvore $10-35 \mathrm{~m}$ de altura; tronco até $55 \mathrm{~cm}$ de diâmetro; raminhos muitas vezes grossos, pardo-tomentelos (tricomas irregularmente ramificados, até $0,2 \mathrm{~mm}$ de comprimento). Pecíolo levemente canaliculado, $1,5-4 \mathrm{~mm}$ de diâmetro, $7-20 \mathrm{~mm}$ de comprimento, tomentelo como os raminhos. Lâmina foliar coriácea ou finamente coriácea, oblonga, $160-350 \mathrm{~mm}$ de comprimento, $60-110 \mathrm{~mm}$ de largura, levemente cordada ou arredondada na base, obtusa a cuspidada no ápice, glabra na parte superior, tomentela na inferior (tricomas séssil-estrelados, 4-7 ramificados, cerca de $0,2 \mathrm{~mm}$ de diâmetro), glabrescente; nervura mediana elevada na pá- gina superior, saliente na inferior; $17-30$ nervuras secundárias de cada lado, geralmente algo ascendentes; vênulas ligeiramente impressas na face superior ou obscuras. Inflorescência masculina paniculada, ramificação livre, multiflora, $100-180 \mathrm{~mm}$ de comprimento, e quase o mesmo de largura, amarelo-clara com tricomas ferrugíneos; pedúnculo levemente achatado e muito grosso (até $8 \mathrm{~mm}$ de diâmetro), $15-60 \mathrm{~mm}$ de comprimento, com os raminhos e flores inteiramente puberulentos ou glabros: flores em fascículos laxos de 3-8, pedicelos até $3,5 \mathrm{~mm}$ de comprimento; perianto finamente carncso, em geral densamente tomentelo com tricomas séssil-estrelados, muitas vezes puberulento internamente, infundibuliforme, 2,3-3,2 $\mathrm{mm}$ de comprimento, 3-4-lobado cerca de $1 / 3$ de seu comprimento, lóbulos obtusos; androceu de 1,2-1,5mm de comprimento; andróforo carnoso, $0,4-0,6 \mathrm{~mm}$ de comprimento; 3 ou 4 anteras, $1,1-1,6 \mathrm{~mm}$ de comprimento, soldadas até o ápice, apiculadas, com apículos geralmente inteiros, cerca de $1 \mathrm{~mm}$ de comprimento. Inflorescência feminina de $30-50 \mathrm{~mm}$ de comprimento, tomentela como a inflorescência masculina; ovário elipsóide, densamente tomentoso (tricomas de cerca de $0,2 \mathrm{~mm}$ de comprimento, com alguns apêndices laterais indistintos). Infrutescência até $100 \mathrm{~mm}$ de comprimento, glabrescente; 5-15 frutos maduros por infrutescência, pedicelados (pedicelos grossos, 4-6mm de comprimento) elipsóides, $20-28 \mathrm{~mm}$ de comprimento, $15-22 \mathrm{~mm}$ de largura, ferrugíneo-tomentosos, como o ovário, glabrescentes, agudos ou apiculados no ápice, distintamente carinados; pericarpo $0,5-1,5 \mathrm{~mm}$ de espessura, na maturidade muitas vezes levemente pontuado; arilo grosso. Fig. 62 .

TrPo: Ruiz \& Pavon s.n., Peru, Pozuzo, 1855 fl. (holótipo: G-DC, não visto; isótipos: B, destruido; $\mathrm{BM}, \mathrm{F}, \mathrm{K}, \mathrm{P}$ ).

Nome vUlgar: Ucuuba: xá-kee (ex Garcia-Barriga 14006 apud Schultes \& Holmstedt I.c. 1971); rá-pa (ex Schultes \& Cabrera 17736 apud Schultes \& Holmstedt I.c. 1971).

UTILIDADES: Segundo Schultes \& Holmstedt (I.c. 1971) e Garcia-Barriga (I.c. 1974), a planta pode ser empregada como alucinogêni- 


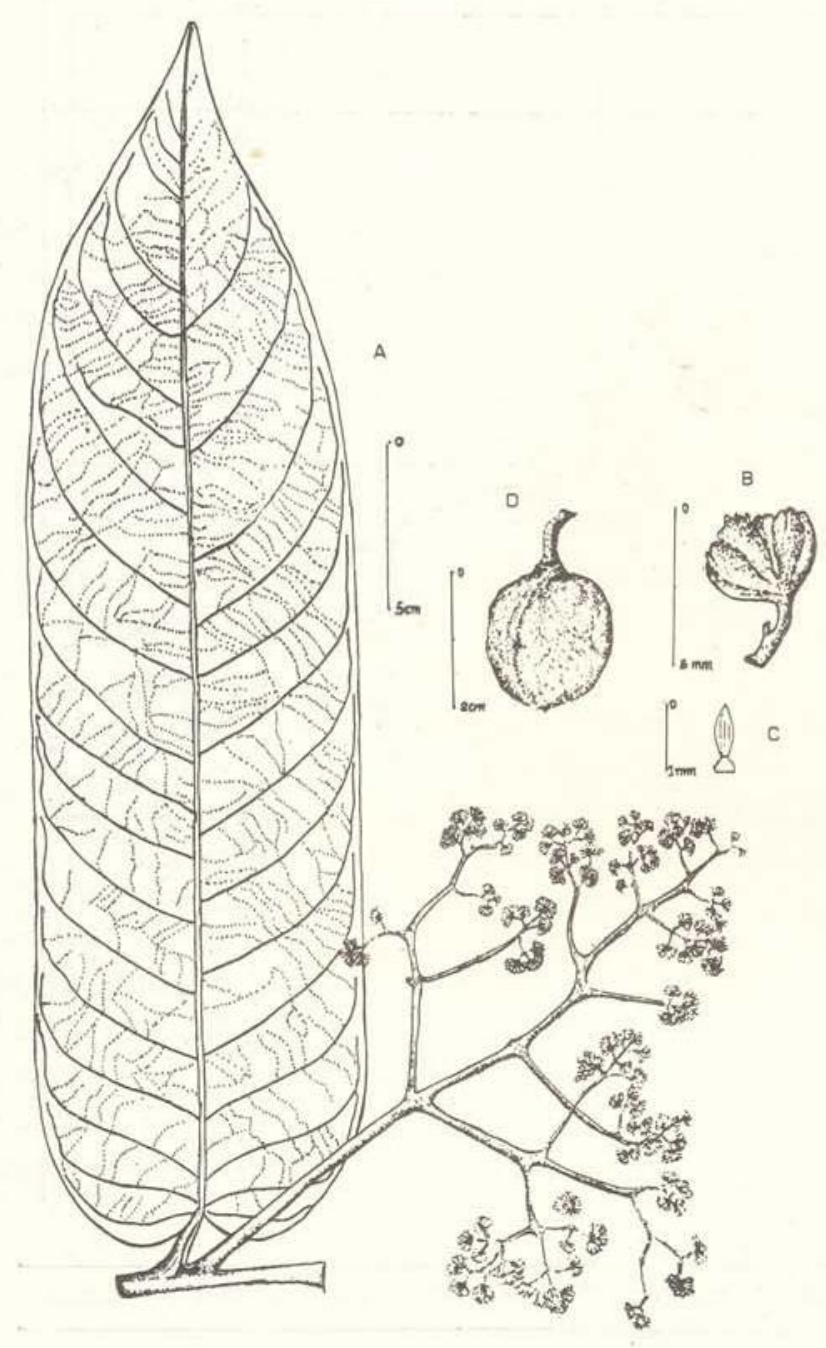

Fig. 62 - Virola peruviana. A-C (C. C. Berg et al. 19742 e A. Ducke s.n., RB 24552): A, hábito do ramo florífero masculino; B, fascículo floral; C, androceu; D (J. Schunke V. 3243), fruto.

ca não só porque deu resultado positivo para alcaloide no campo como pelo nome local "yá-Kee" usado pelos índios Puinave da Colômbia o qual sugere seu possível emprego no preparo do rapé alucinogênico do mesmo nome. Ainda, de acordo com os primeiros autores citados (I.c. 1971), em Letícia costuma-se empregar a resina da casca contra dores de dente.

Fenologia: Colhida em flor nos meses de abril a outubro e com frutos em julho e dezembro.

HABITAT: É assinalada sua ocorrência não só nas matas de terra firme como nas margens inundáveis de rio. Em geral, aparece nas regiões de baixa altitude, porém no Departamento de Huanago, Peru, foi encontrada, excepcionalmente, na cordilheira andina a cerca de $2100 \mathrm{~m}$ de altura (ex C. M. Belshaw 3091 NY.).

Distribuição: Amazônia brasileira, colombiana, equatoriana e peruana. Para o Equador é pela primeira vez que esta espécie é registrada (ex P. J. Grubb et al. 1629, cercanias de Tena, (lat. $0^{\circ} 30^{\prime} \mathrm{S}$; long. $78^{\circ} \mathrm{W}$ ), Set. $1960 \mathrm{fr}$. (K, NY)). Fig. 63.

\section{MATERIAL ADICIONAL EXAMINADO:}

AMAZONAS: - Bacia do rio Purus: - Lábrea: G. T. Prance et al. 8106, Out. $1968 \mathrm{fr}$. (INPA); id. 13692, Jun. 1971 fl. (INPA, NY); - Boca do Acre: A. Ducke s.n., Mar. 1933, fl. (RB 24552, INPA). - AutazMirim: C. C. Berg, Bisby \& Monteiro P19742, Ago. 1973 fl. \& fr. (INPA).

ACRE: - Tarauacá: G. T. Prance, Ramos \& Farias 7510, Set. 1968 fr. (GH, INPA, M, NY). - Sena Madureira: G. T. Prance et al. 7862, Out. 1968 fr. (GH, INPA, M, NY).

Afim à $V$. elongata Warb., diferencia-se pelas folhas em geral bem mais longas, amplamente arredondadas ou subcordadas na base, flores maiores, anteras pelo menos duas vezes maiores que o andróforo, e também pela forma e tamanho do fruto.

É freqüentemente confundida $\operatorname{com} V$. calophylla na ausência de flores masculinas; distingue-se desta facilmente pelo androceu.

28. Virola polyneura W. Rodr., Ciência e Cultura, Suplemento, 29(7):559. 1977; Acta Amazonica 7(4):467, fig. 5. 1977.

Árvore de 20m de altura; tronco cerca de $40 \mathrm{~cm}$ de diâmetro; raminhos novos achatados, estriados, tênue e irregularmente rufotomentosos (tricomas irregularmente ramificados desde a base, 0,2-0,3mm de comprimento), glabrescentes. Pecíolos fortemente canaliculados, cerca de 2-3mm de diâmetro, $10-25 \mathrm{~mm}$ de comprimento, rufotomentosos como os raminhos continuando na nervura mediana. Lâmina foliar tenuemente coriácea, elíptica ou obovado-elíptica, $55-110 \mathrm{~mm}$ de comprimento, $40-85 \mathrm{~mm}$ de largura, pouco discolores, opaca em ambas as fa- 


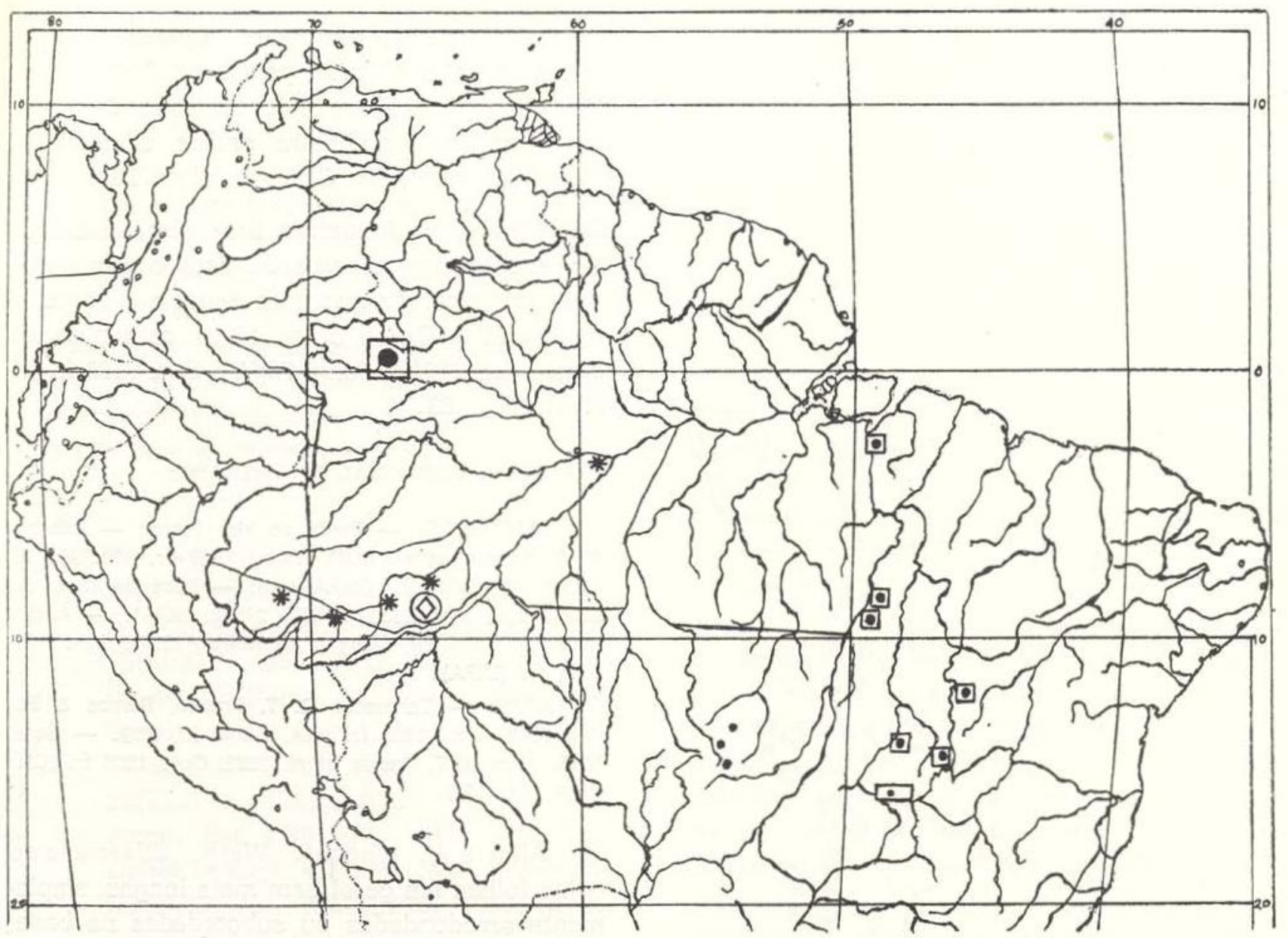

Fig. 63 - Distribuição atual de Virola peruviana V. polyneura, v. rugulosa, v. sessilis e v. subsessilis no Brasil.

ces, ou levemente brilhosa na face superior, cordada a truncada ou desigual na base, subaguda ou obtusamente cuspidada no ápice, glabra na página superior, exceto sobre a nervura mediana, página inferior tomentosa com tricomas estipitado - estrelados cerca de $0,2-0,5 \mathrm{~mm}$ de comprimento; nervura mediana plana ou ligeiramente imersa na página superior, saliente na inferior; 30-50 nervuras secundárias de cada lado afastadas $3-7 \mathrm{~mm}$ entre si ((16) $19-27$ por $10 \mathrm{~cm}$ ) retilíneas, paralelas, anastomosadas perto das margens, levemente impressas na página superior, salientes na inferior; vênulas transversais e reticuladas levemente imersas na página superior, promínulas na inferior. Inflorescência masculina ainda não desenvolvida de todo, paniculada, até cerca de $50 \mathrm{~mm}$ de comprimento e quase o mesmo tanto de largura, constituída de 4 ramos laterais principais; pedúnculo robusto, $5-9 \mathrm{~mm}$ de com- primento, raminhos densa e uniformemente rufotomentosos, tricomas irregulares ramificados, cerca de $0,5-0,7 \mathrm{~mm}$ de comprimento; brácteas ferrugíneo-tomentelos amplamente ovais, acuminadas ou agudas no ápice, $5-7 \mathrm{~mm}$ de comprimento, logo decíduas; fascículos florais densos, multifloros, robustos, cerca de $6-8 \mathrm{~mm}$ de diâmetro. Inflorescência feminina desconhecida. Infrutescência até cerca de $40 \mathrm{~mm}$ de comprimento, muito pouco ramificado; $4-5$ frutos por infrutescência, pedicelados (pedicelos, cerca de $3-6 \mathrm{~mm}$ de comprimento), elipsóides ou obovados, 20-23mm de comprimento, $15-18 \mathrm{~mm}$ de largura, carinados em ambas as extremidades, curtissimamente estipitados, arredondados, levemente apiculados no ápice, verdes, glabros, com vestígio de tênue tomento ferrugíneo apenas na base (tricomas irregularmente ramificados, cerca de $0,2-0,3 \mathrm{~mm}$ de comprimento), pericarpo tênue, cerca de $1-2 \mathrm{~mm}$ de 
espessura; sementes elipsóides ou obovóides revestidas de arilos laciniados até quase a base. Fig. 64 .

TIPo: G. T. Prance et al. 14425, Brasil, Amazonas, bacia do rio Purus, rio Curuquetê subafluente do rio Ituxi, São Paulo, a $30 \mathrm{~km}$ acima da boca do rio Coti, 19 Jul. 1971, flores em botão (holótipo INPA 32641; isótipo NY); H. Garcia-Barriga 14979, Colômbia, Vaupés, rio Vaupés, cachoeira de Yurupari, 24-26 Out. 1952 (COL).

Habitat: Mata das margens elevadas do rio. Altitude até 400m (ex Garcia-Barriga 14979), na Colômbia.

Distribuição: Amazônia brasileira e colombiana. Fig. 63.

Próxima de $V$. rugulosa Warb., distingue-se principalmente pelos raminhos novos glabrescentes, pecíolos bem mais longos, fo!has, inflorescência e infrutescência mais curtas, nervuras secundárias nitidamente mais condensadas e aparentemente mais numerosas, e também pelos frutos arredondados e um tanto estipitados na base.

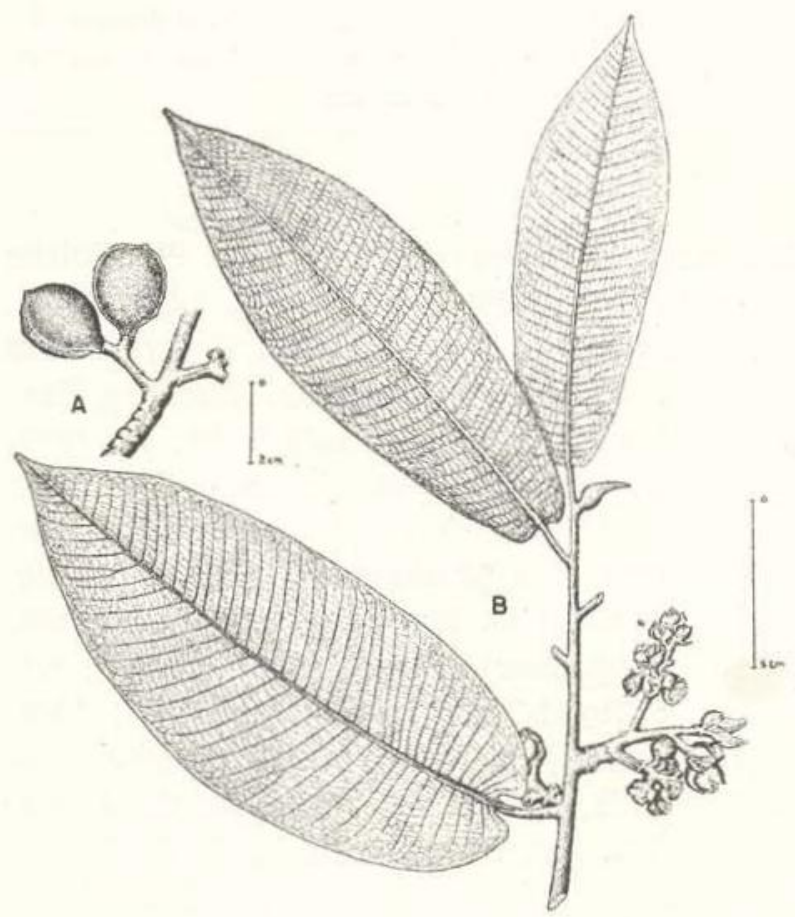

Fig. 64 - Virola polyneura. A (G. T. Prance et al. 14425), hábito florifero; B (H. Garcia-Barriga 14979), infrutescência.
29. Virola rugulosa (Spruce) Warburg, Nova Acta Acad. Leop.-Carol. 68:227, tab. 5, fig. 1-5. 1897; A.C. Smith \& Wodehouse, Brittonia 2(5):485. 1937; A. Ducke, Bol. Técn. Inst. Agron. Norte 19:6. 1950; J.C. Th. Uphof in Engl. \& Prantl, Nat. Pflanzenfam., 2. ${ }^{a}$ ed., 17a(2):207. 1959; descr. ampla.

Myristica rugulosa Spruce, Journ. Linn. Soc. 5: 4. 1861, nom. nud.

Palala rugulosa (Spruce) O. Kuntze, Rev. Gen. PI. 2: 567. 1891, nom. nud.

Árvore até $35 \mathrm{~m}$ de altura; tronco de cerca de $30 \mathrm{~cm}$ de diâmetro; raminhos densamente tomentosos (tricomas ferrugíneos, pouco ramificados, até $1 \mathrm{~mm}$ de comprimento). Pecíolo grosso, 3-4mm de diâmetro, fortemente canaliculado, $8-11 \mathrm{~mm}$ de comprimento, tomentoso como os raminhos. Lâmina foliar finamente coriácea, meio bolhosa, oblonga, 200-270mm de comprimento, $70-95 \mathrm{~mm}$ de largura, arredondada a cordada na base, cuspidada no ápice, muitas vezes nitidamente revoluta nas margens, glabra na página superior, só excepcionalmente densamente tomentela na nervura mediana, tomentosa na página inferior (tricomas estipitados, pouco ramificados, 0,2-0,4 mm de comprimento); nervura mediana plana ou ligeiramente imersa na página superior, muito saliente na inferior; 23-27 nervuras secundárias de cada lado, retas, nitidamente anastomosadas perto das margens, recurvadas em direção à base, impressas ou ligeiramente elevadas na página superior, salientes na inferior; nervuras terciárias impressas na face superior, obscuras na inferior. Inflorescência masculina até $250 \mathrm{~mm}$ de comprimento, e quase o mesmo de largura, ramificação livre, amplamente paniculada, densiflora, raminhos e flores densamente tomentosos (tricomas irregularmente ramificados, até $1 \mathrm{~mm}$ de comprimento nos raminhos e cerca de $0,2 \mathrm{~mm}$ de comprimento nas flores); pedúnculo, $30-60 \mathrm{~mm}$ de comprimento; brácteas indistintas, logo decíduas; 20-50 flores em fascículo razoavelmente compacto, 5-8mm de diâmetro; pedicelos tênues, até $2 \mathrm{~mm}$ de comprimento; perianto amarelopálido, submembranáceo, $1,3 \mathrm{~mm}$ de comprimento, 3-4 lobado quase até a base, lóbulos 
oblongos, obtusos, estendidos na maturidade; androceu $0,8-0,9 \mathrm{~mm}$ de comprimento; andróforo tênue; 3 anteras subiguais ao andróforo ou ligeiramente menor, soldadas em direção ao ápice, obtusas ou livremente retusas. Inflorescência feminina não vista. Infrutescência 120-150mm de comprimento, ramificação simples; pedúnculo, raminhos e pedicelos densamente ferrugíneo-tomentosos; pedúnculo $45-80 \mathrm{~mm}$ de comprimento, levemente achatado; 2-6 frutos por infrutescência, pedicelados (pedicelos grossos de $5-7 \mathrm{~mm}$ de comprimento), $15-20 \mathrm{~mm}$ de comprimento, $15-17 \mathrm{~mm}$ de largura, ovóide-elipsóides, obtusos no ápice e truncados ou subcordados na base, carinados, escassamente ferrugíneo-tomentosos e enegrecidos, glabrescentes; pericarpo duro de $3 \mathrm{~mm}$ de espessura; sementes não vistas. Fig. 65 .

TIPo: Spruce 3140. Venezuela, Amazonas, rio Negro, São Carlos, Out. 1853 fl. (holótipo: B, destruído; lectótipo: $\mathrm{K}$; isótipos: $\mathrm{BM}, \mathrm{NY}, \mathrm{P}$; W, destruído).

HaBtTat: Beira de igarapé.

Distribuição: Espécie rara, só conhecida da localidade típica na Venezuela e do alto rio $\mathrm{Ne}-$ gro, no Brasil. Fig. 63.

\section{MATERIAL ADICIONAL EXAMINADO:}

AMAZONAS: - Rio Içana, afluente do rio Negro: Cobari: R. L. Froes 21473, Dez. 1945 fr. (IAN, K, NY, US).

Os frutos, conforme Ducke (I.c. 1950) já havia observado, é morfologicamente semeIhante aos de $V$. calophylla Warb., embora noutros aspectos nada tenha a ver com esta espécie. A descrição da infrutescência foi baseada na coleção Froes 21473.

Distingue-se de V. polyneura Rodr. pelos raminhos densamente ferrugíneo-tomentosos, pecíolos mais curtos, nervuras secundárias mais espaçadas, e pelo fruto truncado ou subcordado na base e indistintamente estipitado. V. duckei Smith é a espécie mais próxima, da qual se diferencia pelo reticulado bem mais distinto e pela lâmina foliar nitidamente bolhosa.
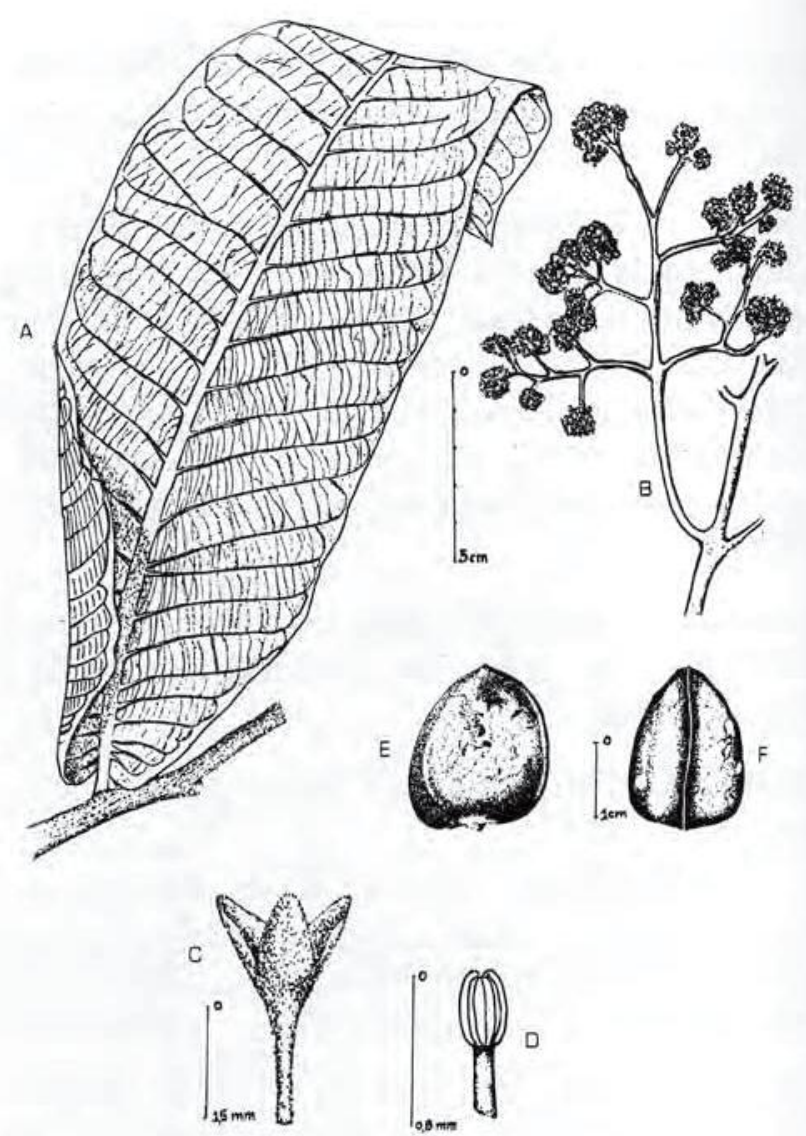

Fig. 65 - Virola rugulosa. A e B (recopiado de Warburg, 1897): A, folha; $B$, inflorescência masculina; $C$ e D (Spruce 3140): C, flor masculina; D, androceu; E-F (R. L. Froes 21473): E, fruto de lado; F, fruto, mostran. do a carena.

30. Virola sebifera Aublet, Hist. PI. Guiane Franc. 2:904, tab. 345, fig. 1-5. 1755; E. Twining. Illustr. Natural Orders Plants 2:118, tab. 2. 1868; O. Warburg, Ber. Pharm. Ges.. 225 e 228, fig. 12. 1892; O. Warburg, Ber. Deutsch. Bot. Ges.: 13:81, tab. 29, fig. 1 a-b. 1895; O. Warburg, Die Muskatnuss: 388 , tab. 4 , fig. 3. 1897; O. Warburg, Nova Acta Acad. Leop.-Carol, 68:169, tab. 1, fig. 5-6; tab. 5, fig. 1-3. 1897; J. Huber, Bol. Mus. Goeldi 6:173. 1909; Van Ooststroom in Pulle, FI. Surin. 2:118. 1934; G. Malme, Ark. Bot. 26 A (9):29. 1935; A. Ducke, Journ. Wash. Acad. Sci. 26(6):255. 1936; L. Williams, Field Mus. Nat. Bot. 15:139. 1936; A. C. Smith \& Wodehouse, Brittonia 2 (5) :463. 1937; A. Ducke, Arq. Serv. Forest. 1(1):25. 1939; A.C. Smith, Britto- 
nia 3(2):339. 1939; F.C. Hoehne, Arborização Urbana: 170. 1944; P. Le Cointe, Amazonia Brasileira III, Brasiliana, 2. ${ }^{a}$ ed., 251:481. 1947; G. Erdtman, PolIen Morphology and Plant Taxonomy: 278, fig. 163 A. 1966; A. Lemée, FI. Guyane Franc. 4:33. 1956; J.C. Th. Uphof in Engl. \& Prantl, Nat. Pflanzenfam., 2. ${ }^{a}$ ed., 17a(2):206. 1959; J.A. Duke, An. Missouri Bot. Gard. 49:221, fig. 170. 1962; J.C. Lindeman \& A.M.W. Mennega, Meded. Bot. Mus. Herb. Rijkuniv. Utrecht 200:244, tab. 69, fig. M 1-3. 1963; A.L. Camargo, Catálogo ilustrado de las plantas de Cundinamarca 4:94, fig. 31. 1970; R.E. Schultes \& B. Holmstedt, Lloydia 34(1):74. 1971; C.T. Rizzini, Árvores e madeiras úteis do Brasil: 186. 1971; Fitoquímica-INPA, Acta Amaz. 1(3):50. 1971.

Myristica sebifera Swartz, Nova Gen. Sp. Pl.: 96. 1788; M. Lamarck, Mém. Acad. Roy. Sci. Paris: 154 e 165. 1788 (1791); Gmelin in C. Linné, Syst. Nat. 2: 11. 1791; M. Lamarck, Encycl. Méth. Bot. 4: 389. 1791; Willdenow in Linné, Sp. PI. 4: 872. 1805; Spix \& Martius, Reisen Bras. 3: 1130. 1828 (1966); M. C. Spach, Hist. Nat. Veg. Phanerog. 7: 537. 1839; Endlicher, Enchiridium Bot.: 1841; R. Schomburgk, Reisen Brit. - Guian. 3: 979 e 1162. 1848; G. Bentham, Hook. Journ. Bot. 5: 5. 1853; A. De Candolle in DC., Prodr. 14: 195 e 696. 1856; A. De Candolle in Mart., FI. Bras. 5 (1): 109, tab. 39, fig. 4; tab. 40, fig. 1. 1860; M. J. Caminhoá, Comp. Bot. Geral e Med. 3: 2322. 1884; T. Peckolt \& G. Peckolt, Hist. Plantas Medicinais e Úteis do Brasil: 1341. 1889; Rusby, Mem. Torrey Bot. Club 5: 112. 1896; M. H. Stone, An. Mus. Col. Marseille 8 (2): 2. 1922; J. B. Spix \& C. F. P. Martius, Viagem pelo Brasil 3: 232. 1938.

Myristica sebifera var. cordifolia A. De Candolle in DC., Prodr. 14: 195. 1856; A. De Candolle in Mart., Fl. Bras. 5 (1): 109. 1860. Tipo: G. Gardner 3566, Brasil, Goiás. 1841 fl. (holótipo: G-DC, n.v.; isótipos: B, BM, K, NY, P).

Myristica cordifolia Mart. ex A. DC. in DC., Prodr. 14: 195. 1856, pro syn.

Myristica sebifera var. curvinervia A. De Candolle in DC., Prodr. 14: 195. 1856; A. De Candolle in Mart., FI. Bras. 5 (1): 109.
1860. Tipo: Manco \& Lhotzby 57, Brasil. Mato Grosso, Cuiabá, s/data, fl. (holótipo: G-DC, n.v., isótipos: $B$ e W destruídos; M., n.v.).

Virola sebifera var. curvinervia (A. DC.) Warburg, Nova Acta Acad. Leop.-Carol. 68: 174. 1897, incl. var. cordifolia A. DC. pro syn.

Palala sebifera (Aubl.) O. Kuntze, Rev. Gen. PI. 2: 567. 1891, nom. illegit.

Myristica mocoa A. De Candolle in DC., Prodr. 14: 195. 1856; A. De Candolle in Mart., Fl. Bras. 5 (1): 110. 1860.

Virola mocoa (A. DC.) Warburg, Nova Acta Acad. Leop.-Carol. 68: 183. 1897; A. Ducke, Journ. Wash. Acad. Sci. 26 (6): 256. 1936; L. Williams, Field Mus. Nat. Hist. Bot. 15: 137. 1936. Tipo: Poeppig 2390. Peru, Loreta $(=$ Maynas). Yurimaguas. Huallaga, 1830 fl. (holótipo: G-DC, n.v.; isótipos: B e W destruídos; F, L, US; fotos: F 1963, IAN, NY).

Palala mocoa (Poepp.) Kuntze, Rev. Gen. PI. 2: 567 . 1891, nom. illegit.

Myristica virola Raeusch in Steud., Nomencl. Bot. 2: 175. 1841, nomen.

Myristica panamensis Hemsl., Biol. Centr. Am. Bot. 3: 67. 1882 e 5: tab. 74, fig. 1-4. 1882. Tipo: Seemann 545, Panamá, St. Cruce, s/data fl. (lectótipo: $\mathrm{K}$; isolectótipo: BM); Hayes 618, Panamá, Lion Hill Station, $\mathrm{s} /$ data (parátipo: $\mathrm{K}$ espécim. misto).

Virola panamensis (Hemsl.) Warburg, Nova Acta Acad. Leop.-Carol. 68: 185. 1897.

Palala panamensis (Hemsl.) Kuntze, Rev. Gen. PI. 2: 567. 1891, nom. illegit.

Virola venezuelensis Warburg, Nova Acta Acad. Leop.-Carol. 68: 182. 1897; H. Pittier, Las Plantas Usuales de Venezuela: 458. 1936. Tipo: Karsten s.n., Venezuela, Pt. Cabello, s/data fr. holótipo: B, destruído; isótipo: W, destruído; fotos: F 1971, IAN, NY).

Virola boliviensis Warb., Nova Acta Acad. Leop.--Carol. 68: 184, tab. 7, fig. 1-5. 1897. Tipo: H. H. Rusby 1216, Bolivia, Mapiri, $2500 \mathrm{ft}$., Maio $1886 \mathrm{fl}$. \& fr. (holótipo: B, destruído; isótipos: BM, F, G, K, M, NY, P, US).

Virola peruviana var. tomentosa Warb., Nova Acta Acad. Leop.-Carol. 68: 189. 1897. Tipo: Ruiz \& Pavan s.n., Peru, s/data fl. (holótipo: B, destruido; isótipo: F, n.v.).

Myristica fulva Richard ex Warburg. Nova Acta Acad. Leop.-Carol. 68: 169. 1897, pro syn. Origem do nome: Lamarck, G. Francesa, Caiena $(P)$. 
Virola mycetis Pulle, Rev. Trav. Bot. Neerl. 4 (1-2): 125. 1907; van Ooststroom in Pulle, FI. Surin. 2: 119. 1934 e 2 (1): 474. 1939. Tipo: Van Hall 8, Suriname, Ago. ano (!), pro parte excl. infl.

Virola warburgii Pittier, Contr. U.S. Nat. Herb. 18: 143, tab. 57, 1937. Tipo: H. Pittier 3505, Panamá, Panamá, Alhajuela, rio Chagres 12 Maio 1911 fr. (holótipo: US; isótipo: $\mathrm{BM}, \mathrm{GH}$ ).

Árvore pequena a grande até $30 \mathrm{~m}$ de altura, muitas vezes com sapopemas; tronco acima das sapopemas até $1,3 \mathrm{~m}$ de diâmetro; ramos distintamente verticilados; raminhos freqüentemente rugosos, a princípio densamente tomentosos (tricomas estrelados desde a base ou irregularmente ramificados, cerca de $0,2 \mathrm{~mm}$ de comprimento), passando a puberulentos ou glabrescentes com a idade. Pecíolo levemente canaliculado, $2-5 \mathrm{~mm}$ de diâmetro, $10-15 \mathrm{~mm}$ de comprimento, tomentoso como os raminhos. Lâmina foliar coriácea, geralmente lustrosa na página superior, oblonga, ovada ou elíptico- ou deltóide-oblonga, $150-470 \mathrm{~mm}$ de comprimento, $60-150 \mathrm{~mm}$ de largura (folhas às vezes menores nos raminhos floríferos), cordada, arredondada, truncada ou amplamente obtusa na base, acuminada, aguda ou cuspidada no ápice, glabra na página superior, uniformemente tomentosa na face inferior (tricomas dendríticos, estrelados ou irregularmente estrelados, 3-6-ramificados, $0,2-0,3 \mathrm{~mm}$ de comprimento, o estipe, às vezes, obscuramente articulado), passando, às vezes, a mais ou menos glabrescente com a idade; nervura mediana saliente em ambas as faces, muito elevada na página inferior; 10-28 nervuras secundárias de cada lado, retas ou arqueadas, levemente impressas ou elevadas na página superior, salientes na página inferior; vênulas planas ou levemente impressas na página superior e promínulas na inferior. Inflorescência masculina amplamente paniculada, livremente ramificada, densiflora, $80-230 \mathrm{~mm}$ de comprimento e largura; pedúnculo de $15-70 \mathrm{~mm}$ de comprimento, com os raminhos e flores inteiramente tomentelos (tricomas estrelados ou irregularmente ramificados, $0,1-0,2 \mathrm{~mm}$ de comprimento), às vezes glabrescente; brácteas indistintas ou nulas; 3-10 flores laxas nos fascículos mais novos, subsésseis ou com pedicelos tênues até $3 \mathrm{~mm}$ de comprimento; perianto tenuemente carnoso, infundibuliforme, glabro internamente, $1,8-2,5 \mathrm{~mm}$ de comprimento (raramente 1,3 ou $3 \mathrm{~mm}$ de comprimento), 3 (ocasionalmente 4 ou 5) - lobado cerca de $1 / 3$ de seu comprimento, lóbulos obtusos; androceu de 0,9-2 $\mathrm{mm}$ de comprimento; andróforo carnoso de $0,2-0,6 \mathrm{~mm}$ de comprimento, comumente túrgido na base; 3 anteras normalmente (às vezes 4 ou 5) de $0,7-1,5 \mathrm{~mm}$ de comprimento, soldadas até o ápice ou mais ou menos divergentes distalmente, mas raro nitidamente deste modo, apiculadas no ápice, o apículo simples ou dividido com $0,1-0,2 \mathrm{~mm}$ de comprimento. Inflorescência feminina, $30-70 \mathrm{~mm}$ de comprimento, quase o mesmo de largura, tomentela como a inflorescência masculina; pedúnculo de $5-40 \mathrm{~mm}$ de comprimento; flores isoladas ou em pequenos fascículos de 2-5, pedicelos grossos de 1-2mm de comprimento; ovário subgloboso, freqüentemente mais ou menos agudo no ápice, densamente tomentoso (tricomas de 0,2-0,3mm de comprimento, com apêndices esporoniformes, laterais curtos); estigma pequeno, séssil. Infrutescência freqüentemente maior do que a inflorescência, ramos às vezes achatados; 10-30 frutos maduros por infrutescência, pedicelados (pedicelos tênues de $1-4 \mathrm{~mm}$ de comprimento), elipsóides ou subglobosos, lisos ou levemente carinados; $10-19 \mathrm{~mm}$ de comprimento (raramente até $21 \mathrm{~mm}$ ), $7-14 \mathrm{~mm}$ de largura (raramente até $17 \mathrm{~mm}$ ) densamente tomentosos na maturidade (tricomas de 0,2-0,8, raramente até $1 \mathrm{~mm}$ de comprimento, com numerosos apêndices esporoniformes laterais, curtos) depois glabrescentes; pericarpo de $0,5-1 \mathrm{~mm}$ de espessura (raramente até $2 \mathrm{~mm}$ ); arilo laciniado ao menos até o meio de seu comprimento e geralmente mais profundamente. Figs. 3-66.

TIPO: Aublet s.n., Guiana Francesa, Caiena fl. e fr. (holótipo (?): BM)

Nomes vulgares: Árvore-de-cera (fide Peckolt \& Peckolt I.c. 1889); árvore-de-graxa (fide Peckolt \& Peckolt, I.c. 1889); árvore-de-sebo (fide Peckolt \& Peckolt, I.c. 1889); bicuíba; bicuíba-vermelha; bequíba (fide Pinto, I.c. 1873); lacre (fide Acher 8300); pindaíba (fide Mattos \& Rizzini 129); pindaíba-roxa (ex RB 120103, 
Goiás); pau-de-mato (ex Carauta 300); ubucuba (fide Peckolt \& Peckolt I.c. 1889); ucuuba $=$ ucuhuba (Amazonas); ucuuba-de-capoeira (ex Pinheiro 24); ucuuba-da-folha-larga (ex Huber, MG 133); ucuuba-da-terra-firme (ex Ducke 596); ucuuba-do-mato (ex Oliveira 2401); ucuuba-preta (fide LeCointe 1947); ucuuba-vermelha (ex Capucho 595, Ducke, MG 2638); ucuubarana (ex Oliveira 3296); ucuubinha (ex Froes 11644); urucuuba (fide Peckolt \& Peckolt I.c. 1889) urucurana-vermelha (ex Froes 1752), ucuuba-de-sebo (fide Peckolt \& Peckolt, I.c. 1889).

UTILIDADES: A casca da árvore é usada pelos nativos como alucinogênico, segundo Schultes \& Holmstedt (I.c. 1971). Contém como princípio ativo básico as substâncias $\mathrm{N}, \mathrm{N}$-dimetiltriptamina e 2-metiltetrahidro- $\beta$-carbolina. A resina vermelha, que exsuda da casca por incisão, é empregada popularmente contra aftas, dor de dente cariado, reumatismo, gripes, em gargarejos, nas anginas, em loções, e nas erisipelas. Como medicamento é também usado nos embaraços de cabeça, enfraquecimento ou perda da memória e inflamação da faringe O sebo ou matéria gordurosa que se obtém da amêndoa do fruto é também receitado casei-

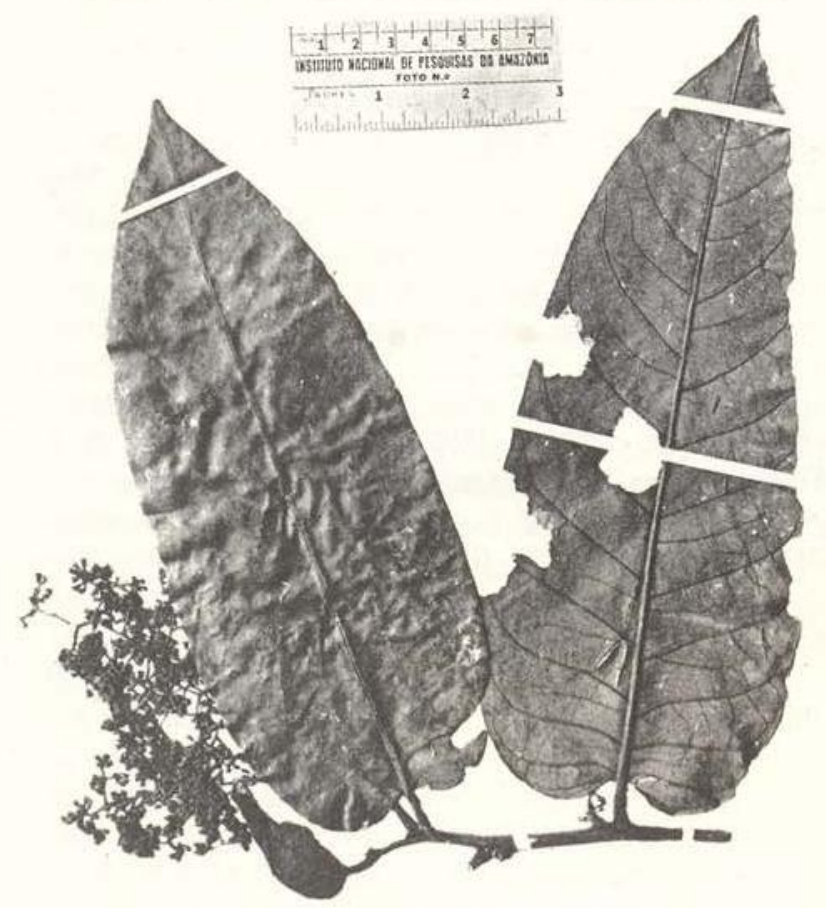

Fig. 66 - Virola sebifera. G. Gardner 3566 (NY, isótipo de Níyristica sebifera var. cordifolia). ramente contra cólicas, dispepsias, afecções reumáticas, tumores artríticos e contusões. Sob a forma de supositório, a gordura é aplicada nas hemorróidas. O cozimento da casca tem largo emprego como cicatrizante de úlceras rebeldes. Do sebo semi-aromático fabricam-se sabões e velas. O óleo, que se obtém da amêndoa, também serve para iluminação. Da madeira se obtêm tábuas para embalagem e construções civis.

Segundo Heringer, os jacus são vorazes apreciadores do arilo carnoso, que envolve as sementes. As sementes também são procuradas por animais silvestres (ex Heringer 2797).

FEnologia: Tem sido encontrada florescendo durante todo o ano e com frutos, entre fevereiro e outubro. Os meses entre fevereiro e maio se destacam pela floração e entre maio e outubro, pela frutificação. Fig. 18.

Habitat: Espécie de larga distribuição, ocorrendo tanto nas matas de terra firme, como nos campos cerrados, comumente em baixas elevações, mas podendo aparecer também no alto de serras até cerca de $1300 \mathrm{~m}$ de altura sobre o nível do mar, como na serra dos Pirineus, perto de Corumbá de Goiás (ex Anderson 10244).

Distribuição: Espécie de larga dispersão ocorrendo em quase toda a América tropical desde Nicaragua ao Peru, Bolívia e Brasil. Fig. 67.

\section{MATERIAL ADICIONAL EXAMINADO:}

TERRITÓRIO DE RORAIMA: - Serra de Tapequém, $1200 \mathrm{~m}$ de altura: G. T. Prance et al. 4567, Fev. $1967 \mathrm{fr}$. (INPA, NY). Serra de Malacacheta: J. G. Kuhlmann 814, Ago. 1913 fl. (RB 3558). Jaru: J. G. Kuhlmann s.n., Ago. 1913 fr. (RB 16378), Caracaraí: A. Ducke s.n., Jul. 1933 fl. (RB 24464).

TERRITÓRIO DO AMAPÁ: - Bacia do rio Oiapoque: entre Oiapoque e Santo Antonio: H. S. Irwin et al. 47164, Jul. $1960 \mathrm{fr}$. (IAN, MG, NY). Oiapoque: G. A. Black 49-8212, Set. 1949 fr. (IAN). Monte Tipac (lat. $3^{\circ} 36^{\prime} \mathrm{N}$; long. $51^{\circ} 19^{\prime} \mathrm{W}$; alt. $0-2000 \mathrm{~m}$ ): H. S. Irwin 48670, Out. 1960 fr. (IAN, MG, NY). Macapá: J. G. Kuhlmann 2078, Abr. 1924 fl. (RB).

AMAZONAS: - São Paulo de Olivença: A. Ducke 1494, Abr. 1944 fl. (IAN, MG, NY, R); B. A. Krukroff 8920, Out./Dez. 1936 fr. (NY); Santo Antonio do Içá: R. L. Froes 20859, Maio $1945 \mathrm{fl}$. (IAN, NY); id. 34854, Maio $1945 \mathrm{fl}$. (IAN). - Bacia do rio Purus: 


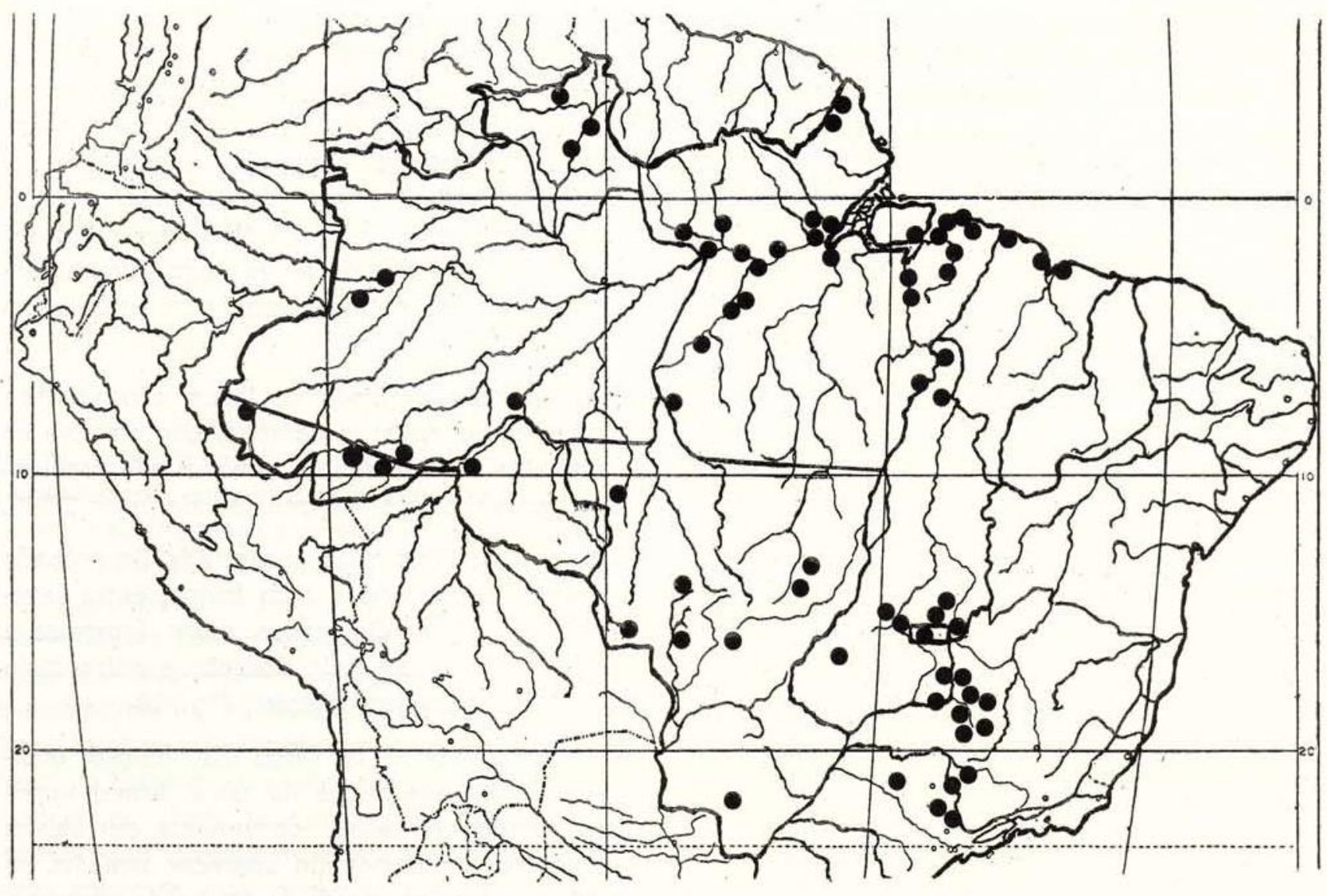

Fig. 67 - Distribuição atual de Virola sebifera no Brasil.

rio Puciari, tributário do rio Ituxi: G. T. Prance et al. 13850, Jul. $1971 \mathrm{fr}$. (INPA, NY). - Bacia do rio Madeira: Humaitá: A. Ducke s.n., Jun. 1936 fr. (RB 30149).

PARÁ: - Bacia do rio Trombetas: estrada de acesso da Cachoeira Porteira à Perimetral Norte, Km 109: D. G. Campbell et al. 22282, Maio $1974 \mathrm{fr}$. (INPA). Faro: J. T. Baldwin 2991, Ago. 1943 fr. (IAN, US); A. Ducke s.n., Set. 1907, fr. (MG 8682). Região dos Campos de Ariramba: A. Ducke s.n., Jun. 1912 fl. (MG 11871). Óbidos: - Serra da Escama: G. A. Black et al. 57-19458, Maio $1957 \mathrm{fl} .($ IAN); id. 57-19459, Maio $1957 \mathrm{fr}$. (IAN). P. Cavalcante 212, Maio $1957 \mathrm{fr}$. (MG), id. 213, Maio $1957 \mathrm{fl}$. (MG). Bacia do rio Tapajós: Fordlândia (=Boa Vista) Capucho 595, Maio $1933 \mathrm{fl}$. (IAN); id. 4018, Jan. 1592 fl. (IAN); - rio Cururu: W. A. Egler, 1353, Fev. 1960 fl. (MG, NY); - Missão Cururu: W. R. Anderson 10562, Fev. 1974 fl. (INPA). - rio Cupari: M. Costa 60, Set. 1931 fl. (IAN). Regiăo de Santarém: G. A. Black 52-15569, Jul. 1952 fr. (IAN); J. G. Kuhlmann 1739, Mar. 1924 fl. (RB); R. Spruce 468, Nov./Mar. $1849-50$ fl. (K, NY). Monte Alegre: A. Lima 53-1367, Maio $1953 \mathrm{fl}$. (IAN). Almeirim: A. Ducke s.n., Maio $1903 \mathrm{fl}$. (MG 3490); id. s.n., Maio 1903 fl. (MG 3607); Serra de Tabatinga: Ducke s.n., Abr. 1923 fl. (RB 18631); Serra de Almeirim, E. Oliveira 2401, Mar. $1963 \mathrm{fl}$. (IAN). Região do rio Ja ri: E. Oliveira 4719, Jul. $1968 \mathrm{fr}$. (IAN); N. T. Silva 1236, Out. $1968 \mathrm{fr}$. (IAN, INPA); id. 2066, Maio 1969 fr. (IAN). Bacia do rio Xingu: - Porto de Moz: M. Silva 1484, Ago. 1968 fr. (MG); id. 1487, Ago. 1968 fr. (MG). - Mun. Marapanim, povoação de Matapiquara: E. Oliveira 3296, Mar. $1965 \mathrm{fl}$. (IAN). - Santa Isabel: J. Huber s.n., Maio $1896 \mathrm{fl}$. (MG 133, INPA); id. s.n., Abr. 1897 fl. (MG 655). Rio Capim: R. L. Froes \& Pires 34153, Mar. $1949 \mathrm{fl}$. (IAN); Aproaga: J. Huber s.n., Jun. 1897 fl. (MG 838, INPA); G. A. Black 48-2386, Mar. $1948 \mathrm{fl}$. (IAN). - Ilha do Marajó: Mun. de Muaná: B. S. Penna 18, Abr. 1962 fl. (IAN). Bacia do rio Tocantins: - Coqueiro: J. G. Kuhlmann, 2121, Abr. 1924 fl. (RB); - Baião, id. 2097, Abr. $1924 \mathrm{fl}$. (RB). Tomé-Açu: Distrito Acará: Y. Mexia 5920, Jul. $1931 \mathrm{fr}$. (NY). Bacia do rio Araguaia: Conceição do Araguaia, R. L. Froes 29709, Jun. 1953 fr. (IAN). Belém: W. A. Acher 8244, Fev. 1943 fl. (IAN); id. 8300. Mar. 1943 fl. (IAN, NY); Baker 464, Jul. 1908 fr. (MG); G. A. Black 51-11703, Jun. 1951 fr. (IAN); id. 52-14156 Fev. 1952 fl. (IAN); P. Cavalcante 2712, Jun. 1970 fl. (MG); A. Ducke 596, Dez. 1940 fl. (MG, NY); id. 603, Out. $1940 \mathrm{fr}$. (IAN, MG); id. 1253, Maio $1943 \mathrm{fl}$. (IAN, 
MG, NY); id. s.n., Maio 1902 fl. (MG 2638); id. s.n., Set. 1936 fr. (RB 30148); R. L. Froes \& Barkley 26900, A.br. 1951 fl. (IAN); J. Huber s.n., Jul. 1896 fr. (MG 237); id. s.n., Out. 1909 fr. (MG 10784); E. P. Killip \& Smith 30253, Out./Nov. 1929 fl. (NY); B. A. Krukoff 1008, Set. 1931 fr. (NY); E. Oliveira 3085, Jul. 1964 fr. (IAN); J. M. Pires \& Black 577, Nov. 1945 " (IAN, RB); id. 784, Nov. 1945 fl. (IAN, NY); id. 819, Dez. 1945 fl. (IAN, RB); id. 1540, Abr. 1947 fl. (IAN, RB, NY); J. M. Pires \& Silva 10369, Mar. 1967 fl. (IAN); id. $11713, \mathrm{Abr} .1968 \mathrm{fl}$. (IAN); J. M. Pires 51722, Set.j Out. 1961 fr. (RB, NY). J. E. Paula 215, Mar. $1966 \mathrm{fl}$. (MG); M. Pinheiro 24, Maio $1970 \mathrm{fl}$. (MG); A. Silva 201. Maio 1944 fl. (IAN); id. 268, Jun. 1944 fr. (IAN); M. B. Silva 152, Out. $1942 \mathrm{fr}$. (IAN); N. T. Silva 57850, Out. $1963 \mathrm{fl}$. (NY). Quatipuru: W. Rodrigues 5176 Abr. 1963 fl. (INPA).

MARANHÃO: - Região do rio Maracaçumé, Cândido Mendes: R. L. Froes 1752, Jul. 1932 fl. (NY). Alcântara: R. L. Froes 30775, Abr. 1954 fl. (IAN). São Luiz: A. Ducke s.n., Jun. 1907 fl. (MG 517); R. L. Froes 11644, Fev./Mar. 1939 fl. (NY); id. 24202 Maio 1949 fl. (IAN); id. 24226, Maio $1949 \mathrm{fl}$. (IAN).

ACRE: - Cruzeiro do Sul; Serra de Moa: G. T. Prance et al. 12308, Abr. fr. (INPA). Bacia do rio Purus: boca do rio Macauã, Tributário do rio laco: (lat. 9. $20^{\prime}$ 5, long. $69^{\circ}$ W); B. A. Krukoff 5314, Ago. 1933 fl. (NY). Rio Acre: Seringal Iracema: A Ducke s.n., Mar. 1933 fl. (RB 24551).

TERRITÓRIO DE RONDÔNIA: - Bacia do rio Madeira: Mutumparaná: G. T. Prance et al. 5431, Jul. 1968 fr. (INPA, NY); Abunã: G. T. Prance et al. 5755 Jul. $1968 \mathrm{fr}$. (INPA, NY).

MATO GROSSO: Aripuanã, Cachoeira Dardanelos: M. R. Cordeiro, 67, Jun. $1974 \mathrm{fr}$. (INPA, IAN). Região da Serra dos Paricis, Salto Utiariti: J. G. Kuhlmann 1971, Abr. 1918 fl. (RB 12622); entre Diamantino e Cabeceira do Lobo: id. 1972, Abr. 1918 fl. (RB). Regiăo da Serra do Roncador: Garapu (lat. $13^{\circ} 12^{\prime}$ S, long. $52^{\circ} 34^{\prime}$ W): H. S. Irwin \& Soderstrom 6529, Out. 1964 fr. (IAN, NY, RB); G. T. Prance et al. 59149, Set. 1964 fr. (NY); - Vizinhança de Xavantina: H. S. Irwin et al. 16140, Maio 1966 fr. (INPA, NY, RB); id. 16444, Jun. $1966 \mathrm{fr}$. (INPA, RB); id. 17058, Jun. $1966 \mathrm{fr}$. (INPA, NY, RB). G. T. Prance \& Silva 59378, Out. 1964 fr. (NY); E. Onishi \& Taituba 925", Fev. 1969 fl. (NY, UB). Regiāo da estrada Cuiabá-Goiânia: Km 300: B. Maguire et al. 56929, Set. $1963 \mathrm{fr}$. (INPA, NY, RB). Município do Rio Brilhante: G. Hatschbach 23892, Fev. 1970 fl. (MBM, NY).

GOIAS: - Araguatins: E. Oliveira 1754, Ago. 1961 fr. (IAN). Araguaiana: H. S. Irwin et al. 21053, Mar. 1968 fl. (IAN, NY); id. 21126, Mar. 1968 fl (IAN, NY, RB). Guaraí: H. S. Irwin et al. 21599, Mar. $1968 \mathrm{fl}$. (IAN, NY, RB). Ceres: P. Carauta 300, Fev. $1966 \mathrm{fl}$. (Inst. Conservação da Natureza R. Jan., INPA). Região da Serra Dourada: Goiás Velho: W. R. Anderson 10006, Maio 1973 fr. (INPA, NY). Glaziou 460, Fev. $1893 \mathrm{fl}$. (RB); H. S. Irwin et al. 11782, Jan. $1966 \mathrm{fl}$.
(IAN, NY, RB): A. Rizzo 47081969 fl. (RB). Região da Chapada dos Veadeiros: Terezinha: W. R. Anderson 7229, Mar. 1973 fr. (INPA, NY); Cavalcante: H. S. irwin et al. 23991, Mar. $1969 \mathrm{fl}$. (INPA, NY). Região da Serra do Paraná: São Joăo da Aliança: W. R. Anderson 7707, Mar. $1973 \mathrm{fl}$. (INPA). Formosa: H. S. Irwin et al. 15447, Abr. $1966 \mathrm{fr}$. (IAN, NY, RB); Glaziou 22037, Out. 1894 fr. (C, GH, K, NY, P, S). Região da Serra dos Pirineus: Corumbá de Goiás: W. R. Ander. son 10244, Maio $1973 \mathrm{fr}$. (INPA, NY); H. S. Irwin et al. 18787, Jan. 1968 fl. (IAN, NY, RB); id. 19099, Jan. $1968 \mathrm{fl}$. IAN, NY, RB); id. 19(202, Jan. $1968 \mathrm{fl}$. IAN, NY). Região da Serra do Caiapó: Vizinhança de Caiapônia: H. S. Irwin et al. 18015, Jun. 1966 fr. (IAN, INPA, NY).

Sem localidade e coletor definidos: RB 120103.

BRASÍLIA: - H. S. Irwin \& Soderstrom 5321, Ago. 1964 fr. (IAN, NY, RB, UB); id. 5930, Set. 1964 fr. (IAN, NY, RB, UB); Irwin, Sousa \& Santos 8796, Set. $1965 \mathrm{fr}$. (IAN, NY, RB, UB); H. S. Irwin et al. 13085, Fev. 1966 fl. (IAN, NY, RB, UB); id. 14072, Mar. 1966 fl. (IAN, NY, RB, UB); id. 18269, Jul. $1966 \mathrm{fr}$. (INPA, NY,RB, UB); id. 26711, Fev. 1970 fl. (INPA, NY, RB, UB); Smith A-76, Mar. 1965 fl. (IAN); E. Pereira 9042, Mar. 1964 fl. (NY, RB). Região da Serra dos Cristais: Cristalina: W. R. Anderson 8210, Abr. $1973 \mathrm{fr}$. (INPA); H. S. Irwin et al. 13226, Mar. 1966 fl. (IAN, NY, RB, UB); A. Matos, Heringer \& Murça 317, jul. 1963 fr. (RB): Catalão: A. P. Duarte 7, Maio $1960 \mathrm{fl}$. (RB); H. S. Irwin et al. 25085, Jan. 1970 fl. (INPA, NY).

MINAS GERAIS: Regiăo da Serra da Anta: Paracatu: H. S. Irwin et al. 26013, Fev. 1970 fl. (INPA, NY, RB, UB); J. M. Pires, 58054, Jun. 1964 fr. (NY). João Pinheiro: C. T. Rizzini s.n., 1960 fr. (RB 117492); Patos de Minas: A. P. Duarte 2850, Ago. $1950 \mathrm{fl}$. (RB). Corinto: rio Bicudo: H. S. Irwin et al. 26795, Mar. 1970 fl. (INPA, NY, RB, UB). Felixlândia: E. P. Heringer \& Rizzini 7507, Jun. 1960 fr. (RB). Alpinópolis: rio Sapucaí: R. L. Froes 33903, Set. 1957, fr. (IAN). São Sebastião do Paraíso: A. C. Brade \& Altamiro 17827, Abr. 1945 fl. (RB). Entre São Gotardo e Luz: M. Magalhães s.n., Maio 1951 fr. (IAN). Localidade desconhecida: M. Claussén 368, 1838 fl. (K, NY, P).

RIO DE JANEIRO: - M. Glaziou 10030, Dez. 1878 fl., cultivada (NY).

SÃO PAULO: - Matão: J. C. Gomes Jr. 311, Maio 1949 fr. (RB). - Mogi-Guaçu: A. Mattos Filho \& Rizzini 129, Jul. 1961 fr. (RB). - Mogi-Mirim: F. C. Hoehne 28334, Out. 1931 fr. (NY, RB, SP).

V. sebifera é uma espécie de formas muito variáveis de região para região e de lugar para lugar. No Brasil, caracteriza-se, princıpalmente, por apresentar folhas grandes, muitas vezes cordadas na base, nervuras secundárias espaçadas, página inferior densa e persistentemente tomentosa (tricomas dendríticos). 
Como caráter geral da espécie, as flores masculinas têm anteras bem mais longas que 0 andróforo.

No Brasil Central e Sul, ela tem tendência para apresentar folhas mais coriáceas, base acentuadamente cordada e nervuras basais nitidiamente recurvas.

31. Virola sessilis (A. DC.) Warburg, Nova Acta Acad. Leop.-Carol. 68:190. 1897; G.O.A.N. Malme, Ark. Bot. 26A (9):29. 1935; A. Ducke, Journ. Wash. Acad. Sci. 26 (6) :253. 1936; A. C. Smith \& Wodehouse, Brittonia 2 (5): 508, fig. $8 n$, o. 1937; J.O. Th. Uphof in Engl. \& PrantI, Nat. Pflanzenfam., $2^{\text {a }}$ ed., $17^{a}$ (2) :208. 1959.

Myristica sessilis A. De Candolle in DC. Prodr. 14: 198. 1856; A. De Candolle in Mart., FI. Bras. 5 (1): 117. 1860.

Palala sessilis (DC.) Kuntze, Rev. Gen. PI. 2: 567. 1891, nom. illegit.

Arbusto pequeno até cerca de $1 \mathrm{~m}$ de altura; raminhos rugosos, a princípio tenuemente castanho-puberulentos, tornando-se depois glabros e cinéreos. Pecíolo muito curto, menor que $2 \mathrm{~mm}$ de comprimento. Lâmina foliar cartácea ou finamente coriácea, elíptica ou elíptico-oblonga, $100-180 \mathrm{~mm}$ de comprimento. $35-80 \mathrm{~mm}$ de largura, arredondada, levemente subcordada ou amplamente obtusa na base, obtusa no ápice, página superior verde-escura e lustrosa, página inferior essencialmente glabra e opaca; nervura mediana levemente elevada ou levemente impressa na página superior, saliente na inferior; 13-25 nervuras secundárias de cada lado, muito irregulares, promínulas na página superior, elevadas na inferior, anastomosadas junto às margens; vênulas abundantemente reticuladas, promínulas em ambas as faces. Inflorescência masculina axilar ou subterminal, 1-ou 2-ramificada, 30-100 $\mathrm{mm}$ de comprimento; raminhos e pedúnculo (até $40 \mathrm{~mm}$ de comprimento) distintamente achatados, esparsamente castanho-puberulentos ou glabros; brácteas ovóides, puberulentas, $3-4 \mathrm{~mm}$ de comprimento, logo decíduas; 10-25 flores nos facículos mais novos; os últimos pedúnculos muitas vezes túrgidos distalmente; pedicelos tênues, até $2 \mathrm{~mm}$ de comprimento; perianto tenuemente carnoso, densamente castanhopuberulento (tricomas com diversas ramificações laterais $0,1-0,2 \mathrm{~mm}$ de comprimento), 2-3mm de comprimento, 3- ou 4-lobado quase até o meio, lóbulos deltóides, obtusos; androceu com cerca de $1,6 \mathrm{~mm}$ de comprimento; andróforo carnoso; 3 anteras soldadas em direção ao ápice, obtusas, ligeiramente menores que $\mathrm{o}$ andróforo. Inflorescência feminina não vista. Infrutescência até $60 \mathrm{~mm}$ de comprimento, bifurcada geralmente, raminhos essencialmente glabros na maturidade; $1-5$ frutos maduros por infrutescência, pedicelados (pedicelos grossos, 2-4mm de comprimento), elipsóides, $14-23 \mathrm{~mm}$ de comprimento, $12-17 \mathrm{~mm}$ de largura, lisos, arredondados e tenuemente apiculados no ápice, obtusos na base, tenuemente castanho-puberulentos (tricomas persistentes); pericarpo cerca de $0,5 \mathrm{~mm}$ de espessura; arilo vermelho fendido quase até a base. Figs. 68-69F. (fruto).

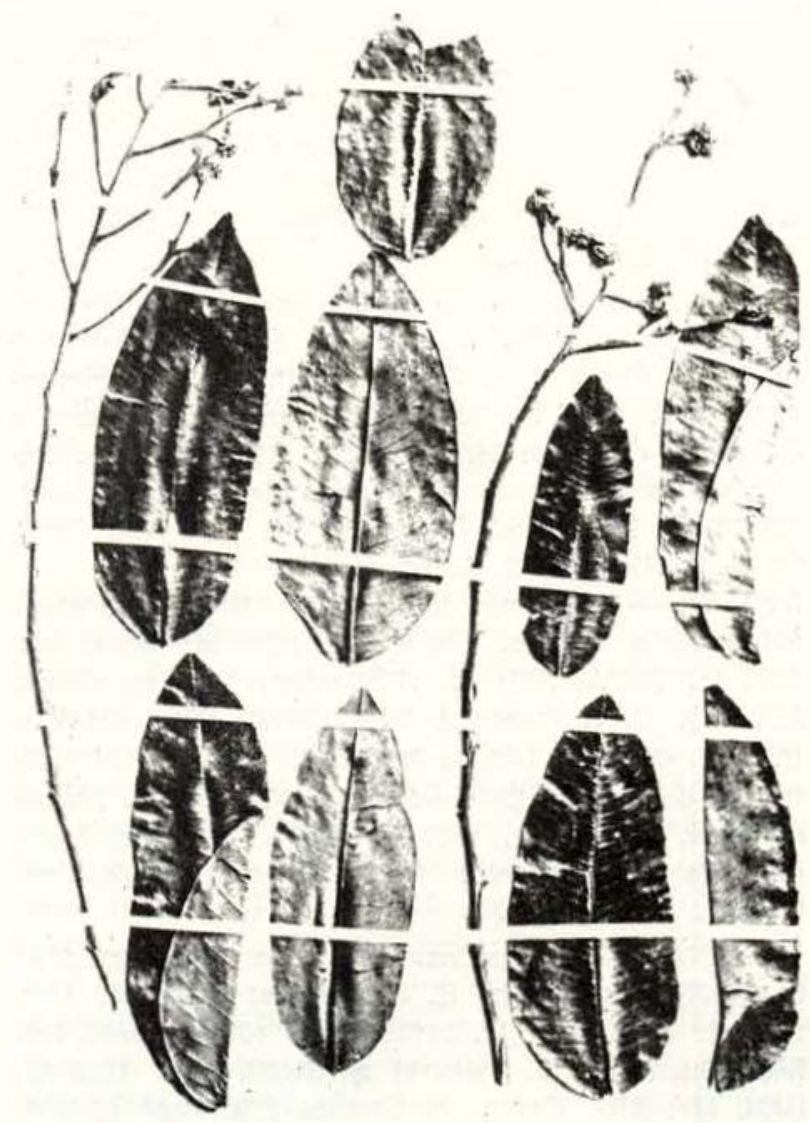

Fig. 68 - Virola sessilis. Manso \& Lhotzky 39 (reprodução da foto $F$ 1968, IAN). 
TIPo: Manso \& Lhotzky 39, Brasil, Mato Grosso, Cuiabá, Serra Cuiabana, s/data fl. (holótipo: G-DC, n.v.; isótipos: RB, n.v., M, n.v., P; $B$ e W destruídos; fotos $F$ 1968, IAN, NY).

Fenologia: A floração é assinalada para os meses de abril e outubro e a frutificação, para maio e outubro.

Habitat : Freqüente no cerrado aberto ou campina sobre solo arenoso, até $720 \mathrm{~m}$ de altura sobre o nível do mar.

Distribuição: Conhecida apenas de Mato Grosso e do Sudeste do Território de Rondônia. Fig. 63.

\section{MATERIAL ADICIONAL EXAMINADO :}

TERRITORIO DE RONDONIA: - Vilhena: B. Maguire et al. 56558, Set. $1963 \mathrm{fr}$. (INPA, NY, RB).

MATO GROSSO: - Paricis: J. T. Baldwin, Jr. 3131, Out. $1943 \mathrm{fr}$. (IAN). Entre Paricis e Santo Antonio: J. G. Kuhlmann 1973, Abr. 1918 fl. ( R, RB, SP). Chapada dos Guimarães: G. O. N. Malme 2007", Ago. 1902 fl. (R, S); G. T. Prance, Lleras \& Coêlho 18932 , Out. 1973 fl. (INPA, NY); Riedel s.n., ou 1012, Maio $1827 \mathrm{fl}$. e fr. (C, P; B, destruido); N. Saddi 036, Out. $1973 \mathrm{fl}$. (SHMT); id. 1048, Jun. 1974 fl. (SHMT); id. 1223, Nov. $1974 \mathrm{fl}$. (SHMT).

Esta espécie se distingue de $V$. subsessilis Warb. pelas características apresentadas na chave.

32. Virola subsessilis (Benth.) Warburg, Nova Acta Acad. Leop.-Carol. 68:191. 1897; A. Ducke, Journ. Wash. Acad. Sci. 26 (6) :253. 1936; A.C. Smith \& Wodehouse, Brittonia 2 (5):507, fig. 8 p. 1937; J.C. Th. Uphof in Engl. \& Prantl, Nat. Pflanzenfam., 2 $2^{\mathrm{a}}$ ed., $17^{a}$ (2) :208. 1959.

Myristica subsessilis Bentham, Hook. Journ. Bot. 5: 4. 1853; A. De Candolle in DC., Prodr. 14: 197. 1856; A. De Candolle in Mart., FI. Bras. 5 (1): 115. 1860.

Palala subsessilis (Benth.) Kuntze, Rev. Gen. PI. 2: 568. 1891, nom. illegit.

Virola officinalis sensu Luetzelburg, Insp. Fed. Obras Contra Secas 57 (3): 200. 1923, (Warming, spharm.), non Warburg; specim. Luetzelburg 410 mihi tantam visum.

Arbusto de menos de 1 a $5 \mathrm{~m}$ de altura; raminho estriado, castanho-puberulento quando novo, logo glabro. Pecíolo muito curto, 1-3mm de comprimento, rugoso, tenuemente puberulento ou glabro. Lâmina foliar finamente coriácea, oblonga ou elíptico-oblonga, $4,5-16 \mathrm{~cm}$ de comprimento, $20-45 \mathrm{~mm}$ de largura, subcordada e muitas vezes subamplexicaule na base, subaguda ou obtusa no ápice, pálido-puberulenta na página inferior (tricomas séssil-estrelados, pouco ramificados, cerca de $1 \mathrm{~mm}$ de diâmetro), passando a glabrescente com a idade; nervura mediana plana ou levemente imersa na página superior, saliente na inferior; $13-30$ nervuras secundárias de cada lado, fortemente impressas ou planas na página superior, elevadas na inferior; vênulas obscuras ou levemente impressas. Inflorescência masculina 1-ou 2-ramificada, $30-90 \mathrm{~mm}$ de comprimento, uniformemente castanho-puberulenta; pedúnculo até $40 \mathrm{~mm}$ de comprimento, nitidamente achatado; brácteas ovóides, puberulentas, $2-3 \mathrm{~mm}$ de comprimento, logo decíduas; 10-25 flores em fascículos sésseis ou subsésseis (pedúnculos mais novos até $3 \mathrm{~mm}$ de comprimento, muitas vezes túrgidos distalmente); pedicelos indistintos, menores que $2,0 \mathrm{~mm}$ de comprimento; perianto finamente carnoso, infundibuliforme, $2,5-3,0 \mathrm{~mm}$ de comprimento, 3-lobado cerca de $1 / 3$ do seu comprimento total, lóbulos deltóides, obtusos; androceu, 2,2-2,5mm de comprimento; andróforo carnoso, $1,3-1,5 \mathrm{~mm}$ de comprimento; 3 anteras, cerca de $1 \mathrm{~mm}$ de comprimento, soldadas até o ápice obtuso. Inflorescência feminina menor que a masculina, comparativamente pauciflora, 4-8 flores por fascículo; pedicelos grossos, $2 \mathrm{~mm}$ de comprimento ou menores; ovário subgloboso, tênue e inteiramente puberulento; estilete curto, grosso; estigma fendido. Infrutescência até $40 \mathrm{~mm}$ de comprimento, tênue, uniforme e densamente castanho-tomentela; 2-5 frutos maduros por infrutescência, pedicelados (pedicelos grossos de $2-3 \mathrm{~mm}$ de comprimento), oblongo-elípticos, $14-17 \mathrm{~mm}$ de comprimento, $7-9 \mathrm{~mm}$ de largura, lisos, obtusos ou tenuemente apiculados no ápice, arredondados a truncados na base; pericarpo, cerca de $0,5 \mathrm{~mm}$ de espessura; arilo fendido mais da metade do seu comprimento total. Fig. 69-A-E.

TIPO: Gardner 2775, Brasil, Piauí, 1841 fl. e fr. (holótipo: K; isótipo: BM, G n.v., P; B e W destruídos; fotos: F 1967, IAN, NY). 
Fenologia: Tem sido registrada a floração entre os meses de fevereiro e abril e julho e agosto e a frutificação em outubro e novembro

Habitat : Planta característica dos campos cerrados do Brasil Central. No extremo oeste da Bahia foi encontrada a $900 \mathrm{~m}$ de altura (Irwin et al. 14893).

Distribuição: Conhecida de Piauí, Goiás e Bahia. Smith (I.c. 1937) aponta também para - Maranhão uma coleção Snethlage 740 , vista por ele do Herbário de Berlim-Dahlen. Esta coleção foi infelizmente destruída durante a Segunda Guerra Mundial. Fig. 63.

\section{MATERIAL ADICIONAL EXAMINADO :}

GOIAS: - Guará: H. S. Irwin, Maxwell \& Wasshausen 21508, Mar. $1968 \mathrm{fl}$. (GH, IAN, NY, RB, UB); B. Maguire et al. 56123, Ago. $1963 \mathrm{fl}$. (INPA, NY). Novas Colinas: G. T. Prance \& Silva 58503 (L. S. 40), Jul. 1964 fl. (NY, RB, UB). - Serra do Tombador: A. P. Duarte 9498, Out. 1965 fr. (RB). - Rio Preto: Lut. zelburg 1282 e $1372,1912 \mathrm{fl}$. e fr. (RB).

BAHIA: - Cercanias de Barreiras: Zehntner $416=3054$. Nov. $1912 \mathrm{fr}$. (RB); ibid.: Roda Velha: H. S. Irwin et al. 14893, Abr. 1966 fl. (IAN, NY, UB)

Espécie muito próxima de V. sessilis Warb. da qual se distingue pelas características apresentadas na chave.

33. Virola surinamensis (Rol.) Warburg, Ber. Pharm. Ges. 19, fig. 15. 1892, hipônimo; Warburg, Nova Acta Acad. Leop.-Carol. 68: 208, tab. 1, fig. 1-4; tab. 6, fig. 1-5. 1897; Pulle-Enum.: 179. 1906; J. Huber, Bol. Mus. Goeldi 6:173. 1909; Martin-Lavigne, Trav. Lab. Matiére Medicale 4(2): 61, fig. 13-15. 1909; P. Le Cointe, Apont. sobre sementes oleaginosas, bálsamos e resinas da floresta amazônica: 29. 1924; Van Ooststroom in Pulle, FI. Surin. 2:120. 1934; A. Ducke, Journ. Wash. Acad. Sci. 26(6):258. 1936; A.C. Smith \& Wodehouse, Brittonia 2(5):491. 1937. A. Ducke, Arch. Inst. Biol. Veg. 4(1):3. 1938; A. Ducke, Arq. Serv. Florest. 1(1):27. 1939; C. Pesce, Oleaginosas da Amazônia: 60, ilustr. 1941; L. Williams. Expl. bot. Guayana Venezolana: 198

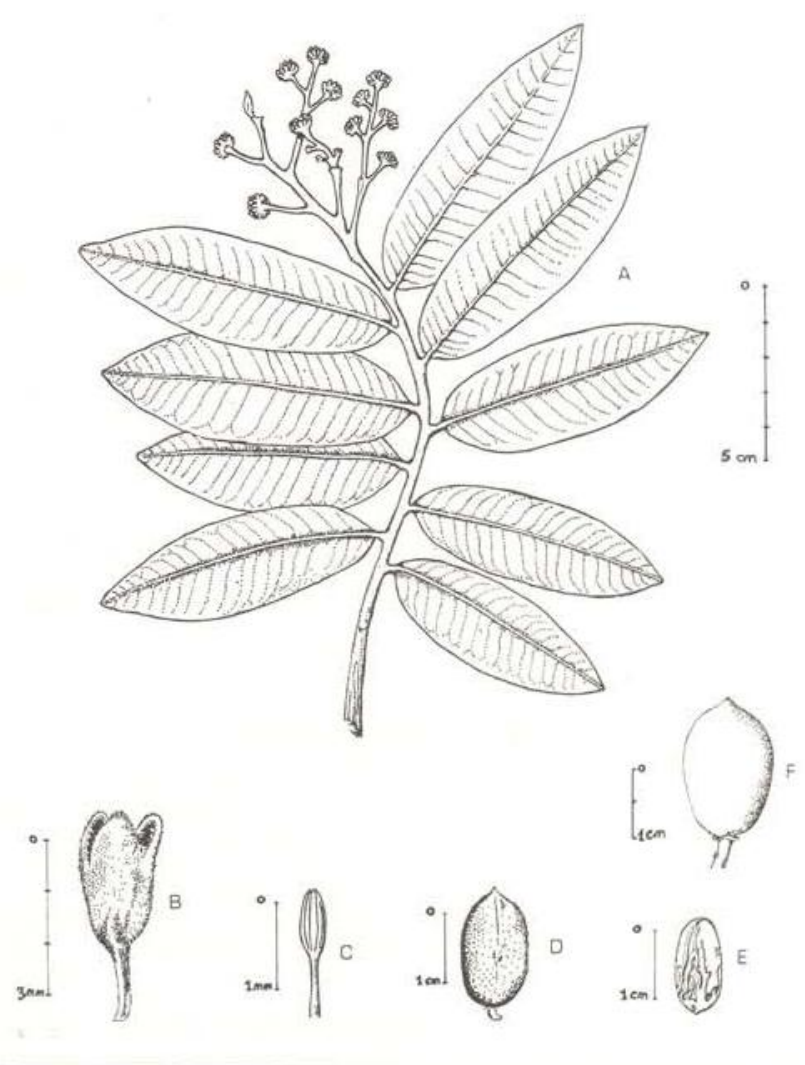

Fig. 69 - A-E: Virola subsessilis. A-C (H. S. Irwin et al. 14893 e B. Maguire et al. 56123): A, ramo florifero masculino; B, flor masculina; C, androceu; D-E (A. P. Duarte 9498): D, trutos; $E$, semente com arilo. F: V. sessilis (B. Maguire et al. 56558), fruto.

1942; A. Ducke, Bol. Técn. Inst. Agron. Norte 4:10. 1945; P. Le Cointe, Amazônia Brasileira, III, $2^{\text {a }}$ ed.: 480. 1947; A. Ducke, Bol. Técn. Inst. Agron. Norte, 19:6. 1950; K. Arens, Rodrig. 25:251, fig. 1-2. 1950; A. Lemée, FI Guyan. Franc. 4:33. 1956; J.C. Th. Uphof in Engl. \& Prantl, Nat. Pflanzenfam. 2a ed., $17^{a}$ (2) :207. 1959; P. Bena, Essences forestières de Guyane: 32, fig. 3-5. 1960; J.C. Lindman \& A.M.W. Mennega, Meded. Bot. Mus. Herb. Rijks Univ. Utrecht 200:245, tab. 70, fig. A-H. 1963; W. B. Mors \& C. T. Rizzini, Useful Plants of Brazil: 32, fig. 3-3. A-B. 1966; A. A. Loureiro \& M. F. Silva, Catálogo das Madeiras da Amazônia 2:209, ilust. 1968; R. E. Schultes \& B. Holmstedt, Lloydia 34 (1):75. 1971; C. T. Rizzini, Árvores e Madeiras Úteis do Brasil: 186. 1971; INPA-Fitoquímica, Acta Amaz. 1 (3) :49. 
1971; W. A. Rodrigues, Acta Amaz. 2(2):29, fig. 1-7. 1972; L.E.S. Barata \& P.M. Baker, Ciência e Cultura - Suplem. $25(6): 169.1973$.

Myristica surinamensis Rolander in Rottboell, Acta Lit. Univ. Hafn. 1: 281. 1778; O. Swartz., Fl. Ind. Occ. 2: 1126. 1800. Poiret in M. Lamarck, Encycl. Méth. Bot. Supl. 4 (1): 35. 1816; G. Bentham, Hook. Journ. Bot. 5: 4. 1853; A. De Candolle in DC., Prodr. 14: 196. 1856; A. De Candolle in Mart., FI. Bras. 5 (1): 114, tab. 42-43. 1860; J. M. Caminhoá, Compêndio de Bot. Geral e Med. 3: 2322. 1884; T. Peckolt \& G. Peckolt, Hist. pl. medicinais e úteis do Brasil: 1947. 1889; H. M. Stone, An. Mus. Col. Marseille 8 (2): 1. 1922.

Palala surinamensis (Rol.) Kuntze, Rev. Gen. PI.: 5677. 1891, nom. illegit.

Nux moschata sylvestris surinamensis Jak Breyne, Prodr. fasc. rar. pl. secund.: 36. 1739; Plukenet, Almag. bot., ed. 2: 41. 1769. Topótipo: Suriname.

Myristica fatua Swartz (non Houttuyn, 1774 nec. Blume, 1835). Nova Gen. \& Sp. PI.: 96. 1788; Swartz, FI. Ind. Occ. 2: 1126. 1800; Poiret in M. Lamarck, Encycl. Méth. Bot. Suplem. 4: 35. 1816; S. Endlicher, Enchiridium Bot.: 421. 1841: R. Schomburgk, Reisen Britisch - Guiana: 1162. 1848; Eentham, Hook. Journ. Bot. 5: 4; A. De Candolle in DC., Prodr. 14: 196. 1856, como sinôm.; E. Twining, Illustr. Nat. Orders of Plants 2: 118. 1868; Gmelin in C. Linné, Syst. Nat. 2: 11. 1791; Willdnow in C. Linné, Sp. PI. 4: 870. 1805. Topótipo: Illha de Tobago.

Myristica sebifera var. Iongifolia Lamarck in Lamarck, Encycl. Méth. Bot. 4: 391. 1796; G. Bentham in Hook. Journ. Bot. 5: 4. 1853, pro syn; A. De Candolle in DC., Prodr. 14: 196, pro syn. Tipo: Herb. Lamarck, Guiana Francesa, Caiena, fl. (holótipo: P).

Myristica angustifolia Lam. ex Warburg, Nova Acta Acad. Leop.-Carol. 68: 208. 1897. (referência bibliográfica de Warburg, e outros possivelmente errada!).

Virola glaziovii Warburg, Nova Acta Acad. Leop.-Carol. 68: 219, tab. 6, figs. 1-5. 1897; A. C. Smith \& Wodehouse, Brittonia 2 (5): 494. 1937; J. C. Th Uphof in Nat. Pflanzenfam., 2." ed. 17: (2): 207. 1959, syn. nov. Tipo: Glaziou $16317\left({ }^{\circ}\right)$ Brasil, Rio de Janeiro, Sete Pontes (Gete Pontes, sphalmate), 27 Jan. $1887 \mathrm{fl}$. (holótipo: B destruido; isótipos: $\mathrm{C}, \mathrm{K}$; fotótipo, NY).

Virola mycetis Pulle, Rec. Trav., Bot. Neérl. 4: 125. 1907, pro parte. Tipo: Van Hall 8, Suriname, Ago. ano (?) fl. (holótipo: U).

Virola melinonii sensu Schultes \& Holmstedt in Lloydia 34 (1): 72, ilustr. 1971, non A. C. Smith.

Árvore até $25 \mathrm{~m}$. de altura; tronco até $80 \mathrm{~cm}$. de diâmetro; ramos nitidamente verticilados; raminhos muitas vezes flexuosos, castanho-tomentelos (tricomas dendríticos ramificados desde a base, até $1 \mathrm{~mm}$. de comprimento), passando depois a glabrescentes. Pecíolo fortemente canaliculado, tomentelo ou glabro, $1,5 \mathrm{~mm}$ de diâmetro, 2-9mm. de comprimento. Lâmina foliar coriácea, estreitamente oblonga, margens paralelas, $100-220 \mathrm{~mm}$ de comprimento (às vezes mais curtas nos raminhos floriferos), $20-50 \mathrm{~mm}$ de largura (às vezes até 350 por $60 \mathrm{~mm}$ ), subcordada, arredondada, obtusa ou aguda na base, cuspidada, aguda ou curtamente acuminada no ápice, pálido-puberulenta na página inferior (tricomas séssil-estrelados, 5-8 ramificados, até $0,1-0,25 \mathrm{~mm}$ de diâmetro); nervura mediana plana ou estreitamente impressa na página superior, saliente na inferior; 16-30 nervuras secundárias de cada lado, planas ou levemente impressas na página superior, fortemente elevados na inferior; vênulas obscuras ou levemente impressas em ambas as faces. Inflorescência masculina paniculada, densiflora, levemente ramificada, $7-17 \mathrm{~mm}$ de comprimento e quase o mesmo de largura; pedúnculo em geral levemente achatado até $4-5 \mathrm{~mm}$ de comprimento, com os raminhos e flores castanho-puberulentos (tricomas séssil-estrelados, pouco ramificados, com cerca de $0,2 \mathrm{~mm}$ de diâmetro) pedúnculos mais novos distalmente túrgidos; brácteas oblongas, puberulentas, $3-8 \mathrm{~mm}$ de comprimento, visíveis na inflorescência nova, mais tarde decíduas; 5-20 flores por fascículo; pedicelos tênues até $4 \mathrm{~mm}$ de comprimento; perianto finamente carnoso ou submembranáceo, 1,6-2,4mm de comprimento,

(*) - Possivelmente esta coleção de Glaziou não passa de mais um furto da coleção Schwake ou Jobert, feita na Amazônia e etiquetada erra. 
3-lobado quase até a base, lóbulos oblongos, obtusos, muitas vezes esparsamente pelúcidopuncteados e às vezes com vênulas distintas: androceu de $1,3 \mathrm{~mm}$ de comprimento; andróforo tênue de $0,8-1,3 \mathrm{~mm}$ de comprimento; 3 anteras de $0,5-0,8 \mathrm{~mm}$ de comprimento, soldadas até o ápice, obtusas. Inflorescência feminina de 20-110mm de comprimento na antese; 3-10 flores por fascículo; pedicelos até $3 \mathrm{~mm}$ de comprimento; brácteas como na inflorescência masculina até $9 \mathrm{~mm}$ de comprimento; ovário subgloboso, inteira e densamente puberulento ou pardo-tomentelo, estilete grosso, menor que $0,5 \mathrm{~mm}$ de comprimento; estigma notável e fortemente fendido. Infrutescência essencialmente glabra por inteiro, de $60-110 \mathrm{~mm}$ de comprimento; 3-8 frutos maduros por infrutescência, pedicelados (pedicelos grossos de $3-7 \mathrm{~mm}$ de comprimento), ovóides ou subglobosos, $13-21 \mathrm{~mm}$ de comprimento, $11-18 \mathrm{~mm}$ de largura, apiculados no ápice, levemente estipidados na base, ligeira ou distintamente carinados; pericarpo de $1.2 \mathrm{~mm}$ de espessura coriáceo; arilo fendido quase até a base; semente levemente elipsóide. Fig. 7A-D, 70.

TrPo: Rolander s.n., Suriname, fl. (possivelmente inexistente).

Nomes vulgares: Andiroba (ex Lisboa MG 2436); árvore-de-sebo (ex Allemão 1340); bicuiba (ex Glaziou 16317, Kuhlmann 10) ; landim lex Lisboa MG 2636); jupara (índios Paumari, ex Campbell \& al. P21212); saraguela (ex Silva 47); tinauva (ex Rodrigues \& Mello 7795); ucuuba; ucuhuba; ucuuba-branca (ex Huber MG 1845 e outros); ucuuba-de-igapó (ex Prance 1567), ucuuba-de-várzea; ucuúba-verdadeira (ex A. Silva 327); urucurana (ex Froes 1971).

UtilidAdES : É atualmente uma das plantas de maior valor econômico da Amazônia. Dados gerais sobre suas várias aplicaçōes são comentados especialmente por Warburg (I.c. 1897) e Rodrigues (I.c. 1972).

De suas sementes extrai-se uma gordura conhecida por "sebo de ucuuba" de largo emprego tecnológico como na saboaria, fabricação de velas etc. Sua madeira é amplamente usada pelas indústrias de laminados, permitindo também a sua aplicação na produção de papéis kraft de boa qualidade.

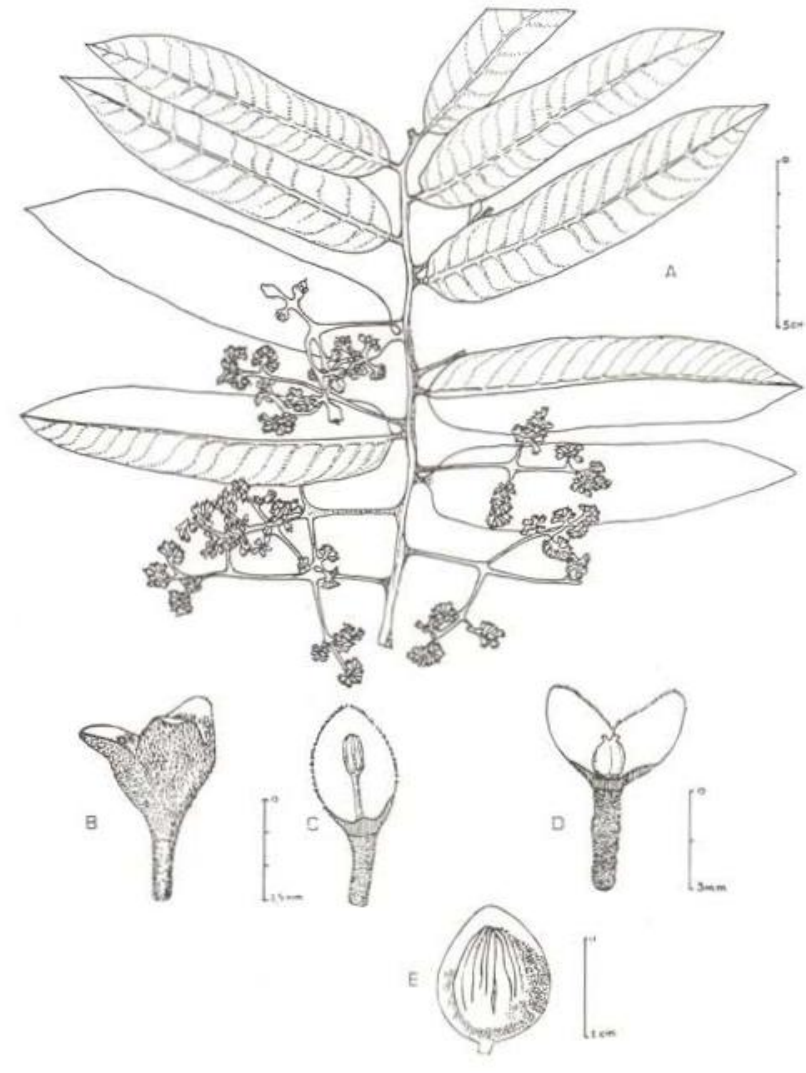

Fig. 70 - Virola surinamensis. A-C (Glaziou 20463): A, ramo florifero masculino; $B$, flor masculina; C, flor seccionada, mostrando o androceu; $\mathrm{D}$ e $\mathrm{Z}$ (reproduzido de Warburg, 1597): D, flor feminina seccionada, mostrando o gineceu; $E$, fruto aberto mostrando a semente com arllo.

Medicinalmente, tem diversas aplicações caseiras. Pesquisas recentes de Barata \& Baker (I.c. 1973) reputam a espécie importante na quimioprofilaxia da esquistossomose. Do extrato das folhas obtiveram galgravina, galbacina e uma terceira lignana ainda não identificada.

Segundo dados levantados e citados pelo INPA-Fitoquímica (I.c. 1971), a semente produz as seguintes substâncias: dilauromiristina $(1 \%)$, laurodimiristina $(31 \%)$, trimiristina $(43 \%)$. lauromiristopalmitina $(10 \%)$, lauromiristo-oleina $(12 \%)$, dimiristo-oleina $(\%)$ além de outras concentrações menores.

Fenologia: Colhida com flores e frutos durante todo o ano, sendo que a floração se dá com mais freqüência entre abril e novembro (notadamente setembro) e a frutificação, entre setembro e maio. Fig. 19. 
HABItAT: Habita preferentemente lugares pantanosos e férteis, ilhas baixas e quase toda a zona fluvial do Acre, Amazonas e seus afluentes, acompanhando as margens dos rios, igarapés, furos e paranás até onde a terra possa ser alagada, limitando-se à mata periodicamente inundável dos aluviões recentes, que acompanham os cursos de rios de água rica de sedimentos (água branca). Não ocorre geralmenie nos rios de água preta (com exceção do baixo rio Negro) sendo aí substituída principalmente pela sua vicariante, $V$. carinata. É uma essência heliófila.

Distribuição: Atinge as Antilhas Menores desce Guadalupe até Granada, Tobago, Trinidad, Guianas, Venezuela Meridional, Amazônia colombiana e peruana, Bolívia e Brasil. No Brasil, ocorre em quase toda a Amazônia, Maranhão, Ceará e Goiás. No estuário amazônico, constitui uma das espécies mais abundantes entre as árvores de grande por. te nas ilhas baixas inundáveis pela maré do Atlântico. Ducke (I.c. 1945) aponta que esta espécie é freqüente também perto de Recife, Pernambuco, porém a informação é duvidosa, porquianto de toda a sua coleção botânica examinada, feita nesse Estado, só foi encontrada por ele V. gardneri. Consultando pessoalmente Dárdano de Andrade Lima, que o acompanhou em suás viagens por aquele Estado, o autor foi informado que $V$. surinamensis nunca foi vista por eles lá. Fig. 71 .

É cultivada no Jardim Botânico do Rio de Janeiro e no Museu E. Goeldi, em Belém, Parả, em cujos lugares floresce e frutifica regularmente.

\section{MATERIAL ADICIONAL EXAMINADO :}

TERRITÓRIO DE RORAIMA: - Rio Surumu: M. Silva 47, Fev. $1964 \mathrm{fr}$. (MG); E. Ule, 7988, Fev. 1909 fl. (MG). São Marcos: A. Ducke 1369, Set. $1943 \mathrm{fr}$. (IAN, MG, NY): E. Ule 7850 Dez. 1908 fl. (MG). Ca-

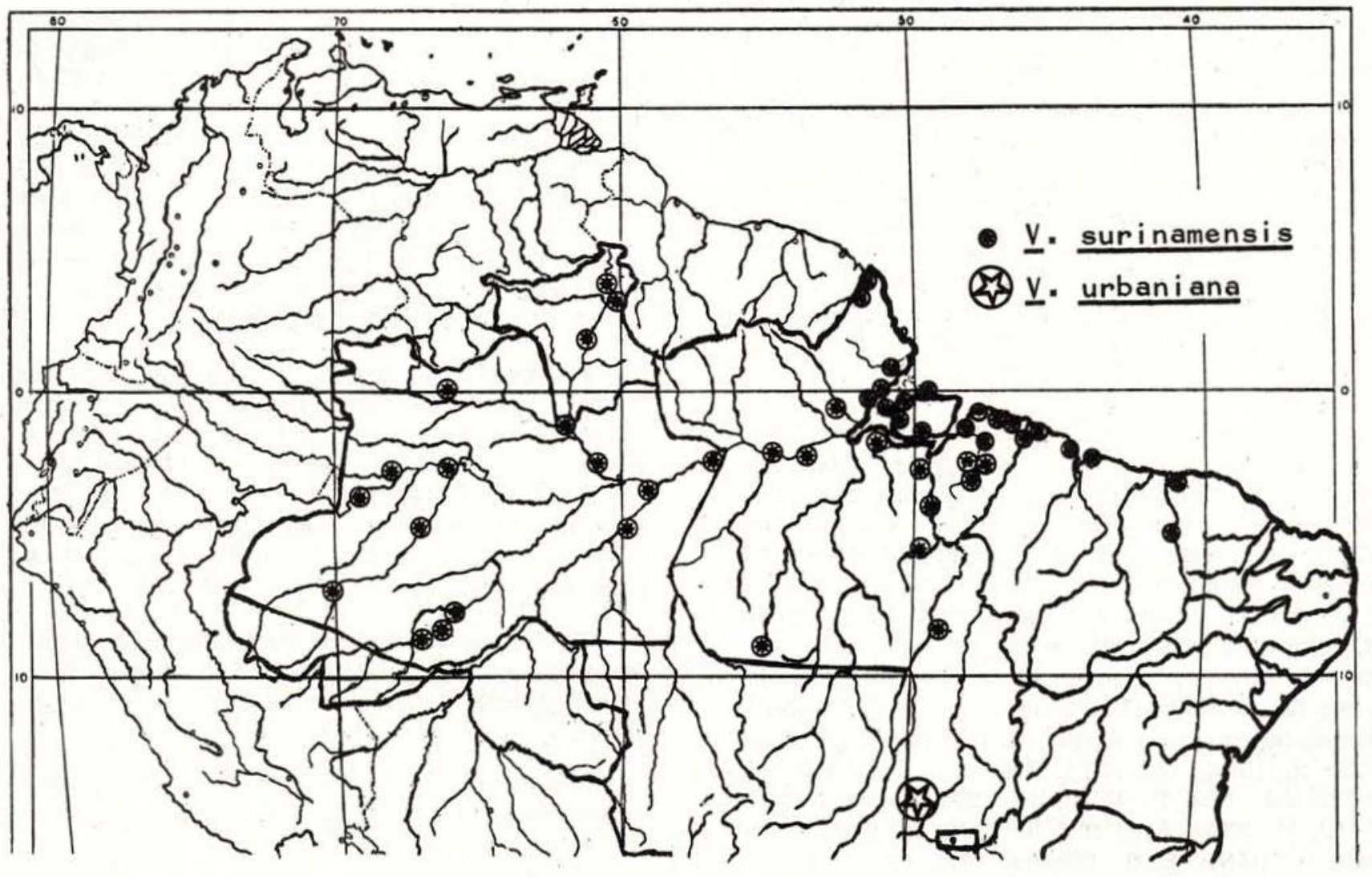

Fig. 71 - Distribuição atual de Virola surinamensis e V. urbaniana no Brasil. 
racaraí: R. L. Froes 22956, Fev. 1943 fr. (IAN, NY); J. M. Pires \& Leite 14728a (203), Jun. 1974 est. (IAN, INPA).

TERRITÓRIO DO AMAPA: - Rio Oiapoque: G. A. Black 49-8437, Out. 1949 fl. (IAN, NY); R. L. Froes, 25913, Fev. $1950 \mathrm{fr}$. (IAN); H. S. Irwin 48752, Out. 1960 fl. (IAN, MG, NY). Rio Caripi: R. Spruce s.n. ou 456, Ago. 1948 fl. (C, M, NY, P). Rio Araguari; entre Restauração e Ferreira Gomes: R. L. Froes \& Black 27649, Jul. 1951 fl. (IAN, NY). Macapá:Briglio 15, Ago. 1945 fl. (RB(; R. L. Froes \& Black 27285, Jul. $1951 \mathrm{fr}$. (IAN, NY). Mazagão: P. Ledoux 56-1503, Nov. 1955 fl. (IAN); rio Vila Nova: A. Ducke s.n., Out. 1900 fl. (MG 1991). Rio Maracá: M. Guedes s.n., Set. 1896 fl. (MG 628, INPA).

AMAZONAS: - São Paulo de Olivença: R. L. Froes 34815, Mar. $1945 \mathrm{fl}$. (IAN); id. 34844, Mar. 1945 fl. (IAN). Santo Antonio do Içá: R. L. Froes 20827, Maio $1945 \mathrm{fr}$. (IAN, NY). Bacia do rio Juruá: Carauari, seringal Santa Rosa: D. Coêlho \& Aniceto s.n., Ago. 1975 est. (INPA 52371); desembocadura do rio Embira, tributário do rio Tarauacá (lat. $7^{\circ} 30^{\prime} \mathrm{S}$; long. $70^{\circ} 15^{\prime}$ W): B. A. Krukoff 4663, Jun. $1933 \mathrm{fl}$. (NY). Fonte Boa: R. L. Froes 20996, Maio 1945 fl. (IAN, NY); id. 20998, Maio $1945 \mathrm{fl}$. (IAN, NY). Bacia do rio Purus: - Lábrea: G. G. Campbell et al. P 21212, Jun. $1974 \mathrm{fl}$. (INPA); entre rios Arauã e Santa Luzia do Sacado: G. T. Prance et al. 16300, Nov. $1971 \mathrm{fl}$. (INPA, NY); - rio Curuquetê, subafluente do rio Ituxi: G. T. Prance et al. 14505, Jul. 1971 fl. (INPA, NY). Bacia do rio Negro: rio Cauaburi, curso médio: R. E. Schultes 24569, Jul./Ago. $1967 \mathrm{fl}$. (ECON, IAN, INPA); entre rio Branco e o paraná do Jacaré: M. F. Silva et al. 1824, Maio $1973 \mathrm{fr}$. (INPA). - desembocadura do rio Apuaú: W. Rodrigues 747, Dez. 1958 fr. (F, INPA). Autaz-Mirim: W. Rodrigues \& Mello 7795, Abr. 1966 est. (INPA). Bacia do rio Madeira: - Borba: A. Ducke 483, Abr. 1937. fl. (NY); id. 484, Abr. $1937 \mathrm{fl}$. (NY). Parintins: A. Ducke s.n., Jan. 1937 fr. (RB 30147).

PARA: - Região de Santarém: M. Silva 1418 . Fev. 1968 fl. (MG); id. 1421, Fev. 1968 fr. (MG). Serra do Cachimbo: rio Cachimbo: E. Pereira 1861, Set. 1955 fl. (RB); J. M. Pires et al. 6397, Dez. $1956 \mathrm{fr}$. (IAN). Monte Alegre: D. A. Lima 53-1398, Maio 1953 fr. (IAN). Região do rio Jari: entre Monte Dourado e Mumbaca: E. Oliveira 3512, Nov. $1967 \mathrm{fr}$. (IAN); N. T. Silva 1312, Out. $1968 \mathrm{fl}$. (IAN); id. 3060, Abr. $1970 \mathrm{fr}$. (IAN). Antonio Lemos, rio Tajapuru, ilha Nazaré: G. A. Black 48-3014, Jul. 1948 fr. (IAN, NY). Portel, região do rio Anapu: R. L. Froes 32699, Set. $1956 \mathrm{fl}$. (IAN); id. 32766, Set. $1956 \mathrm{fr}$. (IAN); id. 32822, Jul. 1956 fl. (IAN); id. 32909, Ago. $1956 \mathrm{fl}$. (IAN); id. 32932, Ago. 1956 fl. (IAN), id. 32983, Maio $1956 \mathrm{fr}$. (IAN); E. O. Oliveira, 1271, Fev. $1961 \mathrm{tr}$. (IAN). Rio Pacajá (long. $50^{\circ} 38^{\prime}-50^{\circ} 50^{\prime} \mathrm{W}$; lat. $2^{\circ}$ $33^{\prime}-2^{\circ} 50^{\prime}$ ) : G. T. Prance et al. 1331, Set. $1965 \mathrm{fl}$. (IAN, NY, RB); id. 1567, Out. 1965 fl. (NY). Rio Ara- má: J. Huber s.n., Fev. 1900 fr. (MG 1845). Região de Marajó: ilha Mexiana: M. Guedes s.n., Out. 1901 fl. (MG 2458); - Sempre Viva, paraná do Miriti Pucu: J. G. Kuhlmann 2125, Maio $1924 \mathrm{fr}$. (RB). Colares: A. Ducke s.n., Ago. $1913 \mathrm{fl}$. (MG 12638, INPA). Breves: G. A. Black et al. 50-9823, Jul. 1950 plântulas (IAN); P. Cavalcante 2026, Set. 1968 fl. (INP, MG). Cercanias de Belém: W. A. Acher 7539, Nov. 1942 fr. (IAN, NY, US); id. 7882, Nov. 1942 fl. (IAN); id. 7910, Dez. 1942 fr. (IAN, NY, US); id. 8082, Dez. 1942 fr. (IAN, NY, US); D. F. Austin, 4196, Jun. 1969 fl. (IAN); G. A. Black 55-18493, Jul. 1955 est. (IAN); P. Cavalcante 346, Fev. Fev. $1958 \mathrm{fl} .(\mathrm{MG})$; id. 1847, Jan. 1968 fl. (MG); A. Ducke s.n., Nov. 1934 fl. (RB 25106); M. Guedes s.n., Ago. 1901 fl. (MG 2209, INPA); B. A. Krukoff 1000, Set. $1931 \mathrm{fl}$. (NY): Pessoal do Museu s.n., Nov. 1908 fl. (MG 9767, INPA). J. M. Pires 615, Jul. 1947 fl. (IAN, NY); id. 7090, Ago. 1958 fl. (IAN, UB, US), J. M. Pires \& Silva, 11092, Ago. 1967 fl. (IAN); id. 11695, Mar. 1968 fr. (IAN). Belém: J. M. Pires \& Silva 11927, Ago. 1968 fl. (IAN): J. M. Pires, 51732, Set./Out. 1961 est. (NY); B. Ribeiro 8A, Out. 1969 est. (IAN); W. A. Rodrigues, s.n., Abr. 1972 plântula (INPA 37127); Schwacke 4678, $1877 \mathrm{fl}$. (RB, fragmentos); A. Silva 17, Jan. 1944 fl. (IAN); id. 327, Nov. 1944 fr. (IAN, NY, US); N. T. Silva 272, Abr. 1949 fr. (IAN, NY). Tomé-Açu: Y. Mexia 5956, Jul. $1931 \mathrm{fl}$. (NY, US). Rodovia Belém-Brasília: E. Oliveira 233, Dez. $1959 \mathrm{fr}$. (IAN); Km 97: M. Kuhlmann \& Jimbo 246, Set. $1959 \mathrm{fl}$. (IAN, INPA, MG, SP): Km 254: E. Oliveira, 924, Jul. 1960 fl. (IAN). Região do rio Tocantins: Tucuruí: E. Oliveira 1187, Dez. $1960 \mathrm{fr}$. (IAN); rio Itacaiúna: R. L. Froes \& Black 24506, Jun. 1949 fl. (IAN). Bragança: J. G. Kuhlmann 10, Ago. 1923 fl. (RB); J. S. dos Santos s.n., Ago. 1906 fl. (MG 7288, INPA). São Miguel do Guamá: Dárdano \& Black 48-3185, Ago. 1948 fl. (IAN, NY). Rio Capim, Aproaga: J. Huber s.n., Jun. 1897 est. (MG 850). Peixe-Boi: R. Siqueira s.n., Out. $1907 \mathrm{fl}$. (MG 8754, INPA); id. s.n., Out. $1907 \mathrm{fl}$. (MG 8781, INPA).

MARANHÃO: - Região do rio Gurupi: R. Froes 1, Jun. $1933 \mathrm{fl}$. (NY, US). Região do rio Maracaçumé: R. Froes 1971, Out. 1932 fl. (NY). Alcântara: A. Ducke s.n., Set. 1903 fr. (MG 417); R. L. Froes 30751, Abr. 1954 fr. (IAN). São Luiz: A. Ducke s.n., Set. 1903 fl. (MG 366); R. L. Froes 11891, $1940 \mathrm{fl}$. \& fr. (NY); id. 24223, Maio $1949 \mathrm{fl}$. (IAN). Caxias: G. A. Black et al. 54-16700, Jul. 1954 fl. (IAN, NY).

CEARÁ: - Granja Serra da Ibiapaba: M. A. Lisboa s.n., Out. 1909 fl. (MG 2436, RB). Vale do Itacolomi: F. Allemão \& Cysneiro 1340, Dez. 1860 fr. (P, R, $\mathrm{RB})$.

GOIÁS: - Região do rio Araguaia, estrada para os campos gerais de Andorinhas, igarapé Gameleirinha: R. L. Froes 30181, Jun. 1953 fl. (IAN).

(!) MINAS GERAIS: - Santa Luzia: Glaziou 20463, Nov. 1893 fl. (B, destruído: GH, IAN, NY, P, UB). 
Sem localidade precisa: Glaziou 11594, 1879 ? fr. (B, destruído, C.). ( ${ }^{*}$ )

RIO DE JANEIRO: - Jardim Botânico de Rio de Janeiro (cultivada): J. G. Kuhlmann 6081, Dez. 1939 fl. (RB).

Warburg (I.c. 1897) e Smith (I.c., 1937) distinguem $V$. glaziovii Warb. da presente espécie por pequenas diferenças encontráveis nas folhas, flores e frutos, as quais poderiam ser consideradas como variações locais de uma espécie paramorfa, abundante e de ampla dispersão. Ao se examinar uma vasta coleção disponível desta espécie, nota-se que essas supostas diferenças encontradas na coleção típica de Glaziou, também aparecem de certa forma com freqüência em espécimes da região amazônica, admitindo-se, portanto, que melhor seria reduzí-la a sinônimo.

$\checkmark$. surinamensis distingue-se das demais afins, particularmente, por apresentar densa pilosidade amarelo-ouro ou ferrugínea nas pontas dos ramos e, também, pelas folhas em geral de margens paralelas.

34. Virola urbaniana Warburg, Nova Acta Acad. Leop.-Carol. 68:168. 1897; A.C. Smith \& Wodehouse, Brittonia 2 (5):462, fig. 8 a-c. 1937; J.C. Th. Uphof in Engl. \& Prantl, Nat. Pflanzenfam., $2^{\mathrm{a}}$ ed., $17^{a}$ (2) :206 et 207. 1959.

Árvore de $10 \mathrm{~m}$ ou mais; raminho robusto, densa e persistentemente tomentoso (tricomas ferrugíneos, ramificando-se desde a base ou irregularmente, $0,5-1 \mathrm{~mm}$ de comprimento). Pecíolo canaliculado, grosso, $3-4 \mathrm{~mm}$ de diâmetro, $5-8 \mathrm{~mm}$ de comprimento, tomentoso como os raminhos. Lâmina foliar finamente coriácea, oblonga, $140-240 \mathrm{~mm}$ de comprimento, $45-90 \mathrm{~mm}$ de largura, subcordada na base, subaguda ou cuspidada no ápice, glabra na página superior, somente tomentela na nervura mediana, página inferior densamente tomentosa (tricomas dendríticos, irregularmente ramificados, cerca de $0,5 \mathrm{~mm}$ de comprimento); nervura mediana plana ou levemente imersa na página superior, saliente na inferior; 20-30 nervuras secundárias de cada lado, retas, ligeiramente impressas na página superior, elevadas na inferior, as mais perto da base muito curtas e levemente recurvadas; vênulas reticuladas, quase planas e obscuras. Inflorescência masculina amplamente paniculada, livremente ramificada, densiflora, até $150 \mathrm{~mm}$ de comprimento e largura; pedúnculo de $30-50 \mathrm{~mm}$ de comprimento, com os raminhos densamente tomentosos com tricomas iguais àqueles dos raminhos vegeta. tivos; cerca de 15-30 flores por fascículo; brácteas decíduas, membranáceas, puberulentas e orbiculares, $5-7 \mathrm{~mm}$ de comprimento e largura; pedicelos muito curtos ou nulos; perianto submembranáceo de $1,7-1,9 \mathrm{~mm}$ de comprimento densamente tomentelo externamente (tricomas ramificados desde a base, cerca de $0,2 \mathrm{~mm}$ de comprimento), 3-lobado até quase a base lóbulos oblongos, obtusos; androceu de 1,2-1,6mm de comprimento; andróforo tênue de $0,4-0,6 \mathrm{~mm}$ de comprimento; 3 anteras de 0,8-1 $\mathrm{mm}$ de comprimento, livres e nitidamente divergentes na metade ou nos $2 / 3$ superiores, oblongas, obtusas ou tenuemente apiculadas no ápice. Inflorescência feminina e frutos não vistos. Fig. 72 .

TIPO: Glaziou 22036, Brasil, Goiás, entre Goiás e rio Uru, 20 Ago. 1895 fl. (holótipo: B, destruído; iectótipo: P; isótipo: C, K, S; foto F 1969, $\mathrm{GH}$, IAN) .

HaBitat: Mata úmida, em região de cerrado. Segundo Rizzo 5527, à margem de córrego.

Distribuição: Só ocorrente em Goiás. Fig. 71. GOIÁS:- Morrinhos: J.A. Rizzo 5527, set. 1970 fl. (UFG, INPA) .

A coleção Rizzo 5527 é a primeira feita depois do tipo. Difere da coleção - tipo pela falta de brácteas, que são decíduas, e inflorescência não congesta. Naturalmente, essa diferença é devida apenas à época de coleta. A coleção Glaziou foi obtida sem dúvida no início de floração, razão pela qual só apresentava inflorescências congestas.

( ) - Estas coleçōes de Glaziou, citadas para Minas Gerais, devem ser, sem dúvida alguma, provenientes da Amazônia, furtadas de Schwacke ou Jobert e etiquetadas erradas. 


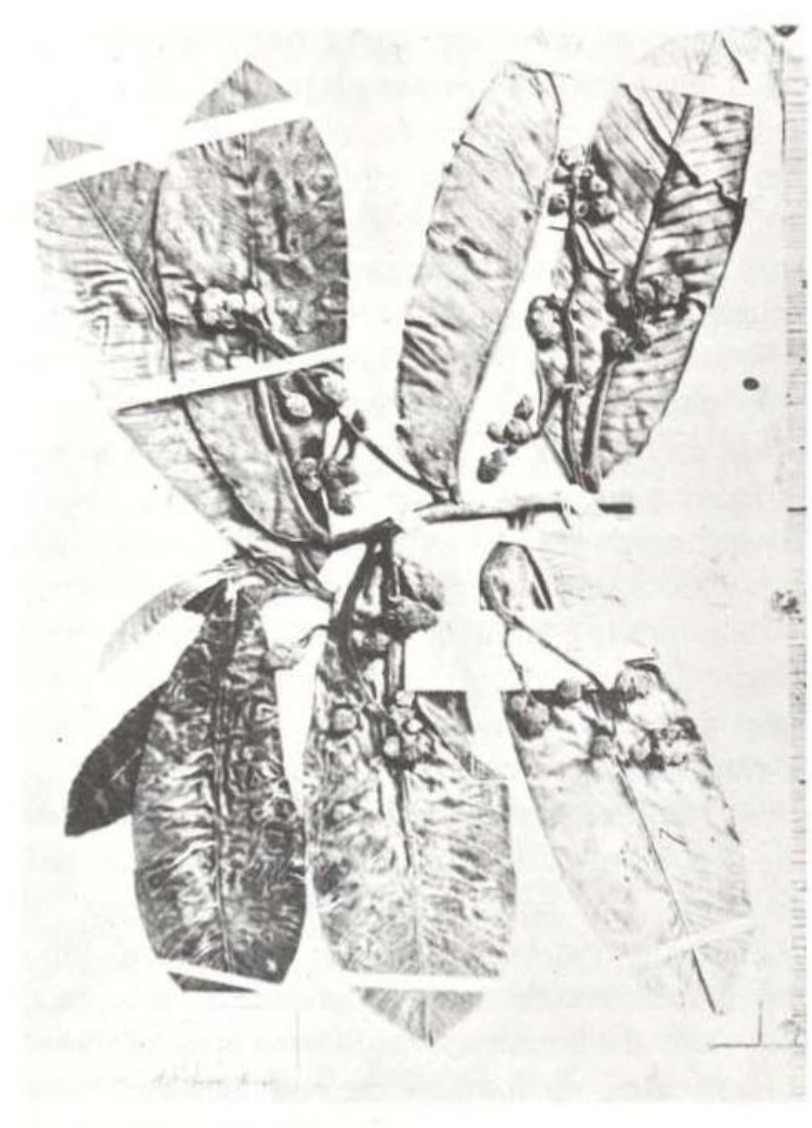

Fig. 72 - Virola urbaniana. Glaziou 22036 (reprodução da foto $F$ 1969, IAN).

35. Virola venosa (Benth.) Warburg, Nova Acta Acad. Leop.-Carol. 68: 224. 1897; A. Ducke, Journ. Wash. Acad. Sci. 26(6): 257. 1936, por parte; A.C. Smith \& Wodehouse, Brittonia 2(5):500, fig. 9a-d. 1937; A. Ducke Arq. Serv. Florest. 1(1): 27. 1939; P. Le Cointe, Amazônia brasileira III, $2^{\text {a }}$ ed. 251.480. 1947; A. C. Smith, Contr. U.S. Nat. Herb. $29(8): 329$. 1950; J.C. Th. Uphof in Engl. \& Prantl, Nat. Pflanzenfam., $2^{\mathrm{a}}$ ed. $17^{a}(2): 208$. 1959; A.A. Loureiro \& M.F. da Silva, Catálogo das Madeiras da Amazônia 2:215, ilust. 1968; R. E. Schultes \& Hohlmstedt, Lloydia 34(1):78. 1971; Fitoquímica-INPA, Acta Amaz. 1(3):49. 1971; O. R. Gottlieb, J. G. S. Maia \& S.L.V. Pinho, Ciência e Cultura 27(7): 172. 1975 .

Myristica venosa Bentham, Hook. Journ. Bot. 5: 3. 1853; A. De Candolle in DC., Prodr.
14: 198 e 697. 1856, pro parte (excl. spec. e Chicoplaya Pavonis); A. De Candolle in Mart., FI. Bras. 5 (1): 118. 1860.

Myristica venosa var. poeppigii $A$. De Candolle, in Mart., FI. Bras. 5 (1): 118. 1960. Tipo: Poeppig 2841 B, Brasil, Amazonas, Tefé (=Ega), fl. (holotipo: W destruido; isótipo: $B$ destruído; $B M$, n.v.).

Virola venosa var. poeppigii (A. De Candolle) Warburg, Nova Acta Acad. Leop.-Carol. 68: 225. 1897.

Myristica eyensis (=egensis) Poeppig ex Warburg, Nova Acta Acad. Leop.-Carol. 68: 225. 1897, pro syn.

Myristica lancifolia Poeppig ex Warburg, Nova Acta Acad. Leop.-Carol. 68: 225. 1897, pro syn.

Palala venosa (Bth.) Kuntze, Rev. Gen. PI. 2: 568. 1891, nom. illegit.

Arvore em geral pequena, mas às vezes até $30 \mathrm{~m}$ de altura; tronco de $10-35 \mathrm{~cm}$ de diâmetro; raminhos a princípio esparsamente puberulentos, passando a glabros e enegrescidos com a idade. Pecíolo fortemente canaliculado, inteiramente glabro, $1-2 \mathrm{~mm}$ de diâmetro, $7-12 \mathrm{~mm}$ de comprimento. Lâmina foliar finamente coriácea ou cartácea, elíptica, 110-230 $\mathrm{mm}$ de comprimento, $35-70 \mathrm{~mm}$ de largura (ocasionalmente até 90 por $25 \mathrm{~mm}$ ), atenuada, aguda ou obtusa na base, curtamente acuminada ou obtusamente cuspidada, no ápice, lustrosa na página superior, esparsamente pálido-puberulenta na página inferior (tricomas séssil-estrelados, 4-6-ramificados, cerca de $0,2 \mathrm{~mm}$ de diâmetro), logo glabra; nervura mediana plana ou levemente imersa na página superior, saliente na inferior; 12-27 nervuras secundárias de cada lado, ascendentes, retas, planas ou promínulas na página superior, elevadas na inferior; vênulas abundantemente reticuladas, promínulas em ambas as faces ou planas, raramente obscuras. Inflorescência masculina sub-terminal ou axilar, 2 ou 3 ramificada, $30-90 \mathrm{~mm}$ de comprimento (às vezes florescendo quando muito mais curta), às vezes mais ampla que comprida; pedúnculo até $20 \mathrm{~mm}$ de comprimento, ligeiramente achatado, com os raminhos e flores tenuemente cinéreo-puberulentos; brácteas oblongas, $3-8 \mathrm{~mm}$ de comprimento, puberulentas, logo decíduas; 3-12 flores por fascículo, os últimos pedúnculos distalmente túrgidos; pedicelos tênues até $2 \mathrm{~mm}$ 
de comprimento; perianto finamente carnoso, $1,8-2,5 \mathrm{~mm}$ de comprimento, obscuramente glandular-punctuado, 3-4 lobado ligeiramente mais do que a metade de seu comprimento total, lóbulos deltóides, obtusos; androceu 1,4-1,7mm de comprimento; andróforo carnoso, 0,7-1,2mm de comprimento; 3 anteras, $0,6-0,8 \mathrm{~mm}$ de comprimento, soldados até o ápice, obtusas. Inflorescência feminina até $30 \mathrm{~mm}$ de comprimento; 1-3 flores por fascículo; pedicelos grossos até $5 \mathrm{~mm}$ de comprimento; ovário subgloboso, puberulento; estilete grosso e curto; estigma fortemente fendido. Infrutescência de $30-70 \mathrm{~mm}$ de comprimento, uniformemente castanho-puberulenta (tricomas ramificados desde a base ou irregularmente ramificados, $0,1-0,2 \mathrm{~mm}$ de comprimento), os raminhos passando depois a glabrescentes; frutos persistentemente puberulentos, normalmente 2-8 por infrutescência madura, pedicelados (pedicelos grossos de 3-6mm de comprimento), subglobosos ou elipsóides, $13-19 \mathrm{~mm}$ de comprimento, $11-14 \mathrm{~mm}$ de largura, levemente carinados, arredondados na base, arredondados e apiculados no ápice; pericarpo liso, $0,7-1,5 \mathrm{~mm}$ de espessura; arilo laciniado até quase a base; semente elipsóide. lisa: Fig. 3A-6A-D, 73.

TrPo: Spruce 1401, Brasil, Amazonas, Manaus, Dez.-Mar. 1850-51 fl. (holótipo: K; isótipos : BM, n.v.; G-DC, GH, M, NY, P; B e W destruídos; fotos: F 7437, IAN, NY).

Nomes vUlgares: Ucuúba; ucuúba-branca (ex Rodrigues 5561); ucuúba-da-mata (ex Bastos 34); ucuúba-da-mata (fide Le Cointe, I.c. 1947); ucuúba-da-matta.

UTILIDADES: Segundo Loureiro \& Silva (I.c. 1968), a madeira pode ser empregada em marcenaria, construção em geral e em compensado. Conforme citação de Schultes \& Holmstedt (I.c. 1971), esta espécie contém traços de 5-metoxi-N,N-dimetiltriptamina na folha e raiz e N,N-dimetiltriptamina na folha apenas. Gottlieb et al. (I.c. 1975) encontrou também diarilpropanos nesta espécie.

Fenologia: A floração tem sido registrada durante quase todo o ano, marcadamente entre abril e julho e a frutificação, de abril a dezembro, acentuadamente nos meses de agosto e setembro. Fig. 20.
Habitat : Habita a mata de terra firme, tanto primária como secundária ou capoeirão.

Distribuição: Assinalada para a Colômbia e Venezuela e no Brasil para os Territórios do Amapá e Rondônia e Estados do Amazonas e Pará. Fig. 74.

\section{MATERIAL ADICIONAL EXAMINADO :}

TERRITÓRIO DO AMAPA: - Regiāo do rio Oiapoque: G. A. Black 49-8409, Out. 1949 fl. (IAN); H. S. Irwin 48606, Out. $1960 \mathrm{fr}$. (IAN, INPA, MG). Clevelândia: H. S. Irwin et al. 47377, Ago. 1960 fl. (NY, MG, IAN); J. M. Pires 7746, Ago. 1960 est. (IAN). Regiăo do rio Araquari: J. M. Pires et al. 50550, Ago. $1961 \mathrm{fl}$ (IAN, MG, NY, RB); id. 50713, Set. $1961 \mathrm{fr}$. (IAN, MG); id. 50923, Set. 1961 fr. (IAN, NY, MG); A. M. Bastos 57, Set. 1955 fl. (IAN, RB). Serra do Navio: W. Rodrigues 2996, Jul. 1061 est. (INPA). Rio Matapé, Torrão: J. M. Pires \& P. Cavalcante 52614, Ago. Ago. $1962 \mathrm{fr}$. (IAN, MG NY).
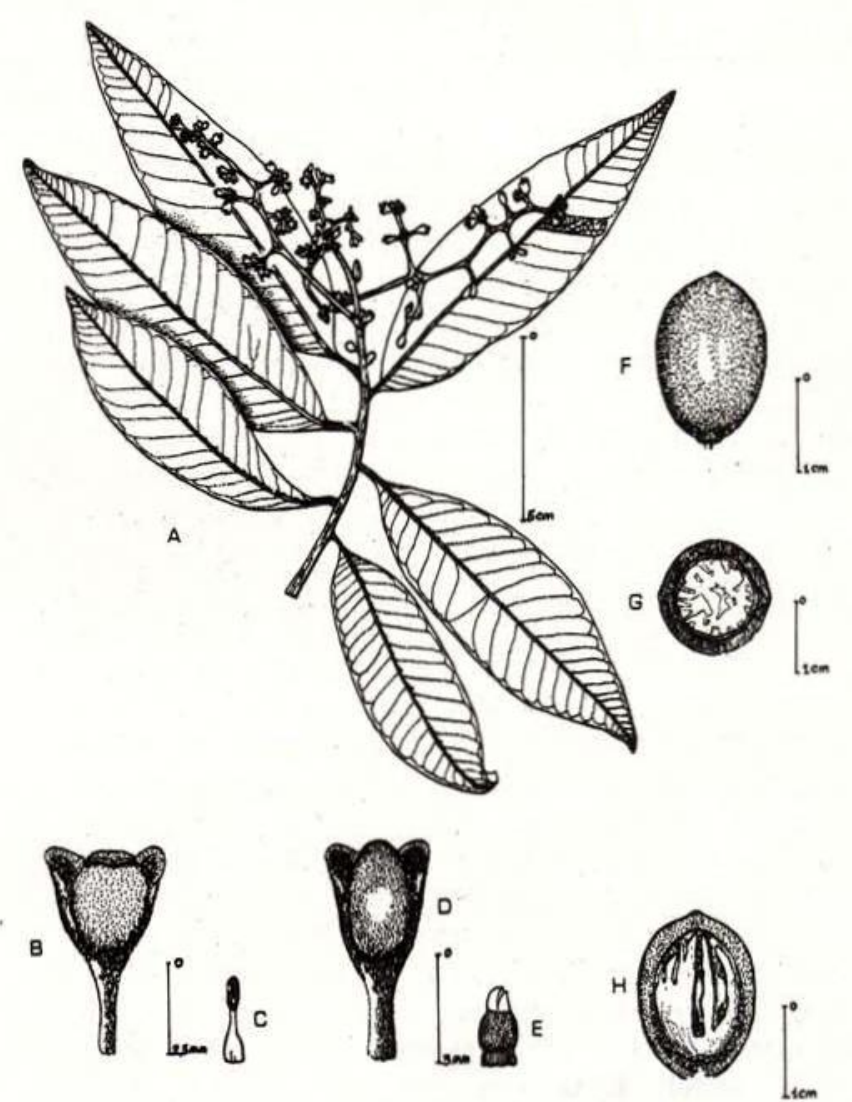

Fig. 73 - Virola venosa. A-C (O. P. Monteiro, INPA 50000): A, hábito do ramo florífero masculino; B, flor masculina; C, androceu; D, flor feminina; E, gineceu; F, fruto inteiro; G, fruto cortado seccionalmente mostrando a semente ruminada; $H$, fruto seccionado longitudinalmente mostrando parte da semente com arilo. 


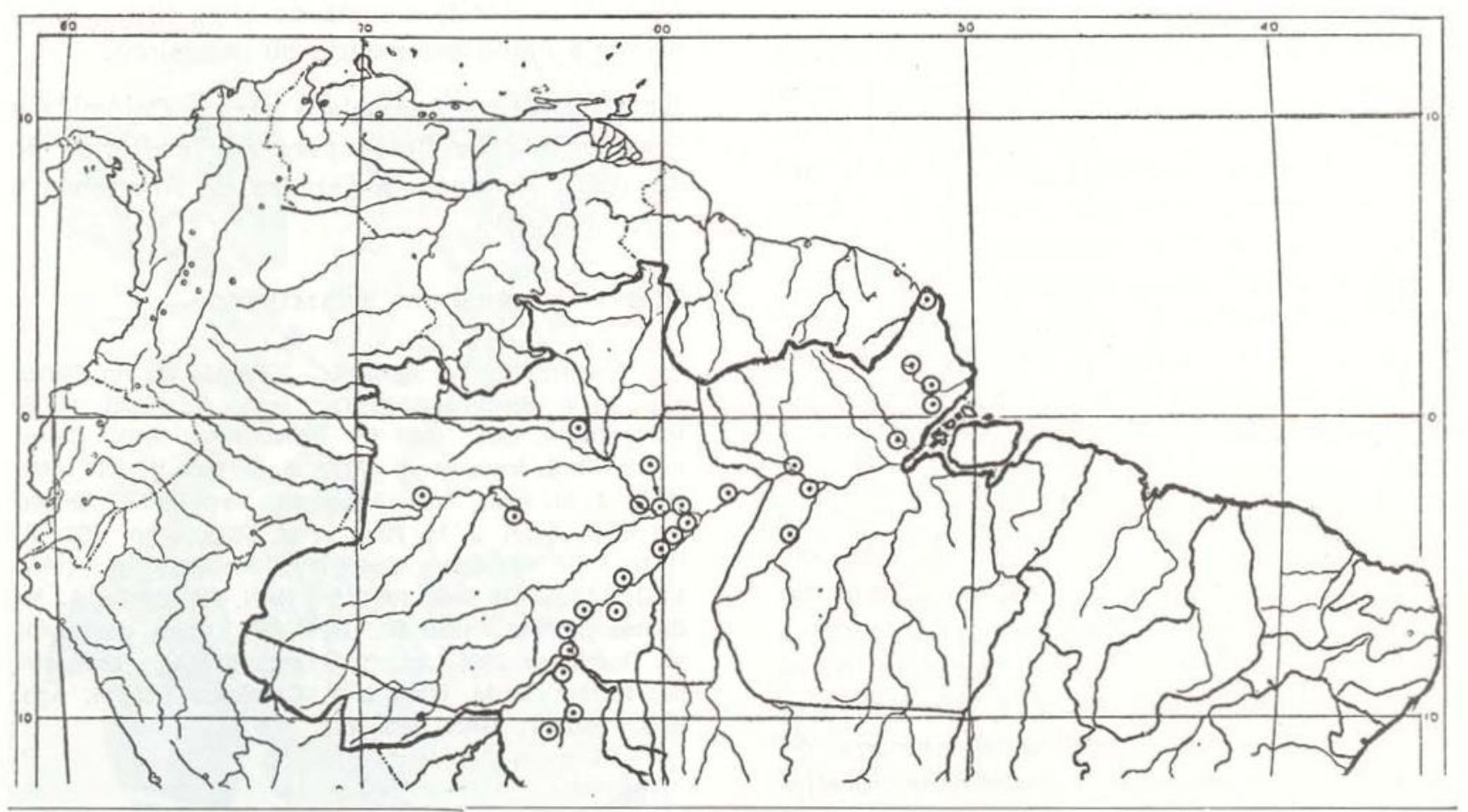

Fig. 74 - Distribuição atual de Virola venosa no Brasil.

AMAZONAS: - Tonantins: A. Ducke s.n., Nov. 1927 fl. (RB 19570). Tefé: E. Lleras et al. P. 16613, Jul. $1973 \mathrm{fl}$. (INPA); id. P 16654, Jul. $1973 \mathrm{fl}$. (INPA). Bacia do rio Negro: - rio Araçá: R. L. Froes \& Addison 29224, Nov. 1952 fr. (IAN); rio Araras: A. Loureiro et al. s n, Abr. 1973 fl. (INPA 37692); id. s.n., Jul. 1973 fl. (INPA 39550); - rio Cuieiras: D. G. Campbell et al. P. $21970 \mathrm{Abr} .1974 \mathrm{fl}$. (INPA); G. T. Prance et al. (INPA); G. T. Prance et al. 17896, Set. 1973 fr. (INPA); W. Rodrigues 6708, Set. $1964 \mathrm{fr}$. (INPA). Cercanias de Manaus: I. Araújo 27, Abr. 1974 fl. (INPA); Byron 180, Jul. 1969 fl. (INPA); J. Chagas s.n., Jul. $1955 \mathrm{fl}$. (INPA 1347); id. s.n., Jul. 1955 fr. (INPA 1520); D. Coêlho s.n., Ago. 1961 fr. (INPA 4073); D. Coêlho s.n., Fev. 1974 est. (INPA 46.527); L. Coêlho 155, Abr. 1972 fl. (INPA); id. s.n., Mar. 1957 fl. (INPA, 5205); ir. s.n., Mar. 1957 fl. (INPA 5207; A. Ducke 1304, Ago. $1943 \mathrm{fr}$. (MG); id. 2143, Jun. 1948 fl. (IAN, MG); id. s.n., Ago. 1932 fl. e Abr. 1933 fr. (RB 24499); id. s.n., Abr. 1932 fl. (RB 24500); B. A. Krukoff 7948, Ago./ Set. $1936 \mathrm{fr}$. (NY): A. Loureiro et al. s.n., Maio 1972 fl. (INPA 35800); O. P. Monteiro s.n., Jul. 1975 fl. (INPA 50000); E. Oliveira 2977, Nov. 1936 fr. (IAN); G. T. Prance et al. 18778, Ago. $1973 \mathrm{fr}$. (INPA); id. 20121, Dez. $1973 \mathrm{fr}$. (INPA). id. 20960, Fev. $1974 \mathrm{fl}$. (INPA); id. 20980, Abr. 1974 fl. (INPA); id. 21668, Ago. $1974 \mathrm{fr}$. (INPA); W. Rodrigues \& Lima 2156, Jul. 1961 fl. (INPA); W. Rodrigues 8807, Abr. 1970 fl. (INPA); R. E. Schultes \& Rodrigues 26130A, Abr. 1972 fr. (ECON, INPA); M. Silva 923, Abr. 1967 fl. (INPA, MG); M. Silva et al. 121, Maio $1972 \mathrm{fr}$. (INPA); R. Spruce s.n., Mar./Ago. 1851 fl. (RB 19395); W. C. Stewart \& Ramos P 20121, Dez. $1973 \mathrm{fr}$. (INPA). Estrada Manaus-Itacoatiara: Reserva Florestal Ducke, $\mathrm{Km} \mathrm{27:} \mathrm{J.}$ Aluísio 69, Jul. $1968 \mathrm{fl}$. (INPA); A. Loureiro s.n., Out. $1965 \mathrm{fr}$. (INPA): W. Rodrigues 5327, Jul. $1963 \mathrm{fr}$. (INPA, RB); id. 5561, Nov. $1963 \mathrm{fr}$. (INPA); W. Rodrigues \& Loureiro 5963, Jul. $1964 \mathrm{fl}$. (INPA); W. Rodrigues \& Osmarino 5968, Jul. $1967 \mathrm{fl}$. (INPA); W. Rodrigues \& Coêlho 7606, Mar. $1966 \mathrm{fl}$. (INPA); W. Rodrigues et al. 9382, Jun. $1974 \mathrm{fl}$. (INPA); W. Rodrigues \& Coêlho 9439, Jul. 1974 fl. (INPA); R. E. Schultes 24613 Jul./Ago. 1967 est. (INPA). - Km 32: W. Rodrigues 1783, Set. $1960 \mathrm{fr}$. (INPA). Km, 60: W. Rodrigues \& D. Coêlho 2231, Mar. 1961 fl. (INPA). Km 133-165: D. Coêlho s.n., Out. 1973 est. (INPA 42241); A. Loureiro et al. s.n., Maio 1972 fl. (INPA 35823); id. s.n., Mar. 1975 fl. (INPA 48317); O. P. Monteiro \& Coêlho 9439, Jul. 1974 fl. (INPA); R. E. Schultes Jul./ Ago. 1967 est. (INPA). - Km 32: W. Rodrigues 1783 , Set. $1960 \mathrm{fr}$. (INPA). - Km 60: W. Rodrigues \& D. Coêlho 2231. Mar. 1961 fl. (INPA). - Km 133-165: D. Coêlho s.n., Out. 1973 est. (INPA 42241); A. Loureiro et al. s.n., Maio $1972 \mathrm{fl}$. (INPA 35823); id. s.n., Mar. 1975 fl. (INPA 48317); O. P. Monteiro \& Lima 116, Jun. 1972 fl. (INPA); W. Rodrigues 8163, Out. 1965 est. (INPA). Rio Castanho: B. Albuquerque et al. 829, Jun. 1973 fr. (INPA); D. Coêlho s.n., Dez. 1974 fl. (INPA 47250). Estrada Manaus-Porto Velho: trecho entre os rios Castanho e Tupana: M. F. Silva et al. 197, Jul. $1972 \mathrm{fl}$. (INPA); id. 345, Jul. $1972 \mathrm{fl}$. (INPA); id. 431, Jul. $1972 \mathrm{fl}$. \& fr. (INPA); id. 480, Jul. 1972 
fl. (INPA); id. 575, Jul. 1972 fl. (INPA); id. 709, Jul. $1972 \mathrm{fr}$. (INPA); id. 826, Jul. $1972 \mathrm{fr}$. (INPA). AutazMirim: A. Loureiro et al. s.n., Jun. $1973 \mathrm{fr}$. (INPA) 38968). Itapiranga, no rio Urucará: M. Silva 1910, Set. 1968, fr. (MG). Bacia do rio Madeira: Marmelos: Ule 6115, Mar. 1902 fl. (MG). Humaitá: B. A. Krukoff 6929, Out./Nov. 1934 fr. (NY).

PARÁ: - Oriximiná: A. Ducke s.n., Jul, $1912 \mathrm{fl}$. (MG 1242). Região do rio Jari: E. Oliveira 4485, Jun. 1968 fl. (IAN, NY); N. T. Silva 2211, Jun. 1969 fl. (IAN). Região de Santarém: A. M. Bastos 34, Jan. 1938 fi. (RB); P. Cavalcante \& Silva 1501. Dez. $1966 \mathrm{fr}$. (INPA, MG): M. Silva \& Souza 2401. Ago. 1969 fl. (INPA, MG): id. 2636, Set. 1969 fl. (INPA, MG). Rio Tapajós: Cachoeiras inferiores: A. Ducke s.n., Jun. 1918 fi. (MG. 17082, INPA, RB); id. s.n., Dez. 1919 fl (RB 2702). Itaituba: A. Ducke s.n., Maio 1923 fl. (RB 18630).

TERRITORIO DE RONDONIA: Porto Velho: J. F. Silva 77, Jun. $1952 \mathrm{fr}$. (IAN); id. 203, Jun. $1952 \mathrm{fl}$. e fr. (IAN). Rio Jamari, cachoeira de Santa Cruz: J. M. Pires \& Martin 9944, Jun. 1965 fl. (IAN, NY). Ariquemes: E. Forero \& Wrigley 7053, Ago. $1968 \mathrm{fr}$. (INPA, NY).

Segundo Smith (I.c. 1937) e Ducke (I.c. 1939), esta espécie estava restrita sobretudo à parte central da Amazônia brasileira, tendo sido depois estendida por Smith (I.c. 1950) à Venezuela e por Schultes \& Holmstedt (I.c. 1971) à Colômbia. Baseado em maior número de exemplares, não temos dúvida em confirmar a sua ocorrência também na zona costeira da Hiléia,

Distingue de sua espécie mais afim, $V$. michelii Heckel, por uma série de caracteres diferenciais, tais como nervuras secundárias retas, mais ou menos paralelas e ascendentes, fino reticulado, em geral, ligeiramente saliente em ambas as faces da folha, face inferior glabra ou esparsamente séssil-estrelada, flores relativamente menores e frutos elípticos menores, cobertos de indumento ferrugíneo, persistente.

\section{ESPÉCIES EXCLUÍDAS}

Virola glycicarpa Ducke, Bol. Técn. Inst. Agron. Norte 4:9.1945 = Dialyanthera parvifolia Markgraf.

Virola papillosa Ducke, Trop. Woods 90:10. $1947=$ Iryanthera crassifolia A.C. Smith. 


\section{AGRADECIMENTOS}

Ao Prof. Dr. Hermógenes de Freitas Leitão Filho pela orientação dada a este estudo.

A John Simon Guggenheim Memorial Foundation, pelos recursos oferecidos para execução deste estudo e visita aos principais herbários mudiais.

Às seguintes pessoas e instituições, pela sua hospitalidade e espírito de cooperação: Dr. Richard E. Schultes, diretor do Economic Herbarium of Oakes Ames, Cambridge, U.S.A.; Dr. Lyman B. Smith, U.S. National Herbarium, Washington, U.S.A.; Dra. Alice Lourteig; Museum National d' Histoire Naturelle, Paris, França; Dr. Ponce de León, Field Museum of Natural History, Chicago, U.S.A.; Dr. Ghillean T. Prance, The New York Botanical Garden, Bronx, U.S.A.; Dr. Davis Philcox, Royal Botanic Gardens, Kew, Inglaterra; Dr. Klaus Kubitzki. Botanische Staatssammlung, Munique, Alemanha; Drs. Álvaro Fernandez Pérez e Enrique Forero, Instituto de Ciências Naturales, Bogotá, Colômbia; Dr. Murça Pires, EMBRAPA e Dr. Paulo B. Cavalcante, Museu Paraense Emílio Goeldi, Belém, Pará; Dr. Ezechias P. Heringer, Herbário da Universidade de Brasília; Dra. Elsie F. Guimarães, Jardim Botânico do Rio de Janeiro e Dra. Margarete Emmerich, Museu Nacional, Rio de Janeiro.

A todo o pessoal dos herbários citados no texto, pelo empréstimo de material botânico ou facilidades oferecidas durante a consulta dos espécimes essenciais a este estudo.

Aos Drs. Paulo Hiepko, Museu Botânico de Berlim-Dahlen, Alemanha, e Luciano A. Bernardi, Conservatoire et Jardim Botanique, Genebra, Suiça, pelas informações sobre as coleções dos herbários de suas instituições.

Ao Conselho Nacional de Desenvolvimento Científico e Tecnológico pelo apoio financeiro recebido.
Ao Dr. Warwick Estevam Kerr, ex-diretor do Instituto Nacional de Pesquisas da Amazônia, Manaus, Amazonas, pelo grande apoio, incentivo e confiança sempre demonstrada durante a execução deste trabalho.

Ao Dr. Anthony B. Anderson, pelos úteis comentários e versão para o inglês do resumo.

Aos Drs. Pedro Ivo Braga, Marilene Braga, Marlene Freitas da Silva, Izonete Araujo, Maria Imelda Leite dos Anjos, Maria das Graças Gonçalves Vieira e a todos os outros pesquisadores e funcionários do Instituto Nacional de Pesquisas da Amazônia, pela colaboração prestada na revisão do texto.

Aos Drs. Maria Lúcia Absy e Osório José M. Fonseca pelas fotografias, respectivamente, dos grãos de polem e cortes histológicos de madeira.

Ao Dr. Arthur A. Loureiro, pelo empréstimo das lâminas histológicas para fotografia.

Aos desenhistas Júlio Dellome Filho, Jorge da Silva Palheta e Alberto Coêlho da Silva, pelo primoroso trabalho artístico das ilustraçōes no textc.

A Srta. Aurea Araujo Pessôa e Sr. José Lira, pelo paciente e eficiente trabalho datilo. gráfico.

Aos auxiliares de campo, Srs. Luiz Fernandes Coêlho, Dionísio Fernandes Coêlho, Osmarino Pires Monteiro, José Ramos, do Instituto Nacional de Pesquisas da Amazônia, pela inestimável ajuda na coleta de material botânico.

A todos que, direta ou indiretamente, deram apoio, incentivo, apontaram erros e aju. daram a corrigi-los,

Meus mais sinceros agradecimentos. 


\section{$S U M M A R Y$}

In this work, the author presents a critical study and revision of the species of Virola Aublet (Myristicaceae) occurring in Brazil, known vernacularly in various regions of the country as "bicuiba", "ucuuba", "urucuba" and, commercially, as "virola". The genus is one of the most important of the american Myristicaceae, not only due to its wealth of species, but also because of the economic and medicinal value that various of its species represent.

This work opens with an explanation of why the study was made, followed by an historical sketch of the principal contributions to our knowledge of the genus in Brazil and a brief description of its economic importance. A discussion of the geographic distribution of the genus Virola within Brazil is included, as well as an examination of its morphological, anatomical and palynological aspects. Data on the phenology of a number of principal species, obtained primarily from herbarium material, are presented and discussed. In a more speculative vein, possible generic and evolutionary relationships of Virola are also discussed, based primarily on external morphology, due to the lack of knowledge concerning cytology within the genus.
The major portion of this study is devoted to the classification and taxonomic descriptions of the genus and its species. A key for the identification of the neotropical genera of Myristicaceae has been included to show intergeneric relationships and affinities, as well as another key for the species of Virola considered in this revision. The descriptions are accompanied by photographs or original analytical drawings, principally of the leaves, flowers and fruits; in adition, distribution maps for each species have been prepared. A list of the specimens consulted is included at the end of each description. Finally, the author has suplied additional information concerning the common names, uses, phenology and habitat of each species.

The groups and sections that have been proposed previously by other botanists are rejected; three binomials are reduced to synonymy; the descriptions of various species are amplified; and the distribution areas of the majority of species are considerably increased. A total of 35 Brazilian species of Virola are recognized as valid in this work. 


\section{INDICE DAS COLEÇÕES CITADAS}

Os números grifados referem-se aos números dos coletores. Quando inexistentes, segue-se ao nome a sigla e o número do herbário onde está localizada a amostra. O número entre parêntese refere-se ao número da espécie nesta monografia.

Acher, W.A. 7539 (33); 7882 (33); 7910 (33); 8082 (33); 8244 (30); 8300 (30).

Albuquerque, B. et al. 229 (35).

Allemão, F., 1340 (33); s.n. (12).

Almeida, J. \& al. 213 (12).

Aluizio, J. 30 (10); 48 (26); 54 (10); 59 (03); 69 (35); 107 (08); 147 (10); 232 (17); 233 (17); 275 (21); 278 (20); 310 (04); INPA 21213 (08); INPA 21288 (17).

Anderson, W.K., 7229 (30); 7707 (30); 8210 (30); 10006 (30); 10244 (30); 10562 (30).

Antenor, 628 (12).

Araújo, 27 (35); 9892 (24).

Argemiro, INPA 49569 (17).

Arinos, G.M., 193 (12).

Arostegui 115 (01).

Austin, D.F., 4196 (33).

Baldwin, J.T. Jr., 2991 (30); 3131 (31).

Barata, L., s.n. (10).

Barreto, Mello 1560 (24).

Barros, W.D., 43 (12); 559 (12); 607 (24).

Bastos, A.M., 34 (35); 57 (35).

Batista, P.C., 2 (10).

Belshaw, C.M., 3091 (27).

Benoist, 666 (17); 1010 (17); 1125 (17).

Berg, C.C. \& al., $P 18530$ (03); $P 18545$ (26); $P 18596$ (10); P 18793 (03); P 19742 (27).

Black, G.A. \& al., 47-1504 (10); 47-2182 (10); $48-2386$ (30); 48-2569 (03); 48-3014 (33); $49-8212$ (30); $49-8409$ (35); 49-8437 (33); 50-9603 (17); 50-9823 (33); 50-10672 (03); $51-11703$ (30); $52-14156$ (30); 52-14640 (03); 52-15569 (30); 54-16700 (33); 55-18493 (33); 57-19458 (30); s. n. (30); 57-19459 (30). Brade, A.C. \& al., 7960 (24); 17827 (30).
Briglio, 15 (33).

Byron, \& al., 180 (35); 604 (10); 622 (10); 921 (03); $923(10)$.

Camargo, F.C., IAN 9 (17).

Campbell, D.G. \& al., P 20814 (10); P 21212 (33); $P 21242$ (10); $P 21253$ (10); $P 21821$ (03); $P 21883$ (03); $P 21893$ (10); $P 21970$ (35); $P 22282$ (30).

Capucho, 391 (10); 594 (17); 595 (30).

Carauta, 300 (30).

Cavalcante, P., 212 (30); 213 (30); 346 (33); 363 (17); 556 (10); 1501 (35); 1539 (17); 1847 (33); 2026 (33); 2712 (30).

Chagas, J., INPA 196 (10); INPA 363 (26); INPA 364 (08); INPA 779 (03); INPA 786 (08); INPA 800 (21); INPA 951 (08); INPA 1341 (21); INPA 1347 (35); INPA 1520 (35); INPA 2178 (10); INPA 3473 (10).

Clausen, M., $368(30)$.

Coêlho, D. \& al., 619 (05); INPA 2948 (09); INPA 3861 (08); INPA 4073 (35); INPA 42214 (03); INPA 42227 (10); INPA 42232 (02); INPA 42241 (35); INPA 46523 (04); INPA 46527 (35); INPA 46533 (10); INPA 47250 (35); INPA 37252 (11); INPA 47272 (03); INPA 47274 (26); INPA 47275 (03); INPA 47280 (26); INPA 47282 (26); INPA 52371 (33); 52388 (11); 53124 (05); 53125 (08); 53738 (26).

Coêlho, L. \& al., 43 (10); 14.3 (03); 149 (03); 155 (35); 349 (14); INPA 1403 (10); INPA 1644 (10); INPA 1842 (08); INPA 5160 (26); INPA 5205 (35); INPA 5207 (35); INPA 7243 (10); INPA 21157 (21); INPA 37128 (26); INPA 39601 (20); INPA s.n. (10).

Cordeiro, M.C., 680 (03).

Cordeiro, M.R. 67 (30); 120 (03); 199 (03).

Costa, R.M., 60 (30).

Curran, H.M., 46 (12).

Dárdano \& al., 48-3185 (33).

Dolcolmo, G., 12 (24). 
Drees, E.M., 7 (09).

Duarte, A.P., 2850 (30); 9498 (32); 9818 (03).

Ducke, A. \& al., 7 (30); 11 (08); s. n. (26); 20 (03); 22 (12); 32 (24); 100 (21); IAN 117 (26); IAN 118 (08); IAN 120 (03); 174 (08); 175 (08); 254 (10); 259 (04); 260 (04); 366 (33); 396 (03); MG 417 (33); 422 (10); 483 (33); MG 517 (30); 530 (10); 583 (10); 596 (30); 603 (30); 658 (04); 670 (03); 701 (21); 755 (09); 761 (03); 882 (14); 933 (10); 1057 (09); 1059 (26); 1147 (2.6); 1203 (09); 1233 (17); 1253 (30); 1268 (17); 1268 (17); 1299 (26); 1304 (35); 1305 (26); 1369 (33); 1494 (30); 1495 (03); 1496 (26); 1509 (22); 1650 (17); 1775 (19); 1894 (03); MG 1991 (33); 2020 (10); 2021 (10); 2143 (35); 2215 (21); 2261 (12); MG 2638 (30); $R B 2702$ (35); MG 2949 (10); MG 3490 (30); MG 3607 (30); MG 6792 (14); MG 7201 (10); MG 7414 (10); $M G 7459$ (10); $M G 7922$ (10); MG 8682 (30); MG 11119 (10); MG 11265 (17); $M G 11472$ (10); MG 11584 (10); $M G$ 11871 (10); MG 12042 (35); MG 12205 (10); MG 12486 (10); MG 12638 (33); MG 14838 (10); MG 15257 (20); MG 15349 (17); MG 17082 (35); $R B 17983$ (14); $R B 18630$ (35); $R B 18631$ (30); $R B 18632$ (03); RB 19569 (17); $R B \quad 19570$ (35); $R B \quad 19571$ (07); $R B$ 21203 (04); $R B 24464$ (30); $R B 24466$ (10); $R B 24467$ (10); $R B 24468$ (10); $R B 24469$ (10); $R B \quad 24470$ (10); $R B 24485$ (03); $R B$ 24486 (03); $R B 24487$ (03); $R B 24494$ (03); $R B 24495$ (10); $R B 24496$ (10); $R B 24497$ (10); $R B 24498$ (10); $R B 24499$ (35); $R B$ 24500 (35); $R B 24501$ (26); $R B 24502$ (04); $R B \quad 24503$ (04); $R B \quad 24504$ (26); $R B 24539$ (03); $R B \quad 24540$ (03); $R B 24541$ (10); $R B$ 24542 (10); $R B 24544$ (10); $R B 24545$ (10); $R B 24548$ (08); $R B 24549$ (08); $R B 24550$ (08); $R B 24551$ (30); $R B 24552$ (27); $R B$ 24553 (25); $R B 24555$ (21); $R B 24556$ (21); $R B 24559$ (18); $R B 24560$ (18); $R B 24562$ (09); $R B 24563$ (01); $R B 24564$ (01); $R B$ 24972 (20); $R B 25105$ (12); $R B 25106$ (33); $R B 25311$ (06); $R B 30138$ (18); $R B 30139$ (03); $R B 30140$ (03); $R B 30141$ (03); $R B$ 30142 (26); $R B 30143$ (26); RB 30145 (26); 30146 (04); $R B 30147$ (33); $R B 30148$ (30); $R B 30149$ (30); $R B 30150$ (10); $R B 34615$ (10); $R B \quad 34617$ (10); $R B \quad 34618$ (10); $R B$
34619 (10); $R B 37641$ (04); $R B 50687$ (04); $R B \quad 50695$ (22); $R B \quad 53227$ (26); RB 53228 (26); RB s.n. (14); RB s. n. (10).

Dusén, P., 15313 (24).

Egler, W.A., 1353 (30).

Ferreira, E., INPA 5055 (26); INPA 6420 (10).

Forero, E. \& al., 6370 (01); 7053 (35).

Francisco \& al., INPA 2995 (08).

Freitas, M. \& al., 19 (26).

Froes, R.L. \& al., 1 (33); 1752 (30); 1971 (33); 11644 (30); 11891 (33); 20469 (04); 20604 (10); 20608 (10); 20610 (10); 20612 (03); 20622 (10); 20629 (26); 20716 (26); 20757 (03); 20766 (26); 20827 (33); 20859 (10); 20883 (09); 20894 (14); 20908 (03); 20925 (03); 20928 (10); 20930 (10); 20986 (10); 20996 (33); 20998 (33); 21015 (10); 21172 (04); 21188 (10); 21222 (03); 21232 (10); 21248 (09); 21266 (03); 21400 (26); 21473 (29); 21637 (10); 21640 (03); 22094 (10); 22127 (03); 22231 (26); 22268 (26); 22532 (10); 22685 (33); 22956 (33); 23255 (03); 23563 (20); 23385 (24); 23594 (17); 23746 (22); 23753 (04); 23816 (10); 23820 (14); 23821 (10); 23910 (10); 23972 (26); 24015 (04); 24153 (30); 24202 (30); 24223 (33); 24226 (30); 24506 (33); 24922 (03); 24978 (26); 25017 (10); 25180 (10); 25212 (10); 25249 (10); 25357 (04); 25368 (10); 25439 (10); 25458 (10); 25485 (10); 25518 (10); 25555 (22); 25591 (10); 25611 (10); 25913 (33); 26195 (04); 26220 (05); 26228 (03); 26548 (10); 26659 (17); 26900 (30); 27285 (33); 27649 (33); 27696 (17); 28063 (03); 28148 (26); 28829 (10); 28955 (03); 29147 (04); 29224 (35); 29578 (10); 29709 (30); 30181 (33); 30751 (33); 30775 (30); 30813 (17); 30963 (10); 30969 (04); 30982 (03); 30998 (10); 31003 (17); 31005 (02); 31048 (10); 31052 (17); 31254 (17); 31512 (10); 31719 (04); 32174 (02); 32215 (17); 32368 (17); 32399 (06); 32494 (17); 32511 (17); 32699 (33); 32766 (33); 32822 (33); 32909 (33); 32932 (33); 32983 (33); 33371 (12); 33385 (24); 33645 (13); 33715 (03); 33903 (30); 34450 (17); 34693 (17); 34789 (14); 34792 (03); 34799 (10); 34802 (03); 34815 (33); 34817 (10); 34837 (10); 34844 (33); 34854 (30); 34879 (10).

Garcia-Barriga, H. \& al., 14979 (28). 
Gardner, 2775 (32); 3566 (30); 5596 (12).

Gevieski, A., 106 (24).

Glaziou, 460 (30); 799 (24); 10030 (30); 11594 (33); 16317 (33); 20463 (33); 22036 (34); 22037 (30).

Goeldi, A., MG 3923 (03); MG 3938 (10); MG 8314 (17); s. n. (21).

Gomes, J.C., 311 (30).

Grubb, P.J. \& al., 1629 (27).

Guedes, M., MG 628 (33); MG 2209 (33); MG 2458 (33).

Guedes, T., 44 (08); 57 (10); 61 (21).

Handro, O., SP 37597 (24).

Hatschbach, G., 3478 (24); 23892 (30).

Hayes, \& al., s.n. (17); 618 (30).

Heringer, E.P. \& al., 2227 (24); 2511 (12); 2759 (24); 2797 (24); 2841 (12); 7507 (30).

Hoehne, F.C., 28334 (30).

Huber, J., MG 133 (30); MG 237 (30); MG 655 (30); MG 838 (30); MG 850 (33); MG 1845 (33); $M G 10784$ (30).

Irwin, H.S. \& al., 5321 (30); 5930 (30); 6529 (30); 8796 (30); 11782 (30); 13085 (30); 13226 (30); 14072 (30); 14893 (32); 15447 (30); 16140 (30); 16444 (30); 17058 (30); 18015 (30); 18269 (30); 18787 (30); 19099 (30); 19202 (30); 21053 (30); 21126 (30); 21508 (32); 21599 (30); 23991 (30); 25085 (30); 26013 (30); 26711 (30); 26795 (30); $34282(30) ; 47164$ (30); 47377 (35); 48606 (35); 48670 (30); 48752 (33).

Karsten, H., s. n. (03).

Killip, E.P. \& al., 27026 (14); 27359 (14); 29671 (14); 30253 (30).

Klein, R., 139 (24); 1104 (24); 1421 (24).

Klug, 1502 (14); 1543 (14).

Krukoff, B.A., 1000 (33); 1008 (30); 1120 (08); 1310 (20); 1333 (26); 1455 (10); 1496 (26); 1590 (10); 4596 (10); 4657 (03); 4663 (33); 4713 (03); 4794 (10); 4802 (10); 4910 (10); 4947 (10); 5314 (30); 5492 (03); 6287 (10); 6626 (10); 6732 (11); 6817 (20); 6885 (10); 6889 (03); 6929 (35); 7172 (26); 7179 (26); 7850 (14); 7948 (35); 8070 (14); 8103 (01); 8305 (10); 8361 (04); 8689 (10); 8787 (10); 8891 (02); 8917 (10); 8920 (30); 8951 (10).

Kuhlmann, J.G., 10 (33); 108 (10); 387 (08); 436 (12); 499 (10); 511 (10); 629 (12); 630 (24); 814 (30); 1409 (21); 1485 (14); 1739 (30); 1971 (30); 1972 (30); 1973 (31); 2078
(30); 2097 (30); 2121 (30); 2125 (33); 2135

(24); 6081 (33).

Kuhlmann, M., 246 (33); 2815 (24).

Lage, RB 120358 (24).

Lamarck, s. n. (33).

Leal, C. G., 71037 (12).

Ledoux, P., 56-1503 (33).

Lima, N.S., 49-350 (12).

Lima, D. \& al., 50-496 (12).

Lima, D.A., 53-1367 (30); 53-1398 (33).

Lindeman, \& al., 13535 (24).

Lisbôa, A., MG 2436 (33); MG 2636 (33).

Lisboa, P. \& al ., 518 (03).

Lleras, E., \& al., $P 16579$ (26); $P 16613$ (35); $P 16654$ (35); $P 16929$ (10); $P 17207$ (03); P 17486 (04); P 19573 (03); P 19589 (10); P 19621 (03); P 19642 (10); P 19668 (10).

Loureiro, A. \& al., INPA 16452 (21); INPA 35764

(21); INPA 35800 (35); INPA 35823 (35); INPA 37587 (10); INPA 37634 (10); INPA 37639 (26); INPA 37692 (35); INPA 37702 (18); INPA 37712 (03); INPA 37740 (08); INPA 37746 (10); INPA 37853 (10); INPA 37933 (08); INPA 38093 (08); INPA 38954 (26); INPA 38968 (35); INPA 38969 (10); INPA 39461 (10); INPA 39473 (10); INPA 39498 (10); INPA 39550 (35); INPA 39553 (03); INPA 48301 (26); INPA 48317 (35); INPA 48416 (26).

Luideman, \& al., 13535 (24).

Luetzelburg, Ph. V., 1282 (32); 1372 (32).

Maas, P.J.M. \& al., P 12659 (03); $P 12718$ (03); $P 12788$ (03); $P 12796$ (07).

Magalhães, M., 83 (24); IAN s. n. (30).

Maguire, B. \& al., 56123 (32); 56267 (15); 56558 (31); 56666 (03); 56777 (10); 56928 (30).

Malme, E.O.A., 2007A (31); 2033A (15); $2033 B$ (15).

Manso, \& al., 39 (31); 57 (30).

Martin, 8 (17) .

Martius, 650 (23); 927 (23); 2611 (33); MUN (10).

Mattos, A. \& al., 129 (30); 317 (30).

Melinon, s. n. (17).

Mello, F. \& al., INPA 1307 (26); INPA 4031 (10); INPA 4176 (10); INPA 51802 (10).

Mexia, Y., 4699 (24); 5920 (30); 5956 (33).

Monteiro, O.P., 25 (02); 116 (35); INPA 50000 (35); INPA 50905 (04). 
Muller, Fr., R 61015 (24).

Nascimento, O.C. \& al., 5 (26); 51 (26); 104 (04); 262 (10); IAN 148263 (152) (14).

Nunes, G.M., SP 22534 (12).

Ochioni, P., RB 21202 (12).

Oliveira, E., 233 (33); 846 (17); 924 (33); 1030 (17); 1187 (33); 1271 (33); 1754 (30); 2277 (10); 2401 (30); 2584 (17); 2697 (02); 2704 (03); 2851 (10); 2977 (35); 3085 (30); 3296 (30); 3512 (33); 3551 (17); 3683 (17); 3975 (17); 4018 (17); 4103 (17); 4485 (35); 4719 (30); 4825 (17).

Onishi, E. \& al., 925. ${ }^{*}(30)$.

Osmarino, 01 (21).

Paula, J.E., 215 (30).

Penna, B.S. \& al., 18 (30); 56 (10).

Pennington, T.D. \& al., P 22636 (26).

Pennington, T.M. \& al., P 22638 (03).

Pereira, E., 1861 (33); 9024 (30).

Pinheiro, M., 24 (30).

Pires, J.M. \& al., 577 (30); 615 (33); 668 (17); 784 (30); 786 (10); 819 (30); 937 (03); 1321 (10); 1540 (30); 3625 (30); 4018 (30); 4036 (20); 6397 (33); 6816 (17); 7028 (17); 7090 (33); 7093 (17); 7272 (17); 7273 (17); 7477 (26); 7478 (26); 7737 (17); 7738 (17); 7746 (35); 7897 (10); 9944 (35); 10369 (30); 10905 (10); 11092 (33); 11229 (17); 11283 (17); 11695 (33); 11713 (30); 11880 (17); 11927 (33); 12221 (17); 12260 (17); 13058 (17); INPA 13245 (26); 14728..$^{a}$ (203) (33); IAN 15086 (106) (10); 50526 (17); 50550 (35); 50556 (17); 50713 (35); 50769 (17); 50923 (35); 50958 (17); 51337 (10); 51722 (30); 51732 (33); 52614 (35); 58054 (30)

Pires, O. \& al., 59 (03); 167 (21); 289 (10).

Pittier, H., 3505 (30).

Poeppig, 2048 (26); 2195 (19); 2390 (30); 2647 (10); 2841B (35).

Pohl, MUN (30).

Prance, G.T. \& al., 1259 (L.S. 158) (17); 1331 (33); 1477 (10); 1567 (33); 1576 (03); 2142 (10); 2143 (08); 2144 (03); 2295 (10); 2779 (10); 2805 (14); 2840 (10); 3079 (03); 3257 (10); 3269 (22); 3357 (10); 3359 (10); 3488 (10); 3536 (10); 3639 (03); 3779 (03); $3845 \quad$ (03); $3875 \quad(10) ; 4567 \quad(30) ; 5431$ (30); 5438 (10); 5489 (10); 5530 (03); 5542 (10); 5563 (10); 5755 (30); 5843 (10); 5990 (10); 6281 (10); 6438 (10); 6645 (04); 6665
(03); 6749 (10); 6781 (10); 6842 (10); 6913 (10); 6944 (03); 6997 (10); 7013 (03); 7033 (03); 7510 (57); 7665 (19); 7862 (27); 8106 (27); 8124 (10); 8208 (10); 8258 (03); 8268 (10); 8775 (03); 8825 (10); 8838 (03); 8950 (19); 9384 (17); 9638 (10); 9684 (10); 9864 (10); 10125 (10); 10399 (10); 10685 (10); 10984 (10); 11035 (17); 11436 (08); 11800 (03); 12057 (10); 12301 (08); 12308 (30); 12448 (10); 12550 (03); 12875 (10); 12996 (10); 13050 (10); 13114 (10); 13205 (10); 13324 (14); 13636 (10); 13692 (27); 13753 (10); 13850 (30); 13994 (10); 14048 (10); 14081 (10); 14219 (10); 14312 (03); 14315 (10); 14384 (10); 14385 (10); 14425 (28); 14505 (33); 14508 (10); 14796 (03); 14945 (10); 14947 (03); 14954 (03); 15084 (10); 15120 (10); 15310 (10); 15486 (10); 15565 (03); 15633 (26); 15778 (10); 16300 (33); 16775 (03); 16791 (10); 16921 (14); 16922 (14); 16993 (03); 17097 (14); 17207 (03); 17741 (03); 17790 (03); 17895 (03); 17896 (35); 18002 (03); 18005 (10); 18120 (08); 18355 (03); 18756 (03); 18778 (35); 18932 (31); 19299 (15); 20025 (10); 20121 (35); 20558 (10); 20565 (10); 20689 (03); 20741 (03); 20960 (35); 30980 (35); 21598 (10); 21633 (10); 21668 (35); 21689 (03); 22608 (03); 22699 (04); 22777 (03); 22810 (26); 22815 (10); 22885 (03); 22920 (03); 22991 (10); 23404 (10); 58503 (32); 58937 (17); 59149 (30); 59378 (30).

Raimundo, INPA 49570 (17).

Ramos, J., INPA 54084 (03); INPA 54123 (14); INPA 54127 (14); INPA 54140 (07); INPA $54144(26)$.

Reitz, \& al., 2006 (24); 2545 (24); 2672 (24); 6552 (24); 8825 (24); 9623 (24).

Ribeiro, B., 8 A (33).

Riedel, 1012 (31); BM (10); NY (12); s. n. (24). Rizzini, $R B 117492$ (30).

Rizzo, A., 4708 (30); 5527 (34).

Rodrigues, J.S., 43 (10).

Rodrigues, W. \& al., 339 (10); 420 (10); 744 (10); 747 (33); 829 (03); 839 (10); 1409 (10); 1413 (10); 1589 (10); 1783 (35); 2064 (10); 2156 (35); 2226 (03); 2231 (35); 2291 (03); 2311 (10); 2415 (10); 2996 (35); 2999 (17); 3000 (17); 4997 (03); 5176 (30); 5212 (08); 5326 (17); 5327 (35); 5434 (10); 5505 
(02); 5534 (03); 5561 (35); 5604 (10); 5610 (17); 5835 (08); 5963 (35); 5968 (35); 5999 (26); 6708 (35); 6833 (08); 6872 (03); 6967 (08); 6968 (17); 6986 (20); 7070 (02); 7119 (10); 7152 (17); 7251 (04); 7269 (03); 7407 (04); 7558 (21); 7606 (35); 7789 (10); 7795 (33); 7839 (17); 7871 (20); 7911 (02); 8163 (35); 8171 (17); 8207 (17); 8210 (17); 8216 (17); 8219 (10); 8220 (08); 8232 (10); 8290 (03); 8293 (21); 8465 (20); 8583 (02); 8584 (02); 8700 (02); 8807 (35); 8879 (08); 8902 (03); 8917 (10); 8919 (03); 8934 (10); 8935 (03); 8976 (10); 9008 (03); 9049 (26); 9054 (04); 9062 (13); 9065 (13); 9067 (13); 9080 (03); 9113 (26); 9255 (13); 9262 (13); 9263 (02); 9265 (18); 9363 (03); 9373 (10); 9382 (35); 9425 (10); 9439 (35); 9493 (03): 9535 (03); $9536 \quad(13) ; 9544 \quad(04) ; 9589$ (03); 9591 (04); 9593 (08); 9597 (17); 9598 (02); 9606 (08); 9617 (21); 9627 (04); 9633 (21); 9636 (21); INPA 37127 (33).

Rolander, s.n. (33).

Ruiz, P., s. n. (30).

Rusby, H.H., 1216 (30).

Saddi, N., 936 (31); 1048 (31); 1223 (31).

Saldanha, 8752 (24).

Santos, J., MG 7288 (33).

Santos, T.L., 1107 (23).

Schott, 4559 (24).

Schultes, R.E. \& al., 8352 (33); 24569 (33); 24574 (10); 24575 (10); 24595 (10); 24603 (03); 24608 (10); 24609 (03); 24611 (03); 24612 (10); 24613 (35); 24614 (21); 24615 (10); 24616 (02); 24626 (10); $26105 A$ (18); 26115A (08); 26127A (02); 26130A (35); $26151 A$ (21); $26153 A$ (17); $26181 A$ (04); 26188A (08).

Schunke, J., 3586 (21).

Schwacke, J., 526 (21); 271 (10); 4678 (33).

Seemann, 545 (30).

Serv. Florest, E.S.P. 52 (24).

Silva, A., 17 (33); 18 (17); 201 (30); 268 (30); 314 (17); 320 (17); 327 (33).

Silva, J.F., 77 (35); 203 (35); 208 (10); 458 (10); IAN s.n. (10).
Silva, M . \& al., 47 (33); 121 (35); 196 (13); 923 (35); 934 (10); 1249 (10); 1418 (33); 1421 (33); 1484 (30); 1487 (30); 1910 (35); 1943 (10); 2285 (04); 2351 (03); 2401 (35); MG 2411 (17); 2424 (10); 2433 (17); 2636 (35).

Silva, M.B., 152 (30).

Silva, M.F. \& al., 134 (10); 157 (03); 197 (35); 216 (03); 249 (03); 251 (08); 266 (08); 279 (10); 285 (10); 290 (10); 339 (26); 345 (35); 431 (35); 440 (03); 470 (10); 480 (35); 493 (08); 558 (26); 575 (35); 623 (03); 709 (35); 753 (16); 826 (35); 912 (09); 926 (26); 948 (26); 1003 (03); 1013 (03); 1715 (04); 1719 (10); 1824 (33).

Silva, N.T., 13 (17); 14 (17); 272 (33); 601 (17); 1221 (17); 1236 (30); 1312 (33); 1378 (17); 2066 (30); 2211 (35); 3060 (33); 57850 (30).

Siqueira, R., MG 8754 (33); MG 8781 (33).

Smith, L.B., A 76 (30).

Smith, A.C., 2628 (03).

Snethlage, E., 740 (32); MG 8112 (10).

Souza, J.A., INPA 35457 (10); INPA 37123 (04); INPA 37124 (10); INPA 37125 (03); INPA 49028 (17); s. n., (04).

Spada, J., 168 (12).

Spruce, R., 456 (33); 468 (30); 1245 (10); 1343 (04); 1401 (35); 1444 (10); 1794 (10); 2512 (10); 3140 (29); 3172 (10); 3206 (04); 3207 (03); 3363 (10); RB 19395 (35).

Stewart, W.C. \& al., P 12875 (10); P 12996 (10); $P 13050$ (10); $P 13114$ (10); $P 13205$ (10); $P$ 19682 (10); $P 20121$ (35).

Steyermark, J.H., 104039 (10).

Tessmann, G., 3475 (19).

Uchoa, A.M., 36 (12).

Ule, E., 5024 (10); 5638 (10); 6115 (35); 7850 (33); 7988 (33); 8845 (08); 8846 (03); 8847 (10); 9376 (03).

Veloso, H.P., 1080 (23); s. n. (24).

Van Hall, 8 (33).

Williams, L. \& al., 3077 (07); 18245 (06).

Wurdack, J.J., 2259 (09).

Zehntner, $416=3054$ (32).

Nome não identificado, $M G 9767$ (33). 
INDICE DOS NOMES CIENTIFICOS DE TAXA

As espécies grifadas são as reconhecidas neste trabalho. Os números seguidos do nome correspondem ao $\mathrm{n}^{\circ}$ de ordem das espécies e os $n^{\circ}$ s entre parênteses correspondem ao $n .^{\circ}$ da página do presente trabalho.

\section{Myristica,}

angustifolia, .................. 33

balsamica, ................. 26

bicuhyba, .................. 24

calophylla, ................. 3

carinata, .................. 4

cordifolia, .................. 30

cuspidata, ................. 10

var. globifera, ........... 10

var. rufula, .............. 10

elongata, .................. 10

eyensis, .................. 35

fatua, ................. 33, (103)

fulva, ................... 30

gardneri, .................. 12

gracilis, .................... 4

grandis, ................... 12

hypoleuca, $\ldots \ldots \ldots \ldots \ldots \ldots \ldots . .4$

lancifolia, .................. 35

longicuspis, ................. 10

melinonii, ................... 17

membranacea, ................ 10

mocoa, .................... 30

mollissima, ................. 19

officinalis, ............... 12, 23

oleifera, ................... 24

pacimonensis, ................ 4

panamensis, ................. 30

pavonis, .................... 26

peruviana, $\ldots \ldots \ldots \ldots \ldots \ldots \ldots . \quad 27$

punctata, .................. 10

rufula, ..................... 10

rugulosa, .................. 29

sebifera, ................... 30

var. cordifolia, ........... 30 var. curvinervia, $\ldots \ldots \ldots \ldots \ldots, 30$

var. longifolia, ........... 33

sessilis, ................. 31

subsessilis, ................ 32

surinamensis, ............... 33

theiodora, $\ldots \ldots \ldots \ldots \ldots \ldots \ldots . .10$

uaupensis, $\ldots \ldots \ldots \ldots \ldots \ldots \ldots, 10$

venosa, ................ 26, 35

var. poeppigii, $\ldots \ldots \ldots \ldots \ldots, 35$

Myristica Sect. Otoba, ............. (30)

Myristica Sect. Sychnoneura, ....... (30)

Myristica Sect. Virola, ............. (30)

Nux moschata sylvestris surinamensis, 33

Otoba incolor, ................. 3

Palala, ....................... (30)

bicuhyba, ................ 24

calophyla, ................. 3

carinata, .................. 4

cuspidata, .................. 10

elongata, ................. 10

gardneri, ................. 12

hypoleuca, ................. 4

membranacea, ............... 10

mocoa, ................... 30

mollissima, ................ 19

uaupensis, ................. 10

panamensis, $\ldots \ldots \ldots \ldots \ldots \ldots . \quad 30$

pavonii, .................... 26

peruviana, $\ldots \ldots \ldots \ldots \ldots \ldots \ldots .27$

punctata, ................... 10

rugulosa, .................. 29

sebifera, ................... 30

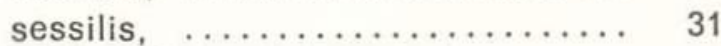

subsessilis, ................ 32

surinamensis, $\ldots \ldots \ldots \ldots \ldots \ldots . \quad 33$

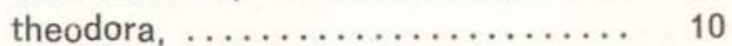

venosa, ................... 35

Sebophora $\ldots \ldots \ldots \ldots \ldots \ldots \ldots \ldots \ldots$ (30)

Virola ....................... (30)

albidiflora, ................. 1

araujovii, ................. 24 
bicuhyba, $\ldots \ldots \ldots \ldots \ldots \ldots \ldots \ldots 24$

var. schenckii, ........... 24

boliviensis, ............... 30

caducifolia, ................. 2

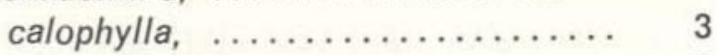

calophylloidea, ............. 3

carinata, .............. 4, 26

var. gracilis, ........... 4

coelhoi, ................ 5

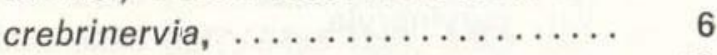

cuspidata, ................ 10

var. membranacea, ........ 10

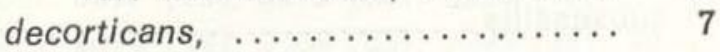

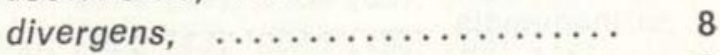

duckei, $\ldots \ldots \ldots \ldots \ldots \ldots \ldots \ldots . \ldots \ldots$

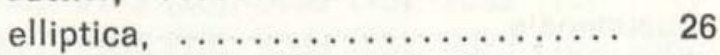

elongata, ...................... 10

var. longicuspis, ......... 10

var. punctata, ............ 10

var. subcordata, .......... 10

flexuosa, ................. 11

gardneri, .............. 12, 17

glaziovii, ............... 33, (103)

var. latifolia, ............ 15

guggenheimii, .............. 13

incolor, ................ 3, (40)

kukachkana, .............. 1, (37)

lepidota, ................ 3, (41)

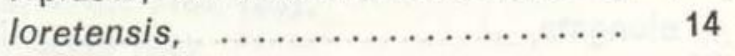

malmei, ................... 15

marlenei, .................. 16

melinonii, ........... 17, 33, (70)

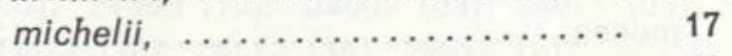

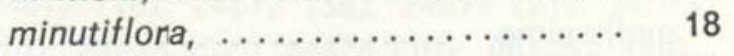

mollissima, ................ 19

multicostata, ................ 20

multinervia, ............... 21

mycetis, ............. 30, 33

obovata, .................. 22

officinalis, ......... 11, 23, 24, 32 oleifera, .................. 24

var. schenckii, ........... 24

panamensis, .............. 30

parvifolia, .................. 25

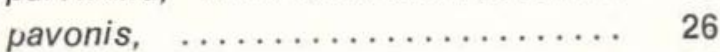

peruviana, ............. 27, 30

var. tomentosa, .......... 30

polyneura, ................. 28

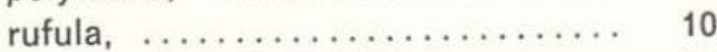

rugulosa, .................. 29

sebifera, .............. 24, 30

var. curvinervia, ......... 30

schwackei, ............... 12

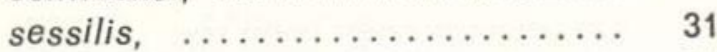

subsessilis, ............... 31

surinamensis, ............ 33 (102)

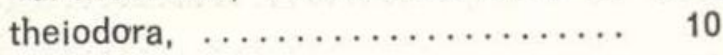

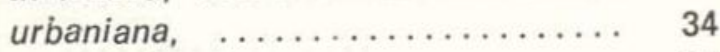

venezuelensis, .............. 30

venosa, ................ 17, 35

var. martii, ............ 4

var. pavonis, ........... 26

var. poeppigii, ............ 35

var. schenckii, ........... 24

villosa, $\ldots \ldots \ldots \ldots \ldots \ldots \ldots \ldots$.

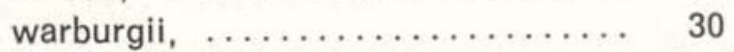

grupo Calophyllae ............. (30)

grupo Mollissimae ............. (30)

grupo Rugulosae ............... (30)

grupo Sebiferae ............... (30)

grupo Subsessiles .............. (30)

grupo Surinamenses ............. (30)

Sect. Amblyanthera .............. (30)

Sect. Calophyllae .............. (30)

Sect. Mollissimae ............. (30)

Sect. Oxyanthera .............. (30)

Sect. Rugulosae ............. (30)

Sect. Sebiferae ............... (30)

Sect. Subsessiles .............. (30)

Sect. Surinamenses ........... (30) 
A

Aiook, .......................... 10

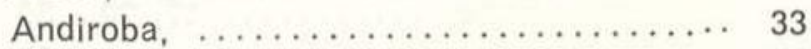

Árvore-de-cera, ................... 30

Árvore-de-graxa, ................. 30

Árvore-de-sebo, ............ 24, 30, 33

Avinház,

B

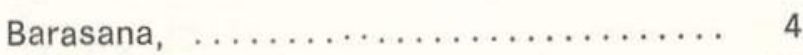

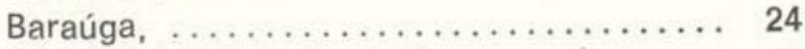

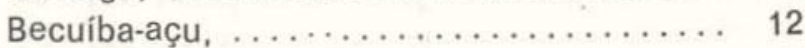

Becuiba-branca, ................. 24

Becuiba-vermelha, .............. 12

Bequiba, ..................... 30

Bicuhyba-macho, ............... 24

Bicuiba, ........... 12, 23, 24, 30, 33

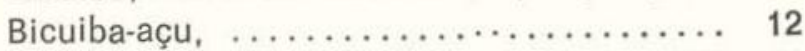

Bicuiba-branca, ............... 23, 24

Bicuiba-cãa-mirim, ................ 24

Bicuibaçu, ..................... 24

Bicuiba-da-folha-larga, ............ 12

Bicuiba-da folha-miúda, ............ 24

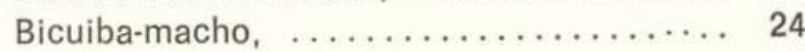

Bicuiba-mirim, ................. 24

Bicuiba-redonda, .............. 23, 24

Bicuiba-vermelha, ............. 12, 30

Bicuiba-vermelha-da-miúda, . . . . . . . . 24

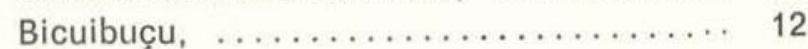

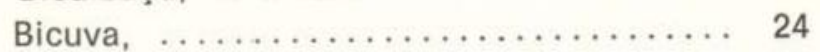

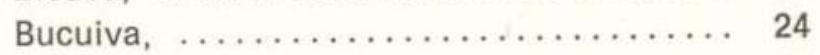

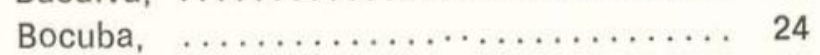

Bom-am, ....................... 4

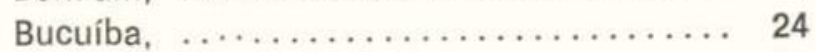

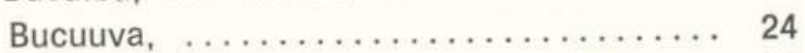

Bucuva,$\ldots \ldots \ldots \ldots \ldots \ldots \ldots \ldots . \ldots \ldots$

Candeia-de-caboclo, .............. 24

Casseriv, .................. 10

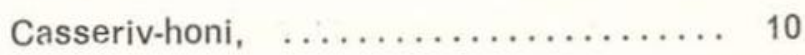

Chee-van, .................... 4

Cigari, $\ldots \ldots \ldots \ldots \ldots \ldots \ldots \ldots \ldots \ldots \ldots \ldots \ldots$

D

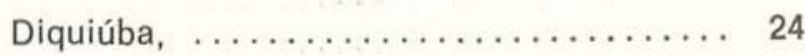

E

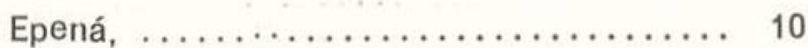

J

Jupara, $\ldots \ldots \ldots \ldots \ldots \ldots \ldots \ldots \ldots, 33$

K

Kawabo, ...................... 10

$\mathbf{L}$

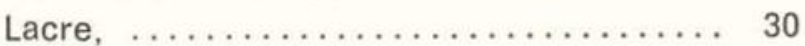

Landim, ........................ 33

Laa-see-ñe-me-hoo, ................ 4

M

Maçaranduba-branca, ................ 3

Mimba-branca, ................... 10

Moscadeira-do-Brasil, ................ 24

Mucuhyba, ..................... 12

\section{$\mathbf{N}$}

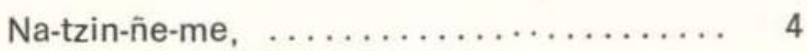

Noz-moscada-do-Brasil, . ........... 23, 24

Nyakwana, $. \ldots \ldots \ldots \ldots \ldots \ldots \ldots . . . \ldots$

Ocuba, $\ldots \ldots \ldots \ldots \ldots \ldots \ldots \ldots \ldots \ldots \ldots \ldots \ldots \ldots$ 
$\mathbf{P}$

Paricá, ......................... 10

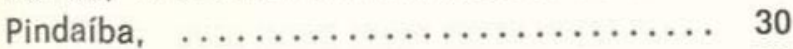

Pindaiba roxa, .................. 30

Piquibuçu. ........................ 24

Piquibussu, $\ldots \ldots \ldots \ldots \ldots \ldots \ldots \ldots \ldots, 24$

Pau-de-mato, .................... 30

Pau-sangue, ..................... 24, 12

Pau-sangue-bicuíba, $\ldots \ldots \ldots \ldots \ldots \ldots \ldots, 24$

\section{S}

Sacuná, ......................... 10

Saconadi, ........................ 10

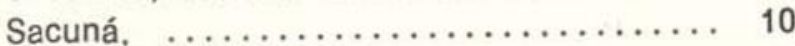

Sacunadi, ........................................... 10

Saraguela, ..................... 33

Shomiá, ....................... 10

Sikania, ........................ 10

$\mathbf{T}$

Tchakiana, ..................... 10

Tinauva,...$\ldots \ldots \ldots \ldots \ldots \ldots \ldots \ldots \ldots \ldots \ldots \ldots$

U

Ubucuba, $\ldots \ldots \ldots \ldots \ldots \ldots \ldots \ldots \ldots . .30$

Ucuhuba, ........... 3, 8, 14, 26, 30, 35

Ucuhuba-da-mata, .................. 35

Ucuúba, $3,4,6,8,9,10,14,17,18,24,26,27$, $30,33,35$
Ucuúba-açu, ....................... 10

Ucuúba-branca, ....... 4, 9, 10, 17, 33, 35

Ucuúba-branca-do-baixio, ......... 4, 26

Ucuúba-da-capoeira, ................ 30

Ucuúba-da-folha-grande, .......... 3, 21

Ucuúba-da-folha-graúda, ............. 21

Ucuúba-da-folha-larga, $\ldots \ldots \ldots \ldots \ldots \ldots, 30$

Ucuúba-da-Guiana, ................ 17

Ucuúba-da-mata, ............ 2, 17, 24, 35

Ucuúba-da-folha-peluda, $\ldots \ldots \ldots \ldots \ldots \ldots, 21$

Ucuúba-de-sebo, ................... 30

Ucuúba-de-terra-firme, ......... 17, 20, 30

Ucuúba-de-várzea, ................. 33

Ucuúba-do-baixio, .................. 4

Ucuúba-do-igapó, $\ldots \ldots \ldots \ldots \ldots \ldots \ldots$ 10, 33

Ucuúba-do-mato, .................. 30

Ucuúba-preta, ............... 10, 17, 30

Ucuúba-silvestre, .................. 9

Ucuúba-verdadeira, $\ldots \ldots \ldots \ldots \ldots \ldots \ldots, 33$

Ucuúba-vermelha, ... 2, 3, 8, 10, 21, 24, 30

Ucuubarana, ................ 3, 17, 30

Ucuubinha, .................. 10, 30

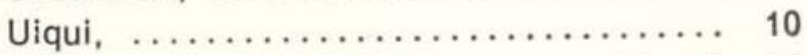

Urucuba, ................ 12, 24, 30

Urucuba-de-sebo, $\ldots \ldots \ldots \ldots \ldots \ldots \ldots . \ldots \ldots$

Urucurana, .................... 33

Urucurana-vermelha, $\ldots \ldots \ldots \ldots \ldots \ldots \ldots, 30$

\section{V}

Vicuiba, $\ldots \ldots \ldots \ldots \ldots \ldots \ldots \ldots \ldots, 23$ 
Agurell, S.; Holmstedt, B.; Lindgren, J.E. \& SCHULtes, RE.

1969 - Alkaloids in Certain Species of Virola and other South American Plants of Ethnopharmacologic interest. Acta Chem. Scand. 23 (3): 903-916.

Araujo, V.C.

1970 - Fenologia de essências florestais amazônicas. Bol. INPA, sér. Pesq. Florest. 4: 1-25.

AUBLET, J.B.C.F.

1775 - Histoire des plantes de la Guiane Française. London \& Paris.

Aubréville, A.

1961 - Étude écologique des principales formations végétales du Brésil. Centre Technique Forestier Tropical, Nogent-Sur-Marne, France: 268pp. + figs. + quadros.

BARATA, L.E.S. \& BAKER, P.M.

1973 - Quimioprofilaxia da esquistossomose: a atividade de Virola surinamensis (Rol.) Warburg. Ciência e Cultura 25 (6): 169.

BaratA, L.E.S.; BaKer, P.M.; GotTlieb, O.R. \& RUVEDA, E.

1976 - Sintese de neolignanas. Ciência e Cultura, Suplemento, 28 (7): 174-5.

BAstos, A. DE M.

1960 - A Floresta do Amapari - Matapi - Cupixi (Inventário Florestal). Bol. Serv. Florest. Fio de Janeiro 2: 1-54.

BeNTHAM, G.

1853 - Notes on the American Species of Myristica. Hook. Journ. Bot. \& Kew Gard. Misc. 5: 1-7.

BeNTHAM, G. \& HOOKeR, J.D.

1880 - Myristiceae. In: Genera Plantarum, London. 3 (1): 135-139.

BERRY, E.W.

1916 - A fossil nutmeg from the Tertiary of Texas. Amer. J. Sci., sér. 4, 42: 241-245

1919 - The fossil higher plants from the Canal Zo. ne. U.S. Nat. Mus. Bull. 103: 15-44.

1929 - Tertiary fruits and seeds from Northwestern Peru. The Johns Hopkins University, Studies in Geology 10: 137-181.

BESSEY, C.E.

1915 - The phylogenetic taxonomy of flowering plants. Ann. Mo. Bot. Gard. 2: 109-164.
Blair, G.E.; Cassady, J.M.; Robbers, J.E.; Tyler, V.E. \& RAFFAUf, R.F.

1969 - Isolation of $3,4^{\prime}, 5-$ trimethoxy-trans-stilbene; otobaene and hidroxytobain from Virola cuspidata. Phytochemistry 8: 497-500.

hraz Filho, R.; LeIte, M.F.F. \& GotTlieb, O.R.

1973 - The chemistry of Brazilian Myristicaceae. I. The constituions of diarylpropanoids from Virola multinervia. Phytochemistry.12: 417 . 419.

Braz Filloo, R.; Gottlieb, O.R.; Maia, J.G.S. \&

PEDREIRA, G.

1976a - Virolanos e isoflavonas de Virola caducifo lia. Ciência e Cultura. Suplemento, 28 (7): 185.

Braz Filho, R.; Gottllieb, O.R.; Magalhães, M.T. \& MORAES, A.A. DE.

1976b- Isoflavonoides de Osteophloem platyspermum. Ciência e Cultura. Suplemento, 28 (7): 185.

Braz Filho, R.; Gottlieb, O.R. \& Pinho, S.L.V. $1976 c$ - Virolanos e isoflavonas de V. multinervia. Ciência e Cultura. Suplemento, 28 (7): 185.

Cassady, J.M: Blair, G.E.; RafFauf, R.F. \&

TYLER, V.E.

1971 - The isolation of 6-Methoxyharmalan and 6Methoxyharman from Virola cuspidata. Lloydia 34 (1): 161-162.

Cronquist, A.

1968 - The evolution and classification of flowering plants. Houghton Mifflin Co., Boston. 396pp +52 figs.

de Candolle, $A$.

1860 - Myristicaceae. In: Martius, K.F.P. von, Flora Brasiliensis 5 (1): 105-136+t. 38-44.

1856 - Myristicaceae. In: DC., Prodromus 14: $187-$ 208 e 696-697.

DUCKE, A.

1933 - Myristicaceae. In: Plantes nouvelles ou peu connues de la région amazoniénne. Arq. Jard. Bot. Rio Jan. 6: 9-12.

1936 - Notes on the Myristicaceae of Amazonian Brazil, with descriptions of new species. II. Journ. Wash. Acad. Sci. 26 (6): 253-264.

1938 - Plantes nouvelles ou peu connues de la région amazoniénne ( $X^{\prime}$ 'série). Arch. Inst. Biol. Veg. 4 (1): $1-64+5$ planches. 
1939 - Plantes nouvelles ou peu connues de la région amazoniénne ( $\mathrm{Xl}^{\circ}$ série). Arq. Serv. Florest. 1 (1): 1-28.

1945 - New forest trees and climbers of the brazilian Amazon. Bol. Técn. Inst. Agron. Norte $4: 8-12$.

1950 - Plantas novas ou pouco conhecidas da Amazônia. Bol. Técn. Inst. Agron. Norte 19: 3-7.

DUCKE, A. \& Black, G.A.

1954 - Notas sobre a Fitogeografia da Amazônia Brasileira. Bol. Técn. Inst. Agron. Norte 29: $1-62$.

EAMES, A.J.

1961 - Morphology of the Angiosperms. McGrawHill Book Co. Inc., New York. XIII + 518pp. +148 figs.

ENDLICHER, S.L.

1841 - Myristicaceae, Ordo CLXXV in Enchiridium botanicum. Lipsiae, Viennae: 418-421.

EMBRAPA.

1974 - Ante-projeto do Centro de Pesquisas para Desenvolvimento de Recursos da Amazônia. Belém. 301pp.

ENGLeR, A. \& DIELS, L.

1936 - Syllabus der Pflanzenfamilien. Berlin, II* ed.

ERdTMAN, G.

1966 - Pollen morphology and plant taxonomy. Angiosperms, Hafner Publ. Co., New York London, $2^{*}$ ed. 553pp. +261 figs.

FERRI, M.G.

1974 - Ecologia: temas e problemas brasileiros. Belo Horizonte, ed. Itatiaia; São Paulo, Ed. da Universidade de São Paulo, Col. Reconquista do Brasil, vol. 3: 188pp. +76 figs. + XLIII ilustrs. a cores.

Franca, N.C.; Diaz, P.P.D.; GotTlieb, O.R. \& Rosa, B.P. 1974 - The chemistry of Brazilian Myristicaceae. III. Flavans from Iryanthera species. Phytochemistry 13: 1631

Franca, N.C.; Gottlieb, O.R. \& Rosa, B.P.

1975 - The chemistry of Brazilian Myristicaceae. IV. Juruenolide, a - lactone from Iryanthera juruensis. Phytochemistry 14: 590.

GARRATT, G

$1933 a$ - Systematic anatomy of the woods of the Myristicaceae. Trop. Woods 35: $6-48+2$ plates +9 figs .

1933b- Bearing of wood anatomy on the relationships of the Myristicaceae. Trop. Woods 36: $20-44$.

GLERUM, B.B.

1962 - Inventário de ocorrência da ucuuba na regiăo do Baixo Tocantins. Inventários Florestais FAO/SPVEA. Tradução A.M. Bastos. 17p. + indice.

Gothan, W. \& WeYLAND, H.

1964 - Myristicaceae. In: Lehrbuch der Paläeobotanik. Akademic-Verlag, Berlin: 427.
Gottlieb, O.R.; Loureiro, A.A.; CARNeiro, M.S. \& ROCHA, A.I. DA.

1973 - The chemistry of Brazilian Myristicaceae. II. The distribution of diarylpropanoids in Amazonian Virola species. Phytochemistry 12: 1830 .

GotTlieb, O.R.; MAIA, J.G.S. \& S. RIBEIRo, M.N. DE. 1975a - Neolignanas de Virola carinata. Ciência e Cultura 27 (7): 172.

GOTTLIEB, O.R.; MAiA, J.G.S. \& PINHO, S.L.V.

1975b- Diarilpropanos de Virola multinervia e V. venosa. Ciência e Cultura 27 (7): 172.

HatschваCH, G.

1972 - Miristicáceas do Estado do Paraná. Bol. Mus. Mun. Curitiba 4: $1-4+2$ figs.

HeINSDiJK, D. \& Bastos, A. DE M.

1963 - Inventários florestais na Amazônia, Bol. Serv. Florest. Rio de Janeiro, 6: 1-100.

Holmgren, P.K. \& Keuken, W.

1974 - Index Herbariorum. Part I. The Herbaria of the World. Regnum Vegetabile 92: 1-397.

HONDA, M.

1971 - Madeiras denominadas ucuúba - I. Virola divergens Ducke e V. multinervia Ducke. Acta Amazonica 1 (2): $79-83+8$ figs.

HUECK, K.

1972 - As florestas da América do Sul : ecologia, composição e importância econômica. Trad. H. Reichardt. São Paulo, Ed. Univ. de Bra. sília e Polígono S.A. 466pp. +253 figs.

HUTCHINSON, J.

1964 - The genera of flowering plants (Angiospermae). Dicotyledones. Clarendon Press, Oxford. vol. 1: XI + 516pp.

1969 - Evolution and phylogeny of flowering plants. Academic Press, London e New York. XXIV $+717 \mathrm{pp} .+550$ ilustrs. + maps.

JoLY, A.B.

1970 - Conheça a vegetação brasileira, São Paulo, Ed. Univ. de São Paulo e Polígono 165pp. + ilustrs.

Jussieu, A.L. DE.

1789 - Genera Plantarum. Facsimile reprint J. Cramer-Weinheim, 1964, Alemanha. XVIII + 498pp.

KUNTZE, C.E.O.

1891 - Myristicaceae. In: Revisio generum plantarum. Leipzig. 2: 566-568.

LE COINTE, P.

1947 - Amazônia brasileira. III. Árvores e plantas úteis (Indígenas e aclimatadas). $8^{n}$ ed. São Paulo, Ed. Nacional. 506pp + ilustrs.

LEENHOUTS, P.W.

1968 - A guide to the practice of herbarium taxonomy. Regnum Vegetabile 58: 1-60. 
LEMOS, J.M.

1973 - Reflorestamento com Virola surinamensis (Ucuúba de Várzea) na ilha do Marajó. Inst. Bras. Desenv. Florest. - Grupo de Operações da Amazônia, Pará-Brasil: 1-13 (mimeografado).

Lima, Oswaldo et al.

1955 - Primeiras observaçōes sobre a ação antibacteriana de extratos de amêndoas de Virola gardneri. An. Soc. Biol. Pernambuco 13 (1): 1-7, fig. 1-2.

LIMA, R.A. DE; FRANCA, N.C.; DIAZ, P.P.D. \&

GOTTLIEB, O.R.

1975a - The chemistry of Brazilian Myristicaceae. V. Diarylpropanes from Iryanthera coriacea. Phytochemistry 14: 1831.

LINDLEY, J.

1847 - The vegetable kingdom. Ed. Bradburg \& Evans, London, $2^{n}$ ed.: 301-302.

MACHADO, O.X.B.

1949 - Bicuiba. Virola bicuhyba (Schott) Warb. Contribuição ao estudo das plantas medicinais do Brasil. Rodriguesia, 24: 53-78 + 2 ests. +6 figs.

MAIA, J.G.S. \& RODRIGUES, W.A.

1974 - Virola theiodora como alucinógena e tóxica. Acta Amaz. 4 (1): 21-23.

MAINIERI, C.

1962 - Madeiras leves da Amazônia empregadas em caixotaria. Estudo anatômico macro e microscópico. Inst. Pesq. Tecnol. São Paulo 686: 1-39, 20 est., 58 fig.

MALME, G.O.A.N.

1935 - Myristicaceae. In: Einige regnellsche Phanerogamen. Arkiv Bot. 26A (9): 29.

MARKGRAF, FR.

1923 - Eine neue Myristicaceae aus Brasilien. Fedde Reper. 19 (531/533: 24.

Martin-Lavigne,

1909 - Recherches sur les bois de la Guyane. Travaux Laboratoire de Matiére Médicale, Paris. 4 (2): 1-184

MELCHIOR, H.

1964 - Myristicaceae. In: Engler's Syllabus der Pflanzenfamilien. $12^{*}$ ed., Berlin, 2: 116-117.

Mello, E.C.

1950 - Estudo dendrológico de essências florestais do Parque Nacional do Itatiaia e os caracteres anatômicos de seus lenhos. Bol. Serv. Florest., Parque Nac. Itatiaia 2: 1-174 + ilustrs.

MENDES-MAGalHães, G.

1955 - Características de alguns tipos florísticos de Minas Gerais (Brasil). I. Bol. Soc. Port. Ciênc. Nat. vol. 5, $2^{n}$ série., 19 (2): 91-113.

MetCALFE, C.R. \& ChalK, L.

1965 - Myristicaceae. In: Anatomy of the Dicotyledons. Claredon Press, Oxford 2: 1132-1139 + figs. 273-274.
NECKER, N.J. DE,

1790 - Elementa Botanica. Moguntiae 2: 188.

Oliveira, A.B.; Braz FILHO, R.; LeITE, M.F.F.;

GotTlieb, O.R. \& SHAat, V.T,

1973 - Novel constituents of Virola multinervia. Ciência e Cultura 25 (6): 563-568.

Oliveira, A.B. \& ShaAT, V.T.

1976 - Sintese de virolanos. Ciência e Cultura, Suplemento, 28 (7): 185.

PEREIRA, A.J.R.

1970 - Caracteres tecnológicos de 25 espécies de madeiras do Nordeste do Brasil. Bol. Recursos Naturais, SUDENE, 8: $5-116+$ tabelas +23 estampas +46 figs.

Pereira, A.P. \& Pedroso, L.M.

1972 - Experimentos de Silvicultura Tropical. Parte I. Informaçōes sobre época de floração, frutificação e desfolha das principais essências florestais que ocorrem na Estação Experimental de Curuá-Una, Estado do Pará - Depart. Recursos Nat. SUDAM, Sér. Rec. Nat. Amazônia: 3-70 + ilustrs.

PIRES, J.M.

1973 - Tipos de vegetação da Amazônia. Museu Par. E. Goeldi, Publ. Avulsa n॰2 20: 179-202.

PIRES, J.M. \& KOURY, H.M.

1959 - Estudo de um trecho de mata de várzea próximo de Belém. Bol. Técn. Inst. Agron. Norte 36: 1-44.

PRANCE, G.T.

1970 - Notes on the use of plant hallucinogens in amazonian Brazil. Econ. Bot. 24 (1): 62-68 +3 figs.

1972a - Ethnobotanical notes from Amazonian Brasil. Econ. Bot. 26 (3): 221-237 + 14 figs.

$1972 \mathrm{~b}$ - An Ethnobotanical comparison of four tribes of Amazonian Indians. Acta Amaz. 2 (2): $7-27+17$ figs.

1973 - Phytogeographic support for the theory of Pleitocene forest refuges in the Amazon Basin, based on evidence from distribution patterns in Caryocaraceae, Chrysobalanaceae, Dichapetalaceae and Lecythidaceae. Acta Amazonica 3 (3): $5-29+25$ figs. + 3 tables.

PRANTL, K.

1891 - Myristicaceae. In: Engler, A. \& Prantl, K., Die Natürlichen Pflanzenfamilien. $1^{\text {" }}$ ed. Leipzig, 3 (2): 40-42.

RATTER, J.A.; RICHARDS, P.W.; ARGENT, G. \& GIFFORD, D.R.

1973 - Observations on the vegetation of northeastern Mato Grosso. I. The woody vegetation types of the Xavantina - Cachimbo expedition area. Philos. Trans., Ser. Biol. 266 (880): $449-492$ 
REITZ, P.R.

1968 - Myristicaceae. In: Reitz, P.R., Flora Ilustrada Catarinense Itajaí. Parte 1 (MIRI): 1-15 +3 figs. + 1 mapa.

RODRIGUES, W.A.

1961 - Estudo preliminar de mata de várzea alta de uma ilha do baixo rio Negro de solo argiloso e úmido. Publ. Inst. Nac. Pesq. Amazônia, sér. Bot., 10: $1-50+4$ figs. +2 tabelas +1 perfil-diagrama

1963 - Estudo de 2,6 hectares de mata de terra firme da Serra do Navio, Território do Amapá. Bol. Mus. Par. E. Goeldi, sér. Bot. 19: 1-22, 2 figs. +8 gráficos +1 perfil +11 quadros.

1972 - A ucuúba de várzea e suas aplicaçōes. Acta Amazonica 2 (2): $29-47+7$ figs. + 8 quadros.

SAUER, W. \& EHRENDORFer, F.

1970 - Chromosomen Verwandtschaft und Evolution tropischer Holzpflanzen, II. Himantandraceae. Österr. Bot. 118: 38-54

Schотт, H.W.

1823 - Isis Oken 12-13: 1050.

ScHOT, $\mathrm{H}$.

1827 - Apendix. In: Linnaeus, C., Systema Vegetabilium, C. Sprengel (ed.), 16:" ed., 4 (2): 409.

SCHULTES, R.E.

1954 - A new narcotic snuff from the Northwest Amazon. Bot. Mus. Leafl. Harv. Univ. 16: 241-260.

1969a - The plant kingdon and hallucinogens. Part I. Bull. Narcot. 22 (1): $1-56$.

$1969 b-$ De plantis toxicaiis e Mundo Novo tropicale commentationes, V. - Virola as an orally administered hallucinogen. Bot. Mus. Leafl. Harv. Univ. 26 (6): 220-240.

1970 - The New World indians and their halluclnogenic plants. Morris Arbor. Bull. 21 (1): 3-14.

SCHultes, R.E. \& Holmstedt, B.

1968 - The vegetal ingredients of the Myristicaceous snuffs of the Northwest Amazon. Rhodora 70: 113-156.

1971 - De plantis toxicariis e Mundo Novo tropicale commentationes. VIII. Miscellaneous notes on Myristicaceous plants of South America. Lloydia 34 (1): 61-78, 7 figs.

Segadas-Vianna, F.

1965 - Ecology of the Itatiaia Range, Southeastern Brazil. I - Altitudinal Zonation of the Vegetation. Arq. Mus. Nac. 53: $7-30+7$ figs.

SмrTH, A.C.

1936 - Myristicaceae. In: Plantae Krukovianae V. Brittonia 2 (2): 151-153.
SMITH, A.C. \& WODEHOUSE, R.P.

1937 - The american species of Myristicaceae. Brittonia 2 (5): $393-510+9$ figs.

SOARES, R.O.

1970 - Inventários florestais na Amazônia. Brazil Florestal 1 (1): 4-9.

SOUKUP, J.

1966 - Las Miristicaceas, Monimiaceas y Borraginaceas, Campanulaceas, sus generos y lista de especies. Biota 6 (48): 125-129.

SpIX, J.B. \& Martius, K.F.P. VoN

1828 - Reise in Brasilien. München. Vol. 2: 543.

Stafleu, F.A. et AL. (ed.)

1972 - International Code of Botanical Nomenclature, adopted by XI International Botanica Congress, Seattle, august-September, 1969, Regnum Vegetabile 82: 1-426.

SWARTZ, O.P,

1788 - Nova Genera \& Species plantarum seu Prodromus - Stockholm, Uppsala, Abo. Facsimile reprint Weinheim, Alemanha 1962. p. 96.

TAKHTAJAN, A.

1969 - Flowering plants. Origin and dispersal. Transl. from the russian, $2^{*}$ ed. 1961 by C. Jeffrey. Oliver \& Boyd, Edinburgh. VII + 310 pp. +32 figs. +13 plates.

Tavares, S.; Paiva, F.A.F.; TAvares, E.J. DE S.;

NeVes, M.A. \& LiMA, J.L.S. DE,

1971 - Inventário florestal de Alagoas - I. Nova contribuiçăo para o estudo preliminar das matas remanescentes do Estado de Alagoas. Bol. Recursos Naturais, SUDENE 9: 5-122.

Tavares, S.; Paiva, F.A.F.: Carvalho, G.H. De.;

TAvares, E.J. de S.; Machado, O. de F.; Lima, J.L.S. de \& SouzA, S.A. DE.

1971 - Inventário florestal de Alagoas: Contribuição para a determinação do potencial madeireiro dos municípios de Săo Miguel dos Campos, Chão do Pilar, Colônia de Leopoldina e União dos Palmares. Bol. Recursos Naturais, SUDENE, 9: 123-231.

THURNE, R.F.

1968 - Synopsio of a putatively phylogenic classification of the flowering plants. Aliso 6 (4): 57-66.

UPHOF, J.C. TH.

1959 - Myristicaceae. In: Engler - Prantl: Die natürlichen Pflanzenfamilien. Berlin, 2* ed., 17. (2): $177-220$ + figs. $43-49$.

VAN DER MYK, R.W. \& CANRIGHT, J.

1956 - The anatomy and relationships of the Annonaceae. Trop. Woods 104: 1-24.

Veloso, H.P.

1946 - A vegetação no municipio de Ilhéus, Estado da Bahia. I - Estudo sinecológico das áreas de pesquisas sobre a febre amare- 
la silvestre realizado pelo S.E.P.F.A. Mem. Inst. Osw. Cruz 44 (1): $13-91+34$ figs.

1947 - A vegetação do município de llhéus, Estado da Bahia. II - Observação e ligeiras consideraçōes acerca de espécies que ocorrem na região. Chave analítica das espécies arbóreas. Mem. Inst. Osw. Cruz 44 (2): 221-268. (Separata)

1966 - Atlas florestal do Brasil. Serv. Inf. Agrícola, Min. Agr., Rio de Janeiro. 82pp. +10 figs. + 3 mapas.

Veloso, H.P. \& KleIN, R.

1957 - As Comunidades e Associações Vegetais da Mata Pluvial do Sul do Brasil - I. As Comunidades do Município de Brusque, Estado de Santa Catarina. Sellowia 8: 81-235.

1959 - As Comunidades e Associações Vegetais da Mata Pluvial do Sul do Brasil. II. Dinamismo e fidelidade das espécies em associações do Município de Brusque, Estado de Santa Catarina. Sellowia 10: 9-124.

Veloso, H.P. \& BARTH, O.M.

1962 - Catálogo sistemático dos pólens das plantas arbóreas do Brasil Meridional. I. Mag. noliaceae, Annonaceae, Lauraceae e Myristicaceae. Mem. Inst. Oswaldo Cruz 60 (1): $59-90+28$ figs. +2 est.

Wallace, R.; Porte, A.L. \& Hodges, R.

1963 - Lignans from Myristica otoba. The Structures of Hydroxyotobain and Iso-otobain. J. Chem. Soc.: 1445-1449.

WARBURG, O.

1895 - Ueber die Haarbildung der Myristicaceen. Ber. Deutschen Bot. Ges. 13: 78-82 + tafel 29.

1897 - Monographie der Myristicaceen. Nota Acta Acad. Leop.-Carol. 68: 1-680 + tafels 1-25.

WETTSTEIN, R.

1944 - Tratado de Botánica sistemática. Traducción $4^{*}$ ed. alemana por el Dr. P. Font Quer. Ed. Labor, S.A., Barcelona, 1039pp. +700 figs. +4 esquemas.

Wrlson, T.K. \& Maculans, L.M.

1967 - The morphology of the Myristicaceae. I. Flowers of Myristica fragrans and M. malabarica. Amer. J. Bot. 54 (2): 214-220 + 16 figs. 